TESIS DE DOCTORADO

\title{
LOS DISPOSITIVOS DE INTERVENCIÓN DE LOS/AS PSICÓLOGOS/AS \\ EN TIEMPOS TUTELARES \\ Y EN TIEMPOS DE SUJETOS DE DERECHOS
}

Un estudio sobre las instituciones del Organismo

de la Niñez y Adolescencia de la Provincia

de Buenos Aires, en el período 2000-2015

Julieta Veloz

Abril 2020 
LOS DISPOSITIVOS DE INTERVENCIÓN DE LOS/AS PSICÓLOGOS/AS

EN TIEMPOS TUTELARES Y EN TIEMPOS DE SUJETOS DE DERECHOS

Un estudio sobre las instituciones del Organismo de la Niñez y Adolescencia

de la Provincia de Buenos Aires, en el período 2000-2015

Doctoranda: Julieta Veloz

Director: Juan Carlos Domínguez Lostaló

Maquetación y normalización de referencias: Adela Ruiz

Abril 2020

Doctorado en Psicología

Facultad de Psicología

Universidad Nacional de La Plata

Buenos Aires | Argentina

\section{(c) (i) (2)(2)}




\section{LOS DISPOSITIVOS DE INTERVENCIÓN DE LOS/AS PSICÓLOGOS/AS}

\section{EN TIEMPOS TUTELARES}

Y EN TIEMPOS DE SUJETOS DE DERECHOS

Un estudio sobre las instituciones del Organismo de la Niñez y Adolescencia de la Provincia de Buenos Aires, en el período 2000-2015 
Las nuevas leyes sancionadas derivarán en nuevas políticas y programas que desafían nuestra imaginación y potencian nuestro pensamiento. Será necesario construir y pensar herramientas específicas, a la vez que se requiere interpelar los modos actuales en que se producen las prácticas concretas que realizan los psicólogos/as en esos espacios. Crear lo nuevo es la tarea pendiente y el desafío de este tiempo.

Edith Pérez, 2015 


\section{Para escribir una tesis}

se necesita una tribu

Esta tesis no surge por mérito exclusivo de quien la escribe, lo que no significa que su autora no sea responsable de cada línea y palabra escrita, ni que no haya sido realizada con mucho esfuerzo personal. Significa que este trabajo es producto de una multiplicidad de determinaciones.

No hubiera sido posible sin un grupo familiar que durante el trayecto de escritura me acompañó con la ternura necesaria de quienes sienten tus miedos y escuchan tus proyectos. Elba Losada y Rubén Veloz, gracias.

No hubiera sido posible si la universidad no fuera pública y gratuita, por eso mi agradecimiento a todos/as los/as que lucharon porque la educación superior sea un derecho.

No hubiera sido posible sin una política de gratuidad de esta carrera de posgrado para los/as docentes. Mi agradecimiento a quienes llevaron a cabo tal decisión política en un marco legal, como es la Ley de Educación Superior, que hace del posgrado un mercado de servicios solo para quienes pueden pagarlo.

No hubiera sido posible sin un director que acompañó el desarrollo del proceso sin definir adónde debía llegar. A Juan Carlos Domínguez Lostaló, mi gratitud.

Esta tesis fue posible porque la ex decana de la Facultad de Psicología, Edith Pérez, estimulaba a los/as docentes a cursar la carrera de Doctorado. 
Fue posible gracias a la disponibilidad y a la predisposición de los/as psicólogos/as entrevistados/as para relatar y para compartir sus prácticas profesionales, porque es sobre tales experiencias que se apuntala. Mi agradecimiento a cada uno y a cada una de ellos/as.

Fue posible gracias a la presencia de una compañera amiga, con quien aprendí la potencia de la interdisciplina en el hospital, en niñez, en los barrios y, ahora, en la lectura atenta de lo escrito. Gloria Mustapich, mi agradecimiento.

A los/as compañeros/as de la agrupación de graduadxs Psiconstruye, porque me bancaron, gracias.

A Carolina y Agustín, cuya hermandad adoro.

A mis amigas de toda la vida, Laura, Cecilia, Verónica y Silvina. A mis amigas de La Plata, Victoria, Laura, Cecilia, Mariana, Teresa y Pato, y a Agustina y Javier, que me animaban e interpelaban a terminarla.

A Adela Ruiz, quien editó con dedicada atención cada trazo escrito y supo acompañarme en el tiempo de concluir.

A quien me acompañó cuando estaba en el laberinto.

A Cata y a Merce, que saben que además de madre soy una mujer profesional, mi agradecimiento por los chistes que hacían mientras escribía y por las insistentes preguntas: ¿La terminaste? ¿Cuándo la terminás? Porque saben que después de la tesis... 


\section{INTRODUCCIÓN / 19}

La construcción del problema de investigación

El escenario legislativo / 19

El rol de los/as profesionales / 24

Los dispositivos de intervención / 30

El problema de investigación / 39

\section{PARTE I}

\section{Andamiaje teórico}

\section{CAPÍTULO 1}

La materialización de estrategias biopolíticas en políticas públicas estatales / 46

Las políticas sociales / 46

La biopolítica y el Estado / 52

Institución-organización-establecimiento / 55

El Síndrome de Violentación Institucional / 60

\section{CAPÍTULO 2}

\section{Los dispositivos de hacer-ser niños/as}

y adolescentes / 65

La niñez, una invención moderna / 66

La niñez en el suelo argentino / 72

Los/as niños/as como objeto de tutela / 79

Los/as niños/as como sujetos de derechos / 85 


\section{CAPÍTULO 3}

Los aportes de los saberes «psi» / 99

Los saberes «psi» y el gobierno de las familias / 100

La creación de la carrera de Psicología / 108

La integración de los/as psicólogos/as en las instituciones

de «menores» / 112

La vulnerabilidad y la mediación de la ternura / 118

\section{PARTE II}

\section{Abordaje metodológico e indagaciones}

\section{CAPÍTULO 4}

La estrategia de investigación / 125

Los instrumentos / 128

Las herramientas de análisis / 131

\section{CAPÍTULO 5}

\section{Los elementos normativos en la Provincia}

de Buenos Aires / 134

El Patronato de Menores / 135

El Sistema de Promoción y Protección de los derechos

de niños, niñas y adolescentes (SPPID) / 143

El Fuero de Responsabilidad Penal Juvenil / 150

\section{CAPÍTULO 6}

Los dispositivos de intervención / 156

Institutos penales / 157

Hogares convivenciales / 163

Centros de Responsabilidad Penal Juvenil / 169

Hogares de Protección de Derechos / 180 


\section{PARTE III}

\section{Entrecruzamientos}

\section{CAPÍTULO 7}

Las determinaciones que orientan los dispositivos / 188

Determinaciones normativas / 189

La judicialización de la pobreza / 189

El carácter auxiliar de los/as psicólogos/as / 191

La producción de sujetos de derechos / 194

El distanciamiento territorial / 198

La claridad del debido proceso / 199

Determinaciones institucionales / 200

Violentaciones y miedos / 202

Las fragmentaciones entre los/las asistentes

y el equipo técnico / 206

Las fragmentaciones en los equipos técnicos / 210

La resistencia a los dispositivos grupales / 212

Determinaciones teóricas / 214

La búsqueda de efectos sujeto / 215

Los modos de pensar la demanda / 216

CONCLUSIONES / 222

\section{REFERENCIAS,}

NORMATIVAS Y FUENTES / 240 
PRESENTACIÓN 
Los profesionales «psi» tienen, en general, poca disposición a genealogizar el surgimiento de sus campos de saberes y de prácticas; es decir, a realizar análisis críticos de la «urgencia» social para la cual sus profesiones fueron y son respuestas. Esto no es bueno, ya que los coloca en una rentable ingenuidad respecto de la inscripción social de sus profesiones. Esto no es bueno, ya que les impide diferenciar cuándo intervienen en problemáticas donde es absolutamente pertinente su bagaje de saberes y de prácticas, y cuándo realizan ortopedias sociales.

Dichas ortopedias llenan de saberes «psi» aquello que debería errar en sus propias vacancias, aquello que debería quedar abierto -errante- para no cesar de interpelarnos, aquello que podría instituir nuevas significaciones sociales. Despolitizar lo social no ha sido gratis. Tampoco la cultura «psi» es su único responsable, ni el terror de la Dictadura dejó explicar todas las dificultades para pensar en términos políticos los procesos de desarticulación comunitaria que padecemos (Fernández, 2011, p. 94).

Las líneas que componen la presente tesis doctoral tuvieron su origen en los debates y en los interrogantes producidos a partir de la sanción de las leyes 26.061 de Protección Integral de los Derechos de las Niñas, Niños y Adolescentes (2005) y 13.634 del Fuero de Familia y del Fuero Penal del Niño, en los diversos ámbitos públicos; entre ellos, los de formación universitaria y, en particular, en aquellas facultades en las cuales se forman profesionales psicólogos/as, trabajadores/as sociales y abogados/as.

Entre tales debates, uno que resulta de particular interés es el que delinea como problema la tensión entre la formación profesional y las políticas públicas; al situar que las reformas legislativas darán lugar a nuevas políticas sociales que no solo demandan otros contenidos en los planes de estudios sino que requerirán de nuevas subjetivaciones sobre las prácticas profesionales, en tanto las nuevas normativas «originan nuevos programas en el orden de las políticas sociales e interpelan nuestra capacidad de crear-inventar los dispositivos que puedan vehiculizar los principios que allí se formulan» (Pérez, 2015, s/p).

¿Por qué las nuevas normativas interpelan nuestra capacidad de crear-inventar dispositivos? 
El Decreto Ley 10.067 del Patronato de Menores de la provincia de Buenos Aires, sancionado durante la última Dictadura cívico militar, el 25 de octubre de 1983, materializó con mayor claridad y coordinación un modo histórico de intervenir sobre un sector de la población de los/as niños/as y adolescentes y sobre sus grupos familiares: la judicialización de la pobreza y la producción del menor como objeto de tutela del Estado. Las leyes que lo derogaron, sancionadas e implementadas entre los años 2005 y 2007, luego de veinticuatro años de democracia, implicaron en lo normativo otros campos y otros objetivos de intervención, y una ruptura que permitió pasar a la concepción de «niños/as y adolescentes como sujetos de derecho».

Uno de los cambios centrales fue que la anteriormente denominada «medida de internación» es en la actualidad una medida de último recurso, lo que implica la implementación de dispositivos de intervención para la permanencia de los/as niños/as y adolescentes con sus grupos familiares y en sus comunidades de pertenencia. Esto es relevante en tanto concluye con un movimiento de pujas políticas e inicia la apertura de otro: la invención de nuevos dispositivos de intervención.

Es aquí donde situamos el punto de partida de la presente tesis, que se inicia con una INTRODUCCIón en la que se recupera el camino mediante el cual fue construido el problema de investigación que orientó el trabajo. ${ }^{1}$ El apartado comienza con la descripción del recorrido de indagación bibliográfica que permitió reconstruir el escenario legislativo a partir de dar cuenta de los cambios en las normativas y de los efectos que esto produjo en las instituciones y en los establecimientos de los organismos estatales, la importancia que las nuevas leyes tienen para la implementación de políticas públicas en clave de derechos y las coincidencias que persisten a la hora de demostrar su escaso impacto en las prácticas institucionales efectivas.

Tal estado de la cuestión apuntaló la construcción del problema a investigar: los dispositivos de intervención diseñados e implementados por los/as profesionales psicólogos/as en los establecimientos del Organismo Provincial de Niñez y Adolescencia,

\footnotetext{
1 Para facilitar el acceso a las normativas que se mencionan a lo largo del trabajo, se ofrece el hipervínculo a los sitios oficiales en los que es posible consultarlas.
} 
dependiente del Ministerio de Desarrollo Social de la provincia de Buenos Aires, entre los años 2000 y 2015. Ubicado en un punto de cruce entre el ejercicio profesional de la psicología y las políticas públicas, los desarrollos de este apartado se detienen, luego, en el rol de los/as profesionales que han integrado e integran tales instituciones y en los dispositivos de intervención que se buscaba caracterizar, para visibilizar los principales elementos que los determinaban. De este inicial recorrido por los antecedentes y de la delimitación de estas primeras herramientas teóricas se desprenden la relevancia y la justificación del problema de investigación, así como los interrogantes y los objetivos que orientaron las búsquedas, y cuyo detalle cierra este apartado introductorio.

A continuación, se presentan los desarrollos que dan cuerpo a este trabajo, estructurados en TRES PARTES principales que permiten organizar el «Andamiaje teórico» (caps. 1, 2 y 3), desde el que se construyó la mirada de investigación; el «Abordaje metodológico e indagaciones» (caps. 4, 5 y 6), a partir del cual se diseñó y se implementó la estrategia de investigación; y los «Entrecruzamientos» (cap. 7), que permitieron arribar a los diferentes tipos de determinaciones que orientan los dispositivos analizados.

En el CAPítulo 1, titulado «La materialización de estrategias biopolíticas en políticas públicas estatales», se delimitan categorías teóricas como políticas sociales, biopolítica y Estado, institución-organización-establecimiento y síndrome de violentación institucional, recorrido que nos permite sostener que tanto el Patronato del Menor como el Sistema de Protección Integral de Derechos componen una formación, una disposición de elementos (leyes, normativas, procedimientos, establecimientos), unos regímenes de saberes disciplinares (como el derecho, el trabajo social, la medicina, la pedagogía y la psicología), entrelazados por unos juegos de fuerzas de poder y de estrategias que resultan productores de modos singulares de hacer-ser niños, niñas y adolescentes.

Tales dispositivos son los que se despliegan en el CAPítulo 2, titulado «Los dispositivos de hacer-ser niños/as y adolescentes». Los desarrollos que se presentan en este apartado muestran que no siempre hubo «niñez», que no se trata de una categoría ahistórica ni con validez universal, sino que constituye una creación moderna, producida por prácticas estatales, a partir de la cual se diferenció el mundo adulto del mundo de los/as niños/as, 
y cuya significación movilizó afectos, representaciones y acciones. Invento moderno que ha mutado de la concepción jurídica del niño/a como objeto de tutela a la de niños/as que, al igual que los/as adultos/as, son concebidos/as como sujetos de derechos.

Cierra esta primera parte el CAPítULO 3, titulado "Los aportes de los saberes "psi"». Se delinean, aquí, algunos de los saberes «psi» que intervinieron en la producción de un tipo de niñez para el gobierno de las familias. Saberes que, con la creación de las carreras de psicología, disputaron el campo de la infancia, en el cual el psicoanálisis cobró un lugar central. De allí el bosquejo de las pujas políticas generadas por la apertura de esta carrera en la Universidad Nacional de La Plata y por la sanción de la Ley 23.277/85 de Ejercicio Profesional de la Psicología, restringida, hasta entonces, a las indicaciones que emanaban de las disciplinas médicas. Completa este capítulo, la caracterización de las primeras prácticas profesionales de los/as psicólogos/as en los establecimientos del ámbito que nos ocupa: las instituciones de la otrora denominada Dirección de Menores, y de aquellos dispositivos que fundan un encuentro inaugural entre un dispositivo sociohistórico de intervención sobre un sector de la población de niños/as y adolescentes, y dispositivos diseñados por profesionales psicólogos/as.

La perspectiva metodológica, los instrumentos y las herramientas de análisis se presentan en el CAPítULo 4, titulado «La estrategia de investigación». En este apartado, que da inicio a la segunda parte, se describen los pasos que organizaron el proceso de abordaje metodológico, el modo en el que se aplicaron los instrumentos de análisis (por un lado, el análisis documental que se efectuó sobre las normativas; por el otro, las entrevistas que se realizaron a los psicólogos/as) y las herramientas de análisis que, a partir de las operaciones de distinción y de puntuación, permitieron caracterizar, comprender e interpretar los insumos obtenidos.

En el CAPítulo 5, titulado «Los elementos normativos en la provincia de Buenos Aires», se ofrece el análisis documental de los elementos dispuestos por el Decreto Ley 10.067 del Patronato de Menores (1983), la Ley 13.298 de Promoción y Protección Integral de los Derechos de los Niños (2005) y la Ley 13.634/07 de Fuero de Familia y del Fuero Penal del Niño, así como de sus normativas complementarias. Se aborda el modo en que tales 
normativas concebían y proponían intervenir sobre un sector de la población de niños/as y adolescentes: en un caso, a partir de tutelar a quienes se encontraban en situación de «peligro moral o material»; en otro, de proteger y de restituir derechos a quienes se encuentran en situación de vulneración efectiva de derechos y a quienes deben cumplir una medida de responsabilidad penal.

En el CAPíTULO 6, titulado «Los dispositivos de intervención», se analizan las conversaciones sostenidas con los/as profesionales entrevistados/as y se recuperan a partir de su voz los principales dispositivos de intervención diseñados e implementados en los establecimientos del actual Organismo de la Niñez y Adolescencia de la provincia de Buenos Aires, entre los años 2000-2015. En línea con el criterio utilizado en el capítulo anterior, las descripciones se ordenan según el tipo de establecimiento (institutos penales, hogares convivenciales, centros de responsabilidad penal juvenil y hogares de protección de derechos) y se organizan de acuerdo al tipo de dispositivo implementado (grupales, individuales, singulares), a los propósitos que los orientaron y con quiénes se intervenía en cada caso (niño/as y adolescentes, familias / referentes vinculares). Para potenciar la visibilidad de los dispositivos referidos en acción se incluye la transcripción de escenas experienciadas, que ofrecen la descripción detallada de los diálogos y de los efectos producidos.

Los diferentes desarrollos efectuados durante el proceso de investigación confluyen en la construcción del CAPíTULO 7, titulado «Entrecruzamientos». A partir de la operación de distinción y de puntuación de insistencias se ofrecen en este apartado las principales determinaciones que operan en los distintos dispositivos analizados y que la mirada de quien investiga construyó en torno a tres categorías centrales: normativas, institucionales y teóricas. Como en el capítulo anterior, la caracterización de tales determinaciones se articula con las escenas que al respecto relatan los/as psicólogos/as entrevistados/as.

Se ofrece, por último, el apartado con las conCLUSIONES que condensan las reflexiones que se desprenden de las indagaciones realizadas. En tanto punto de partida para interrogantes que guíen futuras investigaciones, estas líneas pretenden no solo recuperar los elementos que determinan los dispositivos abordados y dar cuenta de las resistencias que insisten en los distintos tiempos normativos sino contribuir a uno de los campos del 
ejercicio profesional de la psicología y aportar a la revisión de las prácticas institucionales que deben promover y garantizar la producción efectiva de niños/as y adolescentes como sujetos de derechos.

Cierra el trabajo el apartado «Referencias, normativas y fuentes» en el que se ofrece el detalle completo de los materiales bibliográficos, ${ }^{2}$ las normativas legales y las fuentes personales que fueron consultados para el desarrollo de la presente investigación. 


\section{Referencias}

Fernández, A. M. (2011). Política y subjetividad. Asambleas barriales y fábricas recuperadas. Ciudad Autónoma de Buenos Aires, Argentina: Biblos.

Pérez, E. A. (2015). Ejercicio de derechos y producciones de subjetividad. Un estudio en redes intersectoriales en instituciones de La Plata y Gran La Plata (2016-2018) [Proyecto de investigación]. La Plata, Argentina: Universidad Nacional de La Plata.

Mendoza, F. y Ruiz, A. (abril de 2019). Cómo citar con las normas APA. [Presentación]. Taller Cómo citar con las normas APA. Facultad de Artes, Universidad Nacional de La Plata. Recuperado de http://sedici.unlp.edu.ar/handle/10915/73909

Ruiz, A. (2018). La incorporación de citas en los textos científico académicos. Estilos y consideraciones para su redacción (apunte de cátedra). Taller de Edición Técnica, Facultad de Periodismo y Comunicación Social, Universidad Nacional de La Plata. Recuperado de http://sedici.unlp.edu.ar/handle/10915/73792

\section{Normativas}

Decreto Ley Provincial 10.067 (1983). Patronato de Menores. Boletín Oficial de la Provincia de Buenos Aires. La Plata, 9/12/1983.

Ley Nacional 23.277 (1985). Ejercicio Profesional de la Psicología. Boletín Oficial de la República Argentina. Buenos Aires, 15/11/1985.

Ley Nacional 26.061 (2005). Protección Integral de los Derechos de las Niñas, Niños y Adolescentes.

Boletín Oficial de la República Argentina. Buenos Aires, 26/10/2005.

Ley Provincial 13.298 (2005). Promoción y Protección Integral de los Derechos de los Niños.

Boletín Oficial de la Provincia de Buenos Aires. La Plata, 27/1/2005.

Ley Provincial 13.634 (2007). Principios Generales del Fuero de Familia y del Fuero Penal del Niño.

Boletín Oficial de la Provincia de Buenos Aires. La Plata, 2/2/2007. 
INTRODUCCIÓN 


\title{
La construcción del problema de investigación
}

\author{
El escenario legislativo \\ El rol de los/as profesionales \\ Los dispositivos de intervención \\ El problema de investigación
}

En el presente apartado se traza el recorrido que hilvanó el problema de investigación en el ámbito legislativo en el que se enmarca el trabajo. Tal escenario normativo contiene los cambios acontecidos con la sanción de la ley nacional 26.061 de Protección Integral de los Derechos de las Niñas, Niños y Adolescentes (2005) y, a nivel provincial, con la sanción de las leyes 13.298 de Promoción y Protección Integral de los Derechos de los Niños (2005) y 13.634 del Fuero de Familia y del Fuero Penal del Niño (2007), así como la indagación bibliográfica respecto a los efectos que tales cambios produjeron en las políticas públicas y en los dispositivos institucionales concretos.

Asimismo, aborda el rol de los/as profesionales establecido en las normativas y las posibilidades concretas de su ejercicio. En particular, el rol de los/as psicólogas/as. Tal recorrido derivó en la necesidad de delimitar las categorías de dispositivo y de institución que, a modo de herramientas, orientan nuestra mirada para la construcción del problema de investigación.

\section{El escenario legislativo}

Los cambios legislativos producidos en nuestro país, a nivel nacional, con la sanción de la ley 26.061 de Protección Integral de los Derechos de las Niñas, Niños y Adolescentes (2005), y a nivel provincial, con la sanción de las leyes 13.298 de Promoción y Protección 
Integral de los Derechos de los Niños (2005) y 13.634 del Fuero de Familia y Fuero Penal del Niño (2007) -con sus respectivos decretos reglamentarios-, han significado una ruptura, a nivel normativo, con el Patronato de Menores.

En la revisión bibliográfica, hemos encontrado diversas producciones que interrogan sobre el impacto de las normativas sancionadas e implementadas a partir de 2006 y 2007 en las políticas públicas y en las prácticas institucionales (Oyhandv Cioff, 2004; Aguirre \& Ponce Núñez, 2009; Di lorio, 2010; Lucesole, 2012; Grinberg, 2013; Llobet, Litichever \& Magisttris, 2012; Llobet, 2014; Fasciolo, 2018).

Aguirre y Ponce Nuñez (2009) plantean que resulta una obviedad pensar que la sanción de las leyes produce -por sí misma- un cambio cultural. Las normativas son un punto partida clave pero se requiere de un real compromiso de la totalidad de los/as operadores/as que trabajan en el sistema. Los autores señalan que para la implementación de las nuevas normativas el poder administrador no está a la altura de las circunstancias. La base del sistema -los servicios locales- son incipientes y no hay una adecuada coordinación entre los municipios y el poder central provincial. El sistema provincial, que debe contar con una comisión interministerial que lo regule, también carece de autoridad suficiente. No hay, en definitiva, una política pública general y única que resuelva la diversidad de problemáticas que afectan a los/as niños/as y a los/as jóvenes en sus derechos más esenciales. A esto se suman las anomalías propias del poder judicial, cuyas relaciones con el poder administrador se presentan conflictivas, cuando no inexistentes.

Grinberg (2013) sostiene que este cambio normativo otorgó mayores competencias a los organismos administrativos, a la vez que fijó restricciones a la intervención judicial, lo cual abrió un proceso de adecuación de las normativas provinciales a la nueva ley nacional, así como una reconfiguración de los dispositivos jurídicos-burocráticos en cada ámbito local; transformaciones que han adquirido características particulares en función de la situación jurídica y de las relaciones entre los actores administrativos y judiciales preexistentes en cada ámbito. 
Di lorio (2010) expresa que, desde el punto de vista declarativo, se derogan viejos paradigmas sobre el modo de intervenir con la infancia, pero esto no supone la implementación directa de discursos preformativos; es decir, la transformación de las prácticas, en tanto que estas se producen sobre el trasfondo de creencias sociales compartidas. En este sentido, las transformaciones legislativas no se corresponden, necesariamente, con las transformaciones socioculturales. La autora señala, a la vez, la herencia positivista del siglo XIX que determinó las prácticas y las políticas en torno a la infancia.

En referencia a la transformación de las prácticas, Llobet, Litichever y Magisttris (2012) señalan la existencia en nuestro país de una tendencia investigativa que ubica los problemas del enfoque de derechos de la infancia en la falta de modernización del Estado. Desde su perspectiva, es en el plano de las definiciones prácticas donde debe analizarse tal eficacia y sostienen que los programas parecen considerar como condiciones dadas la «vulnerabilidad» y el «riesgo» sin explicar qué se entiende por ellos, lo que implica la ausencia de las significaciones prácticas de estos criterios, observando que los programas sociales analizados construyen una definición abstracta de los/as beneficiarios/as.

Los autores realizan una revisión de los ejes de las políticas de infancia a partir del análisis de programas y de planes en la Ciudad Autónoma de Buenos Aires y en los partidos del conurbano bonaerense. En una de las líneas de análisis que despliega sostienen:

[...] la inclusión del enfoque de derechos en las políticas sociales para la infancia ha propiciado, en este contexto, una movilización de actores que visibiliza los problemas de este sector y obliga a los actores nacionales e internacionales a proponer un lugar destacado en la agenda institucional para los problemas de la infancia y adolescencia. No obstante, al analizar los procesos de institucionalización y de interpretación mediante los cuales estas ideas son incorporadas en el diseño de programas y de políticas sociales, lo que hayamos es su reenmarcamiento en definiciones de problemas y de estrategias altamente individualizadas y psicologizadas (Llobet, Litichever \& Magisttris, 2012, p. 89). 
En otro trabajo, Llobet (2014) interroga sobre el lugar específico que ocupan las necesidades infantiles en la institucionalidad concreta, pregunta que se abre a dos dimensiones. Por un lado, tal institucionalización se efectúa en un sentido normativo: el niño debe jugar para poder ser niño, «en donde el juego -un tipo de juego por casoconstituye una necesidad universal» (p. 11). Por otro, el lugar del niño es la escuela, que deviene como un lugar constitutivo de la infancia. De este modo, sostiene que se producen oposiciones: «El juego es esencial al desarrollo infantil, si es trabajo no es juego, el trabajo infantil impide el juego y I aprendizaje escolar» (p. 11).

De esto se derivan dilemas en el plano normativo respecto a qué se entiende por trabajo infantil; dilema que se intensifica cuando de las necesidades que definen a la infancia devienen las formas de comprensión de la crianza y de la vida familiar, las funciones de los/as adultos/as a cargo de las mismas y la idea respecto de qué es ser buena madre (Llobet, 2014).

Estos modos de pensar y de entender la infancia son productores de modos de intervención, en particular, en las prácticas de intervención institucionales que ayudan a delimitar los tipos de medidas de protección o de promoción de derechos a tomar.

Entre los estudios sobre programas y sobre dispositivos institucionales creados, se encuentra el trabajo etnográfico realizado por Grinberg (2013) en un organismo administrativo de protección de la Ciudad Autónoma de Buenos Aires, donde analiza un tratamiento institucional. El análisis visibiliza una dimensión moral operante que se presenta en las distintas interpretaciones y diagnósticos que los profesionales realizan. La autora sostiene que entre los profesionales de las defensorías zonales circula un «enfoque moral» social y una mirada que tiende a la individualización y a hacer abstracción del contexto socioeconómico y de violencia estructural que atraviesa la población objeto de las defensorías estudiadas.

Otra de las investigaciones fue desarrollada por Lucesole (2012) en el Sistema de Responsabilidad Penal Juvenil en la provincia de Buenos Aires. La autora indaga cómo se plasman las nuevas normativas en los dispositivos institucionales, en los discursos y en 
las prácticas concretas para el cumplimento de medidas alternativas a la privación de la libertad. Acerca de esto, sostiene:

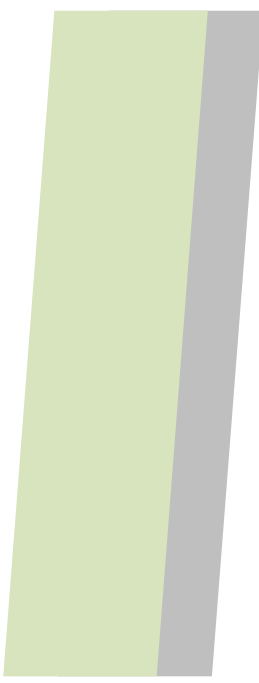

La implementación de la nueva normativa de niñez y adolescencia en la PBA se encuentra en un incipiente proceso de transición, dado que si bien la mayoría de los discursos apuntan -siguiendo el «deber ser» normativo- a la perspectiva de derechos y al garantismo penal, se evidencia en los operadores del sistema el arraigo de representaciones y de prácticas tutelares protectorpunitivas, vestigios de la institucionalidad del patronato, las cuales enmarcadas en un escenario signado por la escasez de recursos y atravesado por disputas y por conflictos políticos, y por la falta de articulación de los actores en el marco de la co-responsabilidad, se tornan un verdadero obstáculo para poner en plena vigencia el sistema (Lucesole, 2012, p. 155).

Oyhandv Cioff (2004) retoma los desarrollos de Guemureman y Daroqui (1999), quienes se proponen describir el funcionamiento de las instituciones que conforman el Patronato de Menores en el ámbito de la provincia de Buenos Aires y de la Capital Federal. El estudio muestra, como un dato central para entender la lógica de funcionamiento de este dispositivo, la inexistencia de una sistematización de datos, producto de que las estadísticas que producen las dependencias públicas son incoherentes, erráticas e insuficientes. «Pareciera existir una negación institucional, un borramiento de las propias prácticas y una irresponsabilidad (nadie es responsable por lo que no sabe) por la ineficacia del sistema de protección a la infancia» (Oyhandv Cioff, 2004, p. 23).

En tanto, la investigación efectuada por Fasciolo (2018) evidencia que si bien en las nuevas normativas se propone la desinstitucionalización se continúa «institucionalizando» a un gran número de niños/as mediante las llamadas «guardas institucionales», «medidas de abrigo» y otras modalidades de intervención propias de los fueros civiles y de familia. Y en cuanto a los cambios normativos, la autora manifiesta que no es posible sostener que hayan impactado en la producción de «prácticas sustancialmente diferentes de aquellas dadas en el espacio socio-ocupacional abierto en la Doctrina de la Situación Irregular» (Fasciolo, 2018, p. 355). 


\section{El rol de los/as profesionales}

En lo que respecta al lugar que se les asigna a los/as profesionales, Kliun y Fernández (2009) sostienen que las nuevas normativas marcan un punto divisorio respecto de la Ley Nacional 10.903/19 del Patronato de Menores, en tanto la tarea profesional se enmarca hacia la concreción de abordajes interdisciplinarios que tienen como protagonistas a los/as niños/as y adolescentes como sujetos de derecho y cuya prioridad es el desarrollo integral.

En este marco, la labor profesional requiere de un trabajo interdisciplinario que implica la existencia de un grupo que conforma un equipo de trabajo y cuya combinación va a depender de cada «aquí y ahora institucional», con definiciones ideológicas de cada integrante y también de la autoridad institucional en la que se referencian. Conformación que requiere de cierta temporalidad, imprescindible para la integración progresiva entre distintos saberes y métodos, para la deliberación y para la concreción ideológica y metodológica.

En relación con la interdisciplina, Fasciolo (2018) sostiene que la posibilidad de producción de espacios interdisciplinares se encuentra limitada por dos variables: la economía del contacto y las condiciones laborales. Respecto de la importancia de considerar las condiciones laborales sostiene que «no son una condición más de la práctica, meros condicionantes externos, sino que constituyen un organizador de esa práctica en tanto integrada a un proceso de trabajo y en este sentido van a delinear los límites de lo posible» (Fasciolo, 2018, p. 222).

En la investigación, realizada en una institución del área de responsabilidad penal juvenil de la provincia de Buenos Aires, la autora señala que los/as profesionales de distintas disciplinas desarrollan tareas muy similares, centradas, fundamentalmente, en la asistencia mediante entrevistas y en la educación respecto de la adecuación a la lógica del encierro y las evaluaciones. «Los/as psicólogos/as también ven interpeladas sus tácticas operativas a partir de la lógica de gobierno institucional y se ubican en un lugar de subordinación en el circuito de información-desinformación respecto a la toma de decisiones sobre algunas cuestiones» (Fasciolo, 2018, p. 223). 
Bouilly y Anderson (2012), integrantes de un equipo de investigación que se propuso dar cuenta de la «cuestión penal juvenil» y, en particular, del encierro punitivo en la provincia de Buenos Aires, sostienen que en estas instituciones los denominados «maestros» son los actores más visibles respecto del gobierno de la vida de los/as jóvenes y de la garantía del orden institucional.

En la dinámica institucional, los/as psicólogos/as y los/as trabajadores/as sociales que integran los equipos técnicos de los institutos son actores centrales, en tanto constituyen

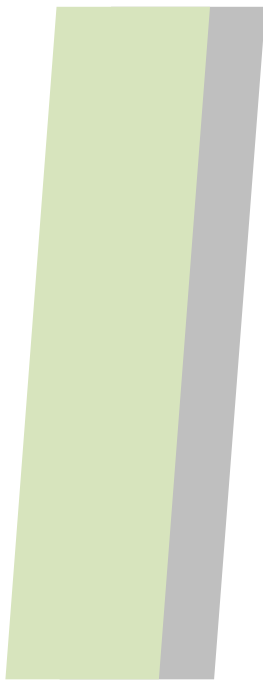

Voces expertas que actúan en varios planos: por un lado, evalúan a los jóvenes y a sus familias extrayendo de allí un saber que se proveerá a demanda a otros actores, tanto del circuito minoril del poder ejecutivo como del judicial. Por otro lado, y en tanto «consejeros», también suelen avalar las dinámicas institucionales vinculadas al régimen de vida en términos formales y de igual modo aquellas que se despliegan informalmente. Asimismo, «hacia afuera de la institución» establecen una relación de intercambio y de consulta, a veces mediatizada por el director, otras de acceso directo, con la agencia judicial a partir de las demandas de juzgados, defensorías, fiscalías (Bouilly \& Anderson, 2012, p. 241).

Respecto a los/as psicólogos/as, afirman, por un lado, que la participación de al menos un/a psicólogo/a en cada equipo técnico suele estar garantizada, no así la de los/as trabajadores/as sociales; y, por otro, que de las relaciones que construyan con los/as directores/as, con los/as «maestros/as» y con personal del Poder Judicial dependerá el grado de incidencia, de negociación, de resistencia o de promoción de propuestas de trabajo.

Además, sostienen que los/as profesionales deben formar parte del análisis que se realice, en tanto participan del encierro punitivo como operadores/as clave del «tratamiento», a través de sus aportes en tanto saberes expertos sobre la personalidad y la conducta de los/as jóvenes, las dinámicas de sus familias, las situaciones socio-familiares o barriales, 
etc. Expertos "devenidos en "consejeros", lo son tanto del joven como de sus familias, pero también de los directores y de los diferentes operadores de la justicia» (Bouilly \& Anderson, 2012, p. 241).

En referencia al nivel formal de la función del equipo técnico en los «institutos de menores», las autoras aluden al Centro Cerrado Dolores que las define como una «evaluación del joven y un relevamiento de datos del mismo y su entorno familiar, tendientes al abordaje integral necesario para su tratamiento» (Bouilly \& Anderson, 2012, p. 242).

De tal definición, sugieren que se trata de prácticas y de discursos profesionales que configuran un sentido del tratamiento para la corrección y la posterior reinserción social, a la vez que constituyen aportes técnicos para la gestión de la seguridad y el castigo en correspondencia con lo requerido por las autoridades. Sin embargo, visualizan que tanto la composición como el campo de acción y las responsabilidades profesionales no se encuentran regulados formalmente, por lo que las prácticas profesionales más o menos informales se configuran de acuerdo con los habitus (Bourdieu, 2013) institucionales.

En relación con los/as psicólogos/as, indican que en el ámbito de las instituciones de Responsabilidad Penal Juvenil el promedio varía entre un/a psicólogo/a cada seis jóvenes detenidos/as y un/a psicólogo/a cada 54 jóvenes.

Del análisis de las entrevistas realizadas, se desprende que la atención psicológica es «a demanda» del/la joven, lo que significa que ante situaciones concretas son ellos/as quienes solicitan la intervención de el/la psicólogo/a, demanda que es canalizada a través de los/as celadores/as. Al respecto, expresan que de acuerdo a las autoridades institucionales las entrevistas psicológicas no son programadas porque no pueden garantizar una frecuencia regular.

Tras analizar las prácticas de los/as profesionales que componen los equipos técnicos de las instituciones de Responsabilidad Penal Juvenil, las autoras señalan que el objetivo de la intervención profesional es 
Estar al servicio de la contención y el control que garanticen la aceptación del encierro y reducir cualquier manifestación de resistencia al mismo. El grado en que la subjetividad del joven es aplacada por este tipo de dispositivos es difícilmente mensurable; pero sea porque la intervención logra docilizar o porque los detenidos aprenden a adoptar la actitud esperada por el personal institucional y judicial, se obtiene lo que se busca: «internos tranquilos» que permitan mantener el buen orden (Bouilly \& Anderson, 2012, p. 247).

En este sentido, concluyen que los/as profesionales son una pieza clave en el dispositivo que sostiene el sistema «punitivo-premial» de los institutos, portan un saber que legitima su palabra y producen informes -que devienen en «pruebas de verdad»- respecto de quiénes son y qué hacen estos/as jóvenes institucionalizados/as.

Fasciolo (2018) realiza una investigación donde analiza las funciones profesionales de los/as trabajadores/as sociales que integran los equipos técnicos de los Centros Cerrados (CC) de la provincia de Buenos Aires para jóvenes privados/as de libertad con causas penales, entre los años 2009-2013. Respecto de los/as profesionales «psi» (categoría en la que incluye a los/as psicólogos/as y los/as psiquiatras) que en tales instituciones integran los equipos técnicos señala que en el organigrama dependen directamente de la dirección de la institución.

Si bien el espacio socio-ocupacional de los/as profesionales no está reglamentado por la normativa del Sistema de Responsabilidad Penal Juvenil de la Provincia de Buenos Aires, en las «actas de ingreso» se establece que psicólogos/as y trabajadores/as sociales deben realizar entrevistas de admisión. A su vez, como indica el autor, la Resolución 370/11 del Ministerio de Desarrollo Social ubica la función del «equipo técnico en conjunto -sin distinguir profesiones- en el período de integración del joven a las actividades institucionales e interviniendo en las decisiones y/o propuestas sobre las visitas que constituyen derechos de los jóvenes» (Fasciolo, 2018, p. 213).

En entrevistas realizadas por la autora a jóvenes que se encuentran cumpliendo una medida en un centro cerrado, los/as psicólogos/as y la función que cumplen son descriptos de la siguiente manera: 
Es una persona que te hace preguntas sobre tu vida, tu familia y te ayuda a recapacitar, manda informes al juzgado sobre lo que hacés, si hacés deportes, si vas a la escuela, si tenés visitas / Me preguntan por qué estoy encerrado y quieren saber todo lo que pasó en mi causa. No estoy hace mucho tiempo acá, pero no lo veo seguido / Te aconseja para bien / Te escucha, te pregunta, te ayuda / Te psicologea, te habla, te ayuda con tus problemas / Les contamos cosas que nos pasaron en el pasado (Fasciolo, 2018, p. 215).

Tales modos de describir el quehacer profesional de los/as psicólogos/as por los jóvenes son interpretados por Fasciolo (2018) como una «relación contradictoria que instala la tensión entre una práctica que al mismo tiempo que representa "ayuda/escucha", representa una "intromisión/evaluación" sobre sus vidas» (p. 215).

Del mismo modo, expone cuáles son las funciones que tendría que cumplir un psicólogo según un Defensor: «Debería salir del escritorio y trabajar sobre las reacciones impulsivas de los pibes en el momento que se dan. Deben intervenir en los momentos en que los pibes están realizando otras actividades para ver cómo funcionan» (Fasciolo, 2018, p. 216).

Acerca de las diferencias sobre las prácticas profesionales de los/as trabajadores/as sociales y los/as psicólogos/as, la autora señala que los/as jóvenes entrevistados/as no observan diferencias entre ambas prácticas. Al tiempo que son ubicados en una tensión en la que, contradictoriamente, quienes «escuchan» y «ayudan» son quienes controlan y evalúan -de cara al poder judicial-, facilitando u obstaculizando, de este modo, su libertad.

Asimismo, plantea que el cambio más sentido en la intervención profesional se relaciona con el proceso penal del joven, proceso en el que intervienen nuevos actores pertenecientes al Fuero Penal Juvenil con quienes se articula el juicio oral como nueva instancia donde, en ocasiones, se convoca a los/as profesionales. En este sentido, afirma que la discrecionalidad, el «mayor cuestionamiento a la Doctrina de la Situación Irregular, pervive, con muy buena salud, en los ámbitos administrativos y judiciales» (Fasciolo, 2018, p. 355). 
En lo que respecta a la intervención profesional de los/as psicólogos/as, la misma se encuentra reglamentada por la Ley Provincial 10.306 de Ejercicio Profesional de la Psicología ${ }^{3}$ (1985) y por el Código de Ética del Colegio de Psicólogos de la Provincia de Buenos Aires (1985). ${ }^{4}$ Tales reglamentaciones delinean la inscripción social del quehacer profesional, de modo tal que la psicología como profesión se localiza en la compleja trama de relaciones entre lo público, la concepción de Estado en cada momento histórico y la conceptualización que desde este se tiene acerca de las políticas sociales y de las cuestiones a incorporar en la agenda (D'Agostino, 2017).

\footnotetext{
3 La Ley define el ejercicio profesional de la psicología como «toda actividad de enseñanza, aplicación e indicación del conocimiento psicológico y de sus técnicas específicas en: a) la investigación y explotación de la estructura psicológica humana a nivel individual y grupal, el diagnóstico, pronóstico y tratamiento de la personalidad, para la recuperación, conservación y prevención de la Salud Mental, mediante métodos y técnicas específicamente psicológicas; b) el desempeño de cargos, funciones, comisiones o empleos por designación de autoridades públicas, incluso nombramientos judiciales; c) la emisión, evacuación, expedición y presentación de consultas, estudios, consejos, informes, dictámenes, peritajes y certificaciones; d) la enseñanza y el asesoramiento» (artículo 2). Tal ejercicio podrá ser en «forma individual y/o integrando equipos interdisciplinarios, en Instituciones o privadamente. En ambos casos podrá hacerlo a requerimiento de especialistas de otras disciplinas o de personas o instituciones que, por propia voluntad, soliciten asistencia y/o asesoramiento profesional. Este ejercicio profesional se desarrollará en los ámbitos individual, grupal, institucional o comunitario» (artículo 3). Asimismo, es requisito previo para el ejercicio profesional que el/la psicólogo/a efectúe «la inscripción en la matrícula que a tal efecto llevarán los Colegios de Distrito creados por la presente Ley y el pago de la cuota que anualmente se fije» (artículo 52).
}

4 El Código de Ética establece y anuncia «las disposiciones, normas y principios éticos que deben inspirar y regular el ejercicio profesional de los psicólogos matriculados en nuestro Colegio». Respecto a la responsabilidad en la práctica profesional, plantea que el/la psicólogo/a «debe abstenerse de participar activa o pasivamente en cualquier acción o forma de tortura, tratos crueles, inhumanos o degradantes y de todo tipo de apremio ilegal que atente contra los Derechos Humanos reconocidos mundialmente; incitar a ellos, encubrirlos o intentar cometerlos». En cuanto al secreto profesional es una obligación y un derecho permanente, «cualquiera sea la relación profesional, ámbito de actividad y tipo de prestación, respecto de todo lo sabido, intuido, percibido o presentido con relación a las personas que lo consulten o las que traten como pacientes, procurando ser tan discreto que ni directa o indirectamente nada pueda ser descubierto, preservando así la intimidad de los mismos. El deber de guardar secreto profesional subsiste aún después de concluida la relación profesional o producida la muerte del paciente (...) El límite del secreto profesional está dado por la existencia de una justa causa, cualquiera sea su origen, que según la conciencia del profesional, en cada caso concreto, amerite la revelación» (artículo 12). En referencia a los informes (escritos o verbales) sobre personas, instituciones o grupos, el Código establece que los mismos «deberán excluir aquellos antecedentes entregados al amparo del secreto profesional y ellos se proporcionarán solo en los casos necesarios cuando, según estricto criterio del profesional interviniente, constituyan elementos ineludibles para configurar el informe». Para aquellas prácticas de ejercicio profesional en las cuales el/la psicólogo/a esté en relación de dependencia laboral, establece que no se deberán acatar «instrucciones emanadas de sus empleadores cuando éstas lo obliguen a contravenir los principios o normas de la ética profesional. En caso de conflicto entre los procedimientos institucionales y los intereses de las personas a quienes va dirigido el servicio, el psicólogo debe optar por defender a estos últimos» (artículo 49). 
En lo que refiere al ejercicio profesional en el ámbito de las políticas públicas para la niñez y la adolescencia, Llobet (2014) sostiene que las codificaciones de las necesidades de los/as niños/as en clave afectiva y subjetiva, emanadas del discurso «psi», se tornaron en indicadores para establecer la intervención. En este punto, señala que las condiciones de desigualdad y de injusticia no son incluidas, produciéndose una psicologización de lo social.

Llobet, Litichever y Magisttris (2012), en tanto, señalan la existencia de narrativas que ubican al/la niño/a como sujeto de derechos, pero que al mismo tiempo sostienen prácticas que los/as abordan como objetos de intervención, con tendencias a la psicopatologización y a la intervención desde una perspectiva individual.

En conclusión, en los materiales encontrados observamos coincidencias respecto a la importancia que las nuevas normativas tienen para la implementación de políticas públicas en clave de derechos para los niños, niñas y adolescentes; coincidencias que persisten a la hora de analizar el escaso impacto de las mismas en las prácticas institucionales efectivas.

\section{Los dispositivos de intervención}

En lo específico a los dispositivos de intervención de los/as psicólogos/as, estos parecen diseñarse a partir de modos de lecturas psicologizantes y/o psicopatologizantes. Así pensadas, las intervenciones suelen invisibilizar las condiciones socioeconómicas por las que atraviesa el sector de la población de niños, niñas y adolescentes que atienden; condiciones por las cuales son «atendidos/as» en las instituciones y/o incluidos/as en los programas para la niñez y la adolescencia.

En relación con los dispositivos de intervención implementados por los/as psicólogos/as en los establecimientos dependientes del Organismo de la Niñez y Adolescencia de la provincia de Buenos Aires, no hemos encontrado materiales bibliográficos. 
En este contexto, el presente trabajo de investigación se ubica en un punto de cruce entre el ejercicio profesional de la psicología y las políticas públicas para los/as niños/as y los/as adolescentes en situación de vulneración de derechos y/o en conflicto con la ley penal. De allí que se propone una caracterización de los dispositivos de intervención que implementan los/as psicólogos/as en los establecimientos dependientes del Organismo de la Niñez y Adolescencia de la provincia de Buenos Aires -entre los años 2000 y 2015-, para visibilizar algunos de los elementos que los determinan; entre ellos, el impacto que las normativas producen en y sobre los mismos.

Para ello, nos apuntalaremos en la noción de dispositivo desarrollada por Foucault (1978) y por Deleuze (2014), así como en el modo de pensar la institución según proponen Castoriadis (1993, 1995, 1997, 2001), Baremblit (1994) y Fernández (2007).

Castoriadis (2001) sostiene que el hombre y la mujer solo existen en y por la sociedad, siempre histórica que, como tal, es una forma. Tanto la institución en general como las instituciones particulares que sostienen una sociedad son creaciones del imaginario social instituyente, categoría que posibilita pensar el nacimiento de la sociedad como la emergencia de lo nuevo radical, no explicable por factores naturales ni trascendentes ni como producto de una actividad racional.

Postula, así, un poder de creación inmanente tanto a las colectividades humanas (imaginario) como a los seres humanos singulares (imaginación), «el lenguaje, las costumbres, las normas, la técnica, no pueden ser explicados por factores exteriores a las colectividades humanas» (Castoriadis, 2001, p. 94). Poder de creación como facultad constitutiva de las colectividades humanas, del campo sociohistórico, creación «ex nihilo, la conjunción de un hacer-ser de una forma que no estaba allí, la creación de nuevas formas de ser. Creación ontológica» (Castoriadis, 2001, p. 95).

Así pensada, cada sociedad dada es una forma particular y singular, lo que implica una organización, un orden. Afirmación que funda para el autor dos preguntas fundamentales: primero, «¿qué mantiene unida a una sociedad? y, segundo, ¿qué es lo que hace nacer formas de sociedad diferentes y nuevas?» (Castoriadis, 1995, p. 66). 
Ante la primera pregunta, responde que es su institución, el complejo total de instituciones particulares, la institución social como un todo. Institución de la sociedad compuesta por múltiples instituciones particulares que forman un todo coherente y conforman una unidad en la institución total de la sociedad. Unidad que es «la unidad y cohesión de la urdimbre inmensamente compleja de significaciones que empapan, orientan y dirigen la vida de la sociedad considerada y a los individuos concretos que corporalmente la constituyen»(Castoriadis, 1985, p. 68). Urdimbre que es denominada por el autor como «magma de significaciones imaginarias sociales que cobran cuerpo en la institución de la sociedad considerada y que, por así decirlo, la animan» (Castoriadis, 1995, p. 68). Como ejemplos puntúa, Dios, polis, ciudadano, dinero, estado, nación, pecado, hombre, mujer e hijo. Respecto a estos últimos tres ejemplos señala que, más allá de definiciones puramente anatómicas o biológicas, son lo que son en virtud de las significaciones imaginarias que los hace ser eso.

La función de las significaciones imaginarias sociales es triple: estructuran las representaciones del mundo, designan las finalidades de la acción y establecen los tipos de afectos característicos de una sociedad (Castoriadis, 1997). De este modo, el imaginario efectivo está compuesto por significaciones que consolidan lo establecido. En esta dimensión, los universos de significaciones operan como organizadores de sentido de los actos humanos (Fernández, 2007).

En este sentido, las significaciones imaginarias sociales y las correspondientes instituciones crean su propio mundo, al modo de un cerco de organización, de información y de conocimiento que define

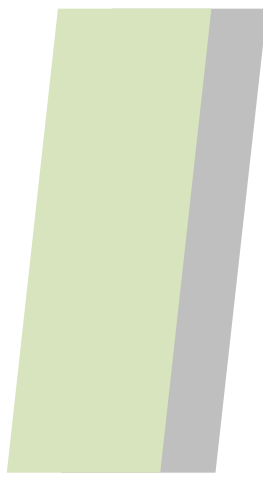

aquello que para la sociedad considerada es información, aquello que es estrépito y aquello que no es nada, o lo que define la pertinencia, el pero, el valor y el sentido de la información; o lo que define el programa de elaboración de una información. En suma, es la institución de la sociedad lo que determina aquello que es real de aquello que no lo es, lo que tiene un sentido y lo que carece de sentido. Toda sociedad es una construcción, una constitución, creación de un mundo, de su propio mundo (Castoriadis, 1995, p. 69). 
La capacidad de autocreación de la sociedad denominada «institución primera», refiere a la capacidad de crearse cada vez a través de la creación de instituciones específicas, denominadas «instituciones segundas transhistóricas», El lenguaje o el individuo son caracterizados por el autor como instituciones segundas transhistóricas, en tanto que el tipo de individuo es diferente en cada sociedad, pero no hay sociedad que no instituya un tipo cualquiera de individuo, o bien la familia: «La organización y el contenido específico de la familia son, cada vez, otros, pero no puede haber sociedad que no asegure la reproducción y la socialización de la generación siguiente, y la institución encargada de eso es la familia» (Castoriadis, 2001, p. 125).

Hay instituciones segundas que son específicas de sociedades dadas y que tienen un rol especial, lo que ubica, por ejemplo, en la polis griega o en la empresa capitalista, en tanto que no hay capitalismo sin empresa y no existe lo que entendemos por empresas en sociedades anteriores al capitalismo.

El autor sitúa, además, otras dos dimensiones que hacen ser a las instituciones: lo simbólico y lo funcional. Respecto del primero, sostiene que las instituciones solo existen en lo simbólico, aunque no se reducen a ello (una organización, un poder instituido, existen socialmente como sistemas simbólicos sancionados; que ligan unos símbolos y unos significados); el componente funcional, en tanto, refiere a que las instituciones cumplen funciones vitales: la producción, la educación, el regulamiento de los litigios, entre otros. De modo tal que no hay nada «natural» en los modos de hacer-ser de la sociedad, «la sociedad crea y define para sí los modos de responder a sus necesidades tanto como sus necesidades» ${ }^{5}$ (Castoriadis, 1993, p. 200).

\footnotetext{
5 «La humanidad tiene hambre, es cierto. Pero tiene hambre ¿de qué? Y ¿cómo? (...) la humanidad tuvo y tiene hambre de alimentos, pero también tuvo y tiene hambre de vestidos $y$, después, de vestidos distintos a los del año pasado, tuvo hambre de coches y de televisión, tuvo hambre de poder y hambre de santidad, tuvo hambre de ascetismo y de desenfreno, tuvo hambre de mística y hambre de saber racional, tuvo hambre de calor y de fraternidad, pero también hambre de sus propios cadáveres, hambre de fiestas y hambre de tragedias, y ahora parece tener hambre de Luna y de planetas. Es necesaria una buena dosis de cretinismo para pretender que se inventaron todas estas hambres porque no se comía ni se jodía bastante. (...) el hombre no puede existir sino definiéndose cada vez como un conjunto de necesidades y de objetos correspondientes, pero supera siempre estas definiciones porque salen de él mismo, porque él las inventa, porque por lo tanto, él las hace haciendo y haciéndose, y porque ninguna definición racional, natural o histórica permite fijarlas de una vez por todas» (Castoriadis, 1993, p. 235).
} 
Fernández (2007) retoma la noción de imaginario social propuesta por Castoriadis (1993) y sitúa la distinción que realiza el autor respecto a dos tipos de significaciones sociales: centrales -creadoras de ideas organizadoras- y segundas o derivadas. Así, la invención de una significación central reorganiza una multitud de significaciones sociales ya disponibles, a las que altera, en un movimiento de transformaciones de las actividades y de los valores de la sociedad en cuestión, a la vez que de los individuos y los objetos sociales.

Como ejemplo, señala que en el capitalismo la economía y lo económico se tornan significaciones centrales y se establece la separación de la esfera económica del resto de las actividades sociales, constituyéndose como un dominio autónomo y predominante; a partir de esto, una multitud de cosas son significadas como económicas pero «se ignora» su carácter de invención imaginaria y se las considera como «naturalmente económicas». De modo tal que la institución de una significación central siempre opera en lo implícito, se trate de la familia, la ley, el Estado. Para Fernández (2007), las significaciones imaginarias sociales, particularmente las centrales de una sociedad, «no denotan nada y connotan prácticamente todo» (p. 54).

Los universos de significaciones, al operar en lo implícito, construyen latencias colectivas que rigen las ideas o las argumentaciones de una sociedad a la vez que sostienen las prácticas y participan en la construcción de los cuerpos propios de una época, de una clase social, un género «comprometiendo tanto sus disciplinamientos como sus resistencias y líneas de fuga, sus afectaciones, potencias y síntomas. Forman parte de los heterogéneos dispositivos de disciplinamiento social y operan como implícitos en las -invisibles pero siempre eficaces-estrategias biopolíticas» (Fernández, 2007, p. 54).

De allí que las significaciones imaginarias sociales forman parte de las múltiples máquinas sociales de producción de objetivación y de subjetivación.

Objetivan, en tanto nominan, narran, argumentan, legitiman científica, política y culturalmente los ordenamientos de sentido. Subjetivan, en tanto producen las modalidades en que piensan, sienten, actúan los integrantes de los colectivos sociales involucrados. Instituyen sus mentalidades y construyen sus cuerpos (Fernández, 2007, p. 104). 
Los desarrollos que se inscriben en el movimiento institucionalista sostienen que no hay disciplina, profesión o teoría que abarque a las instituciones. La insistencia en nominar como movimiento, no como disciplina, responde a que, en tanto movimiento, es un conjunto de saberes y de modos de intervenir interdisciplinares, transdisciplinares y extradisciplinares. En este sentido, se compone de los aportes de distintas áreas del conocimiento, del psicoanálisis, de la antropología científica, de la lingüística, de la semiótica, de lo artístico, de los saberes políticos, de las experiencias políticas de los colectivos militantes, del pensamiento filosófico y del mítico, entre otros (Baremblit, 1994).

D' Agostino (2017) retoma los aportes de Varela (2010) y sitúa que a mediados del siglo $X X$, cobraron fuerza los movimientos que cuestionaban las formas que asumieron diferentes instituciones de la Modernidad: la educación, las prisiones, la familia, la fábrica, los hospitales. A partir de este momento, puede observarse, además, un incremento en la producción bibliográfica de diversas disciplinas acerca del tema.

Desde esta perspectiva, «institución» refiere a prescripciones y a prohibiciones que guían la vida social, de manera consiente o no; prescripciones que son, a la vez, lógicas, estéticas, éticas, y que determinan qué es verdadero o no, qué es justo o injusto, qué es bello o feo, para una sociedad determinada. De acuerdo al grado de formalidad de tales prescripciones, estas devienen en leyes, en principios o en costumbres. Las instituciones, pues, funcionan a partir de la regulación de la actividad social (Baremblit, 1994).

Ahora bien, para que tales funciones se efectúen las instituciones tienen que materializarse en dispositivos concretos, denominados organizaciones y caracterizados como formas materiales variadas, grandes y/o pequeños conjuntos de formas materiales y funcionales. En tal sentido, las instituciones no tendrían existencia real, vida propia, sino a través de las organizaciones, algunas de las cuales se componen de unidades menores denominadas establecimientos. Del mismo modo, las organizaciones no tendrían objetivos, ni dirección sino a través de las instituciones que en ellas se materializan.

Tales dimensiones -institución, organización, establecimiento- solo existen en un juego dinámico de los agentes que realizan las funciones correspondientes, sean estos individuales o colectivos. Así pensadas, las prácticas efectuadas por los agentes son las 
que operan, las que de algún modo les dan vida a las instituciones, en un juego de fuerzas inmanentes que pujan entre mantenerse iguales e inmóviles y variar, transformarse (Baremblit, 1994).

Desde este perspectiva, las instituciones-organizaciones-establecimientos son dispositivos, en tanto que refieren a una red que enlaza un conjunto de elementos heterogéneos -discursos, instituciones, instalaciones, decisiones reglamentarias, leyes, medidas administrativas, enunciados científicos-, heterogeneidad de elementos que pertenecen tanto a lo dicho como a lo no dicho (Foucault, 1978).

Entre tales elementos existe un juego de fuerzas, de cambio de posiciones, de funciones, de allí que el dispositivo se caracteriza por la naturaleza del vínculo que puede existir entre dichos elementos heterogéneos. La formación-creación de un dispositivo responde a la función, en un momento histórico dado, de responder a una urgencia; de allí que Foucault (1977) señala que el dispositivo tiene una función estratégica dominante.

La formación de un dispositivo, su génesis, presenta dos momentos; un primer momento, en el que prevalece un objetivo estratégico; y un segundo momento, en el que se constituye propiamente como tal, en la medida en que es el lugar de un doble proceso de sobredeterminación funcional: cada efecto, sea que entre en resonancia o en contradicción con los otros, requiere de una revisión, de un reajuste de los elementos heterogéneos que surgen por todos lados; reajuste que Foucault (1978) denomina perpetuo relleno estratégico.

La naturaleza del dispositivo supone una cierta manipulación de relaciones de fuerza, sea para desarrollarlas en una dirección, para bloquearlas o para estabilizarlas, lo que hace que el dispositivo esté siempre inscripto en un juego de poder a la vez que ligado a uno de los bordes del saber «que nacen de él pero, asimismo, lo condicionan. El dispositivo es esto: unas estrategias de relaciones de fuerzas soportando unos tipos de saber y soportadas por ellos» (Foucault, 1978, p. 3).

Las relaciones de poder desempeñan un papel directamente productor. El poder viene de abajo: en tanto relaciones de fuerzas múltiples que se forman y que actúan en los aparatos de producción, las familias, los grupos restringidos y las instituciones. El autor, 
señala, además, que «donde hay poder hay resistencia y no obstante (precisamente por eso) la resistencia nunca está en posición de exterioridad respecto al poder» (Foucault, 2008, p. 90).

Acerca de las relaciones de poder, Deleuze (2014) interroga: en tanto son fluidas, puntuales, difusas, móviles, «¿cómo van a fijarse y a globalizarse? Lo cual quiere decir: ¿cómo van a adquirir forma, ellas que no tienen forma?» (2014, p. 141). De este modo, retoma los desarrollos de Foucault respecto a que la informalidad de las relaciones de poder se integra en formas sociales, las instituciones, y abre otro interrogante: «¿Cuál es el rol de la institución? No es en absoluto producir poder, es dar al poder el medio de reproducirse. En la institución, el poder se reproduce, es decir, se estratifica, deviene estable y fijo» (2014, p. 142).

En tanto conjunto multilineal, el dispositivo se compone, al modo de una madeja, de líneas de diferente naturaleza: visibilidad, enunciación, líneas de fuerza y líneas de subjetivación (Deleuze, 2007). La visibilidad, como las líneas de luz que forman figuras variables inmanentes a cada dispositivo. Respecto al régimen de enunciados, estos remiten a líneas de enunciación que distribuyen posiciones diferenciales de sus elementos y que las curvas son ellas mismas enunciados. Existe, entonces, una heterogeneidad irreductible de dos formas que están unas con otras. Entre ambas, hay una relación: lo visible y lo enunciable. Relación que «solo puede venir de otra dimensión. Aquello que hará surgir la relación en la no relación de las dos formas es otra dimensión» (Deleuze, 2014, p. 11).

Las líneas de fuerza presentes en todo dispositivo son caracterizadas como líneas que van de un punto singular a otro de las líneas de visibilidad y de enunciación e implican los trayectos de una a otra. De modo tal que las líneas de fuerza atraviesan todos los lugares del dispositivo, no es visible tampoco decible, en tanto el poder es inmanente al saber. La cuarta dimensión que compone todo dispositivo se denomina líneas de subjetivación. Deleuze (2007) explica que la misma nace con el pensamiento de Foucault, quien postula otros vectores que traspasan los dibujos englobantes trazados por una línea, que escapa de las líneas de visibilidad, de enunciación y de poder, que se fuga de ellas. En este sentido, se trata de un proceso de subjetivación, sea de grupo o de personas, que 
se «sustraen tanto a las relaciones de fuerza establecidas como a los saberes constituidos. No es seguro que todo dispositivo comporte esta línea» (Deleuze, 2007, p. 307). Es decir que los dispositivos tienen diversas líneas que se entremezclan y se entrecruzan, con variaciones o incluso «mutaciones de disposiciones». Ahora bien, el autor señala que estas diferentes líneas se reparten en dos grupos: líneas de estratificación y de sedimentación, o líneas de actualización y creatividad.

Dicho lo anterior, podemos sostener que los dispositivos de intervención que nos proponemos caracterizar se inscriben en dispositivos en los que se anudan una multiplicidad de elementos heterogéneos, fueron creados en respuesta a una urgencia histórica e implican un juego de fuerzas de poder-saber para la producción de unos efectos; a la vez que ellos mismos son una disposición de elementos y una cierta manipulación de fuerzas de poder-saber para producir ciertos efectos.

Ubicamos, allí, un punto de cruce entre políticas públicas para niños/as y adolescentes en situación de vulneración de derechos y/o en conflicto con la ley penal materializadas en dispositivos institucionales concretos y en dispositivos de intervención diseñados e implementados por profesionales psicólogos/as. A su vez, al ubicar las leyes como uno de los elementos que componen el dispositivo resulta claro que su modificación no implica, como afirman los/as autores/as citados/as, un cambio en dicho dispositivo.

A modo de pliegue, interesa delimitar que la potencia de pensar de este modo las instituciones nos posibilitará visibilizar algunas de las dimensiones que anudan en la materialidad de los establecimientos, donde se alojan los/as niños/as y los/as adolescentes en situación de vulneración de derechos y/o en conflicto con la ley penal juvenil, y los efectos de determinación en y sobre los dispositivos de intervención que implementan los/as psicólogos/as; entre ellas, las normativas legales.

Por último, nos posibilitará visibilizar no solo aquellas fuerzas de lo repetitivo tutelar que insiste sino, también, aquello que varía, fuerzas instituyentes presentes que, en ocasiones, por la debilidad de su potencia, no son visibles. 


\section{El problema de investigación}

Es indiscutible la relevancia histórica y política de los cambios legislativos producidos a partir de la sanción de las leyes 13.298 de Promoción y Protección Integral de los Derechos de los Niños (2005) y 13.634 del Fuero de Familia y del Fuero Penal del Niño (2007) de la Provincia de Buenos Aires -y sus respectivos decretos reglamentarios- para la implementación de políticas públicas en clave de derechos, sintetizada por García Méndez y Vitale (2009) como «una deuda de la democracia».

Tales leyes derogaron el Decreto Ley 10.067/83 de la última Dictadura cívico militar, con el cual se materializaron a nivel provincial, con mayor claridad y coordinación que la Ley Nacional 10.903/19 -también conocida como «Ley Agote»-, políticas públicas centradas en la judicialización de la pobreza y en la producción del menor como objeto de tutela del Estado, lo que implica la implementación de dispositivos de intervención diferentes al pasar de una concepción del «niño/a o adolescente como objeto de tutela» al «niño/a y adolescente como sujeto de derecho».

En la revisión bibliográfica se encuentran investigaciones que indagan el impacto de los cambios normativos en las prácticas institucionales, en las cuales observamos, como ya se indicó, coincidencias respecto a la importancia que las nuevas normativas tienen para la implementación de políticas públicas en clave de derechos; coincidencias que persisten a la hora de demostrar su escaso impacto en las prácticas institucionales efectivas. Lo que significa la permanencia de lógicas tutelares en tiempos normativos de sujetos de derechos.

De este modo, las nuevas legislaciones constituyen una herramienta fundamental para el diseño de políticas públicas en clave de derechos, pero no garantizan, por sí solas, su materialización (García Méndez \& Vitale, 2009; Aguirre \& Ponce Núñez, 2009). Tal implementación requiere de la transformación en las prácticas institucionales materializadas en las organizaciones y en los establecimientos. 
Tales organizaciones y establecimientos son dispositivos concretos (Foucault, 1978; Baremblit, 1994), asumidos por los/as distintos/as trabajadores/as estatales; entre ellos los/as psicólogos/as que integran, junto con otros profesionales, los equipos técnicos. Así, tales profesionales componen las tramas de los funcionamientos institucionales que materializan las políticas públicas en materia de niñez y adolescencia.

Sin embargo, en lo que respecta a los dispositivos de intervención de los/as psicólogos/as, no hemos encontrado en nuestra revisión bibliográfica caracterizaciones o descripciones. De allí que nos preguntamos acerca de sus características, tanto en tiempos normativos del «menor como objeto de tutela» como en tiempos de «niños, niñas y adolescentes como sujetos de derechos»: ¿Qué dispositivos de intervención implementan? ¿Qué objetivos los orientan? ¿En qué ámbitos? ¿Qué elementos los determinan? Y, entre ellos, la normativa, ¿determina los dispositivos de intervención?

Tales preguntas requieren de otras que nos posibiliten delinear los elementos que disponen el Patronato del Menor, el Sistema de Promoción y Protección de Derechos, y el Sistema de Responsabilidad Penal Juvenil: ¿Qué elementos se disponen en cada uno para delimitar el sector de la población de niños/as y adolescentes sobre el que se interviene? ¿Qué procedimientos establecen? ¿Quiénes intervienen? ¿Pará que lo hacen? ¿En qué tipo de establecimientos?

El periodo delimitado (2000-2015) define una temporalidad que permite caracterizar los dispositivos de intervención, anteriores y posteriores a la sanción y a la implementación de dichas leyes, y el impacto que tales normativas tuvieron sobre los mismos.

Guiada por los objetivos que se exponen a continuación, la presente tesis se propone contribuir a uno de los campos de ejercicio profesional de la psicología en el ámbito de las políticas públicas -como es el de la niñez y la adolescencia en situación de vulneración de derechos y en conflicto con la ley penal-, a la vez que busca contribuir a la revisión de las prácticas institucionales y ofrecer herramientas para la implementación efectiva de políticas públicas en clave de derechos. 


\section{Objetivo general}

Caracterizar los dispositivos de intervención implementados por los/as profesionales psicólogos/as en los establecimientos del Organismo de Niñez y Adolescencia de la provincia de Buenos Aires, entre los años 2000 y 2015, para visibilizar qué elementos los determinan, entre ellos, el impacto de las normativas legales.

\section{Objetivos específicos}

Delimitar los elementos que dispone el Decreto Ley 10.067 del Patronato de Menores de la Provincia de Buenos Aires.

Delimitar los elementos que disponen el Sistema de Promoción y Protección de Derechos y el Sistema de Responsabilidad Penal Juvenil.

Identificar qué dispositivos de intervención implementaban los/as profesionales psicólogos/as en los establecimientos del actual Organismo de Niñez y Adolescencia de la Provincia de Buenos Aires: con quiénes, cómo, dónde y para qué, entre los años 2000 y 2004.

Identificar qué dispositivos de intervención implementaban los/as profesionales psicólogos/as en los establecimientos del actual Organismo de Niñez y Adolescencia de la Provincia de Buenos Aires: con quiénes, cómo, dónde y para qué, entre los años 2004 y 2015. 


\section{Referencias}

Aguirre, A. y Ponce Nuñez, M. (2009). «Los niños y jóvenes son el ideal de nuestro presente y la base de nuestro futuro». En E. García Méndez y G. Vitale (Comps.), Infancia y democracia en la Provincia de Buenos Aires. Comentario crítico sobre las leyes 73.298 y 13.634 (pp. 7-10). Ciudad Autónoma de Buenos Aires, Argentina: Ediciones del Puerto.

Baremblitt, G. F. (1994). «La concepción institucional de la transferencia». En M. J. Acevedo y J. C. Volnovich (Comps.), El espacio institucional 1 (pp. 11-22). Ciudad Autónoma de Buenos Aires, Argentina: Lugar editorial.

Bouilly, M. R. y Andersen, M. J. (2012). «Directores, "maestros" y profesionales: agentes del habitus minoril». En A. Daroqui, A. L. López y R. F. Cipriano García (Comps.), Sujetos de castigos. Hacia una sociología de la penalidad juvenil (pp. 221-252). Rosario, Argentina: HomoSapiens.

Bourdieu, P. (2013). El sentido práctico. Ciudad Autónoma de Buenos Aires, Argentina: Siglo XXI.

Castoriadis, C. (1993). La institución imaginaria de la sociedad. Vol. 1: Marxismo y teoría revolucionaria. Ciudad Autónoma de Buenos Aires, Argentina: TusQuets.

Castoriadis, C. (1995). Los dominios del hombre: encrucijadas del laberinto. Barcelona, España: Gedisa.

Castoriadis, C. (1997). El avance de la insignificancia. Ciudad Autónoma de Buenos Aires, Argentina: Eudeba.

Castoriadis, C. (2001). Figuras de lo pensable. Ciudad Autónoma de Buenos Aires, Argentina: Fondo de Cultura Económica.

D’Agostino, A. (2017). Imaginarios estudiantiles acerca de las prácticas profesionales de los psicólogos en el campo de las políticas públicas sociales en salud. Un estudio en la Facultad de Psicología, UNLP (2012-2016) (Tesis de doctorado). Recuperado de http://sedici.unlp.edu.ar/handle/10915/61465

Deleuze, G. (2007). Dos regímenes de locos. Textos y entrevistas (1975-1995). Valencia, España: Pre-Textos.

Deleuze, G. (2014). El poder. Curso sobre Foucault. Tomo II. Ciudad Autónoma de Buenos Aires, Argentina: Cactus. 
Di lorio, J. (2010). Infancia e institucionalización: abordaje de problemáticas sociales actuales. Pesquisas e Práticas Psicossociais, 4(2), 143-150. Recuperado de https://tinly.co/GXKkC

Fasciolo, M. (2018). ¿Quién tiene las llaves de la prisión? Funciones del trabajo social en centros cerrados para jóvenes con causas penales. La Plata, Argentina: Dynamis.

Fernández, A. M. (2007). Las lógicas colectivas. Imaginarios, cuerpos y multiplicidades. Ciudad Autónoma de Buenos Aires, Argentina: Biblos.

Foucault, M. (1978). El juego de Michel Foucault (trad. Javier Rubio) [entrevista]. Diwan, (2-3), 171-202.

Foucault, M. [1977] (2008). La voluntad del saber. Historia de la Sexualidad 1. Ciudad Autónoma de Buenos Aires, Argentina: Siglo XXI.

García Méndez, E. y Vitale, G. (Comps.) (2009). Infancia y democracia en la Provincia de Buenos Aires. Comentario crítico sobre las leyes 13.298 y 13.634. Ciudad Autónoma de Buenos Aires, Argentina: Ediciones del Puerto.

Grinberg, J. (2013). La gestión de las «negligencias»: interpretaciones y dilemas en los organismos de protección de la infancia. Revista de Antropología, (22), 11-31.

Recuperado de http://www.ava.unam.edu.ar/images/22/pdf/n22a01.pdf

Guemureman, S. y Daroqui, A. (1999). La niñez ajusticiada. Ciudad Autónoma de Buenos Aires, Argentina: Ediciones del Puerto.

Kliun, M. y Fernández, G. (2009). «Los desafíos de los equipos técnicos en las nuevas leyes de infancia de la provincia de Buenos Aires». En E. García Méndez y G. Vitale (Comps.), Infancia y democracia en la Provincia de Buenos Aires. Comentario crítico sobre las leyes 13.298 y 13.634 (pp. 3-6). Ciudad Autónoma de Buenos Aires, Argentina: Ediciones del Puerto.

Llobet, V., Litichever, C. y Magisttris, G. (2012). La construcción del «beneficiario» en los programas sociales dirigidos a niñas, niños y adolescentes en el área metropolitana bonaerense. Revista de Ciencias Sociales, IV(138), 77-92.

Llobet, V. (2014). Reflections Upon a Misunderstanding: Production of Children's Needs Within Rights Protection Policies. Psicologia em Estudio, 19(3), 1-11. Doi: http://dx.doi.org/10.1590/1413-73722222501 
Lucesole, N. (2012). Políticas Públicas de Niñez y Adolescencia en la provincia de Buenos Aires. Análisis del proceso de implementación del Sistema de Responsabilidad Penal Juvenil: un estudio de caso en el Centro de Referencia La Plata. ¿Asistencialismo penal o penalismo asistencial? (Tesis de maestría). Ciudad Autónoma de Buenos Aires, Argentina: Facultad Latinoamericana de Ciencias Sociales (FLACSO).

Oyhandy Cioffi, A. G. (2004). La infancia en riesgo: entre la caridad y la ciudadanía. Un estudio de caso sobre la gestión de la infancia y la adolescencia en riesgo en la Argentina contemporánea. La Plata, 2000-2003. Ciudad de México, México: Facultad Latinoamericana de Ciencias Sociales (FLACSO).

Varela, C. (agosto de 2010). La psicología institucional argentina. Orígenes y fundamentos. Trabajo presentado en el II Congreso Nacional y I Encuentro Internacional de Psicosociología Institucional de la Universidad Nacional de Salta. Recuperado de http://www.cristianvarela.com.ar/textos/a-institucionalargentinaorigenes-fundamentos

\section{Normativas}

Código de Ética del Colegio de Psicólogos de la Provincia de Buenos Aires (1985). Recuperado de http://www.colpsibhi.org.ar/leyes_profesionales/codigo_de_etica

Decreto Ley Provincial 10.067 (1983). Patronato de Menores.

Boletín Oficial de la Provincia de Buenos Aires. La Plata, 9/12/1983.

Ley Nacional 10.903 (1919). Patronato de Menores.

Boletín Oficial de la República Argentina. Buenos Aires, 27/10/1919.

Ley Nacional 26.061 (2005). Protección Integral de los Derechos de las Niñas, Niños y Adolescentes.

Boletín Oficial de la República Argentina. Buenos Aires, 26/10/2005.

Ley Provincial 10.306 (1985). Colegio de Psicólogos de la Provincia y Regulación del Ejercicio Profesional de la Psicología.

Boletín Oficial de la Provincia de Buenos Aires. La Plata, 6/9/1985.

Ley Provincial 13.298 (2005). Promoción y Protección Integral de los Derechos de los Niños.

Boletín Oficial de la Provincia de Buenos Aires. La Plata, 27/1/2005.

Ley Provincial 13.634 (2007). Principios Generales del Fuero de Familia y del Fuero Penal del Niño.

Boletín Oficial de la Provincia de Buenos Aires. La Plata, 2/2/2007. 


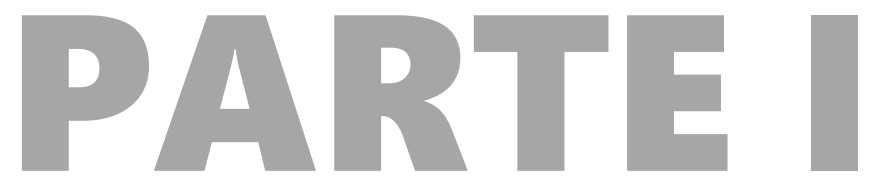




\title{
Parte I
}

\section{CAPÍTULO 1}

\section{La materialización de estrategias biopolíticas en políticas públicas estatales}

\author{
Las políticas sociales \\ La biopolítica y el Estado \\ Institución-organización-establecimiento \\ El Síndrome de Violentación Institucional
}

La presente tesis se inscribe en un modo foucaultiano de pensar «la teoría», en tanto la misma no será aplicada para traducir unos dispositivos, sino que configura una caja de herramientas de utilidad para la localidad en la que se circunscribe este trabajo. En este sentido, caracterizar los dispositivos de intervención que implementan los/as psicólogos/as en las instituciones públicas de niñez y adolescencia para indagar en sus determinaciones exige de herramientas que nos posibiliten indagar en los anudamientos singulares que se producen entre las políticas públicas, las normativas legales, las instituciones que las materializan y el ejercicio de una profesión como la psicología.

\section{Las políticas sociales}

La existencia o no de lo que se denominan políticas sociales, según Aguilo (2005), está profundamente determinada por el tipo de Estado presente en la sociedad y, en consecuencia, por el modelo de crecimiento que esta adopte. Al caracterizarlas, el autor indica que las políticas sociales son la resultante de una acción estatal, característica que comparte con las políticas públicas; que estas acciones se traducen en la regulación, la provisión o la disposición por parte del Estado de ciertos bienes y/o servicios; y que estos bienes y/o servicios se pueden disponer para toda la sociedad, para 
ciertos grupos caracterizados previamente o para determinados individuos calificados con antelación. La definición de los receptores de estas acciones estatales se relaciona con los objetivos de las políticas sociales, lo que compone el cuarto elemento que las caracteriza, por ejemplo: reducir los niveles de pobreza, tender al bienestar de la población, asistir a los desvalidos e indigentes. En otras palabras, «las políticas sociales son las regulaciones y las acciones estatales que tienen por objetivo la superación de situaciones indeseadas que afectan a individuos o a grupos de una sociedad determinada» (Aguilo, 2005, p. 7).

Para este autor, la categoría «situaciones indeseadas» refiere al establecimiento de un umbral por debajo del cual quienes están afectados por estas situaciones se encuentran en condiciones de ser beneficiarios por la acción estatal «que tienda a llevar esta situación indeseada por arriba del umbral mínimo definido» (Aguilo, 2005, p. 7). De este modo, las políticas sociales se caracterizan por ser intervenciones sociales específicas del Estado, que se orientan a producir y a moldear directamente las condiciones de vida y de reproducción de la vida de distintos sectores y grupos sociales (Danani, 1996).

Respecto a la noción de Estado, Foucault (2006) va a diferenciar tres tipos: el Estado de justicia, nacido en la territorialidad de tipo feudal; el Estado administrativo, que corresponde a una sociedad de reglamentos y de disciplina; y el Estado de gobierno, que se define por la masa de población, con su volumen, su densidad y el territorio sobre el cual se extiende. Este último se corresponde con una sociedad controlada por los dispositivos de seguridad, que opera esencialmente sobre la población y cuya instrumentación se asienta en el saber económico. ${ }^{6}$

\footnotetext{
6 Foucault (2006) desarrolla una serie de ejemplos que posibilitan visibilizar lo que denomina modulación en tres tiempos; entre ellos toma la ley penal «no matarás, no robarás», con su castigo, sea este la horca, el destierro o la multa, y ubica allí una primera modulación, asociada a una serie de castigos en caso de infringirla: el código legal. Es entonces un mecanismo legal o jurídico, que rigió desde la Edad Media hasta los siglos XVII-XVIII. Una segunda modulación respecto a la misma ley, con toda una serie de vigilancias, controles, miradas y corrección, que constituyen los mecanismos disciplinarios, va a caracterizarse porque, dentro del sistema binario del código (lo permitido-lo prohibido), aparece un tercer personaje, el culpable, y, con él, toda una serie de técnicas adyacentes, policiales, médicas y psicológicas que corresponden a la vigilancia, al diagnóstico. Tipo de modulación moderna, introducida a partir del siglo XVIII, aunque aparecen ya presente dentro del código jurídico legal. La tercera modulación corresponde al dispositivo de seguridad donde la misma ley penal, el ordenamiento de la prevención, la organización del castigo correctivo, estarán gobernados por establecer el índice medio de la criminalidad. «¿Cómo se puede prever estadísticamente que habrá tal o cual cantidad de robos en un momento dado, en una sociedad dada, en una ciudad determinada,
} 
En la segunda mitad del siglo XVIII ubica la aparición de una tecnología de poder, no disciplinaria, que no la excluye, sino que la engloba, la integra, la modifica parcialmente y se implanta sobre ella, incrustándose ${ }^{7}$ (Foucault, 2000). Tecnología que es de otro nivel, tiene otra superficie de sustentación y utiliza instrumentos completamente distintos a los disciplinares.

Este modo de conceptualizar las políticas públicas las coloca en lo que Foucault (2006) caracteriza como estrategias de poder biopolíticas, un tanto implican un «conjunto de mecanismos por medio de los cuales aquello que en la especie humana constituye sus rasgos biológicos fundamentales podrán ser parte de una política, de una estrategia política de poder» (p. 15). Al igual que las técnicas disciplinarias, la biopolítica está destinada a la multiplicidad de los hombres, pero en la medida en la que forman una masa global afectada por procesos de conjunto que son propios de la vida, como el nacimiento, la muerte, la producción, la enfermedad, entre otros (Foucault, 2006).

Esta nueva tecnología tiene que vérselas con la población, con la población como problema político y problema científico, como problema biológico y problema de poder. El tipo de fenómenos que se toma en cuenta son los fenómenos colectivos, que solo se manifiestan en sus efectos económicos y políticos. Esta tecnología de poder va a introducir mecanismos muy diferentes a los disciplinares, como es la tecnología reguladora de la vida, centrada en la vida, que reagrupa los efectos de masas propios de una población y que Foucault (2000) denomina sociedad de seguridad. ${ }^{8}$

en la ciudad, en el campo, o tal o cual capa social?» (Foucault, 2006, p. 19), ¿cómo se pueden prever?, ¿cuánto cuesta le cuesta a la sociedad este tipo de robos, que perjuicios genera? ¿Cuánto cuesta su represión? Interrogantes referidos a cómo mantener un tipo de criminalidad dentro de parámetros que sean social y económicamente aceptables y alrededor de una media para un funcionamiento social dado. El autor denomina a esta tercera modulación dispositivo de seguridad. Dispositivo en el que aparece toda una inflación del código jurídico legal, en el cual todo el conjunto de medidas legislativas que permiten introducir mecanismos de seguridad es cada vez más gigantesca, al igual que los mecanismos disciplinarios.

7 Las técnicas disciplinarias se dirigen al cuerpo, tratan de regir las multiplicidades de los hombres en tanto que esa multiplicidad puede y debe resolverse en cuerpos individuales que hay que vigilar, adiestrar y utilizar (Foucault, 2000).

8 Foucault (2000) realiza una genealogía de las tecnologías biopolíticas como estatización de lo biológico, para lo cual va a referir al tratamiento de la teoría clásica de la soberanía respecto al derecho de vida y de muerte, donde el soberano tenía este derecho en tanto podía hacer morir y podía dejar vivir; lo que evidencia que «la vida y la muerte no son fenómenos naturales, inmediatos, en cierto modo originarios o radicales, 
Hay una insistencia en los textos de Foucault (2006) respecto de que no se trata de la sustitución de un tipo de sociedad por otra, sino de un triángulo: soberanía, disciplina y gestión gubernamental. Esta última, caracterizada como un conjunto de instituciones, de procedimientos, de cálculos, de tácticas; análisis que posibilita ejercer esa forma de poder que tiene por blanco la población, por campo mayor de saber la economía política y como instrumento principal los dispositivos de seguridad.

Para el autor, las transformaciones acontecidas en el siglo XIX, a nivel del derecho y de los mecanismos, las técnicas y las tecnologías de poder, sucedieron

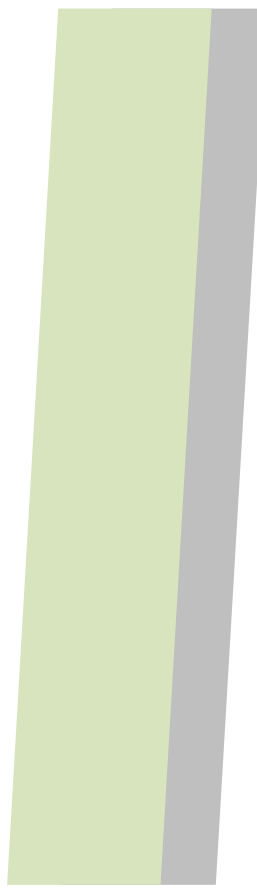

como si el poder, que tenía la soberanía como modalidad y esquema organizativo, se hubiera demostrado inoperante para regir el cuerpo económico y político de una sociedad en vías de explosión demográfica e industrialización a la vez. De manera que muchas cosas escapaban a la vieja mecánica del poder de soberanía, tanto por arriba como por abajo, en el nivel del detalle y en el de la masa. Para recuperar el detalle se produjo una primera adaptación: adaptación de los mecanismos de poder al cuerpo individual, con vigilancia y adiestramiento; eso fue la disciplina [...], en el marco limitado de instituciones como la escuela, el cuartel, el taller, etc. Y a continuación, a fines del siglo XVIII tenemos una segunda adaptación, a los fenómenos globales, los fenómenos de la población, con los procesos biológicos o biosociológicos de las masas humanas. Adaptación mucho más difícil, porque implicaba, desde luego, órganos complejos de coordinación y de centralización (Foucault, 2000, p. 226).

\section{Los mecanismos de seguridad}

Cuatro rasgos caracterizan para Foucault (2006) los mecanismos de seguridad: los espacios, el tratamiento de lo aleatorio, la forma de normalización específica de la seguridad y la correlación entre la técnica de seguridad y la población.

que están por fuera del campo de poder político [...]. En el fondo quiere decir que frente al poder el súbdito no está, por pleno derecho, ni vivo ni muerto [...] es neutro» (p. 218). Esto no significa que el soberano pueda hacer vivir como hacer morir, sino que el poder soberano sobre la vida se ejerce a partir del momento en el que el soberano puede matar; a partir que puede matar, el soberano ejerce su derecho sobre la vida, «el derecho de hacer morir o dejar vivir» (p. 218). 
Respecto al espacio, establece los tratamientos diferenciales en las tres tecnologías del poder, para lo cual recurre al ejemplo de las ciudades. Ubica, a partir de los siglos XVII y XVIII, toda una serie de problemas ligados al desarrollo de los Estados administrativos. La especificidad jurídica de la ciudad, el crecimiento del comercio y el aumento demográfico urbano, y la necesidad de intercambios comerciales y económicos constituían problemas difíciles de resolver, vinculados al enclave espacial, jurídico, administrativo y económico de la ciudad. Constituían, fundamentalmente, un problema de circulación. Respecto del dispositivo de seguridad, el espacio será el medio; la seguridad tratará de acondicionar un medio en función de acontecimientos o de series de acontecimientos posibles que será necesario regularizar. ${ }^{9}$

En cuanto al problema de lo aleatorio, o del acontecimiento, el autor toma el ejemplo de la escasez, a la que diferencia del hambre, en tanto es un estado de penuria que provoca el alza de los precios. De este modo, cuanto más suben los precios, los que poseen los objetos escasos pretenden almacenarlos para que los precios suban aún más y el proceso continúa hasta que las necesidades más elementales de la población dejan de satisfacerse. Es un fenómeno que se manifiesta, en primer lugar, en los medios urbanos.

El tercero de los rasgos que caracteriza a los mecanismos de seguridad refiere a lo que Foucault (2006) denomina normalización. Diferencia los mecanismos de normalización disciplinarios de los de seguridad. Los primeros parten de un modelo y «la operación disciplinaria pasa por intentar que la gente, los gestos y los actos se ajusten a ese modelo; lo normal es, precisamente, lo que es capaz de adecuarse a esa norma, y lo anormal, lo que es incapaz de hacerlo [...] se trata más de una normación» (p. 76). En los dispositivos seguridad hay un señalamiento de lo normal y lo anormal, pero en relación con las diferentes curvas de normalidad. La operación de normalización consiste en hacer

\footnotetext{
9 «¿Qué es el medio? Es necesario para explicar la acción a distancia de un cuerpo sobre otro. Se trata, por lo tanto, del soporte y el elemento de circulación de una acción [...] el medio será entonces el ámbito en el cual se da la circulación. Es un conjunto de datos naturales, ríos, pantanos, colinas y un conjunto de datos artificiales, aglomeración de individuos, aglomeración de casas, etc. El medio es una cantidad de efectos masivos que afectan a quienes residen en él [...] y el medio aparece por último como un campo de intervención donde, [...] en vez de afectarlos como una multiplicidad de organismos, de cuerpos susceptibles de prestaciones como en la disciplina, se tratará de afectar, precisamente, a una población. Me refiero a una multiplicidad de individuos que están y sólo existen profunda, esencial, biológicamente ligados a la materialidad dentro de la cual existen» (Foucault, 2006, p. 41).
} 
interactuar esas diferentes atribuciones de normalidad y en procurar que las más desfavorables se asimilen a las más favorables. De allí que sostiene que no se trata de una normación sino de una normalización (Foucault, 2006).

En cuanto a la población, para las prácticas de gobierno no es un dato primero, depende de una serie de variables. Variará con el clima, el entorno material, la intensidad del comercio; variará según las leyes a las cuales esté sometida (por ejemplo, los impuestos), las costumbres, así como del modo de crianza de los/as hijos/as. La población es accesible a «técnicas de transformación, siempre que esos agentes y esas técnicas sean a la vez ilustrados, medidos, analíticos, calculados y calculadores» (Foucault, 2006, p. 95). Se perfila una técnica que trata de influir sobre las cosas, de actuar sobre una multitud de factores.

Ahora bien, Foucault (2006) va a delimitar un invariante: el deseo. En tanto elemento que impulsa la acción de los individuos, constituye el único motor de acción de la población tomada en su conjunto. El deseo reaparece en las técnicas de poder y de gobierno, en tanto que, por ejemplo, no se puede impedir que la gente viva donde considera que puede obtener mayores ganancias, donde desea vivir, porque ambiciona esa ganancia.

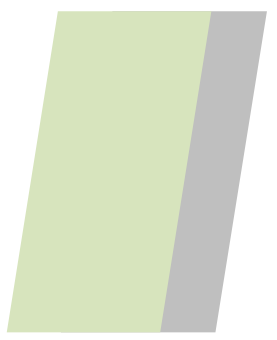

Pero, y aquí la naturalidad del deseo marca la población y la técnica gubernamental, ese deseo es tal que si se lo deja actuar y siempre que se lo deje actuar, dentro de determinados límites, redundará en suma en el interés general de la población. El deseo es la búsqueda del interés para el individuo (Foucault, 2006, p. 96).

En un extremo, la población es la especie humana; en el otro, el público.

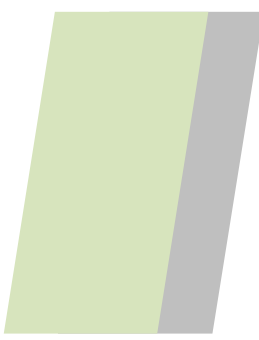

[El público] es una noción capital del siglo XVIII; es la población considerada desde el punto de vista de sus opiniones, sus maneras de hacer, sus comportamientos, sus hábitos, sus temores, sus prejuicios, sus exigencias: el conjunto susceptible de sufrir la influencia de la educación, las campañas, las convicciones. [...] De la especie al público, tenemos un campo de nuevas 
realidades, nuevas en el sentido de que, para los mecanismos de poder, son elementos pertinentes dentro del cual y con respecto al cual se debe actuar (Foucault, 2006, p. 102).

\section{La biopolítica y el Estado}

En su definición de políticas sociales, Aguilo (2005) introduce tres categorías: población, condiciones de vida y acción del Estado sobre ellas; en este sentido, las políticas sociales constituyen estrategias de poder biopolíticas.

Vemos, entonces, que las políticas sociales se inscriben en estrategias biopolíticas propias de la sociedad de seguridad, cuyo campo es la población, a través de la implementación de mecanismos de normalización y de regulación; población que es considerada como público a partir del momento en el que sus opiniones, sus maneras de hacer, sus comportamientos, sus temores, etcétera, componen un conjunto susceptible de influir.

A través de las tecnologías de poder de seguridad, el Estado gubernamental brinda cobertura a la población, lo que se traduce en el desarrollo de prácticas, de dispositivos de intervención que, en el caso de la Argentina, se desplegarán a partir de los años cincuenta, como la medicina social, la higiene pública y la psicología.

En otras palabras y, de acuerdo con la definición que propone Aguilo (2005), tal cobertura se traducirá en un tipo particular de políticas sociales.

En esta línea, la biopolítica caracteriza un tipo particular de Estado, por lo que consideramos oportuno introducir los desarrollos de García Linera (2010), quien sostiene que la globalización significa un proceso de mutación: "No estamos asistiendo a una extinción de la soberanía, sino a una mutación del significado de la soberanía del Estado» (p. 3). Para el autor, hay y habrá Estado con instituciones territoriales, a la vez que hay y habrá instituciones de carácter supra institucional. 
Como concepto de Estado, propone que un gobierno es parte del Estado pero no lo es todo; también lo son el parlamento, el orden legislativo y el acatamiento a dicha legislación, las fuerzas armadas, las cárceles, el sistema de enseñanza, los presupuestos, la gestión y los usos de los recursos públicos. La narrativa de la historia, los silencios y los olvidos, los símbolos, las disciplinas, los sentidos de pertenencia, los sentidos de adhesión, todos ellos son parte del Estado.

Hablar del Estado, señala el autor, implica considerar

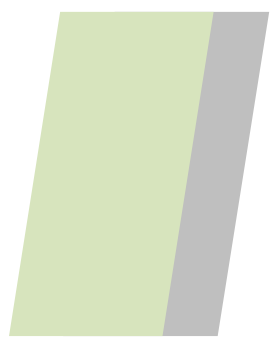

una serie de elementos diversos, tan objetivos y materiales como las fuerzas armadas y el sistema educativo; y tan etéreos, pero de efecto igualmente material, como lo son las creencias, las sumisiones y los símbolos. El Estado en sentido estricto son pues instituciones. No hay Estado sin instituciones (García Linera, 2010, p. 5).

Dichas instituciones constituyen su base material, pero el Estado no se compone solo de instituciones, sino también de un régimen de creencias, de percepciones, que constituyen la parte ideal de su materialidad, y que implican idealidad, ideas, percepción, sentido común. Como tercer componente, el autor agrega la correlación de fuerzas, de luchas, de enfrentamientos, en tanto que el monopolio de la fuerza constituye el cuarto componente. El Estado, en consecuencia, es definido como un aparato social, territorial, de producción efectiva de tres monopolios: recursos, coerción y legitimidad.

La importancia de pensar el Estado de este modo posibilita ver

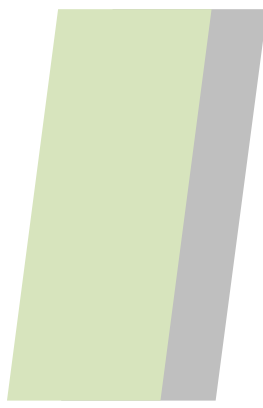

cómo asumimos la relación frente al Estado. Si el Estado es solo máquina, entonces hay que tumbar la máquina, pero no basta con tumbar la máquina del Estado para cambiar el Estado, porque muchas veces el Estado es uno mismo, son las ideas, los prejuicios, las percepciones, las ilusiones, las sumisiones que uno lleva interiorizadas, que reproducen continuamente la relación del Estado en nuestras personas (García Linera, 2010, p. 6). 
En su caracterización del Estado, Oszlak (1997) sostiene que la existencia del Estado es posible de ser verificada a partir de aquellos atributos que definen la estatidad -condición de «ser Estado»-, lo que significa el surgimiento de una instancia de organización del poder y de ejercicio de la dominación política. El Estado es, de este modo, relación social y aparato institucional. El autor puntúa una serie de propiedades ${ }^{10}$ que constituyen o que hacen a la estatidad y, en particular, al tipo de Estado nacional.

Desde esta perspectiva, la estatidad no puede ser pensada por fuera del surgimiento de la nación, donde se conjugan elementos tanto materiales como ideales. Los elementos materiales se relacionan con el desarrollo de intereses que resultan de la diferenciación y la integración de la actividad económica, dentro de un espacio territorialmente delimitado. Los elementos ideales refieren a la difusión de símbolos, de valores y de sentimientos de pertenencia a una comunidad diferenciada por tradiciones, etnias, lenguajes y otros factores de integración que configuran una identidad colectiva.

La formación de un tipo de economía capitalista y de un Estado nacional son aspectos de un mismo proceso cronológico y espacialmente desigual, lo que implica que la formación de esa economía va definiendo un ámbito territorial, «diferenciando estructuras productivas y homogeneizando intereses de clase que, en tanto fundamento material de la nación, contribuyen a otorgar al Estado un carácter nacional» (Oszlak, 1997, p. 3).

Podemos condensar lo expuesto hasta aquí afirmando que uno de los objetivos de las políticas sociales es producir y moldear las condiciones de vida (Danani, 1996). Para esto, se parte de establecer un umbral mínimo que no está fijado de antemano (Aguilo, 2005), lo que conlleva intervenciones previas que implican establecer y caracterizar dicho «umbral mínimo»; un procedimiento propio de los mecanismos de seguridad y que

\footnotetext{
10 «1- La capacidad de externalizar su poder, obteniendo reconocimiento como unidad soberana dentro de un sistema de relaciones interestatales; 2- la capacidad de institucionalizar su autoridad, imponiendo una estructura de relaciones de poder que garantice el monopolio sobre los medios organizados de coerción; 3- la capacidad de diferenciar su control, a través de la creación de un conjunto funcionalmente diferenciado de instituciones públicas con reconocida legitimidad para extraer establemente recursos de la sociedad civil, con cierto grado de profesionalización de sus funcionarios y cierta medida de control centralizado sobre sus variadas actividades; y 4- la capacidad de internalizar una identidad colectiva, mediante la emisión de símbolos que refuerzan sentimientos de pertenencia y de solidaridad social y que permiten, en consecuencia, el control ideológico como mecanismos de dominación» (Oszlak, 1997, p. 3).
} 
Foucault (2006) denomina como normalización. Para ello, ciertos grupos y/o individuos, receptores de tales acciones estatales, serán caracterizados previamente y definidos en relación con los objetivos de las políticas sociales.

Ahora bien, las acciones estatales se materializan a través de instituciones creadas a tales fines y son efectuadas por agentes específicos. De allí que sostenemos que los dispositivos diseñados e implementados por los/as psicólogos/as en los establecimientos del actual Organismo de la Niñez y Adolescencia de la provincia de Buenos Aires componen las tramas de acciones que materializan políticas públicas destinadas a un sector de la población de niños/as y de adolescentes.

\section{Institución-organización-establecimiento}

En la institución, dos son las formas en las que las relaciones de fuerzas se integran y se articulan: formas de visibilidad, como aparatos institucionales, y formas de enunciabilidad, como sus reglas. Entre el saber y el poder, la institución como figura intersticial, como lugar eminente donde el ejercicio de poder es condición de posibilidad de un saber, y el ejercicio del saber es instrumento del poder, sin confundirse (Morey, [1987] 2008).

Respecto de las conceptualizaciones propuestas por Michel Foucault en Vigilar y castigar (1976), Deleuze ([1987] 2008) señala que la forma se manifiesta en dos sentidos: organiza materia y finaliza funciones, les da objetivos. Como ejemplos de materias formadas, propone la prisión, el hospital, la escuela, el taller; mientras que curar, educar, hacer trabajar, constituyen funciones. En esta línea, ubicamos los establecimientos de niñez y adolescencia en los que se alojan niños/as y adolescentes en situación de vulneración de derechos o en situación de transgresión a la ley penal.

En esta línea, fórmula abstracta del panoptismo, implica imponer una conducta cualquiera a una multiplicidad humana cualquiera; en tanto que esa multiplicidad «sea reducida, incluida en un espacio restringido, y que la imposición de una conducta se realice por distribución en el espacio, ordenación y seriación en el tiempo» (Deleuze, [1987] 2008, p. 60). 
Materia y funciones cualesquiera, no formalizadas, no finalizadas, que Foucault (1976) denomina como diagrama; que al modo de un mapa, de una cartografía, es coextensiva a todo el campo social; «una máquina abstracta», dirá Deleuze ([1987] 2008, p. 61). En este sentido, hay tantos diagramas como campos sociales en la historia y toda sociedad tiene su o sus diagramas. Máquina abstracta, en tanto causa de los agenciamientos concretos que efectúan relaciones de fuerza que se sitúan en el mismo tejido de los agenciamientos que producen. Agenciamientos concretos denominados por Foucault como dispositivos (Deleuze, [1987] 2008).

Las instituciones se materializan en dispositivos concretos, denominados por Baremblit (1994) como organizaciones, a las que caracteriza en tanto formas materiales variadas, de modo tal que las instituciones viven y se efectúan a través de las organizaciones en un juego dinámico de los agentes que realizan las funciones correspondientes, sean individuales o colectivas, a través de prácticas verbales, corporales, de acción, teóricas, técnicas, cotidianas o inespecíficas. No es posible pensar unas sin las otras.

Otras de las dimensiones que el autor sitúa para caracterizar una institución son las nociones de lo instituyente, lo instituido y la institucionalización. Respecto a lo instituyente, se trata del efecto de fuerzas que tienden a instaurar o a transformar las instituciones y -en el proceso constante de transformación- es productor de lo instituido y se lo denomina proceso de institucionalización. Lo instituyente es definido como una fuerza productora de instituciones y lo instituido es el efecto del trabajo de tal fuerza instituyente. Mientras que el proceso de institucionalización es el movimiento que lo instituyente produce de transformación de lo instituido.

No es posible pensar lo instituido y lo instituyente como dimensiones opuestas, sino como fuerzas que operan de un modo inmanente; en otras palabras, así como no es posible pensar las dimensiones institución-organización-establecimiento por separado, sino operando siempre interpenetradas, lo instituyente-instituido-institucionalización también constituyen dimensiones que se implican recíprocamente. 
Los instituidos organizados son orientaciones y acciones que regulan y que operan en una sociedad dada, así las funciones son producidas por lo instituyente y la función es propia de los instituidos organizados necesarios. Lo instituyente organizante tiene como característica su funcionamiento, que opera produciendo, inventando transformaciones en los instituidos organizados, de modo tal que el funcionamiento es productivo e inventivo.

Estos movimientos se producen a nivel organizacional, donde se presenta una dimensión organizante, otra organizada y una tercera que denomina proceso de organización. A su vez, plantea que cuando la vida social es regulada por instituciones y por organizaciones en las cuales los instituyentes organizantes, los procesos de institucionalización y de organización, y los instituidos organizados se mantienen siempre fluidos y en movimiento, se potencian mutuamente (Baremblit, 1994).

La interpretación y la integración producidas entre los instituidos organizados las denomina atravesamiento, mientras que aquella producida entre las fuerzas instituyentes organizantes es denominada transversalidad. Así, en cada organización, en cada establecimiento, en cada colectivo, los sujetos agentes son efectores de múltiples instituciones como consecuencia de atravesamientos, lo que indica que tales instituciones no proceden ni se generan en la organización o en el establecimiento mismo.

Existe en las instituciones -como en todo el campo social- una potencia polifónica: instituyente-organizante-productora de efectos sujeto. Afirmación que no anula las fuerzas repetitivas de lo instituido-organizado, sino que estas se presentan a modo de juego de fuerzas interpenetradas.

En el plano repetitivo, las instituciones funcionan a modo de máquinas productivodistributivas y circuladoras-consumidoras de burocracia. El dominio burocrático refiere a la reiteración de lo formal, «pero también se traduce en comportamientos instituidos que transforman las gestiones en portentosas cadenas de montaje de los tiempos modernos institucionales» (Kaminsky, 2011, p. 13), lo que es descripto como cada quien en su puesto, en su función, y donde cada quien sabe o debe saber el lugar que le corresponde. 


\section{Los organigramas}

Ahora bien, cuando se crean dispositivos que trasvasan los límites de las unidades organizacionales formalmente constituidas, movimientos y montajes alternativos, estos son efectos de transversalidad. Al respecto, Kaminsky y Varela (1994) postulan la existencia, en una institución singular, de tres organigramas: formal, funcional e imaginario, a partir de constatar la existencia de niveles, inscripciones, dimensiones y realidades diversas; organigramas que tienen sus propios grados de importancia, donde los actores prescriben unas acciones (organigrama formal), efectúan otras (organigrama funcional) y desean realizar algo más (organigrama imaginario).

El organigrama formal implica la determinación de posiciones, sentidos, asimetrías y direcciones respecto de la producción, la circulación y el consumo de información. En ese sentido, predetermina un cierto orden de información, que no restringe otras formas pero que implica el establecimiento de una normativa comunicacional. Sin embargo, ningún establecimiento funciona tal como está previsto formalmente, debido a que entrelazado al organigrama formal y explícito se dibuja el organigrama funcional. El diseño, realizado de antemano, supone una idealidad que para efectuarse debe transitar por las duras pruebas de su materialización (Kaminsky \& Varela, 1994).

El organigrama funcional es caracterizado como un diagrama de superficie, no superficial, donde se visibilizan las acciones y los sentidos que en sus movimientos dibujan huellas y surcos sobre el plano institucional. El organigrama imaginario, en tanto, no logra realizarse, efectuarse positivamente, por no encontrar sus espacios y sus formas de oposición a lo ya instituido.

Para Kaminsky (2011), las instituciones presentan la apariencia de ser un territorio privilegiado de repetición. Sin embargo, inclusive en las que parecen más estáticas se producen movimientos. La confusión de la mecánica repetitiva con la eficacia interroga el ritmo tolerado, «un ritmo acompasado de lo igual» (p. 10). No obstante, existe en las instituciones, como en todo el campo social, una potencia polifónica. 


\section{Los grupos}

Desde esta perspectiva, Kaminsky (2011) señala que los grupos son «los ojos de las instituciones», sus puertas. El autor recupera los desarrollos teóricos de Guatari (1976) respecto de los grupos objetos y de los grupos sujetos. Los primeros son aquellos sometidos a las consignas institucionales, son los que soportan y sostienen la jerarquía institucional. Los grupos sujetos operan y proponen operar desprendimientos de lo establecido. Ambos grupos no existen en estado puro, sino que se presentan en un movimiento. De este modo, la institución es un proceso siempre en movimiento y los grupos son quienes pondrán en juego este movimiento. No existen grupos sin instituciones ni instituciones que no sean habitadas por grupos.

Los grupos objetos y los grupos sujetos son conceptos móviles que nos hablan de momentos de la institución o del grupo. El grupo sujeto pretende fundarse a partir de su propia ley interna, con movilidad en los roles y como agente de enunciación colectiva que se apropia deseantemente de las tareas, de las ideas. El grupo objeto tiene una máxima jerarquización vertical y funciona de acuerdo al organigrama formal (Del Cueto, 2013).

El grado de comunicación entre los diferentes niveles institucionales y su vinculación con las relaciones de poder institucionales indican el grado de transversalidad, en tanto muestran la posición -individual o de cada grupo- en la red de poder, cómo se ejerce y el impacto institucional que produce. El grado de transversalidad existente en el grupo que posee el poder real determina inconscientemente la regulación de coeficientes de transversalidad de los distintos grupos institucionales. El análisis de los dispositivos de poder visibiliza la dinámica de las fuerzas y la posibilidad que tienen los sujetos institucionales de aceptar o no tales sujeciones que los llevan a padecer (Del Cueto, 2013).

Los estados de dominación que, muchas veces, caracterizan los avatares institucionales se producen por efectos de relaciones cristalizadas, carentes de fluidez, que se fijan en relaciones asimétricas. Este es el modo en que el poder organizacional tiende a reducir la heterogeneidad singular a una totalidad homogénea que, en cada institución, tendrá características propias y variarán los grados de rigidez que tornen posible la inclusión o no de las diferencias. 
La transversalidad introduce, así, la idea de potencia grupal y sus flujos deseantes, como máquina deseante (Del Cueto, 2013).

\section{El Síndrome de Violentación Institucional}

Así pensada, toda institución es un dispositivo de violencia (Kaminsky, 2011) -en tanto dispositivo de las relaciones sociales- anclado históricamente; es un espacio producido y productor de múltiples modalidades de violencias. Estas múltiples formas sutiles de violencias circulan por los espacios institucionales, incluso constituyéndolos. Violencias físicas y discursivas que, según el autor, son invocadas impúdica y orgullosamente.

Acerca de las violencias que circulan por los espacios institucionales, Ulloa (1995) sostiene que la constitución de toda institución supone cierta violentación legítimamente acordada, que hace posible establecer normas necesarias para el funcionamiento de las actividades de esa institución y que es propia de todo proceso que implica el pasaje de lo privado a lo público y a las pautas que requieren ser consensuadas.

Sin embargo, cuando tal violentación se torna arbitraria, en grados y en orígenes diferentes, se configura lo que el autor denomina «Síndrome de Violentación Institucional» (SVI), que implica la presencia de una intimidación, con ciertos grados de sordera según el grado de acostumbramiento, que «conspira contra la imprescindible intimidad para investir de interés personal la tarea que se desarrolla. Frente a este desinterés por lo propio, mal puede alguien prestar atención a la actividad y al decir de los otros» (Ulloa, 1995, p. 248). Una intimidación que imposibilita la resonancia íntima que hace posible alojar el decir del otro, a partir de ser investido libidinalmente de interés.

Uno de los síntomas que se produce como efecto del SVI es la tendencia a la fragmentación en el entendimiento, que obstaculiza la construcción de un acompañamiento solidario y que produce un refugio en el propio quehacer, lo que no equivale a una mayor concentración en uno mismo. Se trata de un aislamiento del que, 
en ocasiones, se sale a través de la construcción de enfrentamientos entre ellos-nosotros, construcción precaria dado que no supone ninguna concordancia interna y, por lo tanto, resulta vulnerable a nuevas dislocaciones.

Otro de los efectos del SVI es el que afecta tanto la modalidad como el sentido del trabajo, que empieza por perder funcionalidad vocacional, a expensas de los automatismos burocráticos que producen la pérdida de lo que Ulloa (1995) denomina «habilidad creativa» (p. 250). Como mecanismo que opera en tales efectos sitúa la renegación, que impide advertir las condiciones contextuales en las que se vive y que es productor de lo que denomina «amputación del pensamiento», con el empobrecimiento propio de la alienación.

El desadueñamiento del propio cuerpo, en distintos grados, es otro de los síntomas propios del SVI. Este se relaciona con la falta de especularidad comunicacional y con la merma de estímulos libidinales producidos por la enajenación: «Desadueñamiento corporal tanto para el placer como para la acción, a cuyo amparo abundan las patologías asténicas; un verdadero genio epidemiológico propio de la mortificación, que abarca varias formas de desgano y cansancio» (Ulloa, 1995, p. 250).

Todos estos síntomas pueden estabilizarse «mortecinamente», donde todo deviene en un presente continuo, y en la medida en que la mortificación se instala como cultura la institución se transforma en «clienta de ella misma», alejada de sus objetivos específicos. En otras palabras, el autor plantea que dicha transformación evidencia una cristalización de lo instituido, donde lo instituyente se encuentra obstaculizado.

A partir de su práctica en instituciones públicas, Ulloa (1995) identifica la vigencia de formas de tormento social que se producen a plena luz del día ante miradas indiferentes de la sociedad. Estas formas, que denomina encerrona trágica, «se dan cada vez que alguien para vivir (amar, trabajar, divertirse, estudiar, tramitar, recuperar la salud, transcurrir su vejez, tener una muerte dignamente asistida) depende de algo o de alguien que lo maltrata o simplemente lo "destrata" negándolo como sujeto» (p. 185). 
Encerrona cuya estructura delimita dos lugares: dominado / dominador, sin terceridad a la cual apelar, que garantice un trato justo por sobre «el imperio de la brutalidad del más fuerte» (Ulloa, 1995, p.187). La frecuencia de tales encerronas trágicas, en muchos ámbitos de la cultura -especialmente, en las instituciones-, hace que presenten una analogía con una suerte de virus epidemiológico causante de la mortificación.

Como afecto específico de toda encerrona, describe lo siniestro, productor de una forma de dolor psíquico en el cual se «termina viviendo familiarmente con aquello que por hostil y arbitrario es la negación de toda condición familiar amiga» (Ulloa, 1995, p. 250). Este cuadro, que al inicio se presenta tumultuoso, de no vislumbrarse una salida, puede dar lugar a la resignación. 


\section{Referencias}

Aguilo, J. C. (2005). Políticas Sociales en Argentina: de la Sociedad de Beneficencia a la focalización compulsiva. Recuperado de http://lanic.utexas.edu/project/etext/lilas/vrp/aguilo.pdf

Baremblitt, G. F. (1994). «La concepción institucional de la transferencia». En M. J. Acevedo y J. C. Volnovich (Comps.), El espacio institucional 1 (pp. 11-22). Ciudad Autónoma de Buenos Aires, Argentina: Lugar editorial.

Danani, C. (1996). «Algunas precisiones sobre la política social como campo de estudio y la noción de población objeto». En S. Hintze (Coord.), Políticas sociales: contribución al debate teórico-metodológico (pp. 21-38). Ciudad Autónoma de Buenos Aires, Argentina: Universidad de Buenos Aires.

Deleuze, G. [1987] (2008). Foucault. Barcelona, España: Paidós.

Del Cueto, A. M. (2013). Grupos, instituciones y comunidades. Coordinación e intervención. Ciudad Autónoma de Buenos Aires, Argentina: Lugar editorial.

Foucault, M. (1976). Vigilar y castigar. Ciudad de México, México: Siglo XXI.

Foucault, M. (2000). Defender la sociedad. Ciudad Autónoma de Buenos Aires, Argentina: Fondo de Cultura Económica.

Foucault, M. (2006). Seguridad, territorio y población. Ciudad Autónoma de Buenos Aires, Argentina: Fondo de Cultura Económica.

García Linera, A. (2010). La construcción del Estado. Recuperado de http://biblioteca.clacso.edu.ar/Argentina/iecconadu/20171115043333/pdf_939.pdf

Guatari, F. (1976). Psicoanálisis y transversalidad. Crítica psicoanalítica de las instituciones. Ciudad Autónoma de Buenos Aires, Argentina: Siglo XXI.

Kaminsky, G. G. (2011). Dispositivos institucionales. Democracia y autoritarismo en los problemas institucionales. Ciudad Autónoma de Buenos Aires, Argentina: Lugar editorial.

Kamisnsky, G. G. y Varela, C. (1994). «Una gramática institucional: organigramas y diagramas y...». En M. J. Acevedo y J. C. Volnovich (Comps.), El espacio institucional 1 (pp. 112-118). Ciudad Autónoma de Buenos Aires, Argentina: Lugar editorial. 
Morey, M. [1987] (2008). «Prólogo». En G. Deleuze, Foucault (pp. 11-21). Barcelona, España: Paidós.

Oszlak, O. (1997). La formación del Estado argentino. Orden, progreso y organización nacional. Ciudad Autónoma de Buenos Aires, Argentina: Planeta.

Ulloa, F. (1995). Novela clínica psicoanalítica. Historial de una práctica. Ciudad Autónoma de Buenos Aires, Argentina: Paidós. 


\title{
Parte I
}

\section{CAPÍTULO 2}

\section{Los dispositivos de hacer-ser niños/as y adolescentes}

\author{
La niñez, una invención moderna \\ La niñez en el suelo argentino \\ Los/as niños/as como objeto de tutela \\ Los/as niños/as como sujetos de derechos
}

Tanto el Patronato del Menor como el Sistema de Promoción y Protección de Derechos (SPPD) y el Sistema de Responsabilidad Penal Juvenil (SRPJ), son dispositivos sociohistóricos productores de modos singulares de hacer-ser niños/as y adolescentes: tutelados unos, sujetos de derechos otros. En tales dispositivos, se inscribieron y se inscriben los dispositivos de intervención de los/as psicólogos/as, y en la medida en que estos implican la disposición de ciertos elementos y una cierta manipulación de relaciones de fuerzas, constituyen focos locales de ejercicio de poder. En otras palabras, entendemos a los dispositivos profesionales de intervención como inscriptos en el juego de fuerzas inmanentes a los dispositivos institucionales y, por ello, determinados por múltiples dimensiones: sociohistóricas, normativas, políticas, institucionales, teóricas, disciplinares y económicas, no siempre visibles.

La niñez fue una invención-creación, visible con el surgimiento de modernidad, y con ella, junto con ella, toda una serie de enunciados científicos que la delimitaron. Desde esta perspectiva, los diferentes dispositivos sociohistóricos implicaron una formación y una disposición de elementos y de juegos de poder específicos. Así, mientras el Patronato del Menor se efectúo a través de un conjunto de elementos, leyes, normativas, procedimientos, establecimientos, juegos de fuerzas de poder y estrategias de las que emergió un tipo de niñez: los/as niños/as y adolescentes tutelados/as; el Sistema de Promoción y Protección de Derechos (SPPD) y el Sistema de Responsabilidad Penal 
Juvenil (SRPJ) dispusieron otros elementos normativos y otros establecimientos, con otros juegos de fuerzas y otras estrategias que produjeron otro tipo de niñez particular: los/as niños/ y adolescentes como sujetos de derechos.

Los dispositivos de intervención que se caracterizan en esta investigación están inscriptos en instituciones singulares, es decir, en los establecimientos dependientes del Organismo de la Niñez y Adolescencia de la provincia de Buenos Aires, cuya formación histórica tuvo como función responder a una urgencia y a una función estratégica dominante. Por tal motivo, se ofrece a continuación un recorrido que recupera el contexto en el que se produjo el nacimiento de estos establecimientos.

\section{La niñez, una invención moderna}

La palabra «niñez», sostiene Giberti (1997), adquirió una calidad emblemática cuya mención produce sensibilidades y decisiones políticas, a la vez que esperanzas inscriptas en una concepción de futuro, en tanto representa el porvenir. De todos modos, la autora ubica la existencia de diferencias entre los historiadores respecto a la época en la cual la «niñez» emerge como construcción (objeto) social.

Los datos etimológicos indican que «niñez» deriva de 'niño', cuyo origen se sitúa entre los años 1220 y 1250. La noción «infancia» -de origen latino-, en tanto, surge en el siglo XIII y se hace extensiva a «niñez». En su recorrido bibliográfico, Giberti (1997) observa una sinonimia entre niñez e infancia sobre la que realiza ciertas observaciones diferenciales: mientras que la infancia promete el comienzo de un nuevo ciclo, infans remite a el o a la que aún no habla.

A su vez, delimita los sentidos de infancia en la teoría psicoanalítica:

La calificación de «infantil» corresponde a un modo de inscripción en el inconsciente, como un tiempo psíquico en la estructuración del aparato psíquico. En cambio, infancia, para esa misma teoría, se reconoce como una 
etapa cronológica en el desarrollo del Yo consciente. «Infantil», en esta teoría, permanece ajeno a la idea de niñez o infancia. En cuanto a niñez, se describe como el momento que circunvala un período de otra índole, más abarcativo que infancia, y no remite necesariamente a un inicio (aunque lo incluya) sino que ciñe un estadio histórico dentro del desarrollo evolutivo de los humanos (1997, pp. 25-26).

La idea de niñez instituida fusionó una determinada concepción de pureza, de inocencia y de ingenuidad, que adquirieron calidad simbólica y le otorgaron un significado propio; significado cuya cristalización produjo un proceso de naturalización de dicha categoría, "como si siempre se hubiese hablado de niñez y se diera por sabido qué es lo que "debe" entenderse por ella, en particular su relación con los adultos» (Giberti, 1997, p. 51). Otro de los resultados producidos por tal proceso de cristalización de sentido es el silenciamiento de los delitos, los desbordes, las penurias, las injusticias y las aberraciones cometidas sobre millones de niños y de niñas.

Diversos autores/as retoman los enfoques propuestos por Ariès (1962) y por deMause (1974). Entre ellos, Volnovich (1999), quien delimita algunas diferencias entre ambos. Según este autor, para Ariès (1962), en la antigüedad existía una suerte de paraíso y los niños circulaban felices, mientras que la familia moderna -que caracteriza como tiránicaes la causa de la ruptura de los lazos de solidaridad y de sociabilidad naturales que privó a los/as niños/as de la libertad de que hasta entonces gozaban, imponiéndoles, por primera vez, la tiranía doméstica como protección y como límite. Por el contrario, señala Volnovich (1999), para deMause (1974) el concepto de infancia existía ya en la Alta Edad Media, cuando los niños eran prácticamente masacrados, y sitúa, con la familia moderna, el comienzo de una política más piadosa que incluyó, progresivamente, la conservación de los/as niños/as y un trato más humano.

Uno de los puntos de coincidencia entre Ariès (1962) y deMause (1974) refiere al infanticidio, respecto al cual ambos coinciden en afirmar la inexistencia en la antigüedad de un sentimiento de culpa asociado a la matanza de los/as niños/as. Actualmente, señala, sí existe una clara sanción reprobatoria generada por la culpa y el castigo: 
«Lo que antiguamente era, si acaso, un error, es ahora, claramente, un horror. Sin embargo, la muerte de un millón de niños por año en América Latina es un dato estadístico con el que convivimos sin mayor problema» (Volnovich, 1999, p. 45).

El mismo autor hace suyo el enunciado: "La historia de la infancia es una pesadilla de la que hemos empezado a despertar hace muy poco», y se pregunta: «¿O es que no hemos salido aún de esa pesadilla?» (Volnovich, 1999, p. 36); un interrogante que pone en tensión al describir las múltiples agresiones que han tomado a los/as niños/as como objetos, y que no solo remiten al pasado sino que pueblan nuestra cotidianidad. "No hace falta más que prender el televisor para observar, al instante, la patética imagen de millares de niños muriéndose de hambre y "pescados" por la cámara para ser transmitidos al instante, en el preciso momento en el que mueren» (Volnovich, 1999, p. 37).

Otro de los autores que retoma los desarrollos de deMause (1974) y de Ariès (1962) es Bustelo Graffigna (2012), quien sostiene que «la cuestión -superando una historiografía de lectura fina- pasa por reconocer que no siempre ha habido infancia en el sentido moderno» (p. 288). Los cambios fundamentales se centraron en la familia nuclear y en la escuela y marcaron el surgimiento de la categoría infancia en el capitalismo industrial.

Bustelo Graffigna (2012) caracteriza la infancia como un colectivo -a diferencia de la categoría de niño o niña singulares y de hijo/a o alumno/a- que define una expresión «del lugar que en la cultura tienen las nuevas generaciones respecto a los adultos. Esta asignación en la cultura es histórica y discursiva. La infancia es situada, incuestionablemente, en una relación de dependencia y de subordinación» (p. 289), asimetría que coloca en el centro de la cuestión los atributos que se le asignan a la infancia y que sirven para la construcción de dispositivos jurídicos y culturales que la sujetan a su «pequeñez».

Corea (1999), por su parte, sostiene que la niñez es un invento moderno producido históricamente por un conjunto de prácticas estatales burguesas, como las prácticas de conservación de los hijos, el higienismo, la filantropía y el control de la población, que dieron lugar a la familia burguesa y que consolidan lugares diferenciados para los/as niños/as como hijos/as, y para los/as adultos/as como padres y madres. 
De allí que hay infancia a partir de la intervención práctica de un numeroso conjunto de instituciones modernas de resguardo, de tutela y de asistencia a la niñez. Prácticas que instituyeron significaciones con las que la modernidad trató, educó y produjo niños: la idea de inocencia, la idea de docilidad, la idea de latencia o de espera.

Asimismo, Corea (1999) indica que las prácticas pedagógicas de mediados del siglo XIX hasta mediados del XX muestran cómo estos enunciados funcionaban. Los manuales escolares son uno de los ejemplos que visibiliza el tratamiento del niño como «el hombre del porvenir», de lo que se desprende que para la institución escolar el/la niño/a no existe como sujeto en el presente sino como promesa de futuro. La separación simbólica del mundo adulto y del mundo infantil es inmanente al mundo moderno y la escuela es una de las productoras clave de tal separación.

En la misma línea, Lewkowicz (1999) postula que las diversas sociedades establecen distintos procedimientos de humanización y que la cría humana no es de por sí un/a niño/a, es cría. Que la cría se constituya en un/a hijo/o, y de él/ella a un/a niño/a, es producto de las prácticas modernas burguesas que así lo han instituido, prácticas que separaron y que distinguieron un espacio diferencial para los/as niños/as.

Por su parte, García Méndez (1991) propone un análisis de la categoría «infancia» desde una perspectiva que parte de los diversos mecanismos y teorías utilizados a lo largo de la historia para su «control social» específico; a la vez que rechaza las concepciones de la infancia que la consideran como un dato ontológico, ahistórico y de validez universal, en tanto que la categoría no existía antes del siglo XVI.

En este sentido, el autor caracteriza la infancia como

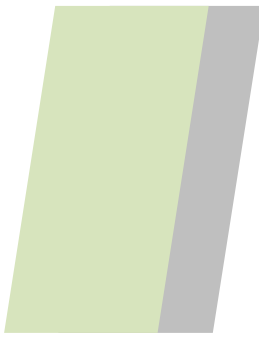

[...] el resultado de un complejo proceso de definiciones, de acciones institucionales y de cambios sociales en los sentimientos. Los mecanismos y las ideas creadoras de la infancia corresponden a los mecanismos y a las ideas creadoras del control de la misma. La historia de la infancia es la historia de su control (García Méndez, 1991, p. 12). 
En el recorrido por los diversos desarrollos teóricos provenientes de distintos campos disciplinares, vemos que un tipo de infancia -la niñez- nace con el dispositivo sociohistórico de la modernidad, producida centralmente por la familia nuclear burguesa y por la escuela.

Ahora bien, distintos autores/as sostienen que asistimos a una transformación en la dimensión sociohistórica y a una

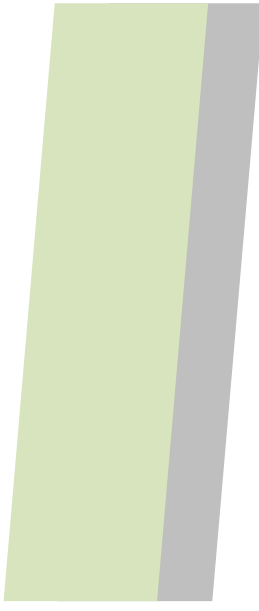

[...] mutación de la experiencia infantil que conmueve a padres y maestros. Mutación producida por el impacto de las políticas neoliberales que definen de otro modo (al de la modernidad) el sentido político y social de la población infantil para los estados-naciones; por la incidencia creciente del mercado y de los medios masivos de comunicación en la vida cotidiana infantil, y por las transformaciones que afectan a la escolaridad pública. Tales mutaciones producen el corrimiento de las fronteras que delimitaba una distancia entre adultos y niños, construida históricamente bajo la regulación familiar, escolar y estatal (Carli, 1999, p. 13).

Los desarrollos de Corea y Lewkowicz (1999) parten de lo que denominan una «corroboración histórica» respecto del agotamiento de la infancia, producido por la impotencia de las instituciones modernas para instituir la infancia en sentido moderno; agotamiento que, sostienen, se produce por las mutaciones socioculturales y la transformación del Estado nación en Estado técnico-administrativo, que «dejan en el aire a las instituciones de asistencia. Tales instituciones, que tradicionalmente funcionaron como un dispositivo más de la lógica estatal, se vuelven prácticamente ineficaces cuando el Estado abandona sus funciones públicas para desplazarse hacia el mercado con el objeto de cumplir funciones gerenciales» (Corea \& Lewkowicz, 1999, p. 92).

Además, afirman que el consumo generalizado produce un tipo de subjetividad que torna difícil el establecimiento de la diferencia simbólica entre adultos/as y niños/as. La alteración de la institución familiar y escolar moderna produjo una variación práctica del estatuto de la niñez. El consumo y la comunicación de masas, como prácticas 
dominantes actuales, instituyen otras «dos figuras que detentan la subjetividad actual del niño: la del consumidor y la del sujeto de derechos, que en el discurso mediático aparece bajo la figura del sujeto de opinión. La diferencia moderna entre el padre y el hijo, producida por el discurso cívico, queda abolida en el discurso mediático bajo una figura equivalente para ambos: la del consumidor» (Corea \& Lewkowicz, 1999, p. 54).

En cuanto al niño como sujeto de derechos, proponen analizarla en relación con la caída del ideal del hombre futuro, que se produjo «al caer el paradigma moderno del progreso» (Corea \& Lewkowicz, 1999, p. 118) y con él, también, la concepción genética de las edades, para la cual la infancia constituye la etapa de espera de la adultez. Es decir, «si el niño es concebido como sujeto de derechos la idea de latencia propia de la edad infantil cae; el niño ya es, y la infancia se disuelve como edad de espera, no hay tutela posible si un sujeto ya es en acto y no pura potencia futura» (Corea \& Lewkowicz, 1999, p. 118).

Para Carli (2010), las tesis propuestas por Corea y Lewkowicz (1999) necesitan ser repensadas cuando aborda el proceso histórico local, debido a sus particularidades:

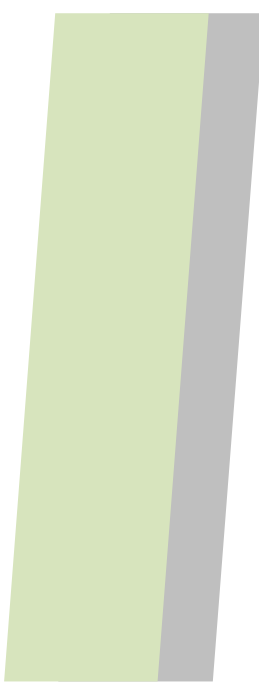

El fin de la infancia moderna en la Argentina debería leerse como el resultado de políticas que desmantelaron o vaciaron de sentido los signos del pasado como el delantal blanco o el acceso democrático de todos los niños a los mismos bienes educativos, signos que al ser leídos como homogeneizantes o disciplinantes no fueron reconocidos como portadores de representaciones de integración social [...]. Reponer desde una perspectiva política el concepto de homogeneidad no implica desconocer la diversidad de la experiencias infantiles, sino que implica aportar a una lectura crítica del aumento de la desigualdad en la historia reciente y plantear políticas de infancia como espacio para un litigio por el acceso y el disfrute del bien educación (p. 369).

De este modo, Carli (2010) plantea que si bien es posible una lectura totalizante de la identidad infantil que tome en cuenta ciertas marcas globales y la permanencia de dispositivos modernos como la escuela, también es necesario un trabajo de «destotalización de las identidades que tenga en cuenta los procesos de apropiación diferencial de los niños» (p. 355). 
A su vez, manifiesta que durante la última Dictadura cívico militar la niñez fue convertida en un motín de guerra -como parte de una política de secuestro- y «encerrada en el ámbito familiar que satanizó la peligrosidad del espacio público y los beneficios del ámbito privado» (Carli, 2010, p. 356). Las transformaciones producidas en el tejido social de nuestro país posibilitan, así, comprender las nuevas figuras de la infancia argentina en el niño de la calle y en el niño consumidor (Carli, 2010). De allí que no sea posible hablar de «la» infancia, en singular, sino de «las» infancias, en plural, pluralidad que refiere, al decir de Carli (1999) a tránsitos múltiples, diferentes y cada vez más afectados por la desigualdad.

\section{La niñez en el suelo argentino}

En línea con el planteo de Carli (2010), respecto a la necesidad de detenerse en el proceso histórico de nuestro país, Giberti (1997) señala que los desarrollos acerca de la niñez, o los estudios de género o de la familia, utilizan los aportes históricos que provienen casi con exclusividad de los textos de Ariès (1962), Donzelot (1990) y deMause (1974) cuyas investigaciones, si bien son esclarecedoras, conducen a pensar la niñez según la historia europea, con el riesgo de convertirla en un modelo ideal enunciado por sujetos «altamente calificados».

Frente a esto, la autora propone pensar la niñez desde la perspectiva de un continente con matrices culturales andinas, precolombinas y coloniales, y sugiere

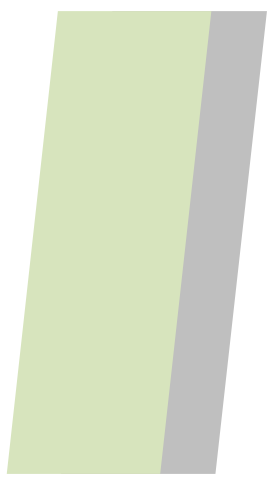

[...] buscar una lógica inclusiva que haga lugar a las diferencias entre diversos continentes, y las relaciones. Es preciso ceder lugar a quienes escribieron y escriben otra historia, la que habla de los ancestros que vivieron en una América mestiza, datos excluidos de un sinnúmero de investigaciones y ensayos; lo cual no debería asombrarnos si tenemos en cuenta los antecedentes europeos de la burguesía y de las clases altas de nuestro país, de las cuales surgió la mayoría de los investigadores. También habría que tener 
en cuenta la influencia de los sistemas educativos de los que proviene nuestro estilo de pensamiento, cuya perspectiva europeizante desemboca en versiones denigratorias de las etnias aborígenes de América Latina (Giberti, 1997, p. 31).

Los desarrollos propuestos por Domínguez Lostaló (1987) permiten caracterizar la población de nuestro continente, denominada como Mestizaje Marginal Originario, que contiene en su composición cuatro vertientes en diversas gradaciones. Una primera vertiente es la población originaria del territorio, que sobrevive en la actualidad a pesar de que desde la época de la conquista se hayan implementado políticas de exterminio. La segunda vertiente la conforma el remanente de población negra, desarraigada de sus lugares de origen, «esclavos, a quienes no se les reconocía su condición de seres humanos» (1999, p. 67); población que no tiene mucha incidencia actual en nuestro país, pero que existió y que en países vecinos es más visible y evidente.

Las otras dos vertientes que componen nuestro Mestizaje Marginal Originario provienen de una doble colonización:

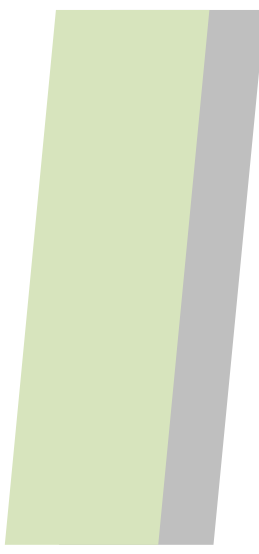

La primera fue la ibérica (luso-hispana) que tenía, por una parte, una característica misionera catequizadora y estaba imbuida de un criterio de predeterminación divina. Pero, por otra parte, tenía un contenido económico: venía con una idea predominantemente extractiva de los recursos naturales. La conquista y la posterior colonización se realizó con objetivos de extracción o más bien de sustracción de las riquezas de este continente y con una consideración de irrespeto hacia sus culturas, por ende, hacia sus habitantes y hacia sus descendientes (Domínguez Lostaló, 1987, p. 61).

La cuarta vertiente llegó a nuestro continente después de los ochenta, compuesta por la población inmigrante proveniente de los países de Europa. Si bien fue recibida en función de un proyecto de modernización del Estado,

[y de] conformación a imagen y semejanza de los países del norte y centro de Europa, no se correspondió con tales expectativas. Esta fue quizás la corriente de colonización más sui géneris porque, aunque frecuentemente hizo que se 
nos definiera como un crisol de razas, se omitió su condición de marginación. Se dijo que esa inmigración llegó para mejorar la raza, para que «nuestras mujeres -como decían algunos autores- fueran mejor fecundadas por europeos», ya que vale más un francés o un inglés, aunque no sepan ni la $\mathrm{O}$, que el más culto hombre de nuestro campo (Domínguez Lostaló, 1987, p. 62).

Sin embargo, y aquí el autor puntúa una paradoja, los italianos, polacos, judíos, y algunos sirios y libaneses, habían sido marginados del proceso de la revolución industrial. Es decir, otra de las características de la vertiente inmigratoria es que se trató de personas que -en su mayoría- tenían en sus países de origen una condición de desarraigo, eran marginales: «Nuestros conquistadores no fueron ni prohombres, ni gentilhombres; eran hombres marginales en su mayor parte» (Domínguez Lostaló, 1987, p. 62). Marginaciones y desarraigos de poblaciones que, según el autor, no se incorporaron al proceso de la revolución industrial europea.

Ahora bien, entre los años 1850-1880 la filosofía del positivismo se implantó en nuestro territorio a través del «mito del desarrollo». «El desarrollo sentido como desarrollo industrial, que permite acceder al confort y que tiene como modelo el hombre que produce, y como modelo de niño, el niño que puede incorporarse, en algún sentido, al modelo de producción» (Domínguez Lostaló, 1999, p. 67), y con él, el modelo de las grandes instituciones de encierro, que hasta 1850-1860 no existían en el continente, o eran muy pocas.

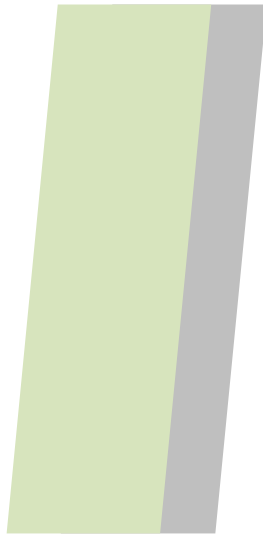

Las llamadas instituciones totales, los clásicos y largos hospitales de muchas camas, los orfanatos, los sistemas penitenciarios de tipo panóptico, etc., fueron traspolaciones de un lugar a otro y, prácticamente, era como si copiar las instituciones y copiar los métodos nos iba a permitir ser como los «más desarrollados» [...]. Es decir, todo lo que de algún modo no está integrado al proceso de producción debe ser mantenido en una suerte de cunas institucionales que son las que, de algún modo, van a impedir que se pierdan y ver si se pueden incorporar (Domínguez Lostaló, 1999, p. 68). 
Al respecto, Blanco (2001) señala que nuestro sistema jurídico, educativo, político e institucional reproduce el modelo de las situaciones coloniales, dado que, en las naciones llamadas desarrolladas, la ley

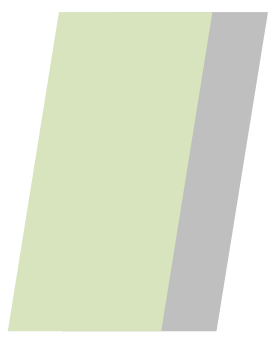

[...] es fruto de una negociación entre distintos sectores e intereses sociales que de otro modo no tendrían más camino que el exterminio, como en nuestro país que surgió fruto del exterminio. La orgullosa ciudad «europea» ubicada en América «por accidente geográfico» fue el principal asiento de esclavos del cono sur (Blanco, 2001, p. 98).

Esta población integró el cuerpo de infantería de las guerras de la independencia que, junto con la fiebre amarilla, «resolvieron el problema expeditivamente», respecto a los criollos que sobrevivieron a las guerras civiles. «Fueron perseguidos a sangre y fuego, sin cuartel, y finalmente utilizados en la campaña contra los indios. Es lo que comúnmente se conoce como matar dos pájaros de un tiro» (Blanco, 2001, p. 98).

Fue sobre ese «campo de batalla», señala Blanco (2001), sobre el que se erigió la «Argentina moderna», sostenida en un sistema institucional -judicial, político, educativo, de seguridad, penitenciario-creado para «impedir la libre expresión popular».

Ahora bien, también plantea como una de las grandes paradojas de nuestra historia que la población de inmigrantes -de quienes se esperaba que reprodujeran Europa en el sur de América- se haya «mimetizado con la población nativa, adoptando sus costumbres, códigos y pautas culturales» (Blanco, 2001, p. 98), paradoja que intentará resolverse a través de diversas normativas entre las cuales (como veremos más adelante) se encuentra la sanción del Decreto ley del Patronato de Menores.

En nuestro territorio, la conformación del Estado moderno incentivó, al compás de una política de exterminio de comunidades originarias, la incorporación de mano de obra -mayoritariamente europea- como fuerza de trabajo asalariada, necesaria para el desarrollo de la sociedad capitalista. Las condiciones materiales de vida de estos «nuevos 
trabajadores» produjeron demandas que terminaban en enfrentamientos atribuidos a «los inmigrantes revoltosos», dado que el movimiento de población inmigratoria trajo consigo nuevas ideologías y experiencias de organización sindical.

En dicho contexto, en 1902 se sancionó la Ley de Residencia, ${ }^{11}$ vigente hasta 1958, que combinaba las políticas de atracción de mano de obra con las condiciones de su expulsión. Para gobernar a esta nueva población se efectuaron diversas respuestas estatales de control y de disciplinamiento (Fasciolo, 2018).

La población de niños/as -en Buenos Aires, entre 1890 y 1910 - se constituyó no solo en una parte diferenciada del todo social, sino que, en un clima general de transformación y de modernización capitalista, comenzaron a diferenciarse de los/as adultos/as y entre sí, clasificándose en tres grupos: los chicos pobres, los chicos de los sectores medios y los chicos de las élites. Tal clasificación «evidencia las políticas seguidas para cada uno: la persecución, la detención y el internamiento cuando se trataba de chicos vagabundos o transgresores y de niñas que se prostituyen, y otras políticas para los chicos de las clases medias y altas» (Giberti, 1997, p. 40).

En la etapa fundacional de la educación, a través de la Ley Nacional 1.420 de 1884 se instituyó un dispositivo de instrucción pública, gratuita, laica y obligatoria, y con ella se desarrolló una concepción moderna de la infancia desplegada por Sarmiento, portadora de una política cultural generacional a partir de un ideal de familia burguesa, escuela pública, escuelas de artes y oficios, y asilos, que implicó todo un proceso de «institucionalización moderna de los chicos. El modelo es un niño subordinado a sus padres y a los docentes, sin derechos propios. De este modo, se vincula la historia de la infancia con la historia de la educación» (Giberti, 1997, p. 33).

\footnotetext{
11 La ley de Residencia, o Ley Cané, establecía: ARTíCULO $1^{0}$ - El Poder Ejecutivo podrá ordenar la salida del territorio de la Nación a todo extranjero que haya sido condenado o sea perseguido por los tribunales extranjeros por crímenes o delitos comunes. ARTíCULO $2^{\circ}$ - El Poder Ejecutivo podrá ordenar la salida de todo extranjero cuya conducta comprometa la seguridad nacional o perturbe el orden público. ARTíCULO $3^{\circ}$ - El Poder Ejecutivo podrá impedir la entrada al territorio de la República a todo extranjero cuyos antecedentes autoricen a incluirlo entre aquellos a que se refieren los artículos anteriores. ARTíCULO $4^{\circ}-$ El extranjero contra quien se haya decretado la expulsión tendrá tres días para salir del país, pudiendo el Poder Ejecutivo, como medida de seguridad pública, ordenar su detención hasta el momento del embarque. ARTíCULO $5^{\circ}$ - Comuníquese al Poder Ejecutivo.
} 
Para el proyecto moderno, la educación de la niñez fue una de las estrategias centrales, en tanto posibilitaba la concreción de un orden social que eliminara el retraso y la barbarie; un proyecto que requirió de «una significación de la infancia a partir de la concepción de la niñez como germen de la sociedad política y civil del futuro, y de su escolarización como garantía de un horizonte de cambio social y de progreso» (Carli, 1999, p. 3) En este sentido, la escolaridad obligatoria se inscribe como un dispositivo disciplinador de los/as niños/as de los sectores populares, hijos/as de la inmigración y de la población nativa.

Este modelo dejó al margen a todo un sector de niños/as como los/as trabajadores/as, huérfanos/as, vagabundos/as y desertores escolares, que los discursos y las prácticas de las mujeres anarquistas, socialistas y liberales democráticas hicieron visibles, a la vez que gestaron alternativas para su atención. De allí que para Giberti (1997) sea posible «articular la historia de la infancia con la historia de las mujeres, sujetos ambos de una opresión común» (p. 33).

De este modo, las modificaciones producidas en el Estado entre 1919 y 1930 se articularon con la historia de la infancia a partir de la modernización pedagógica escolar y de la institucionalización estatal de la niñez no escolarizada, periodo en el cual surge el discurso de la minoridad y la institucionalización del menor.

Los procesos de normalización de la niñez que acompañaron la constitución del Estado argentino produjeron una «escisión original del campo de la infancia [...]. No hubo una sola infancia y luego pobreza y más tarde menores, sino que el propio Estado, en su misma constitución, interpeló a una infancia escindida por él» (Costa \& Gagliano, 2000, p. 104). En nuestro país, la particularidad del control que empezó a implementarse desde la constitución del Estado. mediante la creación de dispositivos legales e institucionales. fue la clasificación en niños/as y en menores.

En esta línea, Llobet (2003) propone a modo de hipótesis que «si la infancia surgiera con la familia -para traducir de manera harto simplista la tesis de Ariès-, su fragmentación en categorías diferenciales es producto de la combinación de la lógica estatal y el proceso de sentimentalización de la infancia que hizo de ésta un objeto relevante de intervención» 
(2013, p. 213). La acción estatal requiere de la clasificación de distintos tipos de niños/as para su interpelación por dispositivos jurídicos e institucionales específicos: hijo/a, alumno/a, menor, niño/a trabajador/a, lo que indica que tales tipos de infancias son producidas por intervenciones estatales diferenciadas y emergen de la segregación de los tipos de familias.

La minoridad, como categoría diferencial, es producida «en el marco del gobierno de la población y constituida en el cruce de los procedimientos institucionales de controlprotección de la infancia» (Oyhandy Cioffi, 2004, p. 11). La carencia de vínculos familiares y de condición de alumno/a define al menor, definición que parte de los atributos que hacen-ser la niñez moderna.

En el mismo sentido, Daroqui y López (2012) sostienen:

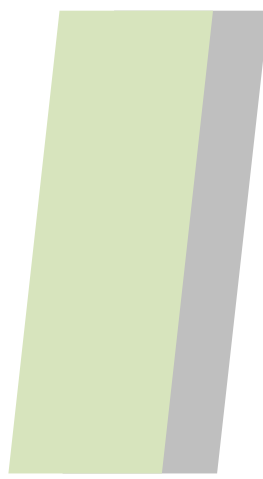

La historia de la «minorización» debe ser leída a la luz de procesos más amplios de control social sobre determinados sujetos y poblaciones tenidas por problemáticas, peligrosas y/o en riesgo, y sobre las cuales se han desplegado diversas y complementarias estrategias de gobierno, sean éstas abiertamente penales, tutelares o asistenciales, en un espectro que contempla tecnologías de cura, corrección, represión, protección, disciplinamiento, segregación o, en sus extremos, incapacitación y eliminación (p. 49).

De este modo, cobró visibilidad la centralidad de ciertos grupos familiares sobre los cuales operaron las normativas, en tanto que la familia fue una preocupación del Estado desde la colonización de nuestro territorio. Etimológicamente, familia deviene de «famulus: creíados del Pather Patron y Mater: matriz, por eso el derecho de posesión, vida, muerte, venta» (Domínguez Lostaló, 1999, p. 67). Mientras que, en la época de la colonia, la estructura familiar respondía al modelo patriarcal, heredero de las costumbres españolas (Giberti, 1997).

Las culturas originarias de nuestra región y las culturas de los inmigrantes del siglo XIX tenían como característica común la organización en «grupos familiares extendidos»; fue con el modelo económico propio de la sociedad industrial que aparece la familia 
nuclear. Pero había familias que no se adecuaban a los requisitos del modelo familiar liberal conservador, familias provenientes de los sectores populares cuya composición presentaba las características del mestizaje marginal originario propio de los procesos de colonización de nuestro continente.

Los/as niños/as que ingresaban al sistema del patronato del menor provenían de estas familias: «El sistema tutelar garantizaba el rescate de estos niños y los ingresaba en circuitos paralelos de socialización que confluían en el imaginario conservador de un pueblo de menores» (Costa \& Gagliano, 2000, p. 73). Hablamos de un sistema tutelar implantado producto de la traspolación que implicó la instalación de instituciones disciplinares en la organización del Estado moderno.

\section{Los/as niños/as como objeto de tutela}

El minucioso recorrido que realiza Larrandart (1991) sobre las diversas normativas del período colonial en nuestra región, permiten visibilizar el pasaje de esta época a la modernidad; pasaje que supuso un progresivo proceso de regulación social expresado en las prácticas jurídicas como formas de normalizar las conductas. ${ }^{12}$

\footnotetext{
12 Como ejemplos, indica que en el derecho indiano -a través de las Reales Cédulas de 1518, 1519 y 1551-, se disponía que la mujer india soltera que fuera huérfana o no viviera con sus padres debiera ser depositada en casa de familia española quien debía hacerse cargo de su educación. Los indios menores de 25 años, en igual condición, debían ser colocados a cargo de un encomendero, quien asumía las obligaciones derivadas de la patria potestad. En 1809, el Virrey Cisneros dictó una instrucción donde encomendaba a los alcaldes de barrio, encargados de la seguridad pública, informar si en los barrios había niños huérfanos o abandonados por sus padres, quienes, de acuerdo a edad y sexo, serían colocados con maestros que les enseñaran algún oficio. En la década de 1820, se crea el cargo letrado de Defensor de Pobres y Menores, quien debía intervenir junto con la Sociedad de Beneficencia -creada en ese momento- para «velar sobre el destino, las fortunas y las personas de los menores, que por su orfandad, indigencia o por el extravío de sus propios padres se hallaban abandonados por sus propios padres [...] pudiendo ser víctimas de la dilapidación de sus bienes por un padre o tutor vicioso, de un descuido criminal de su educación o desnaturalizados por la seducción o el ejemplo» (p. 23). En 1863, el gobernador Domingo Faustino Sarmiento dictó un Decreto en el que disponía la obligación de los padres de mandar a sus hijos a la escuela, estableciendo que los Jueces de Paz y Comisarios de Departamentos rurales y suburbanos harían un registro de los niños en estado de asistir a la escuela, haciendo conocer a los padres la obligación de darles educación (Larrandart, 1991, p. 23).
} 


\section{El periodo colonial}

En los inicios del Estado nacional, la protección de los/as niños/as y los/as adolescentes estaba a cargo de entidades privadas laicas o religiosas; no formaba parte de las políticas públicas estatales. Durante los años de la conquista española, la ciudad de Buenos Aires estaba habitada por gran cantidad de soldados que «abusaban de las mujeres nativas. Fruto de violaciones, los embarazos no deseados devinieron en el abandono en la vía pública de decenas de niños y niñas recién nacidos» (Sardá, 2012, p. 9).

Para evitar su muerte, en 1779 se creó la Casa de Niños Expósitos, bajo el modelo de las casas que existían en Madrid. Dicha casa se sostenía a través de aportes de entidades que efectuaban donaciones. El sistema de ingreso permitía el anonimato de quienes los/as dejaban: los/as niños/as eran depositados/as en un torno de madera, «al mismo tiempo que el sonido de una campana avisaba al encargado, y éste los recogía e ingresaban formalmente para su posterior cuidado» (Sardá, 2012, p. 9).

Sobre el destino de los/as niños/as que ingresaban a dicha Casa poco se sabe; sin embargo, algunas versiones históricas relatan que luego de cierta edad, y tras obtener un determinado nivel de instrucción, eran entregados a familias de la clase alta para actividades de servidumbre. Se señala que en 1821 la Casa fue transferida a la Sociedad de Beneficencia, que posteriormente (en el gobierno del General Justo José de Urquiza) pasó a denominarse Casa Cuna. Se evidencia que la protección a la infancia pobre era motivo de preocupación para la caridad privada, y solo aparecía esporádicamente como asunto de preocupación pública estatal en relación con políticas sanitarias o educativas.

\section{La Ley Agote}

Con la inmigración masiva de ciudadanos europeos surgió el control penal de la minoridad, centrada en el control de los/as hijos/as de los inmigrantes, en tanto se consideraba que la familia extranjera no era capaz de llevar a cabo esta tarea. «Por un lado, [porque] el desarraigo y la diferencia de las costumbres y hasta de la lengua, 
determinaban que los hijos, criados aquí, no les obedecieran. Por el otro, [porque] la presencia de ideas anarquistas en los grupos inmigratorios suponían la necesidad de evitar que tales ideas se propagaran» (Larrandart, 1991, p. 21).

Durante el siglo XIX se produce en la Argentina una creciente ampliación de las funciones estatales en relación con la población de niños/as y jóvenes de los sectores más desfavorecidos (Zapiola, 2010). Funciones estatales cuyos marcos legislativos trazan, orientan y direccionan «discursos y prácticas institucionales en todas aquellas agencias que tratan, penalizan y protegen a un determinado sector social de la niñez en y con problemas» (Daroqui \& López, 2012, p. 51).

Con la Ley Nacional 10.903, sancionada en 1919, y denominada Ley Agote, ${ }^{13}$ se profundizó la intervención estatal, al otorgarle al Estado mayores facultades de control, tanto en los casos de «abandono material o moral» como en los de «comisión de delitos». Para poder facultar al Estado para intervenir y para disponer del menor y no chocar con el concepto de patria potestad ${ }^{14}$ era necesario modificar el Código Civil, lo que se produjo ese mismo año y determinó que los padres también tenían obligaciones. De este modo, si los padres no cumplían con sus obligaciones, el Estado podía intervenir sacando al menor de su poder, dando lugar a su tutela y a su internación en institutos de «menores».

Zapiola (2010) interroga sobre los motivos que hicieron posible que la presentación del proyecto de Agote fuera exitosa. Según la autora, este interrogante no alcanza a ser explicado por las necesidades y por las aspiraciones de control social de los Estados modernos sobre los/as hijos/as de los/as inmigrantes, sino que, además, se vincula con

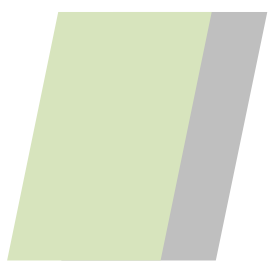

el recrudecimiento de la conflictividad social en los espacios urbanos del país a partir de 1917, que alcanzó su paroxismo durante la Semana Trágica, violenta concatenación de eventos que sacudieron a Buenos Aires y a otras ciudades del país en enero de 1919. Los acontecimientos parecían confirmar las

\footnotetext{
13 Conocida de este modo por haber sido presentada por el diputado conservador Dr. Luis Agote.

14 «La patria potestad es el conjunto de derechos y obligaciones que corresponden a los padres sobre las personas y bienes de sus hijos, desde la concepción de éstos y en tanto sean menores de edad y no se hayan emancipado» (Código Civil, art. 264).
} 
proyecciones más oscuras de las élites acerca de la amenaza política que representaban los menores callejeros y abandonados para el orden social establecido, circunstancia que Agote no dejó de señalar en la Cámara baja poco después de los sucesos (Zapiola, 2010, p. 6).

Lucesole (2016) plantea la importancia de destacar el proceso de grandes migraciones internas del interior a los centros urbanos que se produjo desde 1935 en adelante y que marcó un rumbo diferente para la cuestión social que se instalaba. La autora recupera los desarrollos de Guemureman y Daroqui (1999), quienes sostienen que esta «nueva cuestión social» fue abordada desde la perspectiva de un modelo de crecimiento «hacia adentro» fundado en la industrialización, el pleno empleo y los altos salarios, modelo inspirado en los principios del Estado de Bienestar.

\section{La era de la política social}

A partir de 1943, las medidas económicas tomadas por el Estado, con una mayor transferencia de recursos hacia el sector de los/as trabajadores/as y la ampliación de derechos sociales y laborales, dieron comienzo a «la era de la política social» (Sardá, 2012, p. 11). De este modo, los derechos de los/as trabajadores/as se hicieron extensivos a todos los/as niños/as del país.

En este marco, en septiembre de 1946 se intervino la Sociedad de Beneficencia, lo que incluyó una «serie de medidas tomadas en las instituciones bajo su dependencia, orientadas a una mejor identificación de los niños, a la prohibición de signos -utilización de medallas y de uniformes- y a la apertura de los institutos de menores que cristalizaron el deseo de Eva Perón de eliminar las marcas de la pobreza» (Sardá, 2012, p. 11).

Por su parte, la Dirección Nacional de Asistencia Social implementó políticas novedosas con respecto a la infancia: se reorganizaron todos los institutos que pasaron a ser hogares abiertos, lo que permitió el contacto familiar y la asistencia a escuelas públicas; se eliminóla identificación numérica -por medio de medallas o de distintivos- y se la 
reemplazó por el sistema de legajo civil; se abolió el uso de uniformes y todo tipo de castigos corporales; y se dejó sin efecto la colocación de menores para servicio doméstico (Sardá, 2012).

En 1959, durante el gobierno de Arturo Frondizi, se creó el Consejo Nacional de Protección de Menores como ente autárquico (Ley 15.244). A nivel discursivo, prevaleció la noción de «menor» por sobre las de infancia, niñez y adolescencia; la pobreza pasó a ser visualizada como un fenómeno marginal a la realidad del país -que se concentraba en las villas de emergencia o en asentamientos- y los menores concebidos como los «errores del sistema que no dejaban de constituirse en una amenaza» (Guemureman \& Daroqui, 1999, p. 55). En este periodo se disolvió la Fundación Eva Perón.

En mayo de 1983, se modificó el Decreto Ley 22.278/80 del Régimen Penal de la Minoridad y se promulgó el Decreto Ley 22.803, que estableció la edad de punibilidad en los 16 años. De acuerdo a la normativa, cuando «existiere imputación contra alguno de ellos, la autoridad judicial lo dispondrá provisionalmente» (art. 1). De este modo, la custodia queda en manos del juez y se restringe la patria potestad o tutela. La disposición definitiva podrá cesar, atento a la resolución judicial «fundada», y concluirá cumplidos los 18 años de edad.

En la provincia de Buenos Aires, en 1937 se había sancionado la Ley 4.664, a partir de la cual se creó el Tribunal de Menores, el primero de ese tipo en el país, y se sancionó la Ley 4.547, que creó la Dirección General de Protección a la Infancia. De este modo, dirán García Méndez \& Vitale (2009), «nace el dispositivo institucional para materializar una cultura según la cual la política social para los hijos de los pobres será competencia exclusiva y excluyente del Poder Judicial» (p. 1), cultura perfeccionada en 1983 con el Decreto Ley 10.067.

En 1961 se sancionó la Ley 6.661 (que derogó la Ley 4.547) a través de la cual se disolvió la Dirección General de Protección de la Infancia y se creó el Consejo General de la Minoridad, cuyo propósito fue la planificación y la ejecución de políticas de minoridad para la provincia de Buenos Aires. Dicho Consejo estableció espacios ocupacionales para profesionales médicos, psicólogos, psiquiatras y trabajadores sociales (Fasciolo, 2018). 
En relación con el Decreto Ley $10.067 / 83$, este fue sancionado y promulgado por el Gobernador de la Provincia en ejercicio de las facultades legislativas conferidas por la Junta Militar el 25 de octubre de 1983, y estuvo vigente hasta el año 2007. Con él, se instituyó «un nuevo régimen regulatorio del Patronato de Menores de la Provincia de Buenos Aires».

\section{El retorno a la democracia}

El ciclo que se inició durante los años ochenta con el retorno a la democracia se caracterizó por los efectos que provocaron las políticas del gobierno militar, que arrojó un aumento del desempleo y la informalidad que derivó en un proceso creciente de empobrecimiento del país con la consecuente expulsión del sistema de seguridad social. En palabras de Golbert (2010), las condiciones que dejó la última Dictadura cívico militar a nivel del Estado fueron: «Bajas capacidades institucionales y desintegración social [...], escasos grados de libertad para ejecutar políticas tendientes a reparar el daño causado a la sociedad por la dictadura [...], aumento de la deuda externa generada por la dictadura y deuda social» (p. 133).

A comienzos de 1989, la situación de alta conflictividad social se vio agravada por la hiperinflación, que intensificó de tal modo la crisis política del país que produjo el adelantamiento de la entrega de mando del presidente Raúl Alfonsín al presidente ya electo, Carlos Saúl Menem. El modelo económico de éste último estuvo fundado en una política neoliberal que implicó un fuerte control monetario para, por un lado, combatir la inflación y, por otro, dar una señal a los mercados y a la sociedad de «que no había lugar para políticas de tipo populistas» (Golbert, 2010, p. 137). Para ello, se estableció el valor del peso argentino igual al valor del dólar estadounidense, medidas que fueron acompañadas por otras que respondían al Ilamado Consenso de Washington: irrestricta apertura de la economía a la competencia extranjera, privatización de empresas y de servicios públicos (más intenso que en el periodo de la dictadura militar), privatización de la seguridad social y desregulación del mercado de trabajo, entre otras. 
Paralelamente, para «atenuar» esa situación de crisis, se diseñaron políticas sociales de emergencia que respondieron a las exigencias y a los intereses de los organismos internacionales de crédito y llevaron al país a un mayor endeudamiento. En este marco, se implementaron políticas focalizadas en «asistir» a los más carenciados que fueron acompañadas de amplias redes clientelares.

Como consecuencia de la aplicación de estas políticas públicas, cambió el mapa social del país: «Mientras que las décadas de los cuarenta y los cincuenta se caracterizaron por la incorporación de los trabajadores y ciudadanos -con el consiguiente crecimiento de la clase media-, en la Argentina de fines del siglo XX predomina la exclusión laboral y social y la pobreza urbana» (Golbert, 2010, p. 142).

Respecto a la población infantil, esta empezaba a experimentar el gradual y progresivo deterioro económico de sus padres y madres, constatándose el impacto del ajuste con especial dureza en respecto a la salud, la nutrición y la educación:

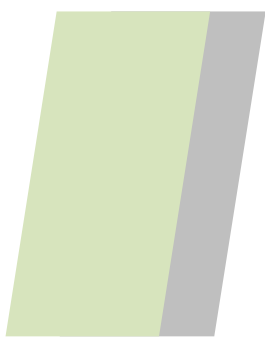

Mientras un sector amplio de la población infantil vivió las consecuencias del empobrecimiento, que sumó a los sectores medios en descenso, un pequeño sector vivió un rápido mejoramiento de sus condiciones de vida, lo que posibilita comprender las nuevas figuras de la infancia argentina: el niño de la calle y el niño consumidor (Carli, 2010, p. 357).

\section{Los/as niños/as como sujetos de derechos}

A mediados de los años ochenta se inició un movimiento de cambios normativos que creó la denominada Doctrina de la Protección Integral. Con ella se estableció el Interés Superior del Niño, el niño como sujeto de derechos en desarrollo, y se ubicó a la familia y a la escuela como instituciones adecuadas para su desarrollo. Entre tales normativas, se encuentran las Reglas mínimas de las Naciones Unidas para la administración de Justicia de Menores (1985), la Convención Internacional sobre los Derechos del Niño 
(CIDN) (1989), las Reglas Mínimas de las Naciones Unidas para la protección de los menores privados de libertad (1990) y las Directrices de las Naciones Unidas para la prevención de la delincuencia juvenil (1990).

La CIDN cierra el siglo de la niñez, «con el reconocimiento jurídico internacional de los primeros dieciocho años de la vida de las personas como una etapa diferencial con características, necesidades y demandas específicas pero, también, con derechos específicos» (Marre, 2013, p. 16). En 1990, la CIDN fue ratificada por la República Argentina mediante la sanción de la Ley 23.849 e incorporada a la Constitución Nacional. Es a partir de la CIDN que se comprende la magnitud del fenómeno de los/as niños/as y adolescentes en situación de calle y su institucionalización. Desde una perspectiva histórica, este periodo muestra tendencias progresivas y regresivas, dado que a la par que se produjeron avances en el reconocimiento de los derechos del niño y una ampliación del campo de saberes sobre la infancia, «el conocimiento acumulado no derivó en un mejoramiento de las condiciones de vida de los niños y en este sentido estos perdieron igualdad para el ejercicio de sus derechos» (Carli, 2010, p. 352).

\section{El debate en la Provincia de Buenos Aires}

En octubre de 1989, se realizó en la ciudad de La Plata el Primer Encuentro Extraordinario de Legisladores sobre los Derechos del Niño en el que se debatió sobre la aprobación y la ratificación del Proyecto de la Convención Internacional sobre los Derechos del Niño. En su exposición, el Director de UNICEF en la Argentina, Dr. Eduardo Bustelo Graffigna, trazó un recorrido sobre las condiciones económicas que atravesaron los países de América Latina y el Caribe durante la década del ochenta interrogando qué pasó con la infancia.

En relación con la Argentina, Bustelo Graffigna (1989) hizo referencia a los altos índices de mortalidad infantil, de analfabetismo y de niños/as en situación de calle: «Estos niños mueren en la más absoluta desprotección y silencio; estos niños no tienen madres de la plaza; no hay operativos de dignidad para estos niños. Estos niños, reitero, mueren en el más absoluto silencio y tolerancia implícita por parte de la sociedad argentina» (Honorable Cámara de Diputados de la Provincia de Buenos Aires, 1989, p. 21). 
Ante la pregunta ¿y por qué el niño es un desprotegido? Bustelo Graffigna (HCD, 1989) sostuvo que los estudios realizados por UNICEF comprobaron que el niño «no se configura como agente social autónomo. Precisa de la ayuda de otro. No vota, no tiene sindicatos, no hace huelgas. A la hora de los repartos de recursos, aun cuando goce de las mayores simpatías, es un ausente» (p. 22), y aseveró que el niño necesita que otros agentes sociales tomen su causa y la constituyan como una agenda prioritaria dentro de las agendas prioritarias sociales.

Los/as disertantes insistieron en caracterizar a la Convención como un instrumento de obligación para los Estados que la ratifican.

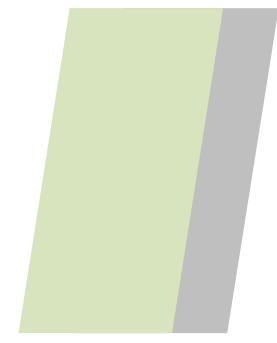

La mayoría de los Estados ya cuentan con legislaciones nacionales cubriendo gran parte de los derechos incorporados en el Proyecto de Convención. Esta situación lleva muchas veces a los países a ser prudentes al aceptar compromisos internacionales que luego por razones de política legislativa nacional tendrán dificultades para la aplicación (HCD, 1989, p. 40).

Respecto del artículo 40 de la Convención, se señaló «la necesidad de armonizar su texto con la ley del Patronato de Menores de la Provincia de Buenos Aires» (HCD, 1989, p. 43). Al respecto, el Juez Nacional de Instrucción, Dr. Luis Miño, propuso tomar el tema del régimen penal del menor «transgresor de la ley penal como Sujeto de derecho» $(H C D$, 1989, p. 45), efectuó un recorrido por la prehistoria de la legislación penal de menores y afirmó: «Un menor de edad -y tenemos que encontrarnos con esa realidad porque es la que transitamos- hoy está mucho más desprotegido que un transgresor adulto frente al mecanismo de control social punitivo. Esta es una realidad a remediar de inmediato» (HCD, 1989, p. 48).

El Subsecretario del Menor, la Familia y la Tercera Edad, Dr. José Andrés Tagliafico, propuso realizar un «análisis político y técnico de la asfixiante situación social que atraviesan las familias pobres bonaerenses y, como lógica consecuencia, todo el desamparo y el dolor a que se someten los hijos de estas familias» (HCD, 1989, p. 58). Luego, transmitió las estadísticas acerca de la población en situación de extrema pobreza y, respecto a la familia, expresó que era necesario el trabajo de los municipios y en los barrios. 
Por su parte, el Diputado y Presidente de la Comisión de Asuntos del Menor y la Familia, Gastón Ortiz Maldonado, expuso sobre aspectos legislativos y sobre las urgencias en torno a «la minoridad», y detalló que el trabajo que realizaban en la Comisión era «con más voluntad que otra cosa», refiriéndose a la escasísima formación en el tema.

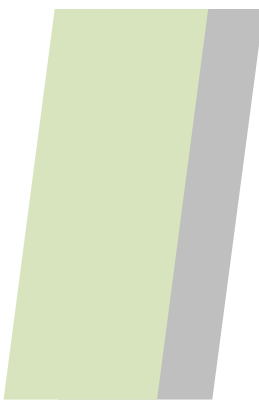

Etiológicamente, la cuestión fundamental de este drama es la pobreza, el subdesarrollo, la dependencia cultural y económica que tenemos los países del sur con los del norte [...]. En la provincia de Buenos Aires, cientos de miles de menores con necesidades básicas insatisfechas se encuentran en los conglomerados urbanos relacionándose permanentemente con la droga, el delito y toda otra forma de marginalidad (HCD, 1989, p. 71).

Respecto al Decreto Ley 10.067/83, el mismo diputado planteó que era necesario reformularlo y que para ello habían presentado un proyecto denominado «Proyecto de Ley de Protección del Menor». La iniciativa fue aprobada y, con ella, el ejercicio del Patronato de Menores en la Provincia en forma coordinada con el Consejo Provincial del Menor, ente autárquico dependiente del Ministerio de Acción Social.

De 1984 a 1991, el área de «minoridad» se mantuvo en la estructura orgánica provincial del Ministerio de Acción Social que, si bien sufrió reestructuraciones a través de decretos, fue ese su período de mayor estabilidad. A fines de 1991, se modificó la conformación del Ministerio de Acción Social y se creó el Ministerio de Salud y Acción Social (Ley Provincial 11.175) quedando la cartera de trabajo (Subsecretaría de Trabajo) bajo la órbita del Ministerio de Gobierno y Justicia. Durante este proceso, el área de «minoridad» sufrió distintos ordenamientos: Familia, Tercera Edad, Discapacidad, hasta llegar, en la estructura orgánico-funcional del nuevo Ministerio, a «la curiosa constitución de la Subsecretaría de Infancia, Familia y Medio Ambiente (Decreto 0026/91)» (Lucesole, 2016, p. 13).

En marzo de 1994, la Ley Provincial 11.519 volvió a darle al área de Salud jerarquía ministerial autónoma, separándola de Acción Social, de lo que derivó la conformación de dos ministerios: el de Salud, y el de Familia y Desarrollo Humano; este último contaba con dos Subsecretarías: Infancia, Familia y Desarrollo Humano, y Asistencia Tutelar del Menor (Decreto 907/94) (Lucesole, 2016). 
En 1995, se modificó la Ley de Ministerio que, entre otras cuestiones, eliminó el Ministerio de Familia y Desarrollo Humano (Ley 11.737) y creó, en su reemplazo, el Consejo Provincial de la Familia y Desarrollo Humano, y el Consejo Provincial del Menor. Esto supuso

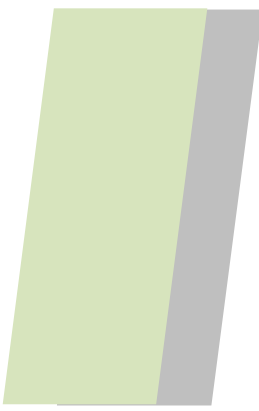

[...] que las políticas sociales se gestionen desde organismos ad-hoc, dependientes directamente de la Jurisdicción de Gobernación, y con lógicas de funcionamiento distintas al común de los ministerios. En el caso del Consejo Provincial del Menor, significó una marcada jerarquización del área, y la definición de su naturaleza como «una entidad autárquica, con personería jurídica para actuar pública y privadamente» (Lucesole, 2016, p. 13).

La autora recupera los desarrollos de Vernet (2009), quien señala que el objeto del cambio se circunscribía a ser «la autoridad de aplicación del Poder Ejecutivo para el ejercicio de las potestades concurrentes del Patronato de Menores que le atribuye el Decreto Ley 10.067/83 (Texto Ordenado por Decreto 1.304/95)» (Lucesole, 2016, p. 14).

Al respecto, Fasciolo (2018) sugiere que las modificaciones efectuadas en la provincia de Buenos Aires evidencian que el cambio doctrinario producido a partir de la Convención Internacional sobre los Derechos del Niño (CIDN) no solo no tuvo impacto sino que la disolución de la Secretaría del Menor y la Familia, y la creación del Consejo Provincial del Menor, mediante la Ley 11.737/95, indican la indiferencia a los cambios doctrinarios.

La Secretaría del Menor y la Familia estaba compuesta por cuatro consejeros: un psicólogo y/o psiquiatra infanto-juvenil, un especialista en ciencias de la educación, un abogado y un trabajador social. A su vez, del Consejo dependían todos los institutos tanto penales como asistenciales, «para el abordaje en clave proteccional-correccional de la minoridad bonaerense» (Fasciolo, 2018, p. 103). Para 1999, había en lo penal 21 institutos cerrados o semi-cerrados, y respecto a lo asistencial, una capacidad de alojamiento para 893 jóvenes (Fasciolo, 2018).

En 2000, se produjo una intervención del Consejo Provincial del Menor, fundada en las graves denuncias sobre abuso de menores en Hogares y la insostenible situación de los chicos detenidos en comisarías ante un sistema colapsado (Vernet, 2009). 


\section{Hacia el paradigma de protección integral}

Por unanimidad, a fines de 2000, la Legislatura de la Provincia de Buenos Aires sancionó la Ley 12.607 de Protección Integral de los Derechos del Niño y el Joven que derogó el Decreto Ley 10.067/83. Sin embargo, a los dos meses fue suspendida por una medida cautelar interpuesta por la Suprema Corte de Justicia de la Provincia de Buenos Aires sobre la base de un recurso de inconstitucionalidad presentado por el entonces Procurador de la Suprema Corte, Dr. Eduardo de la Cruz.

Dos años más tarde, en mayo de 2003, la Suprema Corte de Justicia de la Provincia de Buenos Aires declaró su constitucionalidad, lo que habilitó la puesta en vigencia. Sin embargo, en ese mismo mes,

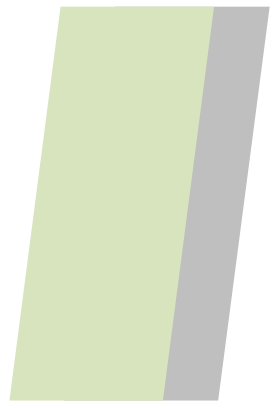

la legislatura bonaerense (aquella que, con prácticamente los mismos legisladores en funciones había sancionado dos años antes dicha ley por unanimidad) suspendió nuevamente la entrada en vigencia de la ley 12.607 argumentando que no estaban dadas las condiciones para la compleja implementación que conllevaba el propuesto cambio normativo e institucional (Lucesole, 2016, p. 15).

A partir de 2003, se inició un nuevo período en el que si bien se evidencian y persisten las drásticas consecuencias de las políticas neoliberales, tiene lugar un progresivo giro en la política socioeconómica del país: paulatinamente, se implementan políticas de corte universal para la niñez, se incrementa la inversión en políticas educativas y se amplía el sistema de protección social para los sectores excluidos del mercado de trabajo formal.

La Asignación Universal por Hijo, implementada en 2006, produjo un alto impacto en la población infantil y en las familias excluidas del sistema de protección social formal en general. Estas políticas, acompañadas de otras como el Programa Conectar Igualdad, incrementaron notablemente la inclusión de niños/as y de jóvenes en el sistema educativo y de salud públicos (Lucesole, 2016). 
De este modo, si bien con el retorno de la democracia, en diciembre de 1983, se inició en lo normativo un periodo que implicó la ratificación y la posterior incorporación de la Convención Internacional sobre los Derechos del Niño a la Constitución Nacional (1994), fue recién en 2005 y 2006 que se sancionaron las leyes acordes a los lineamientos de la mencionada Convención.

En 2005, se sancionó la 26.061 de Protección Integral de los Derechos de las Niñas, Niños y Adolescentes, a través de la cual se adecuó la legislación interna a los postulados de la CDN. A nivel de la Provincia de Buenos Aires, en diciembre de 2004 se sancionó la Ley 13.298 de Promoción y Protección Integral de los Derechos de los Niños y el Decreto Reglamentario 300/05, que derogó el Decreto Ley de Patronato de Menores, sancionado y promulgado por el Gobernador de la última dictadura militar. De todas formas, la Ley 13.298 estuvo suspendida hasta abril de 2007 y su implementación fue complementada por la Ley 13.634 del Fuero de Familia y del Fuero Penal del Niño, sancionada en diciembre de 2006 y promulgada en enero de 2007.

Estas nuevas normativas tuvieron el propósito de regular los derechos de los/as niños/as y adolescentes en dos estamentos diferenciales: por un lado, aquellos/as que se encuentran en una situación de vulneración de derechos; por otro, aquellos/as que hayan transgredido la ley penal (Aguirre \& Ponce Núñez, 2009).

En este sentido, el objetivo de la Ley 13.298 es la contención de los niños/as y adolescentes en los ámbitos familiares y comunitarios. Así, por ejemplo, se establece que «la política respecto de todos los niños tendrá como objetivo principal su contención en el núcleo familiar, a través de la implementación de planes y programas de prevención, asistencia e inserción social» (artículo 3), entendiendo por núcleo familiar, «además de los padres, a la familia extensa y otros miembros de la comunidad que representen para el niño vínculos significativos en su desarrollo y protección» (artículo 3 del Decreto Reglamentario 300/05). Asimismo, se enuncia el «carácter excepcional y provisional de la permanencia temporal en ámbitos familiares alternativos o entidades de atención social y/o de salud» (artículo 35). 
En referencia al artículo 3, Ábalos, Centurión y Vitale (2009) sostienen que al fijarse tal objetivo se enmarca la intervención del Estado como propósito principal de la política pública y, respecto a la separación del/de la niño/a y/o el/la adolescente del grupo familiar, «la ley prevé la excepcional separación de los niños de su grupo familiar en el artículo 35, inciso h. La permanencia temporal en un lugar distinto al familiar debe ser por tiempo limitado y como parte de una estrategia acordada con el niño para, justamente, restituir los vínculos familiares (p. 16).

Respecto al interés superior del niño, se propone: «La máxima satisfacción integral y simultánea de sus derechos en un marco de libertad, respeto y dignidad para lograr el desenvolvimiento de sus potencialidades y el despliegue integral y armónico de su personalidad» (artículo 4).

Para los autores, la Ley 13.298/05 supone un cambio estructural en el sentido de la desjudialización de la pobreza, lo que «implica traspasar el diseño de la política pública de manos del juez al Poder Ejecutivo, que deberá pensar estrategias transversales e integrales para la atención de los derechos vulnerados» (2009, p. 22).

Este sistema involucra un complejo entramado institucional, que establece en el Poder Ejecutivo, a través de las políticas públicas, la obligación de garantizar la plena y efectiva satisfacción de los derechos sociales de los/as niños/as; y en el Poder Judicial, la obligación de asegurar el acceso a la exigibilidad de los derechos toda vez que estos no sean garantizados.

El funcionamiento del sistema en una lógica de transversalidad refiere al diseño y a la implementación de una política pública que contempla una unidad central -unidad de aplicación que dirige la implementación de las políticas públicas- a través del diseño de estrategias de intervención y de la desconcentración. De allí que la política pública de infancia esté coordinada por la Subsecretaría de Niñez y Adolescencia dependiente del Ministerio de Desarrollo Social (Ábalos, Centurión \& Vitale, 2009), denominada en la actualidad Organismo de la Niñez y Adolescencia. 
En este sentido, en diciembre de 2006 se sancionó la Ley 13.634 que instituyó el Fuero de Familia y el Fuero Penal Juvenil, y consagró un procedimiento de garantías procesales mínimas, al establecer la figura del Defensor Oficial especializado en el Fuero de Responsabilidad Penal Juvenil (que supone el acceso al derecho de defensa), lo que significa «un avance respecto del viejo sistema tutelar, en donde el niño no contaba con un Defensor» (Coriolano, 2009, p. 69).

Además de eliminar la vertiente asistencial, la nueva Ley otorga los principios del debido proceso al incorporar al fiscal, al defensor, a los jueces de garantías y a los juzgados de responsabilidad penal juvenil. Del mismo modo, la participación de las Cámaras de apelación como revisoras del proceso y de las sentencias (Ábalos, Centurión \& Vitale, 2009).

En el Paradigma de la Protección Integral de la Niñez, el proceso penal compone una parte a la que debe recurrirse en última instancia y habiéndose garantizado, previamente, todos los derechos económicos, sociales y culturales. 


\section{Referencias}

Ábalos, C., Centurión, F. y Vitale, G. (2009). «Ley 13.298. De la Promoción y Protección Integral de los Derechos de los Niños». En E. García Méndez y G. Vitale (Comps.), Infancia y democracia en la Provincia de Buenos Aires. Comentario crítico sobre las leyes 13.298 y 13.634 (pp. 13-66). Ciudad Autónoma de Buenos Aires, Argentina: Ediciones del Puerto.

Aguirre, A. y Ponce Nuñez, M. (2009). «Los niños y jóvenes son el ideal de nuestro presente y la base de nuestro futuro». En E. García Méndez y G. Vitale (Comps.), Infancia y democracia en la Provincia de Buenos Aires. Comentario crítico sobre las leyes 13.298 y 13.634 (pp. 7-10). Ciudad Autónoma de Buenos Aires, Argentina: Ediciones del Puerto.

Ariès, F. [1962] (1987). El niño y la vida familiar en el antiguo régimen. Madrid, España: Taurus.

Bustelo Graffigna, E. (2012). Notas sobre infancia y teoría: un enfoque latinoamericano. Salud Colectiva, 8(3), 287-298. https://doi.org/10.18294/sc.2012.168

Carli, S. (Comp.) (1999). De la familia a la escuela. Infancia, socialización y subjetividad. Ciudad Autónoma de Buenos Aires, Argentina: Santillana.

Carli, S. (2010). Notas para pensar la infancia en la Argentina (1983-2001). Figuras de la historia reciente. Educacao em revista, 26(1), 351-381. https://dx.doi.org/10.1590/S0102-46982010000100017

Corea, C. (1999). «Ensayo sobre la destitución de la niñez. Introducción». En C. Corea e I. Lewkowicz, ¿Se acabó la infancia? Ensayo sobre la destitución de la niñez (pp. 11-137). Ciudad Autónoma de Buenos Aires, Argentina: Lumen.

Corea, C. y Lewkowicz, I. (1999). ¿Se acabó la infancia? Ensayo sobre la destitución de la niñez. Ciudad Autónoma de Buenos Aires, Argentina: Lumen.

Coriolano, M. L. (2009). «Garantías procesales mínimas. Necesarias e insuficientes». En E. García Méndez y G. Vitale (Comps.), Infancia y democracia en la Provincia de Buenos Aires. Comentario crítico sobre las leyes 13.298 y 13.634 (pp. 69-79). Ciudad Autónoma de Buenos Aires, Argentina: Ediciones del Puerto.

Costa, M. y Gagliano, R. S. (2000). «Las Infancias de la minoridad. Una mirada histórica desde las políticas públicas». En S. Duschatzky (Comp.), Tutelados y asistidos. Programas sociales, políticas públicas y subjetividad (pp. 69-119). Ciudad Autónoma de Buenos Aires, Argentina: Paidós. 
Daroqui, A. y López, R. F. (2012). «Introducción. Contextos socio-históricos en la construcción y gobierno de "la minoridad"». En A. Daroqui, A. L. López y R. F. Cipriano García (Comps.), Sujeto de castigos. Hacia una sociología de la penalidad juvenil (pp. 49-59). Santa Fe, Argentina: HomoSapiens.

DeMause, LL. (1974). La evolución de la infancia. Recuperado de https://es.scribd.com/doc/151505563/La-evolucion-de-la-infanciaLloyd-de-Mause

Domínguez Lostaló, J. C. (1987). Problemática respecto del menor en situación de riesgo. Enfoques e instrumentos eficientes para su protección integral. Ciudad Autónoma de Buenos Aires, Argentina: Honorable Cámara de Senadores de la Nación / UNICEF.

Donzelot, J. (1990). La policía de las familias. Valencia, España: Pre-Textos.

Fasciolo, M. (2018). ¿Quién tiene las llaves de la prisión? Funciones del trabajo social en centros cerrados para jóvenes con causas penales. La Plata, Argentina: Dynamis.

García Méndez, E. (1991). «Prehistoria e historia del control socio-penal de la infancia. Política jurídica y Derechos Humanos en América Latina». En E. García Méndez y M. Bianchi (1991) (Comps.), Ser niño en América Latina. De las necesidades a los derechos (pp. 11-20). Ciudad Autónoma de Buenos Aires, Argentina: Galerna.

García Méndez, E. y Bianchi, M. (Comps.) (1991). Ser niño en América Latina. De las necesidades a los derechos. Ciudad Autónoma de Buenos Aires, Argentina: Galerna.

García Méndez, E. y Vitale, G. (Comps.) (2009). Infancia y democracia en la Provincia de Buenos Aires. Comentario crítico sobre las leyes 13.298 y 13.634. Ciudad Autónoma de Buenos Aires, Argentina: Ediciones del Puerto.

Giberti, E. (1997). «La niñez y el hacer política». En E. Giberti (Comp.), Políticas y niñez (pp. 21-113). Ciudad Autónoma de Buenos Aires, Argentina: Losada.

Golbert, L. (2010). De la Sociedad de Beneficencia a los Derechos Sociales. Ciudad Autónoma de Buenos Aires, Argentina: Ministerio de Trabajo, Empleo y Seguridad Social.

Guemureman, S. y Daroqui, A. (1999). La niñez ajusticiada. Ciudad Autónoma de Buenos Aires, Argentina: Ediciones del Puerto. 
Larrandart, L. (1991). «Prehistoria e historia del control socio-penal de la infancia». En E. García Méndez y M. Bianchi (Comps.), Ser Niño en América Latina. De las necesidades a los derechos (pp. 21-39). Ciudad Autónoma de Buenos Aires, Argentina: Galerna.

Lewkowicz, I. (1999). «Tres observaciones sobre el concepto infancia». En C. Corea e I. Lewkowicz, ¿Se acabó la infancia? Ensayo sobre la destitución de la niñez (pp. 164-173). Ciudad Autónoma de Buenos Aires, Argentina: Lumen.

Llobet, V. (2013). «La producción de la categoría "niño-sujeto-de-derechos" y el discurso psi en las políticas públicas en Argentina. Una reflexión sobre el proceso de transición institucional». En V. Llobet (Comp.), Pensar la infancia desde América Latina. Un estado de la cuestión (pp. 209-235). Ciudad Autónoma de Buenos Aires, Argentina: Consejo Latinoamericano de Ciencias Sociales (CLACSO).

Lucesole, N. (diciembre de 2016). Recorrido legal e institucional de las principales políticas públicas para la niñez y adolescencia en Argentina: de la Sociedad de Beneficencia a la Protección Integral de Derechos. Trabajo presentado en las IX Jornadas de Sociología de la Universidad Nacional de La Plata. Recuperado de http://www.memoria.fahce.unlp.edu.ar/trab_eventos/ev.8980/ev.8980.pdf

Marre, D. (2013). «Prólogo: de infancias, niños y niñas». En V. Llobet (Comp.), Pensar la Infancia desde América Latina (pp. 9-25). Ciudad Autónoma de Buenos Aires, Argentina: Consejo Latinoamericano de Ciencias Sociales (CLACSO).

Oyhandy Cioffi, A. G. (2004). La infancia en riesgo: entre la caridad y la ciudadanía. Un estudio de caso sobre la gestión de la infancia y la adolescencia en riesgo en la Argentina contemporánea. La Plata, 2000-2003. Ciudad de México, México: Facultad Latinoamericana de Ciencias Sociales (FLACSO).

Sardá, L. (Coord.) (2012). Situación de niños, niñas y adolescentes sin cuidados parentales en la República Argentina. Relevamiento nacional y propuestas para la promoción y el fortalecimiento del derecho a la convivencia familiar y comunitaria. Ciudad Autónoma de Buenos Aires, Argentina: Ministerio de Desarrollo Social / UNICEF. Recuperado de https://bit.ly/2Sraefz

Volnovich, J. C. (1999). El niño del «siglo del niño». Ciudad Autónoma de Buenos Aires, Argentina: Lumen.

Zapiola, M. C. (2010). «La ley del Patronato de Menores de 1919: ¿una bisagra histórica?». En L. Lionetti y D. Míguez (Comps.), Las infancias en la historia argentina. Intersecciones entre prácticas, discursos e instituciones (pp. 117-132). Ciudad Autónoma de Buenos Aires, Argentina: Prohistoria. 


\section{Normativas}

Código Civil. Título III. De la patria potestad. Recuperado de http://servicios.infoleg.gob.ar/infoleglnternet/anexos/105000109999/109481/texactley340_librol_S2_titulolll.htm

Decreto Ley Nacional 22.278 (1980). Régimen Penal de la Minoridad. Boletín Oficial de la República Argentina. Buenos Aires, 28/8/1980.

Decreto Ley Nacional 22.803 (1983). Ley N²2.278 - Modificación. Boletín Oficial de la República Argentina. Buenos Aires, 9/5/1983.

Decreto Ley Provincial 10.067 (1983). Patronato de Menores.

Boletín Oficial de la Provincia de Buenos Aires. La Plata, 9/12/1983.

Decreto Provincial 907 (1994).

Boletín Oficial de la Provincia de Buenos Aires. La Plata, 9/05/1994.

Decreto Reglamentario 300 (2005). Decreto Reglamentario de la Ley 13.298.Ley de Promoción y Protección Integral de los Derechos de los Niños.

Boletín Oficial de la Provincia de Buenos Aires. La Plata, 23/3/2005.

Ley Nacional 1.420 (1884). Educación primaria.

Boletín Oficial de la República Argentina. Buenos Aires, 8/7/1884.

Ley Nacional 4.144 (1902). Residencia de Extranjeros.

Boletín Oficial de la República Argentina. Buenos Aires, 25/11/1902.

Ley Nacional 10.903 (1919). Patronato de Menores.

Boletín Oficial de la República Argentina. Buenos Aires, 27/10/1919.

Ley Nacional 15.244 (1959). Consejo Nacional de Protección de Menores.

Boletín Oficial de la República Argentina. Buenos Aires, 24/12/1959.

Ley Nacional 23.849 (1990). Convención sobre los Derechos del Niño. Boletín Oficial de la República Argentina. Buenos Aires, 22/10/1990.

Ley Nacional 26.061 (2005). Protección Integral de los Derechos de las Niñas, Niños y Adolescentes.

Boletín Oficial de la República Argentina. Buenos Aires, 26/10/2005.

Ley Provincial 4.547 (1937). Dirección General de Protección a la Infancia Boletín Oficial de la Provincia de Buenos Aires. La Plata, 15/5/1937.

Ley Provincial 4.664 (1937). Tribunales para menores.

Boletín Oficial de la Provincia de Buenos Aires. La Plata, 11/2/1938. 
Ley Provincial 6.661 (1961). Consejo de la Minoridad de la provincia de Buenos Aires.

Boletín Oficial de la Provincia de Buenos Aires. La Plata, 11/12/1961.

Ley Provincial 11.175 (1991). Ley de Ministerios (Derogada por Ley 12.355/99).

Boletín Oficial de la Provincia de Buenos Aires. La Plata, 11/12/1991.

Ley Provincial 11.519 (1994). Ley de Ministerios (Derogada por Ley 12.355/99).

Boletín Oficial de la Provincia de Buenos Aires. La Plata, 19/4/1994.

Ley Provincial 11.737 (1995). (Derogada por Ley 12.355/99).

Boletín Oficial de la Provincia de Buenos Aires. La Plata, 19/12/1995.

Ley Provincial 12.607 (2000). Protección Integral de los Derechos del Niño y el Joven.

Boletín Oficial de la Provincia de Buenos Aires. La Plata, 29/12/2000.

Ley Provincial 13.298 (2005). Promoción y Protección Integral de los Derechos de los Niños.

Boletín Oficial de la Provincia de Buenos Aires. La Plata, 27/1/2005.

Ley Provincial 13.634 (2007). Principios Generales del Fuero de Familia y del Fuero Penal del Niño.

Boletín Oficial de la Provincia de Buenos Aires. La Plata, 2/2/2007.

Naciones Unidas (1985). Reglas mínimas de las Naciones Unidas para la administración de la justicia de menores (Reglas de Beijing). Recuperado de https://www.ohchr.org/SP/Professionallnterest/Pages/BeijingRules.aspx

Naciones Unidas (1989). Convención Internacional sobre los Derechos del Niño. Recuperado de

https://www.ohchr.org/SP/Professionallnterest/Pages/CRC.aspx

Naciones Unidas (1990). Directrices de las Naciones Unidas para la prevención de la delincuencia juvenil (Directrices de Riad).

Recuperado de

https://www.ohchr.org/SP/Professionallnterest/Pages/Preventio nOfJuvenileDelinquency.aspx

Naciones Unidas (1990). Reglas de las Naciones Unidas para la protección de los menores privados de libertad. Recuperado de https://www.ohchr.org/SP/Professionallnterest/Pages/JuvenilesDepri vedOfLiberty.aspx 


\title{
Parte I
}

\section{CAPÍTULO 3}

\section{Los aportes de los saberes «psi»}

\author{
Los saberes «psi» y el gobierno de las familias \\ La creación de la carrera de Psicología \\ La integración de los/as psicólogos/as \\ en las instituciones de «menores» \\ La vulnerabilidad y la mediación de la ternura
}

La «niñez» no es ahistórica ni tiene validez universal, es un invento propio de la modernidad. Nace con el dispositivo sociohistórico de la modernidad y es producida, centralmente, por la familia y por la escuela. La familia nuclear moderna constituyó uno de los puntos sobre los cuales el dispositivo de normalización se ancló, al modo de bisagra, por contener en su interior un tipo de ejercicio de poder a través del cual es posible inyectar a los/as hijos/as en los dispositivos disciplinares, centralmente la escuela.

Junto con la familia y con la escuela nace un dispositivo que dispone un conjunto de elementos (legales, normativos, saberes, establecimientos) y unas relaciones de fuerza entre ellos, para intervenir sobre los grupos familiares que no cumplen con las funciones disciplinares. La población infantil se escinde, así, en dos tipos: una protegida; otra vigilada, lo que alude a tratamientos diferenciales de acuerdo a la pertenencia de clase.

La centralidad de la institución familiar burguesa y de la escuela requirió de estrategias de poder de soberanía, disciplinares y de seguridad, así como de saberes que le otorgaron racionalidad. En este proceso, los aportes de los saberes «psi» y los procedimientos que estos producían a mediados del siglo $X X$, a través de estrategias singulares, fueron elementos de normalización de las familias burguesas, tal como lo demuestran las políticas de divulgación. 
Esto obliga a situar el contexto en el cual psicólogos/as y psicoanalistas disputaron el campo profesional en el ámbito de la niñez, lo que se produjo tanto al momento de crearse las carreras de psicología como de elaborarse la Ley de Ejercicio Profesional de la Psicología, restringida, hasta entonces, a las indicaciones que emanaban de las disciplinas médicas y que limitaban el ejercicio profesional a la evaluación y al diagnóstico psicológico.

Las condiciones políticas que fundaron estas condiciones de posibilidad también insisten en la integración de los/as primeros/as psicólogos/as en los equipos técnicos de las instituciones dependientes del Organismo de la Niñez y Adolescencia, prácticas que en sus primeras manifestaciones estuvieron movilizadas por modos de pensar la función de los/as psicólogos/as como agentes de cambio y como trabajadores/as de la salud mental.

Estas primeras experiencias se caracterizaron por intervenir sobre los efectos de la institucionalización, sostenidas en un modo de pensar a los niños/as y los/as jóvenes como producidos/as por las condiciones socioeconómicas, familiares y políticas, desde una perspectiva teórica psicoanalítica. Interrumpido por la última Dictadura cívico militar, este proceso es rastreable en las experiencias que los/as profesionales exiliados/as realizaron en instituciones de menores en otros países. Los resultados de tales iniciativas devendrán, con el retorno de la democracia y con el regreso de los/as psicólogos/as al país, en aportes al campo de la niñez en situación de vulneración de derechos y/o en conflicto con la ley penal.

\section{Los saberes «psi» y el gobierno de las familias}

A partir de los años cincuenta se producen transformaciones en los niveles sociohistórico, político y económico de las instituciones, el Estado, la familia y los marcos teóricos de pensamiento a nivel mundial. Para ilustrar el paso del dispositivo social diverso al dispositivo disciplinario, Fernández (1999) toma como ejemplo el tratamiento de las normas y sus transgresiones en la institución escolar a partir del pasaje de los castigos físicos a las amonestaciones, para arribar en la actualidad al gabinete psicopedagógico: más que castigar o sancionar se trata de comprender los motivos de las conductas. 
Esta transformación, señala Borinsky (2005), implicó un cambio en los modos de entender la infancia y la relación madre-hijo, así como una modificación en el lugar del profesional: mientras que durante la primera mitad del siglo XX los expertos eran los médicos, a mediados de los cincuenta serán los psicólogos quienes comiencen a instituirse en dicho campo.

Con la publicación de la obra El libro de las madres (1899), del Dr. Gregorio Araoz Alfaro, se inició una tradición de consejos por parte de especialistas a las madres a través de un «manual práctico de higiene mental». Esta noción incluía tanto la salud física como la psíquica, esta última «como territorio de la moral, el intelecto y el alma» (Borinsky, 2005, p. 118). Se trata de una tradición que se inscribía en la confección, por parte del cuerpo médico, de una serie de obras para uso de las familias burguesas sobre la crianza, la educación y la medicación de los/as niños/as (Donzelot, 1990), que inaugura la alianza madre-médico.

Dicho vínculo es caracterizado por Donzelot (1990) como provechoso para ambas partes: el médico triunfa contra la hegemonía de la medicina popular y la mujer, por la relevancia que adquiere en las funciones maternas y en la esfera doméstica. Ahora bien, «esto vale para las familias acomodadas, las que tienen domésticos y aquellas en las que las esposas pueden dedicarse a la organización de la casa. La intervención sobre las familias populares pasa por otros canales» (Donzelot, 1990, p. 25).

En estos casos, además del analfabetismo, debían considerarse otros problemas como el aumento del concubinato, a causa del proceso de urbanización; las oleadas inmigratorias; y el vagabundeo de niños, que representaban una amenaza política para el orden social establecido. Para ese sector de la población, «no se trata de asegurar discretas protecciones, sino de establecer vigilancias directas» (Donzelot, 1990, p. 25).

Las prácticas de normalización que emanaban del Estado eran un reflejo de la relación de convivencia Estado y familia, orientadas a hacer de esta un dominio de intervención directa. La tutela permite una «intervención estatal correctiva y salvadora, pero al precio de una desposesión casi total de los derechos privados» (Donzelot, 1990, p. 93). 
El polo tutelar es ubicado por Donzelot (1990) como una relación negativa entre las exigencias normativas y los comportamientos económicos-morales, constituyendo vínculos positivos aquellas familias que pueden mantener y conservar su autonomía mediante su capacidad económica. «Mírese por donde se mire [este es] el problema de la clase obrera, en cualquier región que se le considere; la cuestión clave es en todas partes la de la relación adulto-niño» (Donzelot, 1990, p. 74).

En este sentido, el autor señala que con el movimiento de normalización de la relación adulto-niño -a través de la sanción de normas protectoras de la infancia- se trataba de «satisfacer el estado de abandono en el que se encontraban los niños de las clases trabajadoras, pero también de reducir la capacidad socio-política de estas, rompiendo los lazos iniciáticos adulto-niño, la transmisión autárquica de habilidades» (Donzelot, 1990, p. 81).

Donzelot (1990) señala que la posibilidad de anclar en la familia los mecanismos de integración social es «el resultado estratégico de una serie de intervenciones que más que reposar sobre la instancia familiar la hacen actuar. De esta manera, la familia moderna no es tanto una institución como un mecanismo» (p. 95). Se trata de un mecanismo que el autor ubica en una arquitectura social cuyo principio es articular una intervención exterior a los conflictos presentes el interior de la familia: «Protección de la infancia pobre, que permite destruir a la familia como islote de resistencia, alianza entre el médico y el educador con la mujer para desarrollar prácticas de ahorro y de promoción escolar» (Donzelot, 1990, p. 95).

La delimitación que realiza Macchioli (2013) sobre las áreas que -si bien no se plantean explícitamente trabajar con «la familia»- la definen y la problematizan, ubica, entre otras, la pediatría de Florencio Escardó y la Escuela para Padres de Eva Giberti. Sobre la primera, dirá que «su obra sentará las bases de un modelo de abordaje de las enfermedades infantiles entendidas como enfermedades de familia» (p. 488); sobre la segunda, que consiste en una experiencia que -situada en el contexto histórico de cambios que se producían en las familias desde fines de los cincuenta-, refuerza lo impulsado por Escardó y produce las condiciones para la inserción profesional de los nuevos psicólogos en el 
ámbito hospitalario. Teniendo en cuenta el rol del psicólogo como «una suerte de experto sobre la infancia, al que acudirían en los siguientes años profesionales relacionados con la salud, así como los propios padres» (p. 489).

En el recorrido realizado por Borinsky (2005), se visibiliza un modo de pensar al/a la niño/a como portador/a de un potencial que podría desplegar hacia adelante más que como presente. En la revista Viva Cien Años, ${ }^{15}$ Escardó propuso en 1936 el mecanismo de imitación inconsciente, que la mayoría de los autores del período retomaban para referirse «al modo en que los pequeños recibían la influencia del medio ambiente y para explicar, al mismo tiempo, cómo se producía el aprendizaje» (Borinsky, 2005, p. 120).

Entre los temas que se trataban en Hijo mío...! ${ }^{16}$ estaban presentes: la importancia de los primeros años de vida; cómo usar los test de inteligencia en los/as niños/as; la educación sexual; y, en algunos artículos, el esbozo de la psicología como una disciplina moderna y la «nueva exigencia de estudiar a los hijos», para la cual «los test mentales podrían ser una vía para conocer mejor a los niños, sobre todo en lo referido a sus aptitudes mentales» (Borinsky, 2005, p. 120). En la misma revista, se presentaba el relato de tratamientos psicoterapéuticos como respuesta a los problemas en la educación de los/as hijos/as. Borinsky (2005) expone que en la publicación Nuestros hijos ${ }^{17}$ se evidencia la presencia del sentido común psicoanalítico que servía para explicar las causas de los problemas infantiles y familiares.

15 Publicación «científico-higienista», fundada en 1934 por Mariano Barilari, Arturo León López y Godfredo Grasso. «Basada en los principios de la naciente medicina preventiva, su objetivo era la educación para la salud y su meta acceder a un público lo más amplio posible» (Weissmann, 2002, en línea).

16 La revista Hijo mío era publicada por la Sociedad de Orientación y Educación Sanitaria «Viva Cien Años». «Su director fundador fue el médico Arturo León López y su directorio ejecutivo estaba compuesto por los doctores Gofredo Grasso, Mariano Barilari y Leonardo Grasso (Rustoyburu, 2014, p. 5). Se distribuía en Buenos Aires y en el interior del país, en kioscos y por suscripción.

17 La publicación Nuestros hijos «fue impulsada por un grupo de médicos jóvenes entre los que figuraba Raúl López Biel [...]. La asesoraban psiquiatras, pediatras, ginecólogos y pedagogos como Telma Reca, Ovidio H. Senet, Luisa R. Goldenberg y Carlota D. de Rascovsky» (Cosse, 2009, en línea). 
Respecto a la Escuela para Padres, Carpintero y Vainer (2004) sostienen que con ella se inició la difusión de la cultura psi y que, en el contexto de la Segunda Guerra Mundial, se realizaron conferencias internacionales sobre educación para padres. En este contexto, en la Argentina, la asistente social Eva Giberti publicó un artículo en la revista Esto es (1956), dedicado a la crianza de los hijos, y posteriormente, en el diario La Razón, un artículo titulado «¿Se aprende a ser padres?».

Carpintero y Vainer (2004) plantean que «se debía aprender a educar a los hijos más allá de las pautas que el supuesto instinto parental pudiera sugerir. Ese aprendizaje se conseguía a través de la ciencia psicológica apoyada en el conocimiento del psicoanálisis» (p. 126). El discurso que operaba, sostienen los autores, «estaba centrado en cuestionar el autoritarismo imperante en la familia y en la escuela, cuestionando viejos tabúes» (p. 127).

En una entrevista, Giberti ubica el contexto histórico y político de dichas publicaciones, y sitúa que se ingresaba en una época de muchos cambios en la descripción de la familia, cambios entre los cuales las migraciones internas y, con ellas, la constitución del cinturón villero conurbano, aportaron

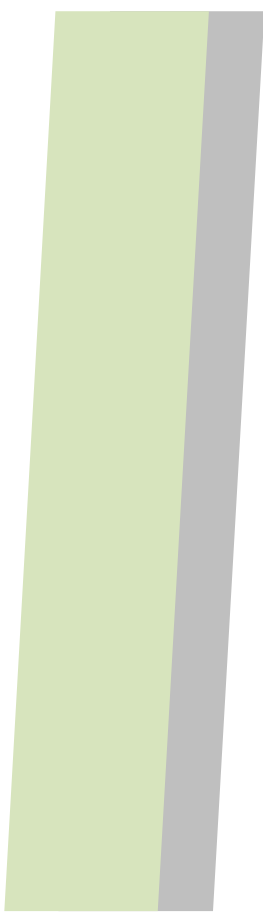

[modelos que] sobresaltaban a quienes defendían el modelo tradicional: por ejemplo, el cambio de «padres» para los hijos de una misma mujer, relaciones sexuales admitidas entre padrastros e hijastras, mujeres solas con hijos de distintos padres, etc. Antiguamente, la familia tradicional se había enfrentado con formas clásicas de «antifamilia» como el prostíbulo y con estilos de convivencia denigrados por la burguesía como el conventillo. Ahora la «villa» aportaba nuevas matrices para la crítica social.

Yo pretendía generar cambios en la educación de los hijos y en las relaciones familiares, ya que atribuía a la familia el máximo de responsabilidad; pensé que para ello podría aportar los conocimientos del psicoanálisis e introduje técnicas de divulgación por medio de las cuales explicaba la dinámica de los conflictos aportando lo inconsciente como idea reguladora (Carpintero \& Vainer, 2004, p. 127). 
Macchioli (2013) sitúa que las experiencias trazadas por Escardó y por Giberti se encuentran en «sintonía con los vientos de cambios que se establecían en las familias desde fines de los cincuenta», dirigidas a «una familia tipo casi estereotipada, de clase media baja que suele vivir en un departamento pequeño, cerca de abuelos y tíos» (p. 4).

En la misma línea, Borinsky (2005) propone que en este proceso de divulgación de la psicología y del psicoanálisis se desplace el eje de la discusión sobre los problemas de crianza de los/as niños/as de una preocupación centrada en la desobediencia infantil y la rebeldía a los trastornos: «Lo novedoso no es el trastorno en sí mismo sino su causa: el mecanismo psicológico que lo produjo» (p. 125).

La creación de Escuela para Padres es inscripta por Llobet (2006) en el giro intimista logrado por el psicoanálisis que, en el movimiento de pliegue sobre la familia, le otorga un nuevo lugar a los padres respecto a sus hijos/as: «La incertidumbre sobre la nueva familiaridad que intranquilizaba las formas de ser hombres y mujeres $y$, en particular, de ser padres, llevó a constituir estrategias pedagógicas privadas y públicas» (p.10).

Interesa puntuar aquí dos dimensiones que visibilizan la instalación -en la dimensión sociohistórica- de otros dispositivos y tecnologías de poder, distintas a las disciplinares. Una, vinculada al proceso de divulgación y otra, al emplazamiento, señalado como capricho y como rebeldía hacia los mecanismos y la motivación inconsciente.

Respecto al proceso de divulgación, vemos operar una estrategia de poder seguridad cuyo blanco es la población. Para esta tecnología, la familia es un segmento privilegiado y un instrumento para el gobierno, que implicó la aparición del público, que es

[...] la población considerada desde el punto de vista de sus opiniones, sus maneras de hacer, sus comportamientos, sus hábitos, sus temores, sus prejuicios, sus exigencias: el conjunto susceptible de sufrir la influencia de la educación, las campañas, las convicciones. [...] De la especie al público, tenemos un campo de nuevas realidades, nuevas en el sentido de que, para los mecanismos de poder, son elementos pertinentes dentro del cual y con respecto al cual se debe actuar (Foucault, 2006, p. 102). 
Respecto al lugar central que ocupó el psicoanálisis, a partir de los cincuenta y durante los sesenta, en la construcción de una nueva verdad sobre la infancia -previamente ocupado por el saber pedagógico y escolar-, Llobet (2013) sostiene que nuevas disciplinas disputaron con la pediatría y la asistencia social el campo de saberes sobre la infancia: el psicoanálisis infantil, los debates sobre la desmanicomialización y la psiquiatría comunitaria en Gran Bretaña, Estados Unidos y Europa

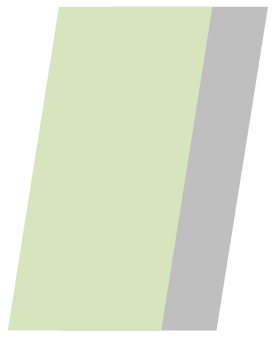

convergieron en colocar a la psicología y al psicoanálisis en un lugar de privilegio para dar cuenta de las necesidades infantiles en contra de los procesos de institucionalización signados como deshumanizados e «iatogénicos» y abrieron paulatinamente al interior del Estado la interlocución con nuevos profesionales psi (Llobet, 2013, p. 217).

De este modo, el proceso de psicologización fue de la mano de una nueva inscripción del/de la niño/a en su familia, en la que el abandono se desplazó de su connotación moral para ser tratado en clave científica a partir de las tesis psicoanalíticas sobre la constitución subjetiva.

A este proceso, Fernández (1999) lo caracterizó como una fractura de la sociedad disciplinar y como la construcción de una sociedad más flexible que «estimula la satisfacción de las necesidades y cambia la significación colectiva de la autonomía. De la obligación moral a cumplir con las reglas consensuadas, pasa a importar la realización personal, el respeto por la singularidad subjetiva» (p. 316). Este movimiento, acompañado de una «psicologización de lo social», implica una cultura «psi» que «naturaliza explicaciones de la interioridad psíquica para fenómenos institucionales y sociales» (p. 316).

\section{Un modo de intervención «psi» para la niñez protegida}

Un modo de intervención desde los saberes «psi» es el caso clínico publicado en 1957 por Arminda Aberastury, en el que se relata el tratamiento de un niño de cuatro años que fue derivado del hospital de niños a una psicoanalista, «para ser psicoanalizado» por presentar una anorexia a partir de ser señalado como asesino. 
En la reconstrucción del caso, publicado por Aberastury en la Revista de Psicoanálisis ${ }^{18}$ -abordado por Macchioli (2014)-, la autora concluye: «El primo se cayó del coche al suelo cuando el pequeño quiso sacarlo y para no oír los gritos le tapó la cara con algodón y cuando vio que eso no era eficaz lo golpeó» (Aberastury, 1957, p. 146 en Macchioli, 2014, p. 1886).

Para Aberastury (1957), la verdad era que la madre había dejado al primo en manos del hijo y el padre había «sugerido» la posibilidad del crimen. La reacción del padre respondería, para la autora, a que cuando este era pequeño había planeado en su inconsciencia a «puertas cerradas» el asesinato de su hermano, justamente el padre del sobrino muerto.

La publicación del caso en los diarios nacionales de mediados de los cincuenta es ubicado por Macchioli (2012) en la coyuntura psi de la época, donde la derivación de niños/as a un psicoanalista marca la legitimidad y el reconocimiento de la especialidad en el campo disciplinar y jurídico. Al mismo tiempo, ubica tal derivación en el marco de desarrollos científicos alrededor del problema del niño que se inician desde fines de siglo XIX en la Argentina, vinculados a preocupaciones urbanas y sociales.

Ahora bien, el tratamiento del caso, reflejado en el examen policial, del juez, en los estudios médicos y en su derivación al psicoanalista, permite suponer que el niño no fue institucionalizado ni tutelado por el juez. Este modo de intervención posibilita inferir la pertenencia de clase de la familia del niño, dado que la intervención sobre las familias populares pasaba por otros canales, y ejemplifica cómo operan los mecanismos de acoplamientos positivos caracterizados por Donzelot (1990), a la vez que la producción práctica de la niñez protegida.

Durante la primera mitad del siglo $X X$, médicos, abogados, pedagogos y trabajadores sociales movilizaron saberes «psi», pero es fundamentalmente desde los sesenta cuando los saberes y los discursos «psi» comenzaron a dialogar con voz propia con las políticas

18 El artículo fue publicado con el título «La inclusión de los padres en el cuadro de la situación analítica y el manejo de esta situación a través de la interpretación» en Revista de Psicoanálisis, 14(1-2), 137-146. 
para menores y para familias. Desde entonces, serán los/as psicólogos/as y los/as psicoanalistas quienes disputen, en el plano estatal, un campo profesional (Llobet, 2013). Disputa que se produce al momento de crearse las carreras de psicología en el país, de las que se graduarán los/as primeros/as psicólogos/as.

\section{La creación de la carrera de Psicología}

En nuestro país, las carreras de psicología y, por consiguiente, los primeros planes de estudio, surgen a partir de 1955, tiempos políticos de ideas desarrollistas en los que «la ciencia era vista como el camino para que la Argentina se incorporara al mundo. Y los psicólogos, como agentes de cambio, posibilitarían el pasaje de una sociedad subdesarrollada a los problemas propios de los grandes centros industriales» (Carpintero \& Vainer, 2004, p. 82).

En el caso de la Universidad Nacional de La Plata (UNLP), desde que se aprobó la propuesta de creación de la carrera de Psicología hasta que efectivamente se la creó pasaron cuatro años. Temporalidad que cobra espesura al introducir en el análisis las «vicisitudes de orden político». En ese periodo de cuatro años se produjo la autodenominada Revolución Libertadora y la carrera se creó a los 19 días de producirse el traspaso al presidente electo, Arturo Frondizi (Lorente, 2018). ${ }^{19}$

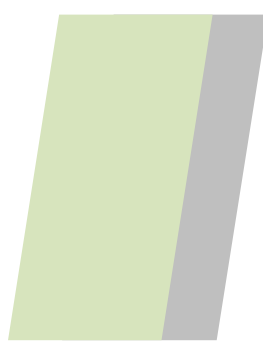

Ese intervalo, del que tenemos poca información, a la luz de la historia de la carrera se torna más significativo. Si miramos los avances y los retrocesos de la institucionalización de la disciplina como carrera académica, encontraremos que avanza cuando avanzan las fuerzas progresistas y retrocede cuando predominan las fuerzas reaccionarias (Lorente, 2018, p. 1).

\footnotetext{
19 En 1954, Francisco González Ríos propuso su apertura y tanto el Consejo Académico de la Facultad de Humanidades como las comisiones de Enseñanza y de Interpretación y Reglamento del Consejo Superior dictaminaron a favor de la iniciativa. Sin embargo, la aprobación por parte del Consejo Superior recién se produjo el 30 de mayo de 1958.
} 
Como fue mencionado, la educación ha sido un instrumento fundamental para la construcción de una nación liberal. Sin embargo, promediando el siglo XX será una herramienta para alcanzar los ideales de justicia social. Durante el gobierno de Juan Domingo Perón, se creó el Instituto de Psicotecnia y Orientación Vocacional que se transformó, en 1949, en la Dirección de Psicología Educacional y Orientación Profesional. Dagfal (2009) señala que esta Dirección permite ilustrar las modalidades particulares de institucionalización de la psicología aplicada durante el período peronista y plantea que la implantación social de la disciplina, producida en esa época, fue una de las condiciones de posibilidad que permitiría la creación de las carreras de psicología a escala nacional.

El crecimiento y el progreso en el ámbito académico y disciplinar fue nuevamente interrumpido en 1967, cuando Juan Carlos Onganía degradó la profesión del psicólogo -tal como se materializó en la Ley Nacional 17.132- subordinándola a un rol de auxiliar del médico (Lorente, 2018). Dicha ley restringía el ejercicio profesional en las áreas clínicas, así como también en las áreas educacionales y laborales, en tanto que establecía que la indicación debía provenir de disciplinas médicas (Domínguez Lostaló, 2001). La inserción profesional en las instituciones públicas era acotado, con restricciones en los ámbitos de salud, de seguridad y de niñez, que limitaban el ejercicio profesional a actividades de evaluación y diagnóstico psicológico, al igual que en infancia (Pérez, 2012).

En este período -de 1962 a 1968-, surgieron las primeras asociaciones de psicólogos/as «como forma reactiva a las restricciones del ejercicio profesional desde el punto de vista del aparato del Estado, cuya culminación fue la Ley 17.132» (Domínguez Lostaló, 2001, p. 13). En 1971, se creó la Confederación de Psicólogos de la República Argentina (COPRA), que en noviembre de ese mismo año publicó su «Declaración de Principios y Estatuto», además de un anteproyecto de Ley de Ejercicio Profesional de la Psicología. En diciembre de 1972, se creó la Federación de Psicólogos de la provincia de Buenos Aires (FePPBA), que se incorporó a la COPRA. En marzo de 1973, se aprobó un plan de trabajo que incluyó la elaboración de un anteproyecto de ley que unificaba el Ejercicio Profesional y Colegiación en un solo cuerpo legal, pero la ley no sería sancionada hasta la vuelta a la democracia. 
En este contexto, en octubre de 1974, en la ciudad de Córdoba, se llevó a cabo el Primer Encuentro Nacional de Psicólogos y Estudiantes de Psicología, fecha a partir de la cual se conmemora el día del Psicólogo.

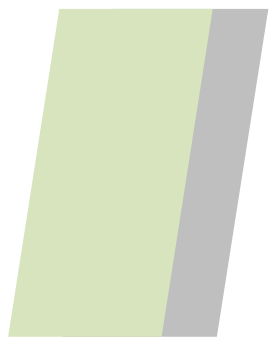

Este Encuentro constituye un hecho sin precedentes para los trabajadores psicólogos, al organizar y concretar un evento como éste sin la participación de otros trabajadores de la salud. [...] Mirando hacia atrás, caemos en la cuenta de que siempre hemos venido viajando en el furgón de cola de la Salud (Domínguez Lostaló, 2001, p. 10).

De este modo, el Encuentro de 1974 fue «la declaración de autonomía e independencia de los psicólogos» (Domínguez Lostaló, 2001, p. 9). No obstante, en el período dictatorial, las distintas organizaciones se fueron desmantelando:

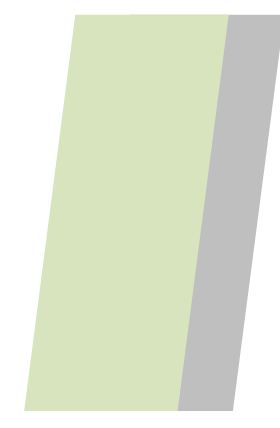

Hay una reactivación y un avance de los intentos de control social autoritario, sobre todo en las áreas clínicas, y un cese de actividades en lo que hace a las prácticas profesionales del orden sanitario y comunitario, además de una disolución de todos los organismos gremiales profesionales. Entre los años 1976 y 1982, se produjo una retracción hacia los consultorios (Domínguez Lostaló, 2001, p. 16).

Retracción que también responde al secuestro y la desaparición de 30 psicólogos y psicólogas, algunos/as de los cuales continúan aún en la actualidad desaparecidos/as.

En 1976, la intervención de la Dictadura en la UNLP supuso el cierre de la carrera de Psicología. Además de asignarle un cupo cero para el ingreso, se redujo su presupuesto y se la dejó agonizar mientras los/as profesores eran cesanteados/as o renunciaban y los grupos de investigación se desarmaban (Lorente, 2018).

El ataque a los espacios públicos de formación y de asistencia, inherente al proyecto de 
incorporar a la Argentina al capitalismo mundializado implicaba, en el campo de la Salud Mental, la represión de todos los planes reformistas y de sus principales actores. Esto se logró mediante el secuestro de algunos de ellos, el cierre de los Servicios de Salud Mental y la prohibición de diferentes prácticas. Las experiencias que habían sido un avance se desmantelaron en todo el país y en este contexto la mayor parte de los trabajadores de la salud mental se recluyeron en el ámbito privado (Carpintero \& Vainer, 2004, p. 330).

Con el retorno a la democracia, las carreras de psicología reabrieron. En el caso de la UNLP, esto sucedió 1984. En lo gremial, la FePRa retomó la gestión en las Cámaras Legislativas para lograr la Ley de Ejercicio Profesional. En este contexto, el 1 de agosto de 1985 la Legislatura de la Provincia de Buenos Aires sancionó la Ley 10.306 de Ejercicio Profesional de la Psicología, a partir de la cual se creó el Colegio de Psicólogos de la Provincia.

En relación con la formación, los planes de estudio no escaparon a la lógica neoliberal:

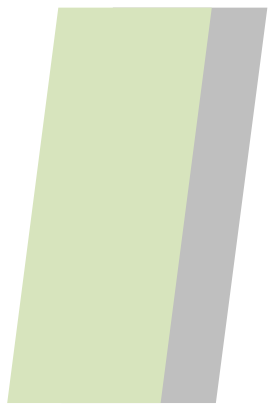

El paradigma que legitima los emprendimientos y espacios privados como servicios de excelencia, también atraviesa la formación de los psicólogos/as; los estudiantes ingresan imaginarizando la profesión con el ejercicio de la clínica, en una amplia mayoría. La atención en consultorio privado es la meta a alcanzar pero, además, es aquello para lo que registran subjetivamente, estar más capacitados (Pérez, 2014, p. 177).

Como plantea Fernández (1996), los/as psicólogos/as de los ochenta no se piensan como agentes de cambio ni como trabajadores de la salud mental, sino que empiezan a denominarse a sí mismos «psicoanalistas». Para la autora, esto posibilitó legitimar la profesión en una práctica que les había sido vedada, pero en un contexto de «represión de las instituciones, ser psicoanalista era sólo ser psicoanalista, solo en el consultorio, solo en el diván, solo interpretando y entonces, en eso empobreció porque se fue creando un imaginario estudiantil y profesional que fue convenciéndose que el mejor profesional era el que era más psicoanalista y nada de otra cosa. Y hasta hoy se mantiene así» (p. 11). 
Cambió, entonces, el emblema del psicólogo y, con él, los lugares elegidos para la formación, además del ideal de intervención. Se generó un fuerte abismo en el modo de pensar el servicio público: estos jóvenes (de los noventa) no pensaban en la especificidad del servicio público, sino que pensaban que al servicio público había que hacerlo lo más parecido posible al consultorio. Se hacía un despilfarro de las posibilidades que el servicio público daba, porque el servicio público permite trabajar con el trabajador social, citar a la familia, hacer algún contacto con la maestra del colegio del chico con problemas.

Respecto a la formación en los ámbitos académicos, el impacto de las políticas neoliberales en la educación superior fue significativo. Uno de los efectos fue el intento de arancelamiento impedido por el movimiento de toda la comunidad universitaria, docentes, no docentes y estudiantes, además de distintos sectores de la población. Sin embargo, las nuevas disposiciones legales para la educación superior permitieron

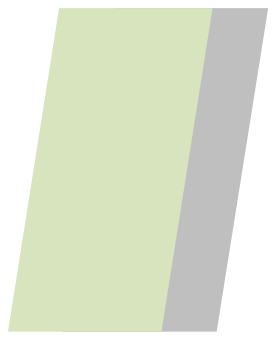

arancelar los estudios de posgrado e intentarán promover el acortamiento de las carreras de grado [...]. Estos principios emanaron de acuerdos formulados para la educación superior por los centros europeos. A esto se sumará el intento de considerarla como un bien comercial, atacando su concepción como un derecho de los habitantes» (Pérez, 2014, p. 177).

En este sentido, se intentó -y en parte se logró- una mercantilización de la educación superior en clave de mercado: se la consideró un servicio, no un derecho. Ahora bien, ¿cómo se produjo la integración de los/as psicólogos/as en las instituciones de menores?

\section{La integración de los/as psicólogos/as en las instituciones de «menores»}

Domínguez Lostaló (1999) sostiene que en las instituciones de menores los/as psicólogos/as fueron reconocidos/as en forma casi inmediata, dado que eran áreas cuyas tareas estaban «muy descalificadas y por lo tanto, más acordes a las asignaciones presupuestarias que se 
daban» (p. 15). No obstante, como no existía una categoría específica para su inserción, los nombramientos de los/as primeros/as psicólogos/as fueron encuadrados en cargos de preceptores/as, asistentes educacionales o enfermeros/as.

En este contexto, la creación del Consejo General de la Minoridad generó un espacio ocupacional para los/as psicólogos/as junto con médicos/as, trabajadores/as sociales y psiquiatras. Entre sus funciones, el Consejo debía: «Estudiar y clasificar los tutelados; derivar de acuerdo a sus características al régimen que corresponda; informar periódicamente sobre el desarrollo de la personalidad y conducta ante las autoridades judiciales correspondientes» (Fasciolo, 2018, p. 95).

Fasciolo (2018) retoma lo expuesto por Varela (2010), quien plantea que, durante los setenta, al interior de los equipos profesionales comenzó a cuestionarse la internación como vehículo para la «rehabilitación social», dados los escasos resultados producidos por el sistema y por el presupuesto que esto implicaba para el Estado. A partir de las corrientes setentistas, se instalaron una variedad de críticas

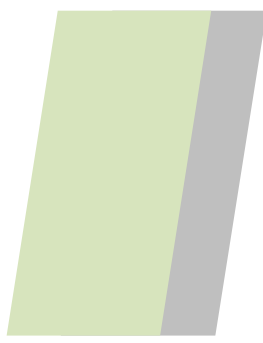

entre las que se incluyen las tendencias «psicoanalíticas», que asignan fundamental importancia a los vínculos tempranos $y$, como consecuencia, se implementaron los primeros programas alternativos a la internación. Este proceso incipiente de los equipos técnicos dedicados al tema fue interrumpido por el Golpe de Estado de 1976 (Fasciolo, 2018, p. 96).

En un análisis institucional sobre un internado de mujeres adolescentes de la ciudad de La Plata, Bugani y Láttaro (1971) describen de la siguiente manera las tareas que desarrollaban allí como psicólogos:

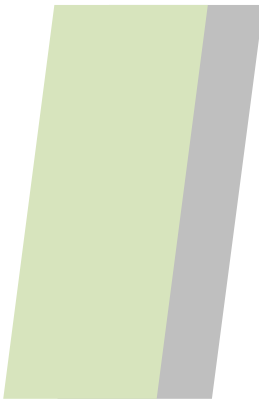

Ingresamos a la institución -dependiente de la Dirección de Menores- para realizar las tareas consabidas, diagnósticos a granel, sin saber bien para qué y para quién se hacían, y también algunas psicoterapias. Al tiempo que realizábamos las tareas formales nos íbamos interiorizando de lo que pasaba ahí adentro. Comenzó a pasar que nuestras tareas de Psicólogos Clínicos de gabinete se transformaban al estar conversando con alguna mucama en el 
patio o en la cocina. Aquí no se podía mantener el encuadre, pero a su vez adquiríamos una rica experiencia e información que nos posibilitaban entender de manera distinta lo que les pasaba a las jóvenes del instituto, más allá de las pruebas diagnósticas y la psicoterapia. A su vez, éstas cobraban otra dimensión a la luz de los conocimientos extraídos de transitar el campo.

Así, comenzamos a sistematizar un poco lo que observábamos y decidimos formalizar un modelo que nos permitiera entender más sistemáticamente la práctica y, a su vez, volcar un informe ante los psicólogos jefes, informe que juntamente con impresiones de otros psicólogos logró cambiar radicalmente la manera de plantearse el trabajo y de actuar (p. 19).

En su estudio, Bugani y Láttaro (1971) describen las características del personal, de las adolescentes institucionalizadas y del cotidiano institucional, y sostienen que el desacople entre la cantidad de población y la escasez de recursos produce un «sobrante excesivo de población». Esta situación fundamenta los traslados masivos de las internas de un instituto a otro y estos movimientos se constituyen en los activadores de la institución por excelencia, dado que la posibilidad de que en cualquier momento puede llegar el traslado es vivenciada por las adolescentes de manera cercana al terror.

Al finalizar el texto, plantean: «A la luz de las indagaciones, la entrevista, ya sea diagnóstica, psicoterapéutica, individual o grupal, percibe un conjunto de sobredeterminaciones que a nuestro juicio es imposible no tener en cuenta» (1971, p. 28).

Uno de los psicólogos que se desempeñó en este periodo en instituciones de «menores», sitúa que trabajaba como psicopedagogo en la Dirección de Menores antes de culminar la carrera de psicología, de la cual egresó en 1970. En ese momento, ingresó al plantel de psicólogos manteniéndose en la misma dirección:

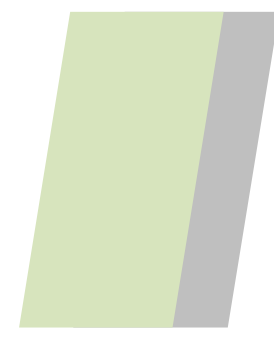

Teníamos uno o dos institutos asignados y hacíamos asistencia directa a determinados chicos, y si no íbamos y entrevistábamos por pedidos de jueces que nos pedían algún tipo de indagatoria sobre algún chico en especial. Tal vez para ver a la madre, a la familia, hacer un cambio de instituto... Más o menos esos eran los pedidos específicos (Moratti, Veloz \& Cattani, 2013, p. 4). 
El equipo de psicólogos/as realizaba asambleas de personal, de las que participaban la cocinera, los/as maestros/as, los/as administrativos/as, la gente que brindaba apoyo escolar y otros/as técnicos/as y profesionales. En dicho espacio asambleario, evaluaban colectivamente las situaciones de cada joven y diseñaban estrategias de intervención, lo que significaba un escenario de conflicto con los directivos.

Dicho profesional era el único psicólogo varón en el equipo, lo que motivó que lo asignaran a trabajar en la Unidad N. ${ }^{\circ}$ 9, una cárcel de máxima seguridad donde alojaban a los adolescentes penales. En ese tiempo, la Dirección de Menores contaba con un ala de 50 celdas individuales de un lado y 50 del otro, para los jóvenes de la provincia de Buenos Aires considerados de máxima peligrosidad. Allí, trabajaba con grupos, supervisados por Armando Bauleo ${ }^{20}$ en Buenos Aires (Moratti, Veloz \& Cattani, 2013, p. 4).

Al caracterizar el trabajo en el ámbito público, el profesional describe:

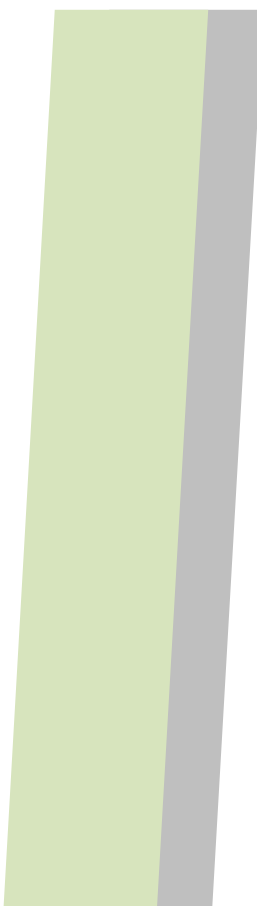

Era un quilombo gigantesco. Por ahí estabas trabajando y a uno se lo llevaban. Lo público era una cosa muy movida, muy peleada, era una lucha permanente; entonces, uno trabajaba en lo público como podía. Yo tenía que trabajar en la cárcel y en la cárcel tenía que ser todo lo contrario al sistema penitenciario porque era siniestro, sobre todo porque había pibes de 17 y 18 años en una cárcel de máxima seguridad. Trabajaba sabiendo que los carceleros eran algo así como los torturadores, entonces estaba caminando por una fina cornisa en la cual en cualquier momento me podía caer.

El objetivo del trabajo era tratar de proteger a los pibes que estaban por salir o que uno se daba cuenta que los iban a limpiar en la misma cárcel, que iban a fabricarle una fuga y que en esa fuga los tiroteaban y los mataban. Me pasó con un chico que yo sabía que le iba a pasar eso. Le hicieron esa trampa y lo liquidaron (Moratti, Veloz \& Cattani, 2013, p. 5).

El entrevistado define a la población de jóvenes detenidos en la Unidad N. ${ }^{\circ} 9$ como

20 Psiquiatra, psicoanalista y psicólogo social argentino, autor de numerosos libros prestigiosos sobre grupos. 
pertenecientes a la clase trabajadora que ya venía en descomposición. Ahí empezaba el país a perder fábricas, a perseguir a militantes y ese contexto se veía. No lo dejabas por fuera del trabajo con los chicos, a mí me servía como un elemento para interpretar o para comprender por qué algún muchacho hacía determinada cuestión (Moratti, Veloz \& Cattani, 2013, p. 6).

En sus estudios, Bugani expuso las prácticas del psicólogo de la época y afirmó que en las instituciones la práctica profesional no estaba desligada de la práctica política de la vida cotidiana. En 1975, renunció a su cargo porque le avisaron que estaba en una lista y tenía que irse:

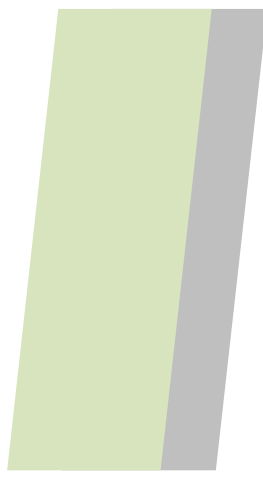

Renuncié y nunca más volví a la administración pública. Ese fue mi pasaje por la Dirección de Menores, y desde entonces trabajé en el consultorio y solamente en el consultorio. [...] Seguí en contacto con Bauleo, hasta que él se fue a Italia, y después, cuando muchas personas se fueron al exterior, yo me quedé, andábamos por las cavernas, por los túneles. Era muy difícil encontrarte pero nos encontrábamos con algunas personas, como se podía, supervisábamos, como se podía (Pérez, 2012).

\section{Un programa para la desinstitucionalización de menores institucionalizados en Costa Rica}

Durante la última Dictadura cívico militar, los/as psicólogos/as que se quedaron en el país se refugiaron en el trabajo privado del consultorio, pero otros debieron exiliarse en el exterior, donde desarrollaron sus prácticas profesionales. En el ámbito que nos ocupa, se iniciaron experiencias de trabajo en instituciones de menores en otros países, fundadas en profundas críticas a la institucionalización de los/as niños/as y los/as adolescentes, que fueron diseñadas y llevadas a cabo por psicólogos/as argentinos/as. Experiencias que se inscriben en un movimiento que derivaría en aportes para la construcción del paradigma de la Doctrina de la Protección Integral. 
Una de ellas fue la realizada en San José de Costa Rica -en el Albergue de Patarrá, un centro abierto para menores infractores, y en el Albergue de Admisión-, a fines de los setenta y principios de los ochenta. El diseño y la implementación del programa se fundó en una investigación efectuada en la Universidad de Costa Rica sobre el problema del menor institucionalizado y tenía como objetivo pensar la institución «como un medio y no como un fin; es decir, que la institucionalización esté unida a la desinstitucionalización» (Facio Fernández, Lavintman Weinstein \& Domínguez Lostaló, 1981, p. 3).

Los/as psicólogos/as diseñaron un modelo denominado Institución Continente, caracterizada como un espacio apto para el desarrollo de la autoestima, la autonomía y la actividad del sujeto, que permitiera la participación y con ella la «elaboración e interpretación de mensajes con el objeto de posibilitar una reinserción satisfactoria y consciente del menor» (Facio Fernández, Lavintman Weinstein \& Domínguez Lostaló, 1981, p. 4). A su vez, organizaron la población de jóvenes en pequeños grupos, armados sobre la base de los diagnósticos realizados, con el propósito de evitar la masificación, y constituyeron equipos técnicos referentes que posibilitaron el tratamiento personalizado.

Respecto al personal de la institución, el modelo incluyó al personal de seguridad, de administración y técnico que participaba en las actividades generales y, especialmente, en las reuniones comunitarias, que se realizaban con una regularidad semanal para construir un espacio específico donde plantear problemas y «evitar, en lo posible, soluciones marginales que excluyeran a algunos miembros de la problemática común» (Facio Fernández, Lavintman Weinstein \& Domínguez Lostaló, 1981, p. 7).

El trabajo con las familias fue parte del tratamiento y se orientó a entender los conflictos de la familia respecto al/a la joven. Además, se consideraba de importancia que la familia conociera las condiciones de vida del/de la menor, «procurando que su experiencia en la institución no establezca distancia física y psicológica entre las dos partes» (Facio Fernández, Lavintman Weinstein \& Domínguez Lostaló, 1981, p. 5). A partir de esto, sostenían una modalidad de trabajo coordinada con el Juzgado Tutelar de Menores que buscaba «unificar criterios y evitar mensajes contradictorios y distintas vías de comunicación que induzcan al menor a la confusión» (Facio Fernández, Lavintman Weinstein \& Domínguez Lostaló, 1981, p. 5). 
En lo que refiere al equipo técnico, el modelo de tratamiento requirió de profesionales que estuvieran en condiciones de captar la demanda de los/as menores a la vez que el reconocimiento de la realidad institucional. Los dispositivos técnicos que implementaron fueron, entre otros, dinámicas de grupos y grupos de discusión, lo que posibilitó «la construcción del esquema común de referencia que proporcionó gran unidad en ciertas pautas ideológicas y consolidó internamente al grupo» (Facio Fernández, Lavintman Weinstein \& Domínguez Lostaló, 1981, p. 3).

El cumplimiento del horario no convencional posibilitó que gran parte de la vida cotidiana en la institución estuviera cubierta, inclusive los fines de semana. Los/as profesionales cumplían funciones en convivencia con los/as menores, dado que «desarrollaban tareas de asistencia pedagógica, psicológica y convivencial general (paseos, gimnasia, momentos de ocio, etc.)» (Facio Fernández, Lavintman Weinstein \& Domínguez Lostaló, 1981, p. 6).

Los resultados de tal experiencia devendrán, con el retorno de la democracia y con el regreso al país de los/as psicólogos/as exiliados, en aportes al campo de la niñez en situación de vulneración de derechos y/o en conflicto con la ley penal.

\section{La vulnerabilidad y la mediación de la ternura}

En el período iniciado por la Convención Internacional sobre los Derechos del Niño (CIDN) (1989) y la construcción del paradigma de Protección Integral, el lugar inicial del discurso «psi»-adjetivado como alternativo- fue el de aportar herramientas de compresión y campos de acción a actores institucionales y políticamente transformadores (Llobet, 2014). Estas herramientas generaron una oposición a las formas de lectura y de intervención moral-punitiva, tanto respecto al delito juvenil como en lo referente a situaciones concebidas como producto del abandono, y posibilitaron redefinir la categoría de abandono moral y material propia del paradigma de Situación Irregular. Aportes que articularon la comprensión respecto de la naturaleza infantil con un tipo de necesidades singulares del sujeto. 
De este modo, en la disputa que se produce en los ochenta en los ámbitos académicos y en el ejercicio profesional de intervención, las «prácticas de restitución de derechos se asocian de manera intrínseca y tácita con las necesidades infantiles, comprendidas como propias a una visualización del niño como sujeto de derechos por oposición al menor objeto de tutela» (Llobet, 2014, p. 11). Así, restituir derechos implica restituir infancia.

Uno de los modelos de abordaje es el propuesto por Domínguez Lostaló (1996), denominado Clínica de la Vulnerabilidad, que parte de sostener que «no existe peligrosidad en las personas si antes no fueron vulnerables» (p. 25). La vulnerabilidad que se juega en lo social -denominada psicosocial- es definida como el grado de fragilidad que la persona tiene por haber sido desatendida en sus necesidades básicas: seguridad afectiva, comida, agua potable, trabajo y salud, protección, educación. Esta vulnerabilidad es la que produce una falla en la función de sostén. En esta línea, el autor sostiene que en la condición humana socio-bio-psico, el grupo de crianza es determinante.

Respecto a lo que denomina «tiempo de invalidez infantil», Ulloa (1995) sostiene que se trata de un tiempo «sin palabras aún», por lo que es un tiempo con pocas posibilidades de pensamiento susceptibles de ser rememorados de forma consciente con posterioridad, «aunque todo lo que se inscriba entonces será constituyente del continente inconsciente del sujeto» (p. 135). Ahora bien, el autor señala que no hay que confundir esta etapa de invalidez con incapacidad y, mucho menos, «con una cosificación del niño, de modo que al negar su condición de sujeto se instauran cultural y jurídicamente sistemas de tutelaje arbitrarios, que para nada lo toman en cuenta como individuo singular» (1996, p. 135).

El autor explica que tal invalidez es presidida por la ternura parental, que caracteriza como una instancia típicamente humana y ética que implica la renuncia al apoderamiento del sujeto infantil. En términos psicoanalíticos, define a la ternura como

[...] la coartación -el freno- del impulso de apoderamiento del hijo, este límite a la descarga no ajeno a la ética, genera dos condiciones, dos habilidades propias de la ternura: la empatía, que garantiza el suministro adecuado (calor, alimento, arrullo, palabra) y, como segundo y fundamental componente, 
el miramiento. Tener miramiento es mirar con amoroso interés a quien se reconoce como sujeto ajeno y distinto de uno mismo. El miramiento es germen inicial y garantía de autonomía futura del infante (Ulloa, 1995, p. 136).

La mediación de la ternura, dirá Ulloa (1995), crea en el niño un sentimiento de confianza, a partir del cual se estructura una relación de contrariedad con lo que daña, con el sufrimiento; este proceso es considerado fundamental para el desarrollo paulatino de la conciencia acerca de que él mismo puede ser causa externa de sufrimiento para el otro. En esta relación de contrariedad con lo que daña radica lo que el autor denomina «imposición de justicia», definida como el sentimiento que además de distinguir entre lo que daña y lo que no, indica también cuándo el mismo sujeto es o no dañino para el otro.

En este sentido, el autor identifica que los atributos de la ternura serán «abrigo frente a los riesgos de la intemperie, alimento frente a los del hambre $y$, fundamentalmente, buen trato, como escudo protector ante las violencias inevitables del vivir» (Ulloa, 1995, p. 241). Entre los efectos que produce el fracaso de la ternura, en tanto, el autor sitúa la adquisición de la imposición de justicia y lo que denomina «inseguridad ontológica», donde el tiempo presente no aparece con un mañana posible. 


\section{Referencias}

Borinsky, M. (2005). «Todo reside en saber qué es un niño». Aportes para una historia de la divulgación de las prácticas de crianza en la Argentina. Anuario de investigación de la Facultad de Psicología, XIII, 117-125.

Bugani, P. y Láttaro, M. (1971). Analítica institucional en un internado de adolescentes mujeres. Polémica en Psicología, I(1).

Carpintero, E. y Vainer, A. (2004). Las huellas de la memoria. Psicoanálisis y salud mental en la Argentina de los '60 y '70. Ciudad Autónoma de Buenos Aires, Argentina: Topia.

Cosse, I. (2009). La emergencia de un nuevo modelo de paternidad en Argentina (1950-1975). Estudios demográficos y urbanos, 24(2). Recuperado de https://estudiosdemograficosyurbanos.colmex.mx/index.php/edu/article /view/1339

Dagfal, A. (2009). Entre París y Buenos Aires. La invención del Psicólogo (19421966). Ciudad Autónoma de Buenos Aires, Argentina: Paidós.

Domínguez Lostaló, J. C. (1996). ¿Cómo contener el conflicto? Presentación de una propuesta. La clínica de la vulnerabilidad. En ¿Es necesario encerrar? El derecho a vivir en comunidad (pp. 25-48). La Plata, Argentina: P.I.F.A.T.A.C.S - Cuadernos del Caleuche - Universidad Nacional de La Plata.

Domínguez Lostaló, J. C. (1999). Los pibes marginados. Por el derecho a ser joven. Ciudad Autónoma de Buenos Aires, Argentina: Cuadernos del Caleuche.

Domínguez Lostaló, J. C. (2001). 30 años de práctica profesional del psicólogo (Conferencia en las Primeras Jornadas sobre la Formación Universitaria y Práctica Profesional del Psicólogo, octubre de 1989). Revista No-Temas, 1(1), 9-19.

Donzelot, J. (1990). La policía de las familias. Valencia, España: Pre-Textos.

Facio Fernández, T., Lavintman Weinstein, S. y Domínguez Lostaló, J. C. (1981). Informe Paterra. Inédito.

Fernández, A. M. (1996). La Psicología como profesión: de la salud de la formación a la formación para la salud [Desgrabación de clase]. La Plata, Argentina: Universidad Nacional de La Plata. 
Fernández, A. M. (1999). Instituciones estalladas. Ciudad Autónoma de Buenos Aires, Argentina: Eudeba.

Foucault, M. (2006). Seguridad, territorio y población. Ciudad Autónoma de Buenos Aires, Argentina: Fondo de Cultura Económica.

Llobet, V. (2006). Las políticas sociales para la infancia vulnerable. Algunas reflexiones desde la Psicología. Revista Latinoamericana de Ciencias Sociales, Niñez y Juventud, 4(1). Recuperado de http://revistaumanizales.cinde.org.co/rlcsnj/index.php/RevistaLatinoamericana/article/view/391

Llobet, V. (2013). «La producción de la categoría "niño-sujeto-de-derechos" y el discurso psi en las políticas públicas en Argentina. Una reflexión sobre el proceso de transición institucional». En V. Llobet (Comp.), Pensar la infancia desde América Latina. Un estado de la cuestión (pp. 209-235). Ciudad Autónoma de Buenos Aires, Argentina: Consejo Latinoamericano de Ciencias Sociales (CLACSO).

Llobet, V. (2014). Reflections Upon a Misunderstanding: Production of Children's Needs Within Rights Protection Policies. Psicologia em Estudio, 19(3), 1-11. Doi: http://dx.doi.org/10.1590/1413-73722222501

Lorente, P. (22 de noviembre de 2018). Discurso brindado en el acto por el «60 Aniversario de la creación de la carrera de Psicología en la Universidad Nacional de La Plata.

Macchioli, F. (2012). Los inicios de la Terapia Familiar en la Argentina. Implantación, configuración y desarrollo de un nuevo campo disciplinar. 1960-1979. Estud. pesqui. psicol., 12(1), 681-689. Recuperado de http://pepsic.bvsalud.org/scielo.php?script=sci_arttext\&pid=\$180842812012000200020

Macchioli, F. (2013). Familia y salud mental en la Argentina de 1957. Salud mental: Interdisciplina e inclusión social como ejes de intervención. Ciudad Autónoma de Buenos Aires, Argentina: Asociación Argentina de Salud Mental.

Macchioli, F. (2014). «La inclusión de los padres en el cuadro de la situación analítica». Familia, disciplinas psi y valores en la Argentina de los cincuenta. Universitas Psychologica, 13(5), 1881-1891.

https://doi.org/10.11144/Javeriana.upsy13-5.ipcs

Moratti, M. F., Veloz, J. y Cattani, J. P. (noviembre 2013). Psicólogos/as y políticas públicas. Una historización acerca de la inserción en el ámbito de Niñez y Adolescencia. 1960-1970. Trabajo presentado en el $V$ Congreso Internacional de Investigación y Práctica Profesional en Psicología de la Universidad de Buenos Aires. 
Pérez, E. A. (2012). Los psicólogos en el ámbito público: ayer y hoy. Salud, desarrollo social, seguridad y justicia (2012-2016). Proyecto acreditado por la Secretaria de Ciencia y técnica, UNLP. Res. N²427/93. Ministerio de Cultura y Educación de la Nación.

Pérez, E. A. (Comp.) (2014). Psicología institucional. La Plata, Argentina: EDULP.

Rustoyburu, C. (2014). Hijo mío...! Disputas por el sentido en torno de la infancia. Argentina, en la década de 1930. Trabajo presentado en el I Encuentro Internacional de Educación de la Universidad Nacional del Centro de la Provincia de Buenos Aires. Recuperado de http://www.ridaa.unicen.edu.ar/xmlui/handle/123456789/144

Ulloa, F. (1995). Novela clínica psicoanalítica. Historial de una práctica. Ciudad Autónoma de Buenos Aires, Argentina: Paidós.

Varela, C. (agosto de 2010). La psicología institucional argentina. Orígenes y fundamentos. Trabajo presentado en el II Congreso Nacional y I Encuentro Internacional de Psicosociología Institucional de la Universidad Nacional de Salta. Recuperado de http://www.cristianvarela.com.ar/textos/a-institucionalargentinaorigenes-fundamentos

Weissmann, P. (2002). Mariano J. Barilari. Medicina psicosomática y educación para la salud en la Argentina de los años `30. Temas de historia de la Psiquiatría Argentina, (15). Recuperado de http://www.polemos.com.ar/docs/temas/Temas15/1a\%20parte.htm

\section{Normativas}

Ley Nacional 17.132 (1967). Arte de Curar.

Boletín Oficial de la República Argentina. Buenos Aires, 31/1/1967.

Ley Provincial 10.306 (1985). Colegio de Psicólogos de la Provincia y Regulación del Ejercicio Profesional de la Psicología.

Boletín Oficial de la Provincia de Buenos Aires. La Plata, 6/9/1985. 

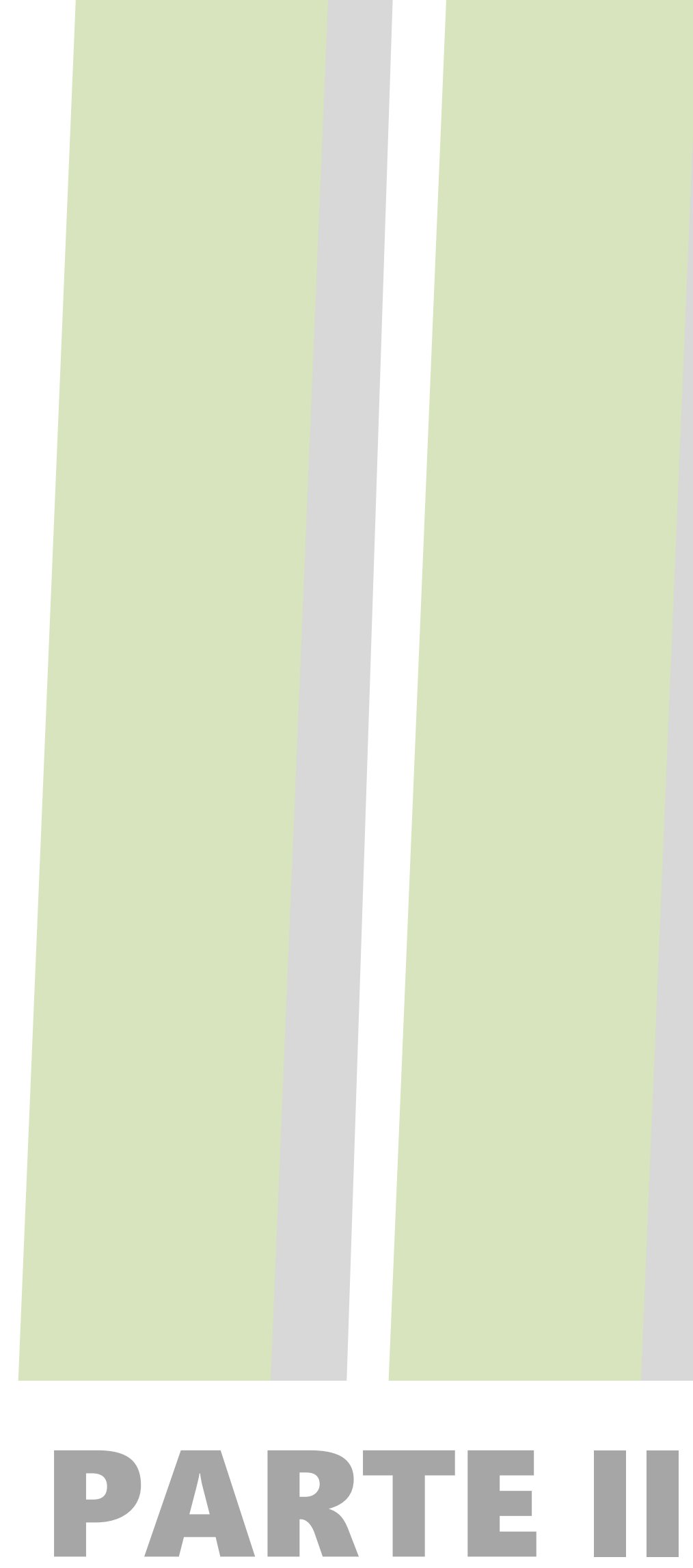


\title{
Parte II
}

\section{CAPÍTULO 4}

\section{La estrategia de investigación}

\author{
Los instrumentos
}

Las herramientas de análisis

El presente estudio se propone aportar a la construcción de conocimiento en un área específica: los dispositivos de intervención que, durante el período 2000-2015, diseñaron e implementaron los/as psicólogos/as en los establecimientos dependientes del Organismo de la Niñez y Adolescencia de la provincia de Buenos Aires, en los cuales se materializan las políticas públicas para niños/as y adolescentes en situación de vulneración de derechos y de conflicto con la ley penal.

Para tal propósito, hemos utilizado una metodología de investigación de tipo cualitativa, en tanto que esta modalidad

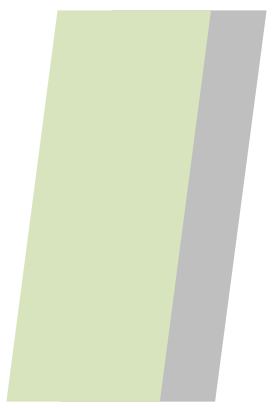

se interesa por la vida de las personas, por sus perspectivas subjetivas, por sus historias, por sus comportamientos, por sus experiencias, por sus interacciones, por sus acciones, por sus sentidos, e interpreta a todos ellos de forma situada, es decir, ubicándolos en el contexto particular en el que tienen lugar. Trata de comprender dichos contextos y sus procesos, y de explicarlos recurriendo a la causalidad local (Vasilachis de Gialdino, 2006, p. 33).

La estrategia de investigación se inscribe, de este modo, en la perspectiva epistemológica que Vasilachis de Gialdino (2006) califica como «epistemología del sujeto que conoce». De este modo, el foco se sitúa en el conocimiento que se produce y este se asume como resultado de un proceso de construcción cooperativa, a partir del cual los sujetos son pensados como productores activos de conocimiento y no como proveedores de datos útiles para que otros/as conozcan. 
Desde esta perspectiva, los/as psicólogos/as entrevistados/as no son concebidos/as como pasivos en el proceso de investigación, a diferencia de lo que postula la «epistemología del sujeto» cognoscente, mediante la cual se piensa a los sujetos como objetos a ser conocidos y por ende pasivos en el proceso de construcción de conocimiento, en la medida en que solo aportan datos (Vasilachis de Gialdino, 2006).

A su vez, la propuesta se inscribe en un modo de pensar la investigación como el diseño de una maquinaria metodológica singular, construida con la intención de visibilizar ciertos campos de experiencia social, en un marco de interacción del investigador con su campo (Salazar Villava, 2004).

De este modo, se diferencia de los modelos metodológicos tradicionales, dado que las estrategias utilizadas no responden a un manual que establezca los pasos a seguir.

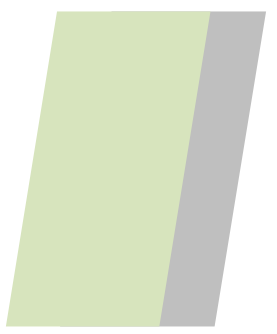

[No refiere a una] regularidad controlada para las formas de la acción que prescribe ciertos procedimientos específicos. No se puede responder a las preguntas ¿cómo es el dispositivo?, ¿cómo se opera correctamente?, ¿en qué consiste? En su vacío, en cambio, es apertura para el conocimiento, en tanto da lugar a la incertidumbre y se niega a pre-ver (Salazar Villava, 2004, p. 1).

En tal sentido, las preguntas de investigación interrogan respecto a qué tipo de dispositivos se diseñan y se llevan a cabo; qué elementos se disponen en su implementación; qué caracteriza a los ámbitos en los que se interviene; y los elementos que los determinan, entre ellos, las normativas vigentes en cada momento histórico.

Es así que nos proponemos caracterizar los dispositivos que diseñan y que implementan los/as psicólogos/as, y los elementos que los determinan, a través del diseño «de una singular máquina de hacer ver». Tal noción implica, siguiendo a Salazar Villava (2004), un deslizamiento de sentido respecto de los desarrollos foucaultianos; esto es, del dispositivo sociohistórico productor de subjetividades «hacia la idea de construcción intencional de una singular máquina para hacer ver en el marco de un proceso de reflexión sobre lo social» (p. 2). 
Desde este posicionamiento, no es posible anticipar hipótesis, por lo que el trabajo no partió de presupuestos sobre los dispositivos diseñados e implementados, como tampoco sobre los elementos que disponían y los elementos que los determinaban, los ámbitos en los cuales fueron efectuados ni los efectos de las normativas en los mismos.

Dado el propósito que guía la presente investigación, se optó por un tipo de metodología cualitativa descriptiva que se caracteriza por especificar propiedades, características y por describir tendencias de un grupo o una población respecto del fenómeno que se busca analizar.

El universo de estudio y las unidades de análisis, en tanto, fueron delimitados a partir de los objetivos de la investigación. El universo de estudio se compone de un grupo de 16 profesionales de la psicología, seleccionados de acuerdo al criterio de tiempo histórico y su correlación con los elementos legales, y de acuerdo al tipo y a la ubicación geográfica del establecimiento en el cual se desempeñaron o se desempeñan como psicólogos/as.

De este modo, los/as entrevistados/as seleccionados/as han integrado o integran los equipos técnicos que se desempeñan en los establecimientos de las distintas áreas del Organismo de la Niñez y Adolescencia de la provincia de Buenos Aires, ubicados en la ciudad de La Plata y Gran La Plata, entre los años 2000-2015. En tal sentido, la muestra es homogénea, debido a que el grupo de psicólogos/as que la compone comparte rasgos similares.

En cuanto a las unidades de análisis, estas fueron construidas en torno a los elementos que disponen las normativas - principalmente, el Decreto Ley del Patronato de Menores, Ley 13.298 de Promoción y Protección Integral de los Derechos de los Niños y la Ley 13.634/07 del Fuero de Familia y del Fuero Penal del Niño- y sobre las líneas de discurso de los/as psicólogos/as acerca de los dispositivos de intervención diseñado e implementado, el tipo de establecimiento (hogar, instituto, centro) en el que estos se inscriben y los objetivos que los orientan. 


\section{Los instrumentos}

\section{El análisis documental}

Para caracterizar los dispositivos de intervención implementados por los/as psicólogos/as en los establecimientos del Organismo de la Niñez y Adolescencia de la provincia de Buenos Aires, durante el período 2000-2015, hemos iniciado el abordaje metodológico a partir de la lectura y el análisis documental de los siguientes instrumentos normativos:

Decreto Ley Nacional 22.278 (1980). Régimen Penal de la Minoridad (B.O., 28/8/1980).

Decreto Ley Provincial 10.067 (1983). Patronato de Menores (B.O., 9/12/1983).

Ley Provincial 13.298 (2005). Promoción y Protección Integral de los Derechos de los Niños (B.O., 27/1/2005).

Ley Nacional 26.061 (2005). Protección Integral de los Derechos de las Niñas, Niños y Adolescentes (B.O., 26/10/2005).

Decreto Reglamentario 300 (2005). Decreto Reglamentario de la Ley 13.298 (B.O., 23/3/2005).

Ley Provincial 13.634 (2007). Principios Generales del Fuero de Familia y del Fuero Penal del Niño (B.O., 2/2/2007).

A esto se sumó, el análisis de aquellas normativas complementarias:

Decreto Ley Nacional 22.803 (1983). Elévase la edad mínima de punibilidad respecto de menores que cometieron delitos (B.O., 9/5/1983).

Convención Internacional sobre los Derechos del Niño (1989).

Ley Nacional 23.742 (1989). Modifícase la Ley Nº 22.278 (B.O., 25/10/1989).

Resolución Ministerial 166 (2007). (B.O., 3/7/2007). 
Decreto Provincial 44 (2007). (B.O., 2/2/2007).

Decreto Ministerial 151 (2007). (B.O., 22/3/2007).

Resolución Ministerial 172 (2007). (B.O., 4/4/2007).

Estos documentos cobran valor de instrumento, en tanto su estudio permite delinear los elementos y los procedimientos que disponen las normativas: quiénes y cuándo intervienen, cómo se reglamenta su implementación (organigrama y tipos de establecimientos) y cuáles son las características de la población destinataria sobre la cual se propone intervenir (qué niños/as y jóvenes, para qué, cuándo y cómo; quiénes y cuándo intervienen).

\section{Las entrevistas}

Pero ¿qué hacen los/as psicólogos/as en la materialidad del encuentro con los/as niños/as y con los/as jóvenes en los diferentes establecimientos? ¿Qué elementos disponen para intervenir?

Para dar cuenta de estos interrogantes, se instrumentaron entrevistas semi-estructuradas con 16 psicólogos/as que han integrado y/o integran los equipos técnicos en distintas instituciones dependientes de la Secretaria de Niñez y Adolescencia de la ciudad de La Plata y Gran La Plata. ${ }^{21}$

Para la selección de la muestra, los criterios utilizados comprendieron: el tiempo histórico en el cual trabajó o trabaja en el establecimiento (dentro del período 2000-2015) y el tipo de institución en la cual se desempeñó o desempeña. De este modo, la muestra se compone de psicólogos/as cuyas prácticas profesionales fueron efectuadas en los distintos tiempos normativos y en los diferentes espacios institucionales que tales normativas disponían.

21 Una de las particularidades que presentan los/as entrevistados/as es la circulación por distintos establecimientos y ámbitos (responsabilidad penal-protección de derechos); esto es, ninguno/a trabajó solo en una institución del actual Organismo de Niñez y Adolescencia sino que, al menos, se desempeñó en dos. 
Las preguntas que orientaron las entrevistas fueron ajustándose al compás del trabajo de campo. A su vez, y de acuerdo al devenir de los intercambios, se introducían preguntas tendientes a precisar y/o a ampliar los puntos considerados de interés. Cabe señalar que una de ellas refería a la posibilidad de que sugiriera a algún/a colega para entrevistar; de allí que el contacto con los/as psicólogos/as se originó en las sugerencias de los propios/as entrevistados/as.

Las entrevistas -que en todos los casos se realizaron en un solo encuentro-, se llevaron a cabo en distintos espacios: en los lugares de trabajo institucionales y/o en los consultorios de atención privada, de acuerdo a la disponibilidad de los/as entrevistados/as. En todos los casos, las conversaciones fueron grabadas y se registraron notas por escrito.

Las líneas de indagación que orientaron las entrevistas se organizaron de acuerdo a los siguientes ejes:

año/s en el/los que se desempeñó como profesional en la institución,

tipo de establecimiento en el que trabajó y/o trabaja (y si lo hizo en diferentes establecimientos de la Secretaría de Niñez y Adolescencia), ${ }^{22}$ dispositivos de intervención implementados (con quiénes y para qué),

impacto de las normativas en los dispositivos implementados en sus prácticas.

Respecto del modo de presentación, para la descripción de los dispositivos de intervención referidos por los/as psicólogos en el marco de las entrevistas realizadas, hemos decidido transcribir el relato de, al menos, una escena experienciada, con el recuerdo detallado de los diálogos y de los efectos producidos, dado que tales escenas tienen la potencia de visibilizar los dispositivos en acción.

22 Esta última pregunta fue introducida luego de comprobar, en las primeras entrevistas, que los/as psicólogos/as han trabajado / trabajan en distintos establecimientos y que efectuaron / efectúan medidas diferentes según se trate de hogares convivenciales y/o de institutos penales, en instituciones del Sistema de Promoción y Protección de Derechos, y/o del Sistema de Responsabilidad Penal Juvenil. 


\section{Las herramientas de análisis}

El análisis de los materiales se inscribe en el paradigma interpretativo, en tanto que los métodos cualitativos de investigación suponen y realizan sus postulados. Al respecto, Vasilachis de Gialdino (1992) sostiene que la investigación cualitativa es una forma de ver.

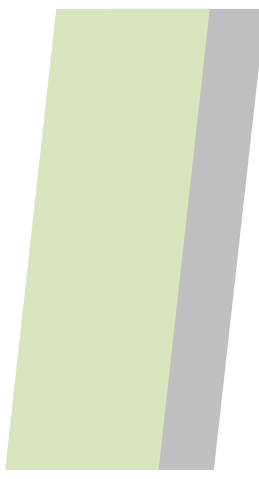

Esa «visión» goza de un plus que es el que le otorga el paradigma interpretativo a través del cual el investigador privilegia lo profundo sobre lo superficial, lo intenso sobre lo extenso, lo particular sobre las generalidades, la captación del significado y del sentido interno, subjetivo, antes que la observación exterior de presuntas regularidades objetivas. Como expresa Silverman (1994), la mayor parte de los investigadores cualitativos ha preferido describir e iluminar el significativo (p. 50).

La autora afirma que los/as investigadores/as cualitativos han preferido describir e iluminar el significativo mundo social de acuerdo con el paradigma interpretativo, centrándose en la comprensión, en el significado de la palabra y de la acción, y en el sentido que se expresa en el lenguaje. En otras palabras, el paradigma interpretativo -no positivista- se apuntala en una concepción orientada hacia el significado, el contexto, la interpretación, la comprensión y la reflexividad.

Por lo anterior, el análisis de las leyes y las normativas se efectúo a partir de puntuar y de delimitar algunos de los elementos y los procedimientos que disponen: sobre qué niños/as y adolescentes, cuándo, para qué y cómo se interviene. Las entrevistas semiestructuradas, en tanto, fueron analizadas a partir de la distinción y la puntuación de los elementos que disponen, lo cual posibilitó caracterizar los dispositivos.

A su vez, las líneas de determinación se trazaron a partir de operaciones de distinción, de puntuación y del establecimiento de conexiones e insistencias en y entre los dispositivos efectuados por los/as psicólogos/as. Un trazado que deviene productivo dado que puntúa un pliegue que al extenderse abre un campo de posibles (Borakievich, Cabrera, Ortiz Molinuevo \& Fernández, 2014), diferenciándose de las operaciones de traducción. 
Tales operaciones se inscriben en la constelación de lo que se ha denominado en ciencias sociales la tradición interpretativa, cuya relevancia se centra en los procesos de construcción de realidades como en la acción que funda una posición y una figura: la del observador (Montenegro, 2004).

Montenegro (2004) describe el trazado de una distinción como un acto, productivo, que establece diferencias y genera un mundo al hacerlo. En el acto de trazar una distinción «co-surge con el mismo la figura del observador, que puede ser definido como aquel que traza distinciones. No es un sujeto posicionado en un punto exterior que observa los datos de un campo fenoménico» (p. 6).

Respecto a la operación de puntuación, señala que es posibilitada por las distinciones previas. De allí que sostiene «una puntuación puede ser pensada como una distinción de segundo grado, una distinción en una distinción que ha producido una diferencia» (p. 8). A su vez, la posibilidad de volver recursivamente sobre las trazas efectuadas, los procesos de puntuación se extienden al infinito. 


\section{Referencias}

Borakievich, S., Cabrera, C., Ortiz Molinuevo, S. y Fernández, A. (2014). La indagación de las implicaciones y el pensar-en-situación: una contribución de la metodología de problematización recursiva. Sujeto, Subjetividad y Cultura, (8), 21-28. Recuperado de https://bit.ly/2OHYONg

Montenegro, R. (2004). Dispositivos de enunciación: las operaciones de distinción y de puntuación. Trabajo presentado en las XI Jornadas de Investigación de la Universidad de Buenos Aires. Recuperado de http://www.aacademica.org/000-029/164

Salazar Villava, C. M. (2004). Dispositivos: máquina de visibilidad.

En Anuario de investigación 2003 (pp. 291-299). Ciudad de México, México: Universidad Autónoma de México.

Vasilachis de Gialdino, I. (Coord.) (2006). Estrategias de investigación cualitativa. Barcelona, España: Gedisa. 


\title{
Parte II
}

\section{CAPÍTULO 5}

\section{Los elementos normativos en la provincia de Buenos Aires}

\author{
El Patronato de Menores \\ El Sistema de Promoción y Protección \\ de los derechos de niños, niñas y adolescentes \\ El Fuero de Responsabilidad Penal Juvenil
}

En el presente apartado se ofrece el análisis documental de los elementos dispuestos por el Decreto Ley 10.067/83 del Patronato de Menores, la Ley 13.298/05 de Promoción y Protección Integral de los Derechos de los Niños y la Ley 13.634/07 del Fuero de Familia y del Fuero Penal del Niño. Tales normativas se proponían, en un caso, tutelar a quienes se encontraban en situación de «peligro moral o material»; en otro, proteger y restituir derechos a quienes se encuentran en situación de vulneración efectiva de derechos y a quienes deben cumplir una medida de responsabilidad penal.

Como se desarrolla a continuación, mientras que el Decreto Ley sancionado durante la última Dictadura cívico militar materializó con mayor claridad y coordinación un modo histórico de intervenir sobre un sector de la población de niños/as y adolescentes: la judicialización de la pobreza y la producción del menor como objeto de tutela del Estado, las leyes sancionadas en 2005 y en 2007 implicaron una ruptura que permitió pasar a la concepción del/de la niño/a o adolescente como sujeto de derecho.

La relevancia histórica y política de estas últimas leyes radica en que establecen otros campos y objetivos de intervención, priorizan la permanencia con los grupos familiares y en las comunidades de pertenencia, y asumen el alojamiento en una institución como medida de último recurso, lo que implica la implementación de dispositivos de intervención diferentes a los establecidos en tiempos tutelares. 


\section{Elementos que dispone el Patronato de Menores}

El Decreto Ley 10.067 del Patronato de Menores de la provincia de Buenos Aires fue dictado por el Interventor Federal de facto en ejercicio de las facultades legislativas conferidas por la Junta Militar, el 25 de octubre de 1983, cinco días antes del acto eleccionario nacional y a meses de la asunción del gobierno democrático.

Una dimensión necesaria de delimitar respecto de este Decreto Ley es la temporalidad: el dispositivo del Patronato de Menores fue diseñado por un régimen dictatorial y estuvo vigente durante veinticuatro años de gobiernos democráticos. De allí que algunos autores hayan caracterizado la sanción de las nuevas normativas como una «deuda de la democracia».

La Convención sobre los Derechos del Niño (1989) adquirió carácter constitucional en 1994, pero no derogó este Decreto Ley sino luego de trece años, cuando se sancionaron y se implementaron la Ley 13.298 de Promoción y Protección Integral de los Derechos de los Niños y la Ley 13.634 del Fuero de Familia y del Fuero Penal del Niño, en 2007. Respecto al Régimen Penal de Menores, sigue en vigencia el Decreto Ley Nacional del mismo régimen dictatorial, dado que la sanción de la Ley 13.634 creó el Fuero de Responsabilidad Penal Juvenil que garantizó el debido proceso para los/as jóvenes pero no derogó el Decreto Nacional.

Para iniciar el desglose de algunos de los principales elementos normativos dispuestos por el dispositivo del Patronato de Menores se parte de los fundamentos y los propósitos que lo orientaron: «Instituir un nuevo régimen regulatorio del Patronato de Menores de la provincia de Buenos Aires que tiende a la reunión en un solo cuerpo legal de todas las disposiciones referentes al tema» (Fundamentos, p. 38).

El propósito fue coordinar las acciones de los Tribunales de Menores, de la Asesoría de Incapaces y del Organismo Tutelar Administrativo, para lo cual se incluyeron normas que delimitaron las competencias: las de creación del Fuero de Menores, las que reglan el procedimiento y las que fijan las funciones de la Subsecretaría del Menor y la Familia. 
Por ejercicio coordinado, entiende:

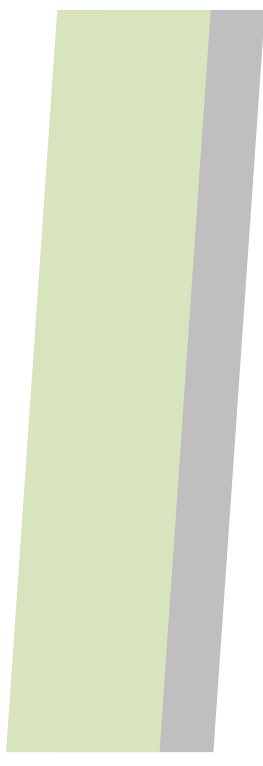

a) El juez tiene competencia exclusiva para decidir sobre la situación del menor en estado de abandono o peligro moral o material, debiendo adoptar todas las medidas tutelares necesarias para dispensarle amparo. b) El Asesor de Incapaces en su carácter de representante del menor y de la sociedad se halla investido de todas las atribuciones necesarias para controlar el efectivo cumplimiento de las normas destinadas a protegerlo. c) La Subsecretaria es la encargada de planificar y ejecutar -por sí o a través de las Municipalidadesla política general de la minoridad, tanto en sus aspectos preventivos cuanto en los relativos a la formación y reeducación de los menores internados en establecimientos de su dependencia o contralor, en ejecución de los mandatos de los Tribunales del fuero (Título I, artículo 2).

En lo referente a los órganos que integran el ejercicio del Patronato de Menores, se establece que «los secretarios cumplimentarán todas las medidas ordenadas por el Juez y podrán, por sí, requerir documentos e información de conformidad con el estado de la causa» (Título II, capítulo I, artículo 7).

De este modo, el juez tiene competencia exclusiva para decidir sobre la situación del menor en estado de «abandono o peligro moral o material». Pero ¿cuándo tiene competencia?

a) Cuando aparecieren como autores copartícipes de un hecho calificado por la ley como delito, falta de contravención, menores de dieciocho años de edad; b) Cuando la salud, seguridad, educación y moralidad de menores de edad se hallare comprendida por actos de inconducta, contravenciones, o delitos de sus padres, tutores, guardadores, o terceros; por infracción a las disposiciones legales referentes a la instrucción y al trabajo; cuando por razones de orfandad o cualquier otra causa, estuviesen material o moralmente abandonados, o corrieren peligro de estarlo, para brindar protección y amparo, procurar educación moral e intelectual al menor y para sancionar, en su caso, la inconducta de sus padres, tutores guardadores o terceros, conforme a las 
leyes que rigen en materia de minoridad y a las disposiciones de la presente; c) Para disponer todas aquellas medidas que sean necesarias para otorgar certeza los atributos de la personalidad de los menores bajo su amparo, y lograr su más completa asistencia; d) En las causas referentes al ejercicio, suspensión o pérdida de la patria potestad; adopción; y venia supletoria de los menores amparados por el Juzgado; e) Cuando actos reiterados de inconducta de menores de edad obliguen a sus padres, tutores o guardadores, a recurrir a la autoridad para corregir, orientar y educar al menor; f) En las contravenciones cometidas por adultos en perjuicio de menores, con auxilio o en compañía de éstos (Título II, capítulo II, artículo 10).

Las causas que originan la competencia del juez -es decir, que le otorgan competencia para intervenir- son denominadas asistencial o penal, y determinan el organigrama de la Subsecretaria, el área de dependencia y el tipo de organización-establecimiento, y con ello la disposición de ciertos elementos -como el tipo de instalaciones, la arquitectura del lugar, reglamentos internos de funcionamiento, medidas administrativas, entre otroscuya función será materializar las medidas que el juez ordena.

\section{En lo penal}

El procedimiento penal establece que «en todos los casos el menor será citado para su identificación a efectos de ser incluido en el Registro General de Menores» (Título II, capítulo IV, artículo 30). Al comparecer ante el Juzgado, «el Juez, previa citación del Asesor y con asistencia del Defensor particular en su caso, lo interrogará personalmente sobre las particularidades de la causa, dirigiendo sus preguntas a conocer la capacidad mental, efectividad, tendencia, hábitos y demás circunstancias de orden psíquico o de ambiente (Título II, capítulo IV, artículo 31).

Concluido el interrogatorio, el juzgado: «a) Dispondrá el destino provisional del menor previo examen médico psicológico; b) Ordenará el estudio de ambiente relativo al menor y su núcleo de convivencia» (Título II, capítulo IV, artículo 32). En un plazo de 48 horas, el juzgado determinará: «a) La existencia del cuerpo del delito, su clasificación y la responsabilidad que prima facie corresponde al causante; b) La ampliación del sumario 
si lo considera necesario; c) El destino del menor conforme a los nuevos elementos aportadas a la causa; d) Cuando lo considere procedente, la suspensión preventiva del ejercicio de la patria potestad o de la tutela, o la privación de la guarda en su caso» (Título II, capítulo IV, artículo 33).

«En los casos en que no se aplique sanción penal o se absuelva, se podrá disponer tutelarmente del menor hasta la mayoría de edad» (Título II, capítulo IV, artículo 38). En tanto, «la sanción privativa de libertad se cumplirá en la forma y con las modalidades que el juez disponga, en establecimientos especiales dependientes de la Subsecretaría del Menor y la Familia, o cuando las circunstancias lo aconsejen bajo el régimen de libertad vigilada, sujeto al control del propio juzgado» (Título II, capítulo IV, artículo 39).

\section{Punibilidad}

En 1980, el Decreto Ley Nacional 22.278 del Régimen Penal de la Minoridad integró el Patronato de Menores y estableció la edad de punibilidad en los 14 años. Tres años más tarde, el Decreto Ley Nacional 22.803 elevó la edad de punibilidad a los 16 años.

No es punible el menor que no haya cumplido dieciséis (16) años de edad. Tampoco lo es el que no haya cumplido dieciocho (18) años, respecto de delitos de acción privada o reprimidos con pena privativa de la libertad que no exceda de dos (2) años, con multa o con inhabilitación.

Si existiere imputación contra alguno de ellos la autoridad judicial lo dispondrá provisionalmente, procederá a la comprobación del delito, tomará conocimiento directo del menor, de sus padres, tutor o guardador y ordenará los informes y peritaciones conducentes al estudio de su personalidad y de las condiciones familiares y ambientales en que se encuentre.

En caso necesario pondrá al menor en lugar adecuado para su mejor estudio durante el tiempo indispensable.

Si de los estudios realizados resultare que el menor se halla abandonado, falto de asistencia, en peligro material o moral, o presenta problemas de conducta, el juez dispondrá definitivamente del mismo por auto fundado, previa audiencia de los padres, tutor o guardador (artículo 1). 
Se prescribe que los menores de dieciséis a dieciocho años son punibles y «cualquiera fuese el resultado de la causa, si de los estudios realizados apareciera que el menor se halla abandonado, falto de asistencia en peligro material o moral, o presenta problemas de conducta, el juez dispondrá definitivamente del mismo por auto fundado, previa audiencia de los padres, tutor o guardador» (artículo 2).

El Decreto determina: «a) La obligada custodia del menor por parte del juez, para procurar la adecuada formación de aquél mediante su protección integral. Para alcanzar tal finalidad el magistrado podrá ordenar las medidas que crea convenientes respecto del menor, que siempre serán modificables en su beneficio; b) La consiguiente restricción al ejercicio de la patria potestad o tutela [...] (artículo 3).

En esta línea, el tiempo que se extienda la disposición definitiva será resuelto por el/la juez/a, dado que la misma puede cesar en cualquier momento por «resolución judicial fundada» y concluirá «cuando el menor alcance la mayoría de edad» (artículo 3). Además, será la autoridad técnico administrativa con competencia en el ejercicio del Patronato de Menores la que se encargará de las internaciones dispuestas por los jueces (artículo 3 bis). ${ }^{23}$

La imposición de la pena, en tanto, está supeditada a los siguientes elementos:

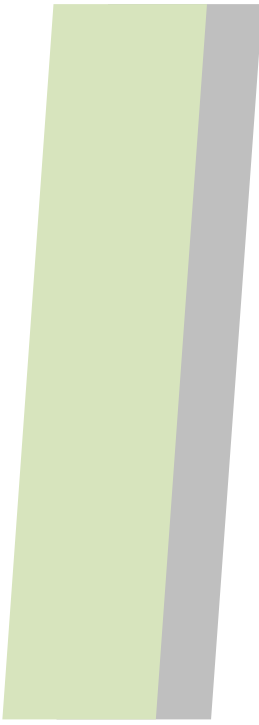

1) Que previamente haya sido declarada su responsabilidad penal y la civil si correspondiere, conforme a las normas procesales; [...] 3) Que haya sido sometido a un período de tratamiento tutelar no inferior a un (1) año, prorrogable en caso necesario hasta la mayoría de edad.

Una vez cumplidos estos requisitos, si las modalidades del hecho, los antecedentes del menor, el resultado del tratamiento tutelar y la impresión directa recogida por el juez hicieren necesario aplicarle una sanción, así lo resolverá [...].

Contrariamente, si fuese innecesario aplicarle sanción, lo absolverá [...] (artículo 4).

23 Artículo incorporado por el art. $1^{\circ}$ de la Ley 23.742/89. 


\section{En lo asistencial}

En lo referente al procedimiento asistencial, el Decreto Ley 10.067/83 establece que el/la juez/a interviene:

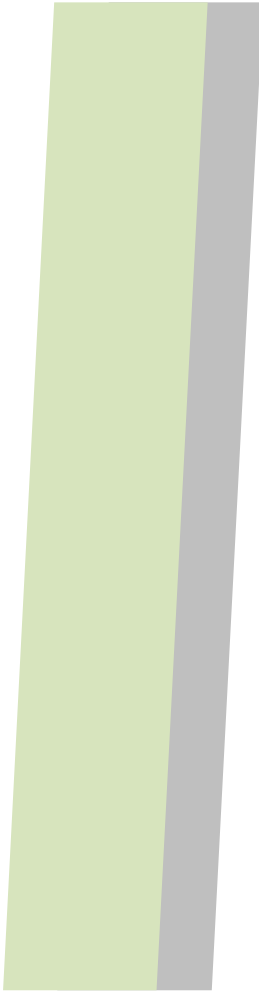

b) Cuando la salud, seguridad, educación y moralidad de menores de edad se hallare comprendida por actos de inconducta, contravenciones, o delitos de sus padres, tutores, guardadores, o terceros; por infracción a las disposiciones legales referentes a la instrucción y al trabajo; cuando por razones de orfandad o cualquier otra causa, estuviesen material o moralmente abandonados, o corrieren peligro de estarlo, para brindar protección y amparo, procurar educación moral e intelectual al menor y para sancionar, en su caso, la inconducta de sus padres, tutores guardadores o terceros [...];

b) Para disponer todas aquellas medidas que sean necesarias para otorgar certeza los atributos de la personalidad de los menores bajo su amparo, y lograr su más completa asistencia [...];

c) Cuando actos reiterados de inconducta de menores de edad obliguen a sus padres, tutores o guardadores, a recurrir a la autoridad para corregir, orientar y educar al menor (Título II, capítulo II, artículo 10).

El juzgado -con citación del asesor- oirá al menor y adoptará las medidas pertinentes previstas por el artículo 32. Producida la prueba, el/la juez/a resolverá «en forma fundada y de acuerdo a su convicción sincera, acerca de: a) El destino del menor conforme con las medidas de seguridad y amparo regladas en las leyes nacionales y provinciales de la materia; b) Las sanciones que corresponda imponer a los padres, tutores o guardadores» (Título II, capítulo V, artículo 42).

El cese de la intervención se podrá producir cuando el/la juez/a -mediante «resolución fundada»- determine que desaparecieron «los motivos que originaron la actuación del tribunal [y] el menor se encontrare en poder de sus progenitores, y debidamente atendido» (Título II, capítulo V, artículo 46). 


\section{Contravenciones}

En lo atinente al régimen de contravenciones en perjuicio de menores de edad, interesa delimitar las que contemplan: incitar a la vagancia; incitar u obligar a mendigar en forma pública o encubierta o a acompañar en tales prácticas; utilizar al menor para la recolección o remoción de desperdicios en lugares públicos o para que acompañe tal actividad (Título III, capítulo I, artículo 58). También, vender, facilitar o exhibir a menores de 16 años, «libros, revistas, imágenes u objetos contrarios a la moral y a las buenas costumbres» (Título III, capítulo I, artículo 59).

A su vez, se establecen sanciones a quienes «sin ser padre, tutor o representante de asociaciones privadas, se hiciera cargo de un menor, sin denunciar el hecho dentro de los cinco (5) días ante las autoridades que corresponda» (Título III, capítulo I, artículo 62). También, «a los padres, tutores o guardadores de un menor en edad escolar, que no proveyesen a su instrucción o admitiesen su abandono sin causa justificada [y a] los Directores de los establecimientos de enseñanza primaria que no denuncien al Juzgado tales situaciones» (Título III, capítulo I, artículo 64). Del mismo modo, se sancionará a «los Directores, Jefes de Servicios Hospitalarios y profesionales que no dieren aviso al Juzgado de Menores dentro de las veinticuatro (24) horas de la atención de una menor en estado de gravidez, que haya concurrido en busca de atención sin sus representantes legales» (Título III, capítulo I, artículo 65).

En lo referente a las disposiciones generales, se establece que «la Subsecretaría del Menor y la Familia, las Municipalidades y la Policía de la Provincia son auxiliares de los Juzgados de Menores, para el cumplimiento de las medidas que los Jueces les encomienden» (Título IV, capítulo único, artículo 91) y será dicha Subsecretaría la «encargada de planificar y ejecutar [...] la política general de la minoridad, tanto en sus aspectos preventivos cuanto en los relativos a la formación y reeducación de los menores internados en establecimientos de su dependencia o contralor» (Título V, capítulo I, artículo 92). 


\section{Internación}

Tanto en establecimientos provinciales, como municipales o privados, la internación de menores «será dispuesta únicamente por los Jueces salvo motivo de urgencia, en cuyo caso la Subsecretaría del Menor y la Familia o las autoridades respectivas podrán efectuarla con carácter preventivo, dando inmediata intervención al Juzgado competente» (Título V, capítulo IV, artículo 100).

El menor internado «quedará bajo la tutela de la Subsecretaría del Menor y la Familia [...]. Sin perjuicio de ello, el Director del Establecimiento es asimismo responsable directo de la vigilancia, integridad física, educación, capacitación laboral y formación moral del menor confiado a su custodia. Se procurará en lo posible que la enseñanza primaria y secundaria se realice en establecimientos o escuelas comunes, fuera de los institutos de internación» (Título V, capítulo IV, artículo 101).

Respecto a las disposiciones edilicias y arquitectónicas, se establece que la Subsecretaría del Menor y la Familia, deberá instalar y atender:

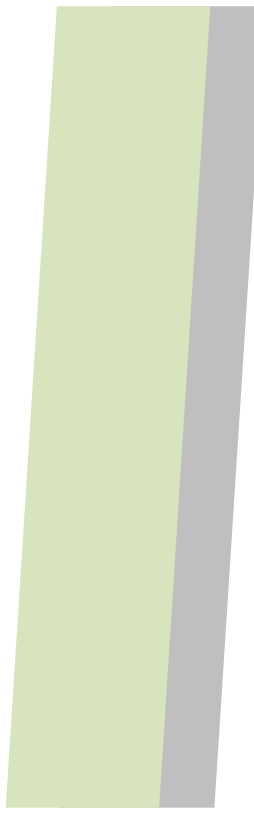

a) Institutos de Seguridad y tratamiento para menores que hayan incurrido en hechos que la ley califica como delitos, en número y ubicación adecuados a las necesidades de los Juzgados.

b) Establecimientos de régimen cerrado para menores de uno u otro sexo con graves problemas de conducta.

c) Institutos de Internación cuya tipificación según sexo, edad y otras características, será establecida por vía reglamentaria.

d) Hogares estudiantiles para nivel secundario que estén estructurados sobre la base de la convivencia con el medio comunitario y la autodisciplina, teniendo como objetivo que el menor asistencial adolescente curse estos estudios (Título V, capítulo IV, artículo 102).

Para la atención de los dos primeros, la Subsecretaría «podrá convenir con el Servicio Penitenciario de la Provincia» y los servicios deberán ser prestados «conforme a un reglamento específico» (Título V, capítulo IV, artículo 103). 


\section{Elementos que dispone el Sistema de Promoción y Protección de los derechos de niños, niñas y adolescentes (SPPD)}

En 2005 se sancionó la Ley Nacional 26.061 de Protección Integral de los Derechos de las Niñas, Niños y Adolescentes, a través de la cual se adecuó la legislación interna a los postulados de la Convención sobre los Derechos del Niño (1989). Un año antes, en diciembre de 2004, en la provincia de Buenos Aires se había sancionado la Ley 13.298 de Promoción y Protección de los Derechos de Niños, Niñas y Adolescentes, y el Decreto Reglamentario 300/05, que si bien derogó el Decreto Ley 10.067/83 del Patronato de Menores de la última Dictadura cívico militar, fue suspendida hasta abril de 2007.

En cuanto al ámbito penal, en diciembre de 2006 se sancionó la Ley 13.634 del Fuero de Familia y del Fuero Penal del Niño, promulgada en enero de 2007 a través del Decreto 44.

Estas normativas se proponen regular los derechos de los/as niños/as y adolescentes en dos estamentos diferenciales: por un lado aquellos/as que se encuentran en situación de vulneración de derechos; por otro, aquellos/as que han transgredido la ley penal.

En los principios generales, se indica que la finalidad de la Ley 13.298 es «la promoción y protección integral de los derechos de los niños, garantizando el disfrute pleno, efectivo y permanente de los derechos y garantías reconocidos en el ordenamiento vigente (Título I, capítulo único, artículo 1). Y se establece que el objetivo principal, será su contención en el núcleo familiar, a través de la implementación de planes y programas de prevención, asistencia e inserción social» (Título l, capítulo único, artículo 3).

En el Decreto Reglamentario 300/05, se indica que además de los padres, el núcleo familiar incluye «la familia extensa y otros miembros de la comunidad que representen para el niño vínculos significativos en su desarrollo y protección» (Anexo I, artículo 3).

En relación con el interés superior del niño, la Ley lo entiende como «la máxima satisfacción integral y simultánea de sus derechos en un marco de libertad, respeto y dignidad, para lograr el desenvolvimiento de sus potencialidades y el despliegue integral y armónico de su personalidad» (Título I, capítulo único, artículo 4). 
Los elementos que se deben apreciar para determinar dicho interés comprenden:

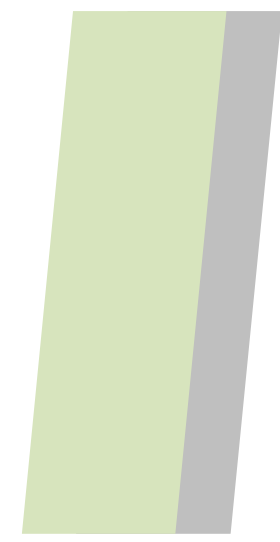

a) La condición específica de los niños como sujetos de derecho.

b) La opinión de los niños de acuerdo a su desarrollo psicofísico.

c) La necesidad de equilibrio entre los derechos y garantías de los niños, y sus deberes.

d) La necesidad de equilibrio entre los derechos y garantías de los niños, y las exigencias de una sociedad justa y democrática (Título l, capítulo único, artículo 4).

Su aplicación será prioritaria cuando existan conflictos entre tales derechos e intereses respecto a otros igualmente legítimos. De allí que sea función del Estado provincial promover la remoción de los obstáculos que limiten la igualdad y la libertad y/o impidan el pleno desarrollo y la efectiva participación en la comunidad de niños/as y adolescentes (Título I, capítulo único, artículo 5). El Estado debe garantizar, asimismo, la prioridad en la realización de sus derechos sin discriminación (Título I, capítulo único, artículo 6).

Tal garantía del Estado, comprende:

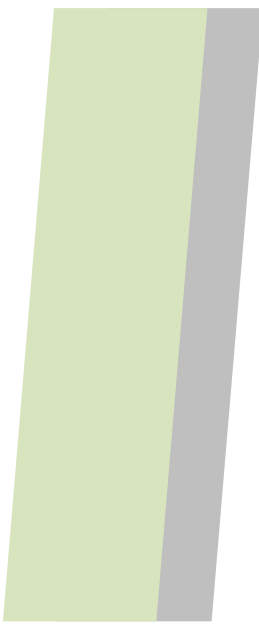

Protección y auxilio a la familia y comunidad de origen en el ejercicio de los deberes y derechos con relación a los niños.

Asignación privilegiada de recursos públicos en las áreas relacionadas con la promoción y protección de la niñez.

Preferencia en la formulación y ejecución de las políticas sociales públicas.

Preferencia de atención en los servicios esenciales.

Promoción de la formación de redes sociales que contribuyan a optimizar los recursos existentes (Título I, capítulo único, artículo 7).

La ley indica que «la ausencia o carencia de recursos materiales del padre, madre, tutor o guardador», no deben producir la separación del niño/a o adolescente «de su grupo familiar o su institucionalización» (Título I, capítulo único, artículo 9). Según el Decreto 
Reglamentario 300/05, tales situaciones deben ser entendidas como «circunstancias en las cuales el niño por sí o en su contexto familiar sufre la vulneración de derechos sociales, económicos y culturales, que impiden en la práctica asegurar su crianza, educación, atención sanitaria, y un ambiente sano». En cualquiera de ellas, «la respuesta estatal deberá dirigirse al sostenimiento del grupo familiar [...] y serán abordados en forma conjunta entre las áreas de competencia de los distintos Ministerios, en el marco de la dinámica que resuelva la Comisión Interministerial, creada por el artículo 23 de la Ley que se reglamenta» (artículo 9).

El SPPID comprende:

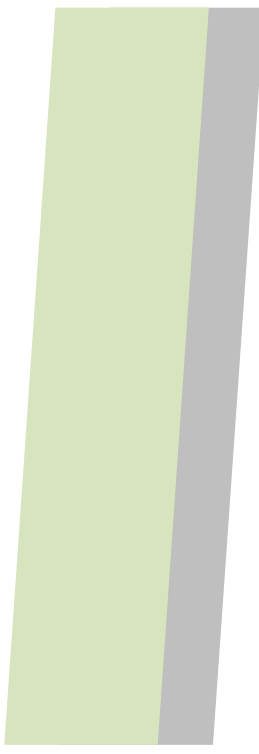

un conjunto de organismos, entidades y servicios que formulan, coordinan, orientan, supervisan, ejecutan y controlan las políticas, programas y acciones, en el ámbito provincial y municipal, destinados a promover, prevenir, asistir, proteger, resguardar y restablecer los derechos de los niños, así como establecer los medios a través de los cuales se asegure el efectivo goce de los derechos y garantías reconocidos en la Constitución Nacional, la Constitución de la Provincia de Buenos Aires, la Convención sobre los Derechos del Niño, y demás tratados de Derechos Humanos ratificados por el Estado Argentino.

El Sistema funciona a través de acciones intersectoriales desarrolladas por entes del sector público, de carácter central o desconcentrado, y por entes del sector privado (Título II, capítulo I, artículo 14).

Para que tales objetivos se lleven a cabo, el SPPID «debe contar con los siguientes medios: a) políticas y programas de promoción y protección de derechos; b) organismos administrativos y judiciales; c) recursos económicos; d) procedimiento; e) medidas de protección de derechos» (Título II, capítulo I, artículo 14).

\section{Servicios locales y zonales}

EI SPPID instituye el establecimiento -en la comunidad de permanencia y pertenenciade dispositivos territoriales como los Servicios Locales de Protección de Derechos. Estos órganos, definidos como unidades técnico operativas, tendrán por función 
[...] facilitar que el niño que tenga amenazados o violados sus derechos, pueda acceder a los programas y planes disponibles en su comunidad. En los casos en que la problemática presentada admita una solución rápida, y que se pueda efectivizar con recursos propios, la ayuda se podrá efectuar en forma directa. Les corresponderá a estos servicios buscar la alternativa que evite la separación del niño de su familia o de las personas encargadas de su cuidado personal, aportando directamente las soluciones apropiadas para superar la situación que amenaza con provocar la separación (Título II, capítulo II, artículo 18).

Al respecto, el Decreto Reglamentario 300/05 instituyó -en cada región del Ministerio de Desarrollo Humano- la creación de Servicios Zonales de Promoción y Protección de Derechos del Niño, que no están previstos en la Ley, cuya competencia territorial será asignada por el Ministerio (artículo 18.4). Tales Servicios Zonales son integrados por equipos técnicos profesionales interdisciplinarios con las siguientes funciones principales: coordinar el funcionamiento de los Servicios Locales de Protección de Derechos de su zona; funcionar como instancia superadora en la resolución de conflictos agotada la instancia local de resolución; actuar en aquellos municipios en los que no existan Servicios Locales e informar al Ministerio de Desarrollo Humano sobre la actuación de los Servicios Locales (artículo 18.4).

En que lo que respecta a su composición, la Ley 13.298 establece que los Servicios Locales deberán contar «con un equipo técnico - profesional con especialización en la temática, integrado como mínimo por: a) Un psicólogo; b) Un abogado; c) Un trabajador social y d) Un médico» (Título II, capítulo II, artículo 20).

De este modo, las funciones de los Servicios Locales de Protección son:

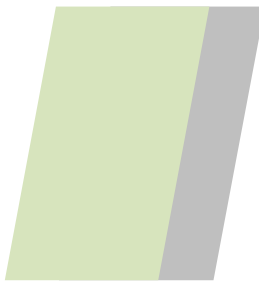

a) Ejecutar los programas, planes, servicios y toda otra acción que tienda aprevenir, asistir, proteger, y/o restablecer los derechos del niño.

b) Recibir denuncias e intervenir de oficio ante el conocimiento de la posible existencia de violación o amenaza en el ejercicio de los derechos del niño. 
c) Propiciar y ejecutar alternativas tendientes a evitar la separación del niño de su familia y/o guardadores y/o de quien tenga a su cargo su cuidado o atención teniendo como mira el interés superior del niño.

d) Participar activamente en los procesos de declaración de la situación de adoptabilidad y de adopción, y colaborar en el trámite de guarda con fines de adopción, con los alcances establecidos en la ley respectiva (Título II, capítulo II, artículo 19).

\section{Programas y medidas de protección}

La Ley 13.298/05 diferencia los programas de promoción y de protección de las medidas de protección, siendo la Autoridad de Aplicación quien debe diseñar, subsidiar y ejecutar dichos programas, cuya reglamentación delimita y diferencia los programas de promoción de derechos de los de protección.

Como se indica en el Decreto Reglamentario 300/05, mientras que los programas de promoción están dirigidos a todos los/as niños/as, adolescentes y familias, y tienen como principal objetivo «prevenir la amenaza o violación de derechos» (artículo 29.1), los de protección están diseñados para «dar apoyo y ayuda específica a aquellos niños y familias que atraviesan situaciones críticas, a nivel familiar, social, jurídico o económico», y tienen como eje organizador «el fortalecimiento de la autonomía de los responsables adultos para superar las adversidades y ser activos protectores de los derechos de los niños» (artículo 29.2).

En la ley, las medidas de protección son definidas como aquellas «que disponen los Servicios Locales de Promoción y Protección de Derechos cuando se produce, en perjuicio de uno o varios niños, la amenaza o violación de sus derechos o garantías, con el objeto de preservarlos o restituirlos. La amenaza o violación a que se refiere este artículo puede provenir de la acción u omisión de personas físicas o jurídicas» (Título II, capítulo IV, artículo 32). Tales medidas, 
son limitadas en el tiempo, se mantienen mientras persistan las causas que dieron origen a la amenaza o violación de derechos o garantías, y deben ser revisadas periódicamente de acuerdo a su naturaleza.

En ningún caso una medida de protección de derechos podrá significar la privación de libertad ambulatoria del niño. El cese de la medida proteccional por decisión unilateral del niño, no podrá ser sancionado bajo ningún criterio o concepto. En consecuencia, queda expresamente prohibido disponer medidas de coerción contra el niño por razón del abandono del programa (Título II, capítulo IV, artículo 33).

Respecto de tales medidas, se establece un orden de prioridad: en primer lugar, se ubican aquellas que «tengan por finalidad la preservación y el fortalecimiento de los vínculos familiares con relación a todos los niños» (Título II, capítulo IV, artículo 34). En los casos en los que causa sea la amenaza o violación de derechos como consecuencia de necesidades básicas insatisfechas, carencias o dificultades materiales, laborales o de vivienda, las medidas de protección son los programas que briden tales recursos, «para el mantenimiento y fortalecimiento de los vínculos familiares» (Título II, capítulo IV, artículo 34).

Entre las medidas de protección de derechos que podrán ser adoptadas, «la permanencia temporal en ámbitos familiares alternativos o entidades de atención social y/o de salud» es de «carácter excepcional y provisional, con comunicación de lo resuelto, dentro de las veinticuatro horas, al Asesor de Incapaces y al Juez de Familia competente. El Juez de Familia deberá resolver la legalidad de la medida» (Título II, capítulo IV, artículo 35).

Al respecto, el Decreto Reglamentario 300/05 dispone que la medida de abrigo tiene por objeto «brindarle al niño un ámbito alternativo al grupo de convivencia cuando en este se encuentren amenazados o vulnerados efectivamente sus derechos y garantías hasta tanto se evalúe la implementación de otras medidas tendientes a preservarlos o restituirlos. Antes de tomar la medida y de acuerdo al derecho a ser escuchado, deberá tenerse en cuenta los deseos y consideraciones del niño» (artículo 35.1). A su vez, se establece que los motivos graves que «por sí mismos autorizan la separación del niño de su grupo familiar, están dados por la letra y espíritu de los artículos $9^{\circ}$ y $19^{\circ}$ y concordantes a la Convención de los Derechos del Niño» (artículo 35.2). 
En lo que refiere a las prácticas institucionales, el Decreto Reglamentario 300/05 dicta:

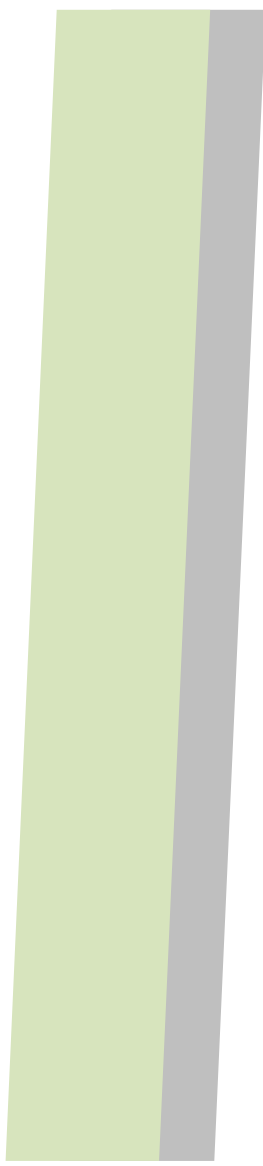

Toda institución educativa social o de salud, sea pública o privada, que desarrolle programas de atención a los niños bajo la modalidad convivencial y/o internativa deberá efectuar una revisión de los modelos y prácticas institucionales, a efectos de adecuarlos a los principios y disposiciones de la Convención sobre los Derechos del Niño. [...]

Cuando a solicitud expresa de los padres o representantes legales un niño haya ingresado en un hogar convivencial bajo cualquiera de las modalidades, la institución está obligada a comunicar al Servicio Local de Protección de Derechos el ingreso y las causas del mismo, en plazo de 72 horas. [...]

En todos los casos, la institución deberá trabajar con la familia del niño a fin de procurarle la orientación y condiciones necesarias para abordar las dificultades que ocasionaron el ingreso y facilitar el retorno del niño a su grupo familiar.

La institución deberá promover y facilitar la comunicación del niño con su familia, excepto expresa disposición judicial en contrario. Bajo ningún concepto podrán disponerse sanciones que impliquen la limitación del contacto familiar del niño (artículo 31.2).

La Resolución 166 del Ministerio de Desarrollo Humano, promulgada en febrero de 2007, establece que la desconcentración de objetivos y acciones de la Subsecretaría de Promoción y Protección de Derechos del Niño, relativas al Sistema de Promoción y Protección de Derechos del Niño, se llevará a cabo a través de los Servicios Zonales de Promoción y Protección de Derechos», que dependen de la Dirección Provincial de Estrategias de Intervención Territorial (artículo 3), la creación de dichos Servicios (Artículo 4) y la creación de Casas de Abrigo (artículo 5).

En síntesis, y de acuerdo con los elementos normativos e institucionales, los/as psicólogos/as que integran los equipos técnicos de los establecimientos de la autoridad de aplicación del SPPID intervienen con niños, niñas y adolescentes que, por encontrarse en una situación de amenaza o de vulneración efectiva de derechos, fueron alojados en un establecimiento para ser protegidos mediante una medida de abrigo institucional. 


\section{Elementos que dispone el Fuero}

de Responsabilidad Penal Juvenil

En diciembre de 2006, se sancionó la Ley 13.634 de Fuero de Familia y del Fuero Penal del Niño que consagró un procedimiento respetuoso de garantías procesales mínimas. El establecimiento de la figura del Defensor Oficial especializado en el fuero de responsabilidad penal juvenil significó el acceso al derecho de defensa que, en el viejo sistema tutelar, no existía. Además, otorgó los principios del debido proceso al incorporar al fiscal, al defensor, a los nuevos jueces de garantías y juzgados de responsabilidad penal juvenil, y a las Cámaras de apelación como revisoras del proceso y de las sentencias. A los fines de la presente tesis, nos detendremos en aquellos artículos de la Ley que delimitan el fuero de Responsabilidad Penal Juvenil.

Respecto a las disposiciones generales del proceso penal, en la normativa se indica que el mencionado régimen «es aplicable a todo niño no punible, según la legislación nacional, imputado de delito en jurisdicción territorial de la provincia» (Título III, capítulo II, artículo 32). La legislación nacional referida son los Decretos Ley Nacional 22.278/80 y 22.803/83, cuyos elementos normativos fueron desplegados en el presente, al desarrollar los elementos normativos dispuestos al respecto por el Patronato del Menor.

Entre los principios rectores para la interpretación y la aplicación de las normas del proceso penal se encuentran: «la protección integral de los derechos del niño, [...], la reintegración en su familia de origen y en la comunidad, la mínima intervención, [...] y que el niño asuma una actitud constructiva y responsable ante la sociedad, adquiriendo respeto por los derechos humanos y las libertades fundamentales de todas las personas» (Título III, capítulo II, artículo 33).

En cuanto al proceso penal, se establece que el niño que se encuentra sujeto al mismo «gozará de todos los derechos y garantías reconocidos a los mayores» y se delimita que, en especial, tendrá derecho a que «la privación de libertad sea solo una medida de último recurso y por el período más breve posible» (Título III, capítulo II, artículo 36). 
Las medidas cautelares que pueden imponerse a un/a joven imputado/a, a través del debido proceso, comprenden:

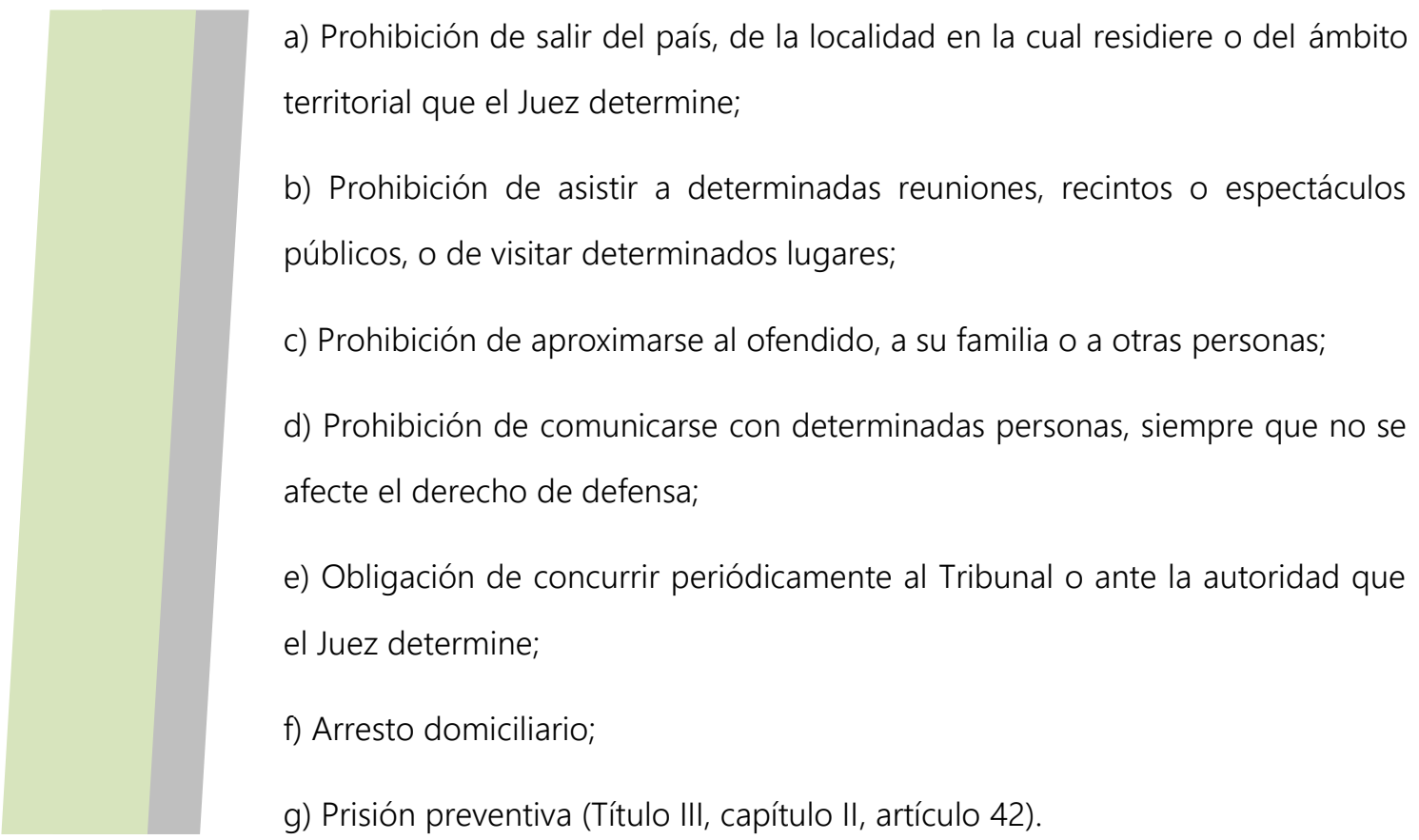

En el artículo 43 se delimitan cuáles son las causas graves ante las cuales el juez podrá decretar excepcionalmente la prisión preventiva de un niño al finalizar la audiencia y a requerimiento del agente fiscal.

En lo referente al juicio, se establece que, «concluido el debate, el juez o en su caso el Tribunal de la Responsabilidad Penal Juvenil, con base en los hechos probados», resolverá: 1) declarar absuelto al niño; 2) declarar penalmente responsable al niño y aplicarle una o varias de las medidas judiciales de integración social (Título III, capítulo IV, artículo 56).

Las medidas que pueden ser aplicadas comprenden: «1) orientación y apoyo sociofamiliar; 2) obligación de reparar el daño; 3) prestación de Servicios a la Comunidad; 4) asistencia especializada; 5) inserción escolar; 6) inclusión prioritaria en los programas estatales de reinserción social; 7) derivación a los Servicios Locales de Protección de Derechos; 8) imposición de reglas de conducta» (Título III, capítulo VIII, artículo 68). Enumeradas tales medidas y para el cumplimiento de las específicas a esta última, 
se delimitan las incumbencias de los operadores especializados (Título III, capítulo VIII, artículo 78). Estos últimos son quienes integran los equipos técnicos de los servicios de promoción y protección de derechos (servicios locales, Centros de Referencias, ONG), que efectúan los programas de cumplimiento de medidas alternativas a la privación de libertad.

Posteriormente, se definen: la libertad asistida (artículo 79), el régimen de semi-libertad (artículo 80) y la privación de la libertad «que deberá ser cumplida en establecimientos exclusivos y especializados para niños» (artículo 81). Estableciéndose en el artículo 83 los derechos del niño privado de la libertad.

\section{El Sistema de Responsabilidad Penal Juvenil}

En febrero de 2007, mediante el Decreto 151 se creó en el ámbito de la provincia de Buenos Aires el Sistema de Responsabilidad Penal Juvenil (SRPJ). Dicho sistema está integrado

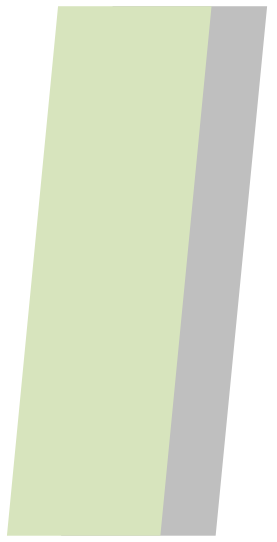

por un conjunto de organismos, entidades y servicios que, en el ámbito provincial y municipal, formularán, coordinarán, supervisarán, ejecutarán y controlarán las políticas, programas y medidas, destinados a promover, implementar y coordinar acciones de prevención del delito juvenil. Del mismo modo, asegurar los derechos y garantías de los jóvenes infractores a la ley penal y generar ámbitos para la ejecución de medidas socioeducativas que, centradas en responsabilidad del joven infractor, posibiliten su real inserción en su comunidad de origen (artículo 2).

El artículo 7 de este Decreto es al SRPJ lo que el artículo 31.2 del Decreto Reglamentario 300/05 al SPPID: «Toda institución, sea pública o privada, que desarrolle programas de atención a niños y jóvenes en conflicto con la ley penal, deberá efectuar una revisión de los modelos y prácticas institucionales, a efectos de adecuarlos a los principios y disposiciones de la Convención sobre los Derechos del Niño» (artículo 7). 
La Resolución Ministerial 166/07 definió que la desconcentración de objetivos y de acciones de la Subsecretaria de PPD (relativas al SRPJ) se efectuará a través de los Centros de Referencia (artículo 9), que dependerán de la Dirección Tutelar.

A la vez que la Resolución 172/07 instituyó como «imperioso adecuar la normativa interna, la organización y prácticas institucionales, en relación al cumplimiento de medidas judiciales cautelares o sancionatorias ordenadas por los tribunales competentes en el marco del proceso penal seguido a personas menores de edad» (considerandos). Por ello, la Subsecretaría debe «redefinir sus misiones y funciones tutelares, adecuando sus establecimientos, programas y prácticas para el cumplimiento de los objetivos relativos al SRPJ (artículo 1); comprometiendo a los establecimientos dependientes de la Dirección Provincial Tutelar a adecuar sus proyectos institucionales (artículo 2).

En este sentido, se delinearon los objetivos y las acciones de las dependencias del SRPJ (Anexo I), definiéndose aquellos que debe cumplimentar la Subsecretaría, las acciones de la otrora Dirección Provincial Tutelar -denominada Unidad de Coordinación del Sistema de Responsabilidad Penal Juvenil- y las acciones que debe efectuar la Dirección de Medidas Alternativas.

En lo que respecta a las instituciones y a los establecimientos para el cumplimiento de medidas judiciales, estos son tipificadas como:

a) Centros de Referencia: su objeto y finalidad es la atención ambulatoria, «para el cumplimiento de medidas cautelares o sancionatorias alternativas a la restricción o privación de la libertad ambulatoria, ordenadas por los tribunales competentes»; y cuya función ser evaluar, atender y/o derivar a los/as jóvenes a programas desconcentrados en municipios;

b) Centros de Recepción: se caracterizan por ser «establecimientos de régimen cerrado para el cumplimiento de la detención y de medidas preventivas de privación de la libertad ordenadas por los Tribunales»;

c) Centros de Contención: se caracteriza por ser «establecimientos de régimen abierto o régimen de semilibertad»; 
d) Centros Cerrados: son «establecimientos de régimen cerrado, para el cumplimiento de medidas privativas de la libertad ordenadas por la Justicia» (Anexo II).

Finalmente, en el Anexo III, se delinean los procedimientos para el ingreso de los/as jóvenes a los distintos establecimientos. En tales establecimientos hay equipos técnicos de profesionales que intervienen para que en el ingreso se cumplan las medidas de Responsabilidad Penal emanadas del debido proceso.

En este sentido, es visible que los elementos que componen y disponen el SRPJ determinan el tipo de población alojada en los establecimientos del Organismo de la Niñez y Adolescencia de la provincia de Buenos Aires, para quienes y sobre quienes los/as psicólogos/as diseñan e implementan dispositivos de intervención que en las páginas siguientes nos proponemos caracterizar. 


\section{Normativas}

Decreto Ministerial 151 (2007).

Boletín Oficial de la Provincia de Buenos Aires. La Plata, 22/3/2007.

Decreto Provincial 44 (2007).

Boletín Oficial de la Provincia de Buenos Aires. La Plata, 2/2/2007.

Decreto Reglamentario 300 (2005). Decreto Reglamentario de la Ley 13.298. Ley de Promoción y Protección Integral de los Derechos de los Niños. Boletín Oficial de la Provincia de Buenos Aires. La Plata, 23/3/2005.

Decreto Ley Nacional 22.278 (1980). Régimen Penal de la Minoridad. Boletín Oficial de la República Argentina. Buenos Aires, 28/8/1980.

Decreto Ley Provincial 10.067 (1983). Patronato de Menores. Boletín Oficial de la Provincia de Buenos Aires. La Plata, 9/12/1983.

Decreto Ley Nacional 22.803 (1983). Ley N²2.278 - Modificación. Boletín Oficial de la República Argentina. Buenos Aires, 9/5/1983.

Ley Nacional 23.742 (1989). Modifícase la Ley № 22.278.

Boletín Oficial de la República Argentina. Buenos Aires, 25/10/1989.

Ley Nacional 26.061 (2005). Protección Integral de los Derechos de las Niñas, Niños y Adolescentes.

Boletín Oficial de la República Argentina. Buenos Aires, 26/10/2005.

Ley Provincial 13.298 (2005). Promoción y Protección Integral de los Derechos de los Niños.

Boletín Oficial de la Provincia de Buenos Aires. La Plata, 27/1/2005.

Ley Provincial 13.634 (2007). Principios Generales del Fuero de Familia y del Fuero Penal del Niño.

Boletín Oficial de la Provincia de Buenos Aires. La Plata, 2/2/2007.

Naciones Unidas (1989). Convención Internacional sobre los Derechos del Niño. Recuperado de

https://www.ohchr.org/SP/Professionallnterest/Pages/CRC.aspx

Resolución Ministerial 166 (2007).

Boletín Oficial de la Provincia de Buenos Aires. La Plata, 3/7/2007.

Resolución Ministerial 172 (2007).

Boletín Oficial de la Provincia de Buenos Aires. La Plata, 4/4/2007. 


\title{
Parte II
}

\section{CAPÍTULO 6}

\section{Los dispositivos de intervención}

\author{
Institutos penales \\ Hogares convivenciales \\ Centros de Responsabilidad Penal Juvenil \\ Hogares de Protección de Derechos
}

\begin{abstract}
A partir del análisis de las entrevistas, ${ }^{24}$ se recuperan en este capítulo los principales dispositivos de intervención -con quiénes, en qué ámbitos y para qué- diseñados e implementados por los/as psicólogos/as en los establecimientos del actual Organismo de la Niñez y Adolescencia de la provincia de Buenos Aires, entre los años 2000-2015.
\end{abstract}

En línea con el criterio utilizado en el apartado anterior, las descripciones se ordenan según el tipo de establecimiento (institutos penales, hogares convivenciales, centros de responsabilidad penal juvenil y hogares de protección de derechos) y se organizan de acuerdo a los siguientes criterios: tipo de dispositivo implementado (grupales, individuales, singulares), propósitos que lo orientan y con quiénes se interviene (niño/as y adolescentes, familias / referentes vinculares).

Tal como se despliega en las siguientes páginas, para el trabajo con los/as niños/as y con los/as adolescentes los dispositivos de entrevista individual son los menos resistidos así como los más demandados por los distintos agentes institucionales, mientras que los dispositivos grupales concentran mayores grados de resistencias y de boicot. En todos los casos, para potenciar la visibilidad de estos y de otros dispositivos en acción se recurrió a la transcripción de escenas experienciadas, con la descripción detallada de los diálogos y los efectos producidos.

24 Tanto en este capítulo como en el siguiente, luego de cada declaración se incluye una referencia sobre el/la entrevistado/a que luego se amplía en el apartado «Fuentes», ubicado al final de cada apartado. 
En el caso de las familias y/o referentes vinculares, los dispositivos implementados no muestran variaciones destacables entre los tiempos normativos: en los establecimientos de cumplimiento de medidas de responsabilidad penal (otrora penales), las entrevistas se efectúan en el centro donde el/la joven cumple la medida; en los hogares de protección de derechos (otrora asistenciales), las distancias geográficas entre el territorio de pertenencia y de referencia, y los establecimientos donde son alojados/as obstaculiza la implementación de dispositivos que resultan centrales en las nuevas normativas.

\section{Institutos penales}

En el periodo en el cual estaba en vigencia el Decreto Ley 10.067/83 del Patronato de Menores, los/as psicólogos/as que integraban los equipos técnicos de los institutos penales implementaban dispositivos de intervención tanto grupales (con los/as jóvenes y sus familias) como individuales.

\section{Dispositivos grupales}

Herramientas psicodramáticas y espacio multifamiliar

Respecto de los dispositivos grupales, una de las psicólogas describe la utilización de herramientas psicodramáticas y entre sus efectos señala:

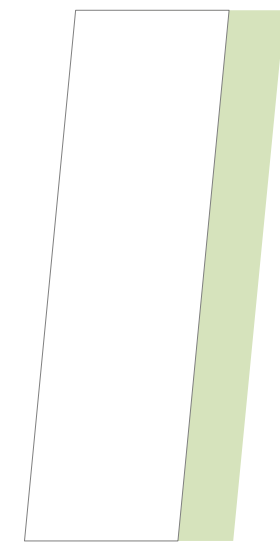

Las chicas laburaban mucho más lo personal, se animaban mucho más cuando se encontraban con esas otras, que transitaban en este espacio lo mismo que transitaban ellas. Y en ese encuentro era increíble cómo salían cosas que en las entrevistas individuales no. Una vez laburamos todo el recorrido que hacían las pibas desde que eran detenidas hasta que llegaban. (...) Lo interesante de eso era cómo iba creciendo la violencia que la chica sentía desde la detención hasta el ingreso en la institución. Pasando por tribunales, que en esa época eran Tribunales de Menores (E1, Psica., 2016). 
La psicóloga también describe los efectos producidos en el equipo que lo coordinaba:

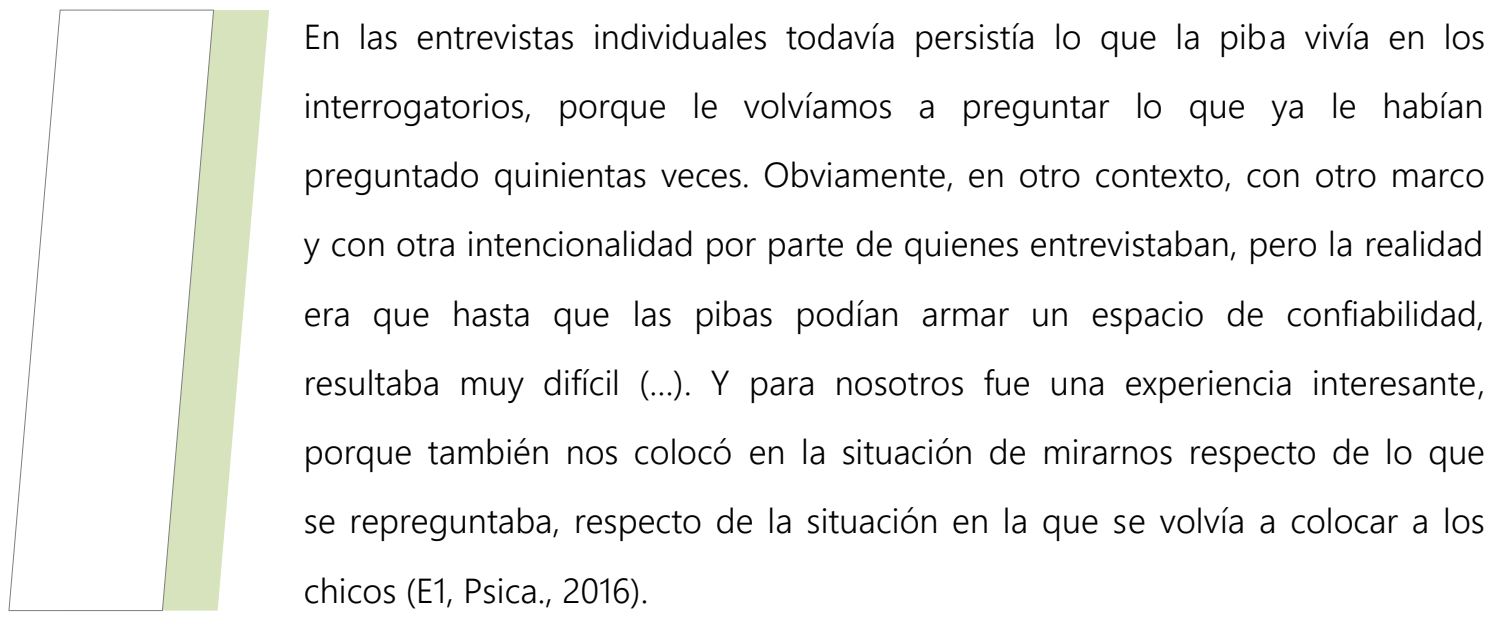

Para la entrevistada, la decisión de utilizar un dispositivo grupal en una institución penal se vincula con implementar un dispositivo que posibilite el encuentro con otros/as y con la palabra. En su experiencia, esto permitió «que se sintieran contenidas y apoyadas por sus pares. Entonces, todo era mucho más fácil. Y sobre todo lo dramático, porque además nosotras pensábamos: «No se van a animar». Pero ¿sabes qué?, salía todo».

En otro instituto penal en el que se implementaron dispositivos grupales con los jóvenes, la entrevistada señala:

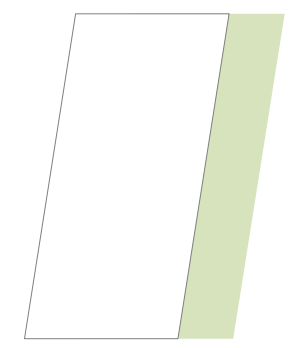

Era muy enriquecedor, ¿viste? Para los pibes, para nosotros y para la institución, porque también se trabajaban cuestiones vinculadas a la violencia institucional, a la vida sexual de los pibes, que eran muy resistidas dentro de la institución, entonces se laburaba mucho con el personal esto, y la verdad que fue muy enriquecedor (E1, Psica., 2016).

Respecto a este dispositivo grupal, se indica que también posibilitaba trabajar con el resto del personal que formaba parte del establecimiento ciertas dimensiones del funcionamiento institucional. 
En un instituto penal de máxima seguridad se implementó un dispositivo de tipo asambleario con las familias de los/as jóvenes. Este recurso, denominado «espacio multifamiliar», era coordinado por un psicólogo y por un trabajador social y su propósito era «alojar a las familias y acompañarlas en el proceso del chico». Tenía una regularidad mensual y se llevaba a cabo el día de visita en la institución.

Ahora bien, la implementación de tales dispositivos grupales dependía de lo que los/as entrevistados/as denominan «momentos institucionales». Con esta expresión refieren a que «a veces, era indicado, conveniente y necesario; otras veces, no», y diferencian tales momentos de acuerdo a la cuestión de «la seguridad» («había directores a los que juntar a más de un pibe en un ámbito les daba mucho miedo») y a la situación, ya que había momentos en los que no estaba indicado («porque la institución estaba pasando por un momento "heavy", como decían los chicos»).

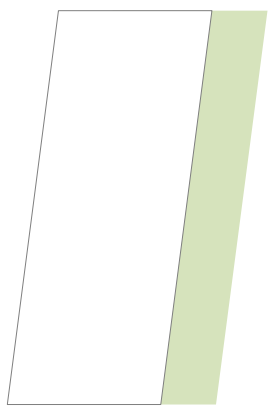

A veces, también teníamos más aceptación de la que pensábamos. Uno también tiene un prejuicio respecto de que la institución lo va a resistir, que la gente no lo va a entender, y cuando empezás a abrir el juego y se empiezan a ver los resultados, hasta después te lo pedían. «¿Qué pasa que no hay grupos esta semana?». La misma gente que en algún momento lo había resistido veía que pasaban otras cosas que si eso no estaba no sucedían (E1, Psica., 2016).

En otra de las experiencias, el dispositivo grupal con los/as chicos/as y con sus familias se pudo sostener «durante poco tiempo y con muchas resistencias, con mucho boicot», porque «no siempre las instituciones lo hacían posible».

\section{Dispositivo individual}

Entrevistas sin encuadre fijo

Los/as psicólogos/as entrevistados/as también implementaban entrevistas individuales. Para algunos/as, era necesario contar con un espacio físico en el establecimiento, establecer un encuadre con días y horarios fijos, a la vez que enunciaban la regla del secreto profesional. Como señala una de las psicólogas, el propósito que orientaba tal 
disposición de elementos era delimitar un «espacio de escucha distinto y construir una relación mínima, una transferencia, que a veces se daba y otras no. Generalmente, se daba con el tiempo, porque el chico te tiene que conocer».

Otros/as profesionales, en cambio, no efectuaban entrevistas individuales con un encuadre fijo, pautado en días y en horarios, ni utilizaban un espacio físico determinado. Las entrevistas eran implementadas fuera del establecimiento o en el patio, durante el almuerzo o en algún espacio-lugar del cotidiano institucional.

Para poder salir con los/as jóvenes del establecimiento contaban con el permiso de los/as jueces/zas que autorizaban tales movimientos.

¿Cuándo y para qué tenían este tipo de entrevistas?

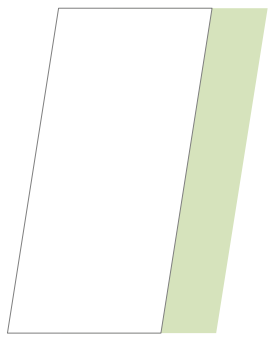

¿Viste cuando ves que un pibe empieza a andar mal y está al borde del acting, de mandarse alguna cagada grande, que algo le está pasando y que adentro no te lo cuentan? Bueno, yo tenía autorización de los jueces para sacarlos. Entonces, nos subíamos al micro para ir al centro a dar una vuelta y a las cinco cuadras ya me habían contado todo (E2, Psic., 2016).

Una de las intervenciones relatadas permite visibilizar cómo y para qué uno de los psicólogos implementaba dispositivos sin encuadre fijo establecido, así como algunos de los efectos que esto producía.

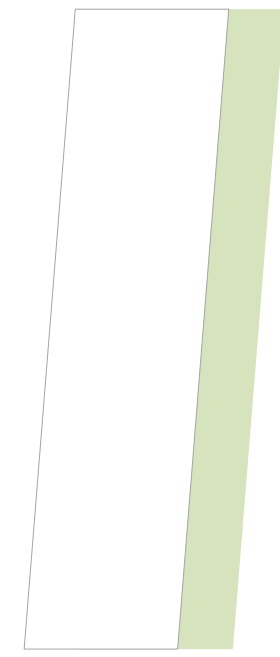

Era un pibe al que lo despreciaba todo el mundo, no lo querían ni ver. El último caso que tenía había subido a un micro a robar, totalmente empastillado y con alcohol, y a un pibito que estaba parado lo había lesionado gravemente. Tenía el semblante de cruel, de pibe muy pesado. No lo quería nadie... Tampoco lo tenía asignado yo, pero un día bajo a fumar, se acerca y me dice:

—Maestro, ¿me das fuego? —y se me pone a hablar. Cuestión importante, se me pone a hablar él.

-Yo cuando me vaya de acá voy a meter caño, porque yo no voy a ir a laburar de mozo, de lavacopas, por dos pesos. 
—Entonces, no estés, tómatela. Si no tenés pensado hacer nada distinto con tu vida, no tiene sentido...

—Eh, pero qué se yo...

—Mirá... No me hinches las pelotas. ¿A dónde vas a ir? Vos sos boleta, en el mejor de los casos.

—Pero yo no le tengo miedo a nada.

—Ah, ¿no? Si cruzás la calle, ¿no mirás para ver si viene un auto?

—No, a mí me atropellaron dos veces.

— ¡Ah, encima sos boludo! Mira pibe, tómatela, no me hinches las pelotas.

—No, yo cuando me vaya voy a...

—QQué vas a robar?

-En una casa de deportes...

—QQué? ¿Zapatillas vas a robar? ¿Te vas a salvar con unas zapatillas?

Mira, si se te ocurre algo inteligente e importante para contar, vení

y me contás, pero sino no me rompas las bolas.

Eso que fue medio intuitivo, ahí picó y empezó a venir. El pibe tenía su speech, y ya la cosa empezó a tomar cierto humor. Pasan, qué se yo, quince días y me dice: «Maestro, la verdad que tiene razón, yo soy boleta...».

Y, al poco tiempo, la gente del personal venía a decirme: «Ese chico no sale de permiso nunca», «iqué buen pibe!». Y el pibe empezó a hablar. ¿Por qué cuento esta anécdota? Porque viendo los programas deportivos que enfocaban la tribuna pasaron la hinchada de River y pusieron la jeta del negro este, a pleno. Y pensé: «Mirá, vive!». Habían pasado unos años y pensé: «Mirá, el negrito este está vivo, iqué bueno!».

A partir de eso, en vez de citar a los pibes, que era lo que tenía que hacer por formalidad, empecé a caminar por el patio, a meterme en las charlas y donde pescaba algo que generaba interrogantes, los provocaba. Con prudencia siempre. Es generarle, si lo querés llevar a la teoría, cuando se habla de entrevistas preliminares, generarle un interrogante para que la persona se cuestione, producir un mínimo de angustia. $Y$ ese es otro tema fuerte, complejo, porque tenés chicos, por historia, con precariedad instrumental, son chicos que ante la angustia van al acting, al pasaje al acto (E2, Psic., 2016). 


\section{Con referentes familiares}

Los dispositivos de intervención con los referentes familiares se llevaban a cabo a través de entrevistas que se realizaban en la institución durante los días de visita, que en general eran los fines de semana.

Una de las psicólogas refiere algunos de los temas que llevaban los padres y las madres:

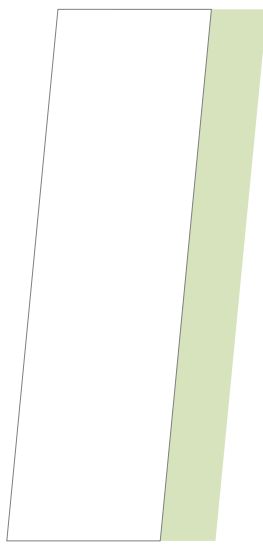

Una señora me dice: «¿Yo puedo hablar con usted? Yo necesito que usted me diga algo. Yo vine a verlo a mi hijo, fui al juzgado y el juez me dijo: "Mire señora, su hijo no está detenido, está retenido, que no es mismo". ¿Usted me puede decir la diferencia entre detenido y retenido?». ¿Vos me entendés? ¡Y estaba encerrado en X! Así funcionaban los juzgados, por eso es que cuando se les empieza a recortar ese poder, por eso es que siempre resistieron. Hacían lo que querían con los pibes y no les explicaban nada (E3, Psica., 2018).

Otro relato nos posibilita visibilizar los temores de los referentes familiares, a la vez que la lectura del/la psicólogo/a sobre los mismos:

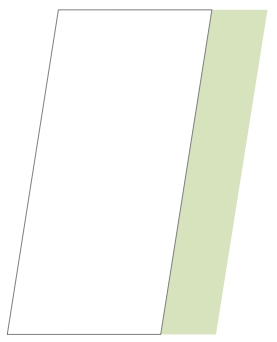

Después trabajé con los pibes en X. Veía a los padres y también hacia informes. Hay cosas muy significativas. Por ejemplo, un padre que lloraba y me decía: «No lo manden a mi casa. Nosotros acá sabemos que está vivo. Si él está en casa, a la noche escuchamos los tiros y salimos a ver si al que mataron es a él (E3, Psica., 2018).

Respecto a los padres y a las madres, señala que a veces están tan absorbidos/as por sus propias condiciones de vida que han perdido toda autoridad, «han perdido lo performativo del lenguaje y no pueden acompañar con la acción lo que dicen». No tiene un efecto. Sitúa, respecto a producciones teóricas sobre la temática, que «es muy difícil, y conduce mucho a error, hablar de esto no habiendo atravesado la experiencia». 


\section{Hogares convivenciales}

Tal como se señaló respecto al dispositivo del Patronato de Menores, los/as niños/as y adolescentes que ingresaban a los hogares convivenciales eran aquellos que el/la juez/a de menores determinaba que se encontraban en peligro moral y/o material, lo que motivaba la separación de sus grupos familiares y vinculares, y su «internación» en hogares para su «cuidado, protección y educación».

Una de las características que presentan los relatos de experiencias de los/as psicólogos/as entrevistados/as que trabajaban en las instituciones denominadas asistenciales es que se han desempeñado en diversos establecimientos, de acuerdo a la tipificación del hogar, delimitada según las edades y las problemáticas: hogares «maternos», para adolescentes madres y sus hijos/as; hogares para adolescentes mujeres y varones; hogares para quienes presentan «discapacidades»; y hogares para adolescentes que fueron dados/as de alta de tratamientos en clínicas psiquiátricas.

\section{Dispositivos singulares}

De los relatos de los/as psicólogos/as entrevistados/as se desprende que los dispositivos implementados se diseñaban de acuerdo a las características de la población de los/as niños/as y adolescentes, y de los objetivos institucionales.

En un hogar asistencial para niños, una de las psicólogas caracteriza el modo de diseñar los dispositivos de intervención de la siguiente manera:

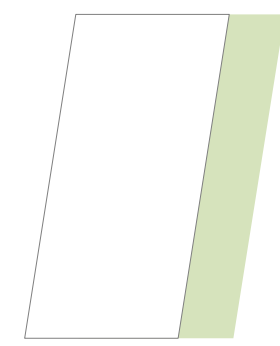

Teníamos una organización que se armaba a partir de la demanda del pibe, alguien se encargaba de esa demanda. Trabajábamos en sus posibilidades de egreso, dentro de la institución y también todos los aspectos que tenían que ver con su vida cotidiana, la escuela, las actividades, los cumpleaños (E4, Psica., 2015). 
En un hogar para adolescentes mujeres que habían transitado por internaciones en clínicas psiquiátricas, y que ingresaban al hogar para iniciar un «proceso de despsiquiatrización», la modalidad consistía en

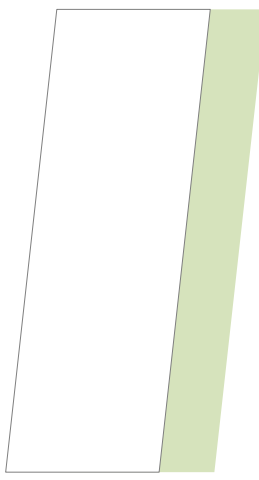

reevaluar la situación de la joven: qué familiares había, qué referentes afectivos existían, con quién se podía empezar a vincular. Se armaba el programa de vida, a qué escuela iba a ir, qué actividades recreativas podía hacer. Eso, con niñas que venían como bastante medicadas. A la vez, se empezaba a revisar el esquema de medicación con el equipo técnico, y en general se intentaba bajarlo. A partir de eso, también aparecían otras cosas sobre las jóvenes que estaban ahí, porque empezaban a hablar (E4, Psica., 2015).

Respecto de los dispositivos implementados, uno de los psicólogos entrevistados diferencia entre lo que denomina «atención psicológica» y «tratamiento psicológico».

Todos los chicos necesitan atención psicológica; no todos tratamiento psicológico (...). El tratamiento tiene un encuadre y una técnica determinada. La atención es cuando vos, por ejemplo, si sabés los tiempos de estructuración y de desarrollo de un chico, tenés que crear mecanismos que propicien eso. Cuando yo te digo, por ejemplo, algo tan chiquito como «¿qué te parece si llevamos a los pibitos a que elijan la ropa que quieren comprarse?». El viejo Freud cuando definía el Yo decía: «El Yo es la proyección de una superficie», ¿no? Entonces, un pibito te dice, como cualquier pibe, «¿cómo voy a patear bien los penales si no me compran la camiseta de Boca?». Tiene razón, claro. Uno también se empilcha con algo para sentir que puede ganar en un baile, ¿no? Es lo mismo. Bueno, si vos tenés que trabajar sobre esa imagen, con ese pibito acompañarlo para que se pruebe y «ay, qué lindo que te queda». Digo cositas chiquitas, ver qué le gusta al pibe, todo lo que tiene, digamos, algún efecto sujeto, a eso me refiero con atención psicológica. Le puse «atención», como podría haber puesto otra cosa. Porque vos vas a atender a un adolescente, a hacerle un tratamiento, en un lugar que viene a hablar con vos, pero después te ve hablando con el Director. (...) Y después estás tomando mate vos ahí, ¿no? (E2, Psic., 2016). 
Una psicóloga sostiene que el trabajo de tramitación psíquica, de elaboración de situaciones traumáticas, lleva mucho más tiempo y requiere de espacios más íntimos que el hogar; a su vez, aclara: "Sin embargo, muchas chicas y chicos han necesitado de mi escucha y yo los he podido escuchar, no quiere decir que no los escucho».

Otra psicóloga interroga sobre el sentido del tratamiento: «¿Por qué hay que trabajar terapéuticamente con los chicos en condiciones de vulnerabilidad? ¿Por qué hay que trabajar terapéuticamente con los pibes que están en el instituto? Es un prejuicio. El problema del pibe está afuera, en los padres, no está en los pibes». Interrogante que evidencia un modo particular de pensar el lugar de la familia.

Ahora bien, en las entrevistas se visibiliza la implementación de dispositivos de intervención con niños/as y adolescentes cuyos propósitos se dirigen a que sus voces sean «escuchadas» en lo que refiere a sus «necesidades y deseos» para, desde allí, diseñar estrategias de trabajo con los/as otros/as trabajadores/as de la institución, con otras instituciones educativas, recreativas y de salud, y con los referentes familiares y vinculares.

A la vez, relatan modos de intervención en la cotidianeidad institucional de los/as niños/as y adolescentes:

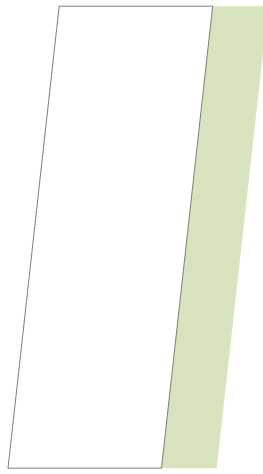

Yo me sentaba a almorzar con los chicos, en una mesa grande, y conversaba con ellos, hablábamos. Intervenía en su cotidianidad. Eran mesas de seis, comíamos todos juntos, era una cuestión mucho más familiar, sobre los problemas cotidianos. Te preguntaban: «¿Por qué no viene mi papá?». Después, estaba en el equipo técnico, se sentaban y hablábamos con los chicos, respecto, por ejemplo, de si iba a salir, no salir, o si el tribunal decía que tal cosa. «¿Vos qué querés?» (E5, Psica., 2017).

En un hogar para chicos con discapacidades, caracterizados como «lo más marginal de lo marginal. Porque los reclamos que pueden existir son los reclamos callados, vacíos de significado. Porque no se los escucha, no importan, porque no pasa nada si reclaman, ¿a quién le importa? Ni siquiera a la familia, porque no hay visitas. Directamente, no los 
visitan», las psicólogas relatan intervenciones a través del juego, por ejemplo de damas, con el propósito de construir un espacio de intercambio: «Había que hacer mucho más acompañamiento desde lo emocional y desde lo social. Mucho esfuerzo».

En la experiencia de otro de los psicólogos entrevistados:

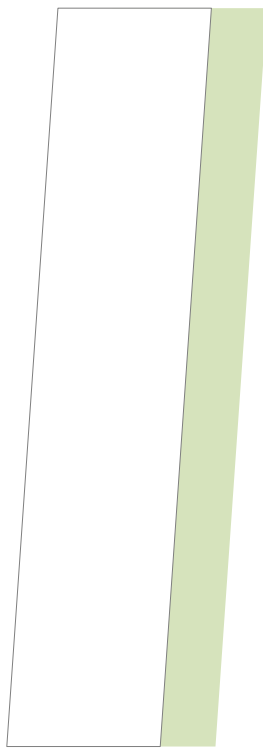

Con la discapacidad hay tan poco margen para laburar. El déficit intelectual, la impulsividad, y hay algo que es ¿cómo trabajar con la gente? Porque ahí trabajás mucho con la gente (...). Porque vos estás ahí y hay algo que te agota mucho, y es que es la misma gente la que genera los desbordes de los cuales después vienen a quejarse. Van al pibe y «ilevántate!» y el pibe hace una crisis, y «uh, ¿viste este chico las crisis que hace?». Todo el tiempo trabajar con la gente para esto del detalle, y te dicen: «Pero si el pibe no me da bola». Pero el pibe no te da bola porque vos no le das bola, porque vos querés que te dé bola cuando le decís «no». Pero para que te escuche el «no», acompáñalo, generá una relación distinta, como para que te pueda escuchar cuando vos le decís: «jNo!» (E2, Psic., 2016).

Una de las intervenciones relatadas que posibilita ver la situación sobre la que interviene, las intervenciones y las herramientas teóricas que las orientaron, es la referida a un «chico psiquiátrico»-así definido por los/as trabajadores/as del hogar-, que había tenido dificultades en varios hogares. El psicólogo inició un trabajo con él, a través de salidas del hogar con el propósito de «construir una relación». En una ocasión, luego de varios meses, lo llamaron del hogar porque «había entrado en crisis: "Está rompiendo todo, pega a todo el mundo"». En el relato de la situación sitúa que, al llegar al hogar, el chico no quería hablar, salía corriendo y golpeaba las cosas.

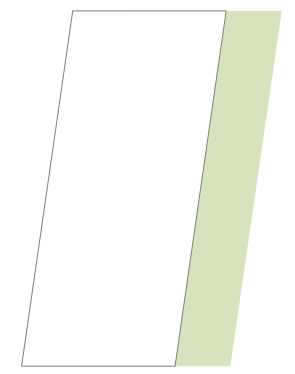

-X, yo te voy a esperar para hablar, porque algún problema tuviste seguro y eso hay que hablarlo.

-No, ¡no quiero!

-Bueno, yo me voy ahora para allá y te voy a esperar. Cuando quieras hablar, me llamás. 
Hago dos pasos y «pum», revolea las camas y yo, a propósito, hago una intervención: pateo la reja y le digo:

- Te voy a aclarar una cosa, y vos sabés que a mí me gusta jugar, pero no me hagas calentar porque te reviento el culo a patadas. Y ni un golpe, ¿eh? Ni un golpe más, y cuando quieras hablar, venís.

Pasaron dos o tres minutos y ya estaba golpeando, y salía corriendo, y yo atrás. "Ya te voy a agarrar». Bueno, dos o tres veces venía así. Golpeaba la pared y salía corriendo. A la tercera ya se reía del otro lado. Después vino y se sentó a upa. «Bueno, ¿qué pasó?» (E2, Psic., 2016).

El psicólogo efectúa la siguiente lectura: «El chico venía a jugarme una pulseada, y me di cuenta que necesitaba que yo la ganara, porque sino se quedaba a merced de sus locuras. Tenía que inventarse a alguien que le haga la función». A su vez, señala que hay algo del miedo a los chicos que se produce en los/as trabajadores/as y que los chicos lo registran. Recurre a Winnicott ${ }^{25}$ para pensar el trabajo, respecto a dos elementos centrales: lograr la confianza y el límite. «Si vos lográs esas dos cosas con los pibes en la institución, la confianza, que crean en vos, que te vengan a contar los problemas, y que te respeten el límite, ahí funciona».

\section{Con las instituciones escolares}

Para el inicio o el reinicio de la escolaridad, algunos/as de los/as psicólogos/as entrevistados/as señalan que al momento del ingreso a los hogares de los/as niños/as y adolescentes se contactan con los equipos de las escuelas cercanas o con aquellas acordes a las problemáticas que presentan; en ocasiones, incluso, dependiendo de las características de ambos equipos, diseñan y efectúan estrategias de abordaje en común.

Una de las psicólogas señala la existencia de un desfasaje escolar importante en casi todos los casos:

25 Donald Winnicott (1896-1971), pediatra, psiquiatra y psicoanalista inglés. 


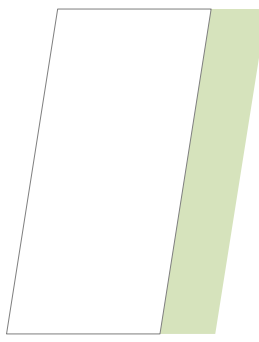

Y, entonces, siempre pasan cosas en las escuelas. A nosotros nos reciben muy bien en la escuela. Pero siempre es necesario trabajar con la escuela, porque tenés un chico grande en un salón con chicos más chicos, como que a vos te pusieran a estudiar chino en 4to año. Todo el tiempo es necesario conversar con la escuela para que no sea expulsiva (E4, Psica., 2015).

\section{Con los grupos familiares y los referentes vinculares}

Respecto a los dispositivos de intervención con las familias y/o referentes vinculares, una de las psicólogas entrevistadas interroga y problematiza el modo de pensar la familia como «abandónica», como una familia «que no va a responder», "con la que no se puede». Plantea que, en tiempos del Patronato del Menor, cuando la separación del niño/a o adolescente de su grupo familiar era la primera medida, ella buscaba alternativas para interrumpir la lógica internativa.

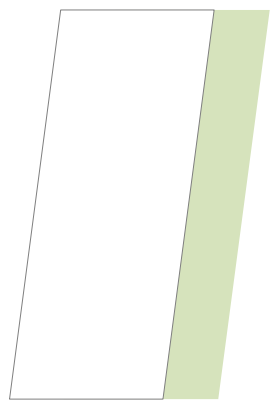

El chico había sido intervenido quirúrgicamente y había sido internado en un hogar para que no fracasara la excelente operación que había hecho el médico, porque el padre no iba a hacerle las curaciones como él pensaba y si no iba a fracasar su operación. Yo le decía: «Pero el chico llora porque quiere a su papá, enséñenle al papá a limpiarle la herida, a hacerle las curaciones» (E6, Psica., 2015).

En muy pocas situaciones, y cuando los/as niños/os y adolescentes provenían de la ciudad de La Plata, sus alrededores y/o del conurbano bonaerense, los/as psicólogos/as realizaban visitas y entrevistas con los grupos familiares, en los barrios y en las comunidades; dado que para concurrir dependían de vehículos del organismo provincial. En general, se realizaban entrevistas telefónicas y en los casos en los cuales algún referente familiar y/o vincular iba al hogar se realizaban entrevistas presenciales.

Estas condiciones laborales son leídas por una de las psicólogas como obstaculizadoras para el trabajo de integración de los/as niños/as y adolescentes con sus grupos de crianza: 
Hay un contexto social que me parece que es tan o más importante, porque vos trabajabas un montón y decías: «Pucha, está todo». Pero después esa chiquita se reintegraba a un lugar, un lugar muy difícil de articular y volvía todo para atrás. Entonces, siempre había una cosa medio renga, faltaba algo y era eso (E7, Psica., 2015).

\section{Centros de Responsabilidad Penal Juvenil}

Respecto a los dispositivos de intervención que se implementan con los/as jóvenes en el periodo iniciado en 2007 con la sanción de la Ley 13.634 del Fuero de Familia y Fuero Penal del Niño, delimitamos tres tipos: grupales, individuales e intervenciones en los espacios del cotidiano institucional (pasillos, patios y celdas).

\section{Dispositivos grupales}

\section{Dispositivo asambleario y de grupos pequeños}

Diferenciamos los dispositivos grupales que disponen los/as psicólogos/as según el propósito que los orienta, de este modo se delimitan el dispositivo asambleario, implementado para trabajar situaciones institucionales, y el dispositivo de grupos pequeños, implementado para trabajar temas o problemas que, a modo de emergentes, surgen de los/as jóvenes.

El relato de una de las psicólogas posibilita visibilizar cuándo y para qué implementan con los/as jóvenes dispositivos asamblearios:

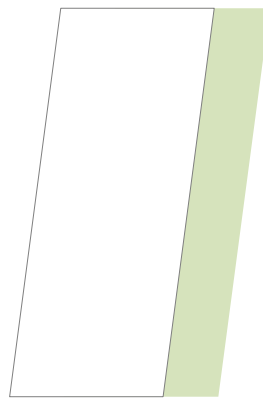

Trabajábamos el régimen de vida. Estoy yo, a veces también está el director y a veces algún maestro; depende de la situación, del grupo y de lo que esté pasando; a veces cuando está el director los pibes le dicen: «Vos estás pidiendo esto, pero esto no se cumple». Entonces bueno, tiene que estar en un momento especial la institución para bancar la crítica, más teóricamente sería la disposición para poder escuchar (E8, Psica., 2018). 
La descripción de uno de los dispositivos grupales visibiliza el modo de lectura de ciertas escenas que acontecen en el cotidiano institucional, y la detección de emergentes que ponen en movimiento el armado del pequeño grupo; por ejemplo, cierta «rigidización», que se acrecienta al compás del tiempo que los/as jóvenes están en la institución. Entre estos efectos, la psicóloga sitúa: «Cuando se centran en sus causas y solo en su causa».

El tiempo de institucionalización produce un modo de estar de los/as jóvenes que la profesional describe como «igual al de los maestros» y que emerge en discursos como: «Si es nuevo, le tenemos que pegar» o «estoy harto, no aguanto la reja», cuando se están por ir. Sostiene que «los pibes» tienen un montón de discursos, como «los maestros al pibe que no se lo bancan: "A este pibe hay que sacarlo, hay que sacarlo, hay que sacarlo". Esas cosas muy de rigidizar así, y los pibes entran en la misma».

Para intervenir sobre tales efectos, la profesional implementó un dispositivo grupal:

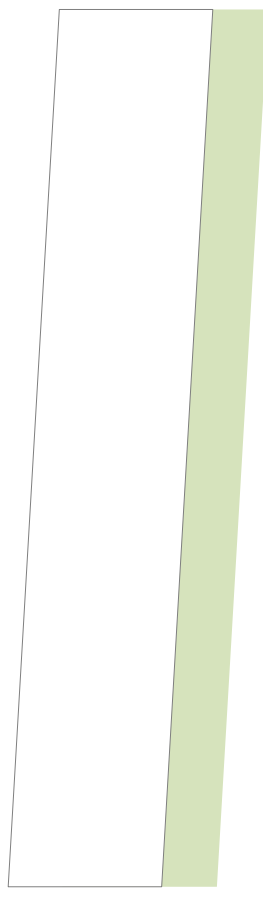

Para que entren a un espacio donde puedan hablar de lo que les pasa, que no tiene que ver solo con lo de ellos. Compartir, escuchar al otro. Por ejemplo, se da esto de «yo me siento discriminado», y otro dice: «Yo también». «Y ¿por qué vos te sentís discriminado?». "Yo me siento discriminado por tal cosa». «Ah! yo no, a mí me pasa por esto otro». Entonces, empezar a entender que, por ejemplo, hay distintas formas de entender la discriminación y que puedan mirar la diversidad, la complejidad de las situaciones sociales donde uno está inserto. Y es un espacio distinto; porque si no siempre que están en grupos están viendo la play, la tele, pero después la palabra no circula, o están haciendo alianzas. Entonces, a mí me da la impresión de que cuando están en el grupo entran en otra cosa, es como sacarlos de esa; incluso no es estanco el grupo, si yo veo que hay una temática emergente la propongo (E8, Psica., 2018).

La producción entre los/as jóvenes de tramas diferentes a las producidas en y por la institución permite la creación de un espacio que, en la experiencia de una de las psicólogas entrevistadas, posibilita el pensarse tanto en la situación de «encierro» como en aquellas que han determinado el ingreso a la institución. 
En las escenas grupales relatadas es posible visibilizar tales efectos:

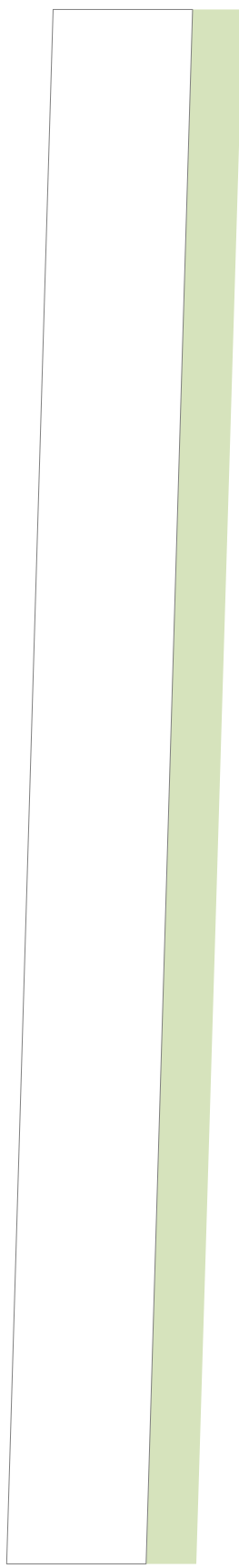

Eran doce chicos, tomábamos mate y circulaba la palabra. Hablamos de situaciones conflictivas. Una que recuerdo es la de «o soy yo, o es él», en referencia a una situación de enfrentamiento con la policía en un robo: «Es él o soy yo», «o es mi vida o es la vida del otro». Muchos decidían disparar para salvar la propia vida en esa situación de enfrentamiento, entonces iba circulando esto. Obviamente, yo no decía nada, porque la solución tenía que salir del grupo, y si yo decía algo seguro obturaba. Entonces, giraba y giraba. Cada uno contaba su situación y todos preferían salvar su vida, «porque es mi vida». Hasta que uno, el más callado, dijo que quería contar su experiencia. Contó que había ido a robar una farmacia, con otros chicos y con una chica, el revólver lo llevaba él. Revisaban por todos lados. «Cuando me doy vuelta, el empleado de la farmacia saca un arma y me apunta. Nos apuntamos mutuamente. Mis amigos se van y la única que queda conmigo es mi compañera, que se queda». "¿Y qué hiciste?», preguntaron todos. Tiré el arma y me tiré boca abajo. ¿Por qué? Porque yo pensé, es tan importante mi vida como la vida del otro, yo quería que me agarren por robo, no por homicidio». En ese momento se hizo mucho silencio. Eso que hace efecto ¿viste? Apareció algo distinto. En su sentido, en su lógica, no habían pensado. Y pensaron algo que hasta el momento no habían podido pensar y a partir de la experiencia de alguien de ellos. Si yo hubiera dicho algo así, no hubiera tenido efectos. Era un pibe respetado por ellos. Desde ese momento, silencio, estaban pensando. «Claro -saltó uno-, no lo había pensado». Y empezó a aflojar, a aparecer otras cosas. Y empezó a aparecer la vida del otro como importante (...). Que esté en el grupo significa que esté el otro. Sentarse, compartir un mate y poder escuchar al otro ya es terapéutico (E9, Psica., 2017).

En otra experiencia, el dispositivo grupal se implementó para trabajar la dimensión legal, a partir de una necesidad fundada en la escasez de recursos profesionales en una institución en la que había 32 jóvenes, con un equipo técnico compuesto solamente por 
una psicóloga y una trabajadora social, sin ningún/a abogado/a. En esta coyuntura institucional, implementaron un dispositivo de pequeños grupos para «limpiar el espacio de trabajo» con el/la psicóloga:

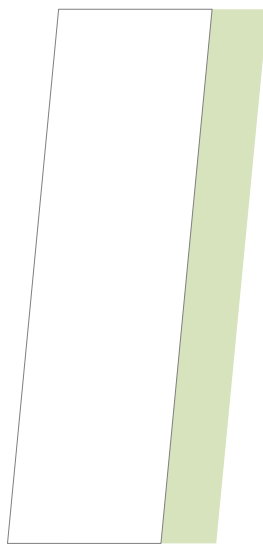

Los chicos están con el discurso «me voy, no me voy», «cuánto me falta». Ellos están parados ahí, por eso hay que poder ubicar qué cosas se hablan en cada espacio, para que después empiecen a entender que ahí, conmigo, tienen que hablar de otra cosa. No todos los chicos lo terminan de entender y es lógico, porque su vida está puesta en juego y están muy atravesados por el discurso del juzgado: «Hacé las cosas bien», «andá a los talleres», «portate bien». ¿Entendés? Entonces, desandar ese camino, conectarlos con ellos, es muy difícil; ellos no eligen venir al espacio con la psicóloga (E8, Psica., 2018).

Con el propósito de delimitar "qué cosas se hablan en cada espacio» diseñaron un dispositivo grupal que se organizó por pabellón, para poner en común, para compartir y para esclarecer los procesos judiciales de cada joven.

El «para qué» de este dispositivo fue modificado en el momento en el cual ingresan otros/as profesionales al equipo técnico, entre ellos un abogado; el dispositivo grupal continua, «ahora trabajamos violencia y género, por demanda de los chicos. En realidad, todos los años me cambia un poco el objetivo del grupo».

\section{Dispositivo individual}

\section{Entrevistas con encuadre fijo}

Respecto a la implementación de dispositivos individuales, cada psicólogo/a tiene asignados casos que, en general y dependiendo tanto de la cantidad de profesionales como de las disciplinas, son trabajados por duplas de psicólogo/a y trabajador/a social.

Para el espacio de trabajo individual, los/as psicólogos/as establecen un encuadre de trabajo, con días y horarios fijos. Refieren que tal espacio requiere de un «hacer prudente», «cuidadoso», de un «estar disponible» respecto a qué y cómo trabajar, «con lo 
que uno puede desarmar», "qué puntos vas a tocar», "como trabajar con la angustia», dado que ubican como un determinante fuerte que luego de las entrevistas los/as jóvenes «tienen que entrar ahí de nuevo», en referencia a las celdas y al encierro.

En la voz de uno de los psicólogos entrevistados:

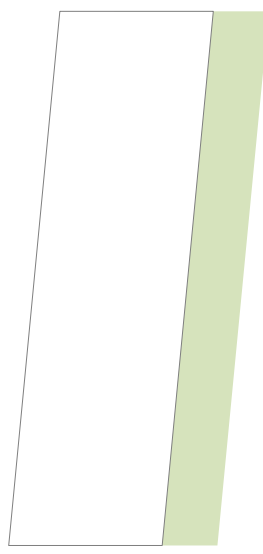

Si te ponés a pensar, cuando en una sesión te tocan algo de la angustia, uno sale y qué sé yo... Me voy a comer, compro un chocolatín en la esquina, qué sé yo... Me voy a la peluquería y me corto el pelo, creyendo que cambio algo, ¿no? Vas a visitar a un amigo, no sé... Vas a hacer algo. Ahora, ¿vos querés angustiar a un chico que tiene muy baja tolerancia a eso y después que vaya a la celda? Lo que digo es que uno tiene que saber hacer con eso. Vos sabés que a veces la intervención es de otro orden. Las intervenciones tienen que ser muy prudentes. ¿No? (E2, Psic., 2016).

Respecto al para qué establecer un encuadre fijo, una de las psicólogas sostiene:

Si hay alguna urgencia, alguna cuestión puntual, estoy disponible los otros días, pero es importante que sepa que ese es su día y que, aunque no tenga ganas de hablar, nos vamos a juntar a tomar mates. Pero ese tiempo yo se lo voy a dedicar, porque es mi trabajo. Que yo estoy. Y eso me ha funcionado, porque al principio es: «Ah, bueno sí, me toca con vos». Y, después, cuando empiezan a comprender de qué se trata el espacio me dicen: "Che $X$, hoy es martes, ¿me ves?». Entonces, vienen y empiezan a hablar: «Me pasó esto, me pasó lo otro, y con mi familia, lo que hablamos la otra vez». Es como que se hace una dinámica en donde ellos saben que hay un día en el que tienen ese rato y trabajamos. Por ejemplo, yo por ahí digo: «Fijate si esto lo podés hablar con tu mamá en la visita. ¿Nunca se lo preguntaste? Con ese chico, por ejemplo, era acerca de quién era su padre, pero que no se animaba a preguntarle a la mamá porque pensaba que era una falta de respeto. Entonces, ahí, trabajar la importancia de saber sobre su historia. Después viene y me cuenta: «Me animé, no me animé...». Qué se yo, la sensación es que se arma como una dinámica donde ellos empiezan, también, a elegir el espacio. Son estrategias que me han ido funcionando y las sostengo (E10, Psic., 2018). 
Los/as psicólogos/as destacan los efectos que produce en las entrevistas la dimensión de los informes que deben realizar y que luego se remiten al juzgado. Dimensión que no solo es tenida en cuenta como un elemento que está presente en el/la joven al momento de estar en el espacio de entrevista, sino que requiere para los/as entrevistadores/as de ciertas intervenciones. «Por ejemplo, cuando vienen y me dicen: “¿Vos me hacés los informes?". Y yo les digo: "No, los informes los haces vos". Y ahí me mira. Entonces, ahí podemos empezar a pensar qué hacemos en ese espacio. O venían y me preguntaban: "¿Esto va al juzgado?". Y yo les decía: "Yo voy a hacer un informe técnico, no si vos robaste o no, esa no es mi tarea"».

Relatan intervenciones que debieron efectuar para que no se obture el espacio de trabajo, cuando lo escrito en el informe es tomado por el defensor para justificar por qué no salió de permiso a su casa.

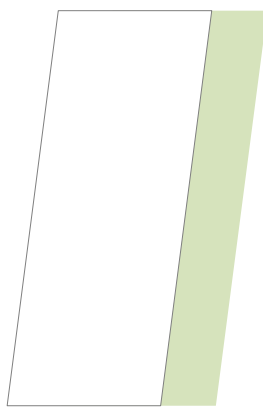

Entonces, vienen reenojados y eso te jode un montón la transferencia. Entonces, les leo los informes. A uno, después de leerle el informe, le dije: «¿A vos te parece que yo mentí?», «No», me respondió. Lo voy leyendo parte por parte, él me va preguntando y construimos algo ahí (...). Porque ellos están tan acostumbrados a la mentira, a que los boludeen; entonces, construir confianza es importante (E8, Psica., 2018).

En las entrevistas es posible ver cómo lo jurídico alojado en el espacio de trabajo individual con los/as jóvenes, sea para trabajar qué les pasa cuando tienen que ir a las audiencias o cuando se encuentran con su defensor, o para trabajar con las notificaciones judiciales, posibilita: que los/as jóvenes puedan preguntar aquello que no entienden de sus causas («porque cuando van a los juzgados no entienden, pero a la vez no preguntan nada») y aclarar lo que corresponde a cada uno de los tiempos y de los agentes judiciales («que sepan, por ejemplo, que en esa instancia, eso que esperan que le digan, no se lo van a decir, ni tampoco esa persona»). 
Entre los efectos que producen tales intervenciones, ubican que los/as jóvenes van instrumentando un posicionamiento más activo e implicado con su proceso judicial, lo que permite trabajar «qué posición tienen respecto a por qué están ahí, y a partir de ahí empezar a trabajar las cuestiones más por el lado de su historia y ahí uno va haciendo intervenciones muy cuidadosas».

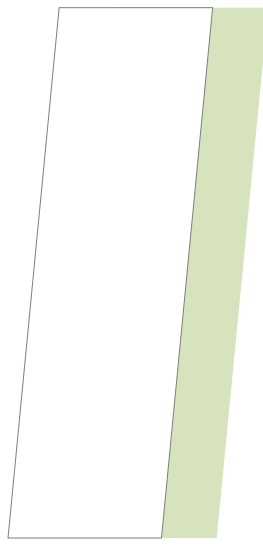

A veces, pasa eso de que «no saben que lo saben», por su experiencia y por las vivencias a lo largo de sus vidas - de sus familias, que tiene que ver con cuestiones de juicios o de cárceles-, pero tienen un montón de conocimientos, que no es algo distinto a lo que es del orden de lo inconsciente, no saben que lo saben. Entonces, hagámoslo juntos, va por ahí la apuesta. Y entones aparece: «A mí me dijeron que la audiencia en el art. 4...», «¿Y cómo es esto de la audiencia?». Es algo que armamos ahí, y además no es lo mismo, porque lo incorpora de otra manera a ese conocimiento (E10, Psic., 2018).

Trabajar de este modo con las notificaciones, los oficios y las audiencias es una oportunidad para que algo del efecto sujeto se produzca, pero eso requiere de unos tiempos y de un estar «disponible», porque «lleva más tiempo y también paciencia, mucha paciencia». Para el profesional, esta dimensión jurídica es parte del «andamiaje» que necesita construir para que algo del sujeto aparezca, para «ir armando algo de una escena posible, que no es sin el marco de ciertos derechos que primero tienen que estar ahí garantizados, sosteniendo, para que el sujeto emerja. La intervención con el pibe no es solo en la entrevista con el pibe. Hay que estar atento».

Otros de los elementos que en la experiencia de los/as psicólogos/as se presenta en las entrevistas son los efectos que el encierro produce en los jóvenes. Entre varias de las situaciones relatadas, la siguiente tiene la potencia de transmitir, a la vez que intervenciones sobre dichos efectos, la vida de los chicos en tales instituciones: uno de los jóvenes llevó al espacio con el psicólogo que se levantaba de mal humor y no entendía por qué. Al desplegarse esta situación, fue posible visibilizar que el levantarse de mal humor se relacionaba con quién y cómo lo despertaban. Un dato no menor es que el 
psicólogo, cuando el joven llevó a la entrevista que se levantaba de mal humor, se preguntó al modo de "voz en off»': «¿Y por qué no se va a levantar de mal humor? Tiene 18 años y se levanta acá, en este lugar. ¡Más vale! La pregunta sería al revés».

Esta situación fue tomada por el psicólogo para trabajar con las guardias y ver quién/es podrían despertar al joven; intervención que, de acuerdo a lo relatado por el profesional, evitó un «quilombo» institucional sin dejar de escuchar al sujeto y «que algo de la cotidianeidad del ese chico sea otra».

\section{En espacios del cotidiano institucional Encuentros en el patio y en las celdas}

Otro de los dispositivos de intervención que efectúan los/as psicólogos/as en distintos centros cerrados $\mathrm{y} / \mathrm{o}$ de semi-libertad con jóvenes que cumplen medidas de responsabilidad penal son aquellos que tienen lugar en distintos espacios del cotidiano institucional; por ejemplo, en el patio o cuando van a buscar a los/as chicos/as a las celdas para entrevistarlos, lo que uno de los psicólogos define como «oportunidades para intervenir, que pueden o no dejarse pasar». En este sentido, una psicóloga relata: «Para laburar voy al patio. Los chicos en esta institución están mucho en el patio tomando mate; me siento a tomar mates con ellos y salen conversaciones, los pibes hablan de todo».

La forma de operar de esta dimensión de «oportunidad para intervenir que puede o no dejarse pasar» se observa en la situación que relata una de las psicólogas: en el patio los «pibes» hablaban entre ellos sobre la violencia contra las mujeres. «¿Cómo un hombre le iba a pegar a una mujer? Eso no se hace», fue parte de la conversación en la que intercambiaban situaciones de violencias en sus familias. En un momento la hicieron participe, y ella propuso trabajar el tema en grupo, con información, con películas, con cortos. Durante ese trabajo, «uno de los pibes escribió sobre lo que había vivido con su papá y pidió que otro chico lo leyera». 
Oportunidades de intervención que «tienen que ver con eso que está ahí, que se dice de diferentes formas, pero que está ahí. Y lo tomás o no lo tomás. Lo ideal es poder tomarlo y ver cómo trabajás con eso. Lo que pasa es que es una decisión, tomarlo o no».

Respecto a la posición profesional en la institución, uno de los psicólogos refiere que hay algo de los modos de estar, de saludar, de hablar, «de si vas a buscar al chico a la celda y abrís vos el candado, y si luego lo volvés a cerrar vos o no» (en palabras del psicólogo: «yo no engomo a los chicos», en referencia a que no es él quien encierra a los chicos en las celdas).

Cada palabra, cada gesto, constituye una forma de intervención que produce «un cierto tipo de vínculo con el chico u otro».

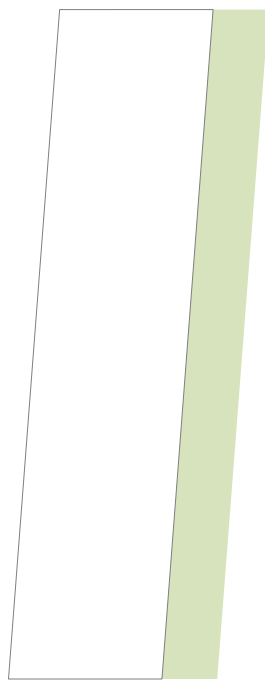

Tienen un efecto, más allá de lo que después uno hable con los chicos, porque hay una lectura por parte de ellos sobre cómo vos te dirigís, te movés, de qué manera mirás; porque hay maneras y maneras de mirar, si vos estás «mirando vigilando» los chicos se dan cuenta, porque fueron vigilados toda la vida, se dan cuenta cómo mira la policía. Entonces, vos podés estar mirando pero de otra manera o desde otros lugares (...), son otro tipo de intervenciones. Mi formación es analítica, pero me parece que son intervenciones que tienen que ver ahí con lo imaginario, con lo real y que habilitan a que después aparezcan estas otras sutilezas, que son del orden de lo simbólico, del significante (E10, Psic., 2018).

\section{Con referentes familiares}

Entrevistas los días de visita

En los distintos centros, los fines de semana los/as jóvenes tienen lo que se denomina «día de visita». Este día van las madres, padres, hermanos/as, novias, hijos/as de los/las jóvenes y se encuentran todos y todas en un mismo lugar del edificio con rejas. 
Una de las entrevistas con uno de los psicólogos fue realizada un sábado en la institución. El espacio donde tuvo lugar es el mismo en el cual los/as psicólogos/as realizan las entrevistas. Para llegar hasta allí debimos pasar, rejas mediante, por el lugar donde estaban los jóvenes con quienes habían ido a visitarlos. Allí estaban todos/as, adultos/as, jóvenes y niños/as, con comida, tomando mate, sin disponer de un espacio de cierta intimidad para estar y para compartir con sus respectivos referentes vinculares.

Esos días los/as psicólogos/as van a la institución para entrevistar a las familias, algunos/as se turnan con sus colegas y van un fin de semana cada uno: «Tratamos de acomodarlo en función de la necesidad que tenemos de entrevistar a las familias, para no ir innecesariamente».

Respecto del para qué tienen las entrevistas con las familias varía: algunos/as consideran que le sirve más al trabajador/a social; otros/as señalan que les permite hacerse «una idea de algún referente familiar»; otros/as indican:

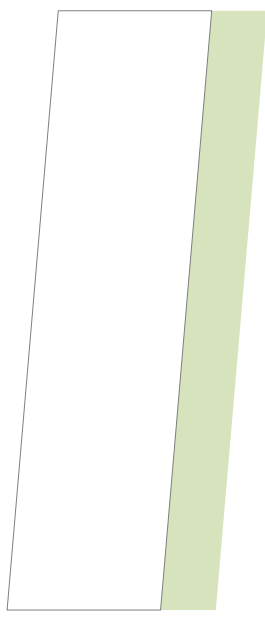

Para que me conozcan, para que vean que en la institución hay gente trabajando ahí, para mí es importante que los papás entiendan eso. Generalmente, lo utilizo para comprometer a los padres en esto, les digo: «Mirá, yo estoy trabajando esto, esto y esto, necesito que ustedes lo refuercen». Me doy cuenta que hay familias que sí y familias que no van a poder acompañar eso. Muchas veces propongo al juzgado, en los informes, que la familia vaya a un espacio de tratamiento afuera. Le digo a la familia que voy a escribir eso y les pregunto si están de acuerdo, también como una forma para entender por dónde van (E10, Psic., 2018).

Otros/as entrevistados/as relatan que las/os psicólogos/as del equipo técnico de la institución no iban los fines de semana a entrevistar a los/as referentes familiares, sino que los citaban durante la semana; lo que producía que los/as familiares no siempre fueran, por distintas razones laborales y económicas. Luego y, a partir de un cambio en la dirección de la institución, el equipo comenzó a ir los fines de semana para entrevistar a las familias en los horarios de visita. 
La necesidad de trabajar con la familia se muestra en el siguiente relato:

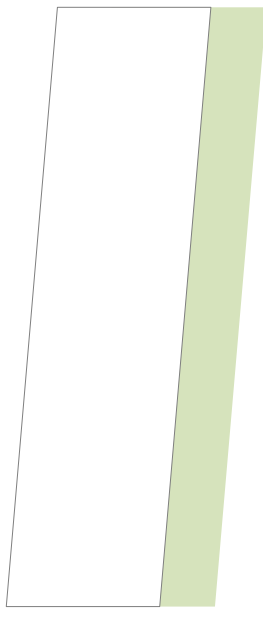

La chica no llegó al instituto porque sí, sino porque hay conflictivas familiares que hacen muchas veces a la conflictiva. Una chica me decía: «Si usted hubiera nacido en mi casa, seguro que estaría acá». Nadie lo pasa bien viniendo acá; entonces, trabajar cómo las ven estando acá. Siempre hay un adulto, siempre hay alguien a quien convocar y que sienta que es parte del tratamiento, eso se lo marcamos siempre. También las chicas acá están por un delito penal y la responsabilidad subjetiva respecto del acto no hay que dejarlo de lado. Y si no se trabaja esto no hay ninguna implicación, del por qué están acá y cómo pueden evitar volver a estar acá (E11, Psica., 2016).

Uno de los psicólogos indica que el trabajo con las familias tiene varias aristas:

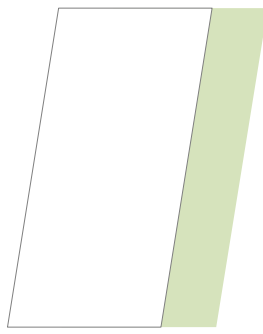

Por un lado, tiene que ver con cómo escuchan ellos a sus hijos, también para ver el lugar que el chico tenía en esa familia, y empezar a despejar esas cosas (...). Escuchar a veces a los otros es solidario con poder escuchar al sujeto. Poder escuchar a esos otros me parece que me abre también la posibilidad de poder escuchar de otra manera a ese chico (E10, Psic., 2018).

Asimismo, señala que el trabajo con las familias es parte de las tareas que realizan en tanto representantes de Estado para que los familiares o los referentes vinculares sepan cómo están sus hijos/as, que se encuentran en un lugar donde no los pueden ver durante la semana, y para que «dejen de ser visita y puedan incorporarse de otra manera al lugar». Sitúa, además, que él conoce a los jóvenes «desde que están acá. Los conozco con el impacto que tuvo esta institución sobre sus cuerpos, sobre su subjetividad», de allí que el trabajo con la familia sea lo que le permite conocer cómo eran antes de estar en ese espacio cerrado.

Otro de los elementos que trabaja con las familias es el acompañamiento orientado a pensar el lugar que tendrá el chico cuando vuelva, para ver «cómo van a hacer, qué imaginan que puede llegar a pasar, qué les preocupa y qué no les preocupa». 
En todos los casos, los/as psicólogos/as entrevistados/as llevan a cabo las entrevistas con los referentes familiares y vinculares en el lugar donde los/as jóvenes cumplen las medidas; es decir, dentro del establecimiento.

\section{Hogares de Protección de Derechos}

Con la sanción y la implementación de la Ley 13.298 de Promoción y Protección Integral de los Derechos de los Niños se diferencian los programas de promoción y de protección de las medidas de protección. Las medidas de protección son aquellas que disponen los Servicios Locales de Promoción y Protección de Derechos cuando se produce la amenaza o la violación de derechos o garantías, con el objetivo de preservarlos o de restituirlos. Tales medidas son limitadas en el tiempo y se mantienen mientras persistan las causas que le dieron origen.

Una de las medidas de protección de derechos, excepcional y provisional, es la separación del grupo familiar y el alojamiento en ámbitos familiares alternativos o en entidades de atención social y/o de salud, denominada «medida de abrigo institucional», que implica el alojamiento en establecimientos como los Hogares de Protección de Derechos.

Dicha medida, que debe ser una «medida de último recurso», tiene un plazo de tiempo estipulado o se extiende hasta que las causas que la originaron sean revertidas. Fue evaluada y decidida por el equipo del Servicio Local de la ciudad de pertenencia del/de la niño/a o adolescente, informada al Servicio Zonal correspondiente y evaluada su legalidad por el/la juez/a de familia.

\section{Dispositivos singulares}

Diseñar «cuidando los detalles»

En la experiencia de una de las psicólogas que integra el equipo técnico en un hogar para niños, al momento de diseñar los dispositivos de intervención parten, primero, de conocer los motivos que dieron origen a la medida de abrigo. Luego, cuando reciben a los/as 
niños/as, los escuchan e intentan recuperar algo de su historia reciente. En palabras de la profesional, «buscamos saber de dónde viene, cuáles fueron sus lazos, con quiénes estaba o cuáles fueron los motivos. Si fue un traslado, de donde viene; eso lo hacemos con los pibes y con los servicios zonales y locales».

Lo que emerge de dichas entrevistas les posibilita diseñar la estrategia de trabajo vinculada con la restitución de sus derechos, a la vez que producir condiciones para que los «los chicos» puedan desplegar «sus propios deseos, sus gustos y acompañar ese despliegue». En este sentido, la psicóloga señala que trabajar con la singularidad es para el equipo lo que para las políticas públicas es el todos/as, lo que implica que lo diseñado para uno «no se repite necesariamente en otro. Y eso es atender la singularidad. En esa tensión estamos pensando todo el tiempo».

Los dispositivos así diseñados tienen como finalidad «alojar» a los/as niños/as en un momento de sus vidas que, "aunque uno crea que tiene que ser un momento de alivio y de restitución de derechos, es altamente traumático, como es la separación del lugar donde estaba y que se lo incluya en un dispositivo que va a convivir con un montón de chicos en su misma situación». De allí que diseñan un dispositivo de acompañamiento para aquello que los chicos requieren o piden: con algunos/as, entrevistas más formales porque lo requieren; con otros/as, propuestas más lúdicas o más ligadas a lo recreativo, a la escolarización y a la búsqueda de las actividades que les gustan.

En ocasiones, incluso, cuando ven que un chico se «engancha» con algún/a otro/a trabajador/a del hogar realizan un acompañamiento de «ese alguien para que pueda sostener», para que lo pueda acompañar. La dimensión de la escucha es un elemento que se desataca. «Si uno pone en marcha la dimensión de la escucha, con todo lo que eso implica, ya es todo un logro; que el pibe sea escuchado y que otro le haga sentir que está alojado», señala la psicóloga, refiriéndose al alojamiento subjetivo del niño/a.

Dispositivos singulares que requieren lo que en otra entrevista aparece como «cuidar los detalles». Una situación que visibiliza el sentido de «cuidar los detalles» es la referida «a un chico que había roto los vidrios de la escuela y había hecho quilombo» y que desde la escuela pedían que «se lo saque». 
Ante la pregunta del psicólogo respecto de lo que había sucedido, le contaron:

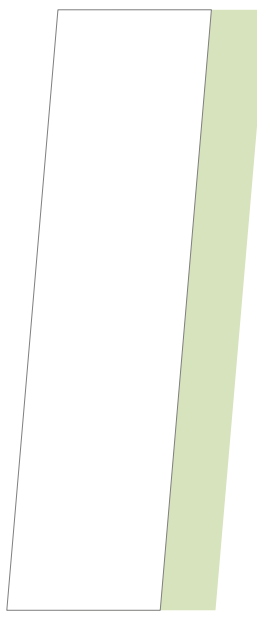

«Tenía que llevar a la escuela una latita para hacer una planta. Nos olvidamos y le agarró un ataque». Y, yo digo, pongámonos a pensar, ¿qué le pasa al pibe cuando los otros que van con la mamá llevan la latita? ¿Qué representa esa ausencia de la latita? Que no le importa a nadie; por suerte explota para afuera y no para adentro. Digo, somos del orden de esos detalles los humanos. Pero no él, sino todos. Entonces, ¿en la institución tenemos que cuidar los detalles? Exactamente. Porque se juega ahí, no se juega en otro lado. Cuando yo cuento lo del detalle, que está ligado con esto, ¿no? Es decir, me saltean a mí en una rueda de mate y puedo llegar a armar un quilombo bárbaro (E2, Psic., 2016).

\section{Tratamiento individual \\ Poner a disposición la escucha y la palabra}

De las entrevistas se desprende la existencia de dispositivos de atención individual para los/as niños/as y adolescentes que lo requieren. En algunas situaciones, tales dispositivos son implementados en el hogar; en otras, se realizan interconsultas y derivaciones a espacios públicos de salud, con el propósito de que se construya un espacio separado de lo convivencial. «Y como nosotros somos parte también de esta institución convivencial, a veces se hace necesario diferenciar los lugares y que los chicos pueden diferenciarse de nosotros también», señala una piscóloga.

Esta decisión se vincula con un modo de pensar el lugar de los/as psicólogos/as en la institución. Al formar parte de la institución, «tal vez está bueno que lo trabajen con alguien que no lo tienen que compartir y que sienta, además, que está resguardada su intimidad», agrega la profesional.

Entre los elementos que delimitan en el dispositivo que implementan destaca la disposición de la escucha y la palabra. Respecto de la escucha, sostienen su importancia dado que los/as niños/as y adolescentes en situación de vulneración no han sido escuchados. Una psicóloga caracteriza una «clave en la escucha» que descubrió en el trabajo en el hogar con niños chiquitos, referida a lo vincular. 


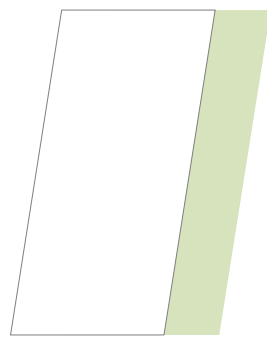

Cuando un niño te dice: «Estoy preocupado porque mi mamá no debe saber dónde estoy», «me debe estar buscando porque no sabe dónde estoy», te está diciendo que tiene una madre que se preocupa por él. Más allá de lo que haya pasado, te está diciendo: «Mi mamá me quiere, me cuida». Ahí hay un anclaje en su subjetividad (E12, Psica., 2015).

Y señala que ha constatado que cuando eso era dicho, efectivamente, había un vínculo a restituir. Tal «clave de escucha» posibilita «el armado de la construcción de sentido para el chico», a la vez que moviliza intervenciones como, por ejemplo, conectarse con la madre o con el referente nombrado por el/la niño/a. En este sentido, la palabra es caracterizada como un elemento que «presta» el/la psicólogo/a, lo que implica

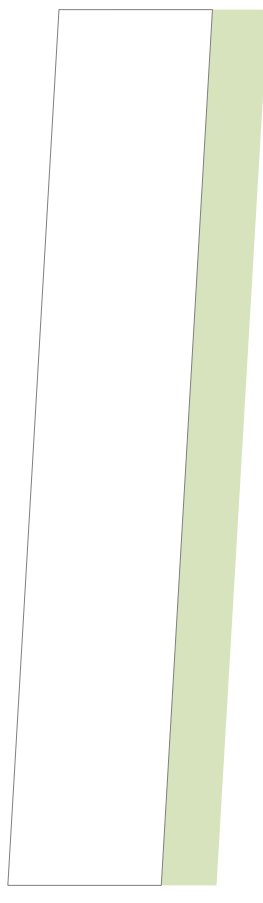

Que los psi hablamos mucho. Que hay mucha necesidad de construir un sentido a la historia de los chicos. Eso, para mí, es fundamental. Porque la mayoría no tiene muy claro cómo es que llegaron acá. Y eso es gravísimo para ellos. No saben por qué. A veces se lo han explicado y se quedaron en su cabecita con un mal entendido. Por ejemplo, con el evento por el cual los han separado de su familia. Porque ha circulado una idea fantaseada de por qué llegaron acá: «Justo ese día que salían a hacer compras y si no hubiéramos vuelto a buscar...». O fantasías más dolorosas, como que las madres los engañaron, que los llevaron a una entrevista y terminaron en el hogar; o que los engañó otra persona, una trabajadora social. Es necesario construir otro sentido, porque lo que ellos sostienen como fantasía, a veces, no es lo que sucedió. O también cuando vuelven a hablar con su mamá. Ahí se arma otro sentido de por qué llegaron acá. Es historizar ese suceso y todo lo previo (E12, Psica., 2015).

\section{Las familias y los referentes vinculares}

\section{El trabajo con los servicios zonales y locales}

En lo que respecta a los dispositivos de trabajo con las familias, refieren que las medidas de abrigo se toman sin un trabajo con las familias que «tenga que ver con superar esa situación, sobre todo si fue una situación transitoria». Una de las entrevistadas señala que es necesario el trabajo con el territorio y con la familia de los/as niños/as; trabajo que se 
facilita cuando pertenecen a la ciudad de La Plata. Con aquellas familias que viven en otras ciudades ese trabajo «sí o si se tiene que hacer con los servicios territoriales. El trabajo en el territorio se tiene que hacer con los servicios zonales o locales. Ese trabajo no lo debe hacer el hogar sino el servicio local».

En su experiencia, cuando realizan un trabajo en conjunto con los servicios locales o zonales la situación de los/as niños/as y adolescentes avanza mejor. Sin embargo, señala que hay servicios zonales y/o locales con los que pueden trabajar de este modo, y otros con los que no.

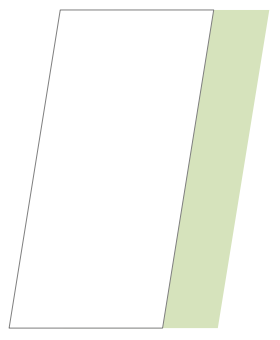

Porque no tienen con qué, realmente, o porque existe mucho prejuicio en relación con el trabajo con el familiar. Por ejemplo, algunos te dicen: «Yo con esta mamá no trabajo más». Entonces, hay servicios con los que es muy difícil trabajar. O cuando no tienen gente. Por ejemplo, en una ciudad, son dos flacas que no dan abasto (E13, Psica., 2018).

En situaciones en las cuales se logró «un enganche» entre el/la psicólogo/a y algún referente del grupo familiar el trabajo lo continúa el/la profesional del hogar; situación que se produce «porque vienen acá, porque nosotros generamos que vengan. Y eso se hace para que después el pibe vaya. Y cuando el pibe va, continua el que está en el territorio».

El trabajo en el territorio con las familias lo efectúan «en la medida de lo posible», para armar una red. Esto implica

Un laburo muy finito con los servicios locales, que rápidamente lo que piensan es que los pibes tienen que ser dados en adopción. Entonces, nosotros somos muy cuestionadores de esa idea si escuchamos que el pibe tiene un lazo con esa familia, si el pibe quiere volver con esa familia o con alguien de esa familia. Ese es un trabajo muy difícil, porque es trabajar con los juzgados y trabajar con los locales. Antes era convencer al juez, ahora es convencer a los mismos compañeros de los distintos organismos de aplicación de la ley (E13, Psica., 2018). 
Para la psicóloga entrevistada, en el trabajo con los/as niños/as y adolescentes, es fundamental pensar en la constitución del sujeto, «el lugar del otro y cuáles son los otros actores en esa constitución», el contexto en el cual ese niño/a adviene, desde un modo de pensar situacional.

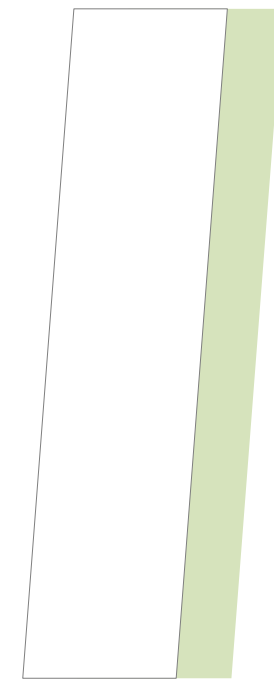

Es decir, rápidamente, no diría que alguien no es deseado porque una mamá le pega a su hijo, porque piensa que no lo quiere criar, no. Seria, o soy, o somos, porque no soy solamente yo, cuando pensamos eso, cuando tenemos una mamá que no se ha podido ocupar de su hijo, y se hace una denuncia desde una escuela y se toma una medida de abrigo. Cuando volvemos y entrevistamos a la mamá vemos a una niña ahí, que tampoco ha tenido a otro. Entonces, a partir de ahí, de pensar que esta madre no ha tenido a otro, y que por eso no puede ser otro para ese niño/a, pensar las estrategias que se pueden poner en juego para que esta mamá pueda y, a la vez pueda encontrar ella un otro, de reconocimiento, de afecto (E13, Psica., 2018). 


\section{Fuentes}

E1 | Psicóloga, actualmente en funciones. Entrevistada en 2016.

E2 | Psicólogo, jubilado. Entrevistado en 2016.

E3 | Psicóloga, jubilada. Entrevistada en 2017.

E4 | Psicóloga, actualmente en funciones. Entrevistada en 2015.

E5 | Psicóloga, actualmente en funciones. Entrevistada en 2017.

E6 | Psicóloga, jubilada. Entrevistada en 2015.

E7 | Psicóloga, actualmente en funciones. Entrevistada en 2015.

E8 | Psicóloga, actualmente en funciones. Entrevistada en 2018.

E9 | Psicóloga, actualmente en funciones. Entrevistada en 2017.

E10 | Psicólogo, actualmente en funciones. Entrevistado en 2018.

E11 | Psicóloga, actualmente en funciones. Entrevistada en 2016.

E12 | Psicóloga, actualmente en funciones. Entrevistada en 2015.

E13 | Psicóloga, jubilada. Entrevistada en 2018. 

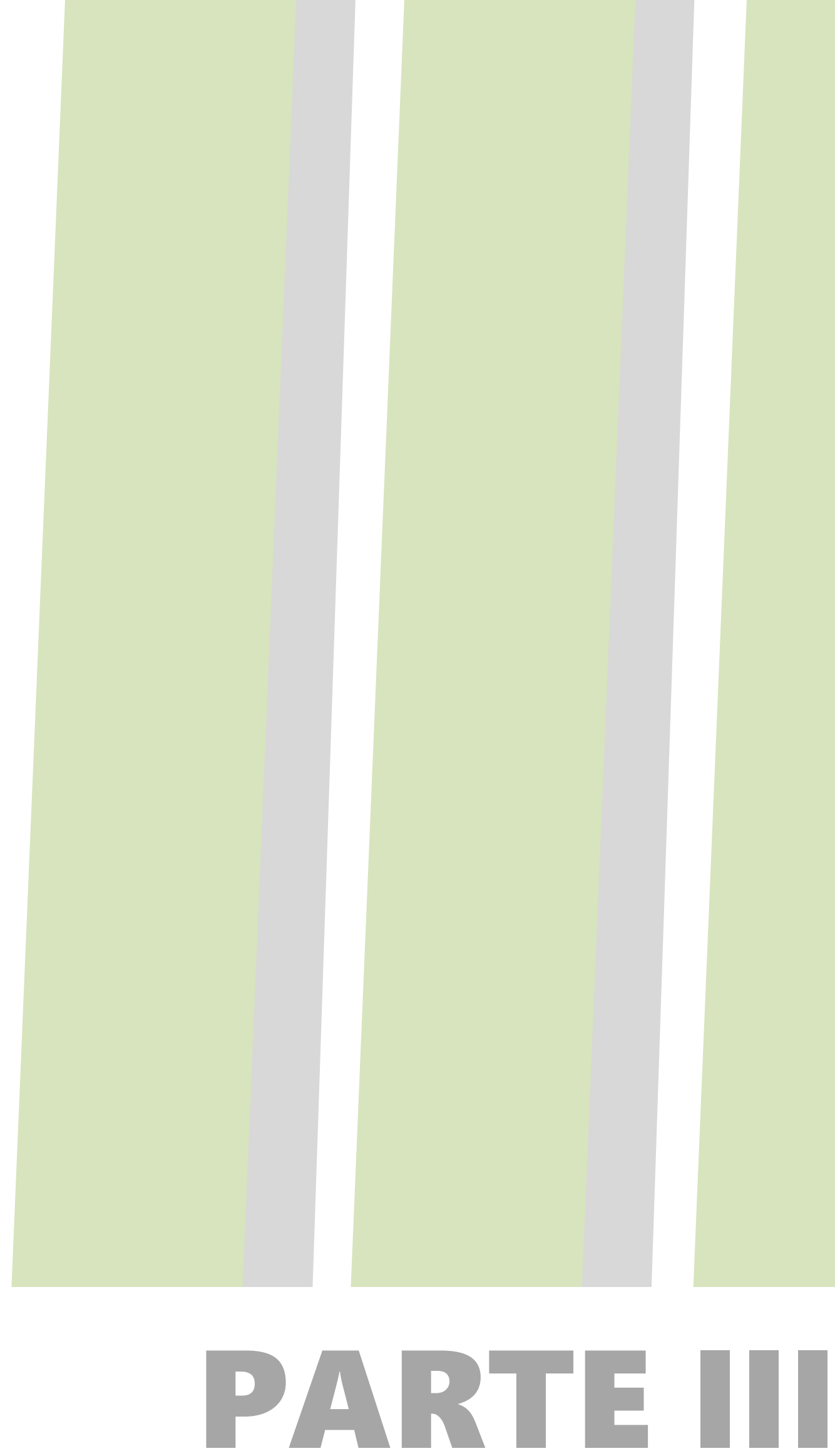

PARTE III 


\title{
Parte III
}

\section{CAPÍTULO 7}

\section{Las determinaciones que orientan los dispositivos}

\author{
Determinaciones normativas \\ Determinaciones institucionales \\ Determinaciones teóricas
}

A partir de la operación de distinción y de puntuación de insistencias hemos visibilizado algunas líneas de determinaciones que operan en tales dispositivos y que la mirada de quien investiga construyó como determinaciones normativas, institucionales y teóricas.

Respecto a las determinaciones normativas trazamos: en tiempos del Patronato de Menores, la judicialización de la pobreza y el carácter de los/as psicólogos/as en tanto auxiliares del/de la juez/a; mientras que en tiempos del SPPID y del SRPJ, estas se anudan con la implementación de políticas públicas que garanticen el acceso a los derechos básicos. En el caso del SPPID, la distancia territorial entre el lugar de pertenencia de los/as niños/as y adolescentes y el lugar donde se lleva a cabo la medida de abrigo institucional, así como entre los equipos profesionales que intervienen, determina los dispositivos de intervención implementados. El efecto que produce el SRPJ, en tanto, se anuda con el derecho al debido proceso judicial, del cual resulta la medida a cumplir.

Otras líneas trazadas se anudan con los efectos que producen las tramas institucionales al momento de diseñar y de implementar dispositivos de intervención; entre ellos, puntuamos las violentaciones y los miedos que estas producen, las fragmentaciones que se generan tanto entre los/as asistentes y el equipo técnico, como hacia el interior de los propios equipos técnicos; y la resistencia a los dispositivos grupales.

Por último, las determinaciones teóricas construidas se anudan con herramientas conceptuales provenientes del psicoanálisis, entre las que destacan las categorías de estructuración subjetiva y de demanda. 


\section{Determinaciones normativas}

\section{La judicialización de la pobreza}

La lectura del Decreto Ley 10.067/83 del Patronato de Menores de la provincia de Buenos Aires nos posibilitó visibilizar la configuración de este dispositivo así como la disposición y las relaciones entre sus elementos: quiénes debían operar y cuándo debían hacerlo; en una distribución de focos locales de ejercicio de poder que anuda, en su ejercicio, tecnologías propias de un tipo de poder soberano, tecnologías disciplinarias y tecnologías de seguridad (Foucault, 2006).

Los artículos 10, 56, 58, 59 y 62 de esta normativa delinean las condiciones de vida sobre las cuales se debía operar y quiénes debían hacerlo, en un movimiento centrífugo que integraba distintas instituciones públicas estatales: desde directores/as de escuelas hasta directores/as, jefes/as de servicios hospitalarios y profesionales. Si tales actores no operaban se establecía que debían ser «sancionados y reprimidos». Ubicamos allí focos locales de ejercicio de poder, cuya función era detectar y derivar al/a la juez/a de menores aquellos/as niños/as y adolescentes en «riesgo moral o material».

Con el Decreto Ley 10.067/83 se perfeccionó el dispositivo de control y de disciplinamiento para la población de los/as hijos/as de inmigrantes -como fue la Ley Agote-, pero dirigido al sector de la población migrante y empobrecida del país, de allí que se afirme que el control social para la familia de los pobres será su judicialización. La normativa determinaba la población sobre la que se debía intervenir y la fuerza de tal determinación se torna visible en la voz de los/as psicólogos/as:

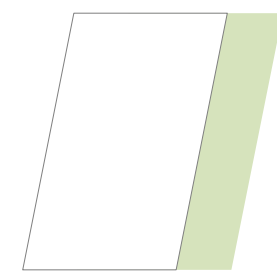

Sobre fines de los noventa, nos fuimos encontrando con una situación social de mucho deterioro, así que lo que nos pasó fue que, por más que la familia tuviera voluntad, abundaban las internaciones (en ese momento se llamaban así) por pobreza. 
Sin recursos, no podían mantenerlos, sobre todo chicos que por diversas circunstancias presentaban modalidades poco comunes, algún problema de conducta, que no podían sostenerse en las instituciones, ni en la escuela ni en las instituciones del barrio.

Entonces, la familia misma pedía auxilio y la ayuda que se le daba era ponerlos en un hogar. Lo que visualizábamos, entonces, era no solamente la precarización económica sino también la precarización subjetiva, que no podían alojar. En ese momento, que fue a finales de los noventa, 2000, 2001, de mucha crisis económica, nos preguntábamos: «¿Qué hacemos con esas familias? ¿Cómo los ayudamos?». Si estaba bueno, o no, que los pibes estuvieran en la institución, con todas las dificultades que tiene la institución. Si ingresaban a una institución, cómo hacían después para volver.

En general, todos esos años siempre pensábamos que era mejor que no estuvieran en la institución, tanto en la época del patronato como en la época de promoción y protección (....). Pero, claramente, para el 2000 se veía una situación social muy acuciante y eso era lo determinante, que esa cantidad de familias no pudiera alojar a los pibes con presentaciones más disruptivas (E13, Psica., 2018).

Tal caracterización muestra la relación de inmanencia entre el crecimiento de sectores empobrecidos y el aumento de la judicialización vía la internación. En tales políticas de judicialización de los/as hijos/as de las familias empobrecidas, vía la institucionalizacióninternación en hogares, vemos operar estrategias de poder biopolíticas-regulatorias sobre un sector de la población y estrategias de poder disciplinarias sobre los/as niños/as y adolescentes, que se constituían en objeto de múltiples miradas: jurídicas, médicas, psicológicas.

De este modo, sobre la individualidad de los/as niños/as y adolescentes intervenían, primero, todos unos regímenes de saberes movilizados por los/as profesionales del equipo técnico del tribunal de menores, que dirían sobre las características de las familias y sobre sus efectos en los/as niños/as y adolescentes. De esto emergían los informes que darían cuenta de su personalidad. Luego, en los establecimientos de internación serían los/as profesionales de los equipos técnicos quienes ejercerían esa función. 
Como veremos, toda la información registrada por los equipos técnicos debía ser informada al/a la juez/a, quien, en cumplimiento de la función soberana, decidía sobre la vida de cada niño/a y/o adolescente, articulándose, de manera coordinada e integrada, tres tipos de mecanismos: soberano, disciplinario y regulador.

\section{El caracter auxiliar de los/as psicólogos/as}

Al ubicar a la Subsecretaria del Menor y la Familia y, posteriormente, a la dependencia del Poder Ejecutivo del estado Provincial como auxiliares del/de la juez/a de menores, el dispositivo del Patronato de Menores logró que todas las acciones y las prácticas que se efectuaban en estas instituciones estuvieran bajo la mirada del/de la juez/a. A ellos/as se les debía responder e informar y eran ellos/as quienes decidían, de manera «fundada y de acuerdo a su convicción sincera» (Título II, capítulo V, artículo 42), sobre la vida del/de la menor.

El/la juez/a determinaba el ingreso y la permanencia de los/as «menores de edad», establecía en qué institución y estipulaba por cuánto tiempo. Todo movimiento de los/as menores debía ser informado al/a la juez/a, quien lo autorizaba o no. Esta dimensión, como se desprende de algunos relatos, constituía un elemento de determinación sobre los dispositivos que implementaban los/as psicólogos/as.

El juez pidió a la Secretaría que me sancionaran, porque yo no había dicho lo que él quería decir; porque él quería dar los chicos en adopción... Terminé con un móvil policial que me vino a buscar a la puerta del instituto para que fuera a declarar. Y después un día cayó él, con cuatro o cinco personas, y me dijo que yo tenía que ser sus ojos.

Trabajábamos directamente con los juzgados y con los jueces, y los jueces decidían si volvían a sus lugares de origen o si los mandaban acá (a La Plata), a lo que los pibes llamaban «el colegio» (E1, Psica., 2016).

Nuestros interlocutores eran los jueces, así que nos comunicábamos directamente con el juzgado (...). Gastábamos mucha energía en convencer a los jueces y en hacer los informes a medida de cada juzgado: es decir, 


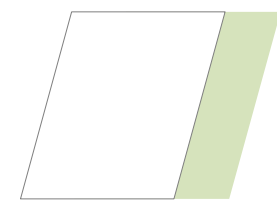

qué teníamos que poner para lograr que el pibe que estaba en una institución, porque había estado en peligro moral y material, pudiera volver a su casa si estaban las condiciones dadas (E13, Psica., 2018).

La función de informar a los/as jueces/zas sobre los/as niños/as y adolescentes es una de las tareas que los/as psicólogos/as enuncian en las entrevistas como problemática, dado que determinaba los espacios de trabajo; en especial, el espacio de entrevista individual. En palabras de una psicóloga:

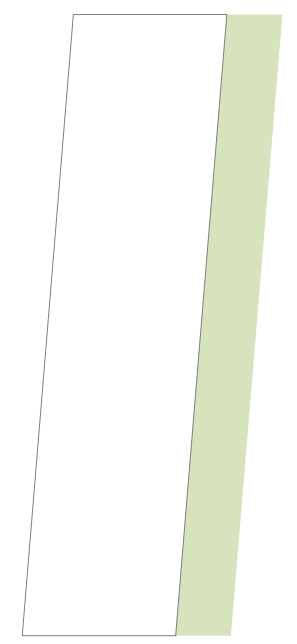

Te dabas cuenta que el chico iba a la entrevista suponiendo que vos eras el que le iba a conseguir el permiso o una salida más rápida. Entonces, el tema era ingeniártelas para poder intervenir.

Trabajaba bastante con el chico en el espacio y aclaraba algunas cuestiones, por ejemplo, que éramos dos sus referentes, pero que yo estaba para escucharlo desde otro lugar, hablando de lo que es el secreto profesional y tratando ahí de construir algo, una relación mínima, una transferencia, que por lo general se generaba con el tiempo, porque el chico también te tiene que ver hacer, te tiene que ver actuar (E9, Psica., 2017).

Desde nuestra lectura, tal operación implicaba el corrimiento del lugar y de la función establecida en la normativa para los/as profesionales, en tanto no se posicionaban como «auxiliares del/de la juez/a». No obstante, leemos puntos de resistencia en el juego de poder soberano que el dispositivo del Patronato de Menores ejercía a través de la figura del/de la juez/a.

La experiencia de una de las psicólogas muestra tales juegos de poder y de resistencias:

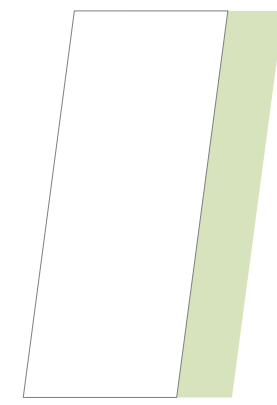

En el caso de los maternos, estaba esta concepción de que si son pobres no son buenas madres. Entonces, había que sacarles los chicos. Yo tuve una pelea con un juez, porque él quería dar los chicos en adopción. De hecho, la piba [por la madre] ingresó acá y los nenes estaban en Casa Cuna, y no había posibilidad que ella los viera. Yo tenía que evaluar si esa chica iba a ser una buena madre (...). Le contesté que no podía evaluar si iba a ser una buena 
madre cuando esa chica no tenía vínculos con sus hijos, que la maternidad no era una cuestión con la que uno nacía, que lo que yo podía determinar era si tenía algún trastorno o algún cuadro psicopatológico que, en principio, pudiera inhabilitarla, pero que eso no era para toda la vida. Pero como ella era pobre, y no sabía ni leer ni escribir, no podía ser una buena mamá. Había que sacarle a las criaturas para cuidarlas y protegerlas. Y nosotros le decíamos que no. Por ejemplo, la nena de un año o un año y medio había hecho una depresión, no comía, por la separación con su mamá, y el bebé vivía de broncoespasmo en broncoespasmo. Bueno, después de tanto pelear, me dio la autorización para las visitas y yo la acompañé a todas. Cuando nosotros empezamos a acercar a la mamá, y a vincularla tres veces por semana, los chicos empezaron a mejorar, la nena empezó a engordar y el bebé empezó a tomar la leche.

Y, bueno, habíamos hecho una conexión con una institución para que se vaya allá y el tipo [por el juez] ya quería darlos en adopción. Pero necesitaba nuestra firma y nosotros nos negamos. Toda una pelea y se la gané: la piba se fue con sus dos hijos a un instituto que estaba en $\mathrm{X}$ y yo la seguí durante muchísimo tiempo, incluso siendo mayor. Se casó, tuvo otros dos nenes más. En esas condiciones, la vulnerabilidad de los pibes en el afuera, a veces, era menor que en el adentro. Había que pelear (E1, Psica., 2016).

Ahora bien, estos puntos de resistencias no se presentan como una práctica homogénea en todos/as los/as psicólogos/as que integraban los equipos técnicos. En las entrevistas se indica que había equipos técnicos que «funcionaban más para los juzgados que para el instituto. Y eso, no sé cómo está ahora, pero se sostuvo mientras yo estuve».

Otro elemento de determinación de la normativa, relacionado con el lugar centralsoberano que ocupaba el/la juez/a de menores, se vincula con el hecho de que para intervenir con los/as niños/as y adolescentes en espacios diferentes a los del instituto penal o el hogar, los/as profesionales debían contar con la autorización del/de la juez/a. Todo movimiento hacia afuera del establecimiento debía ser informado y autorizado. 
De este modo, los establecimientos dependientes del organismo estatal que ejecutaban las disposiciones del/de la juez/a cumplían la función de disciplinamiento de los niños/as y adolescentes tutelados/as, lo que evidencia la función isotrópica de tales instituciones que articularán, por ejemplo, con la escuela.

Puntuamos, allí, otro elemento de determinación sobre los dispositivos de intervención que implementaban los/as psicólogos/as, dado que una de las tareas que debían realizar era la de «articulación» con las escuelas, trabajo que implicaba todo un dispositivo de intervención con los equipos escolares y de articulación entre ambas instituciones (hogarescuela).

\section{La producción de sujetos de derechos}

Como ya hemos situado, con la Ley 13.298/05 de Promoción y Protección Integral de los Derechos de los Niños se delinea un dispositivo mediante el cual los/as niños/as y adolescentes son definidos/as como sujetos de derechos. Para que tal definición se materialice, se establece que el Estado provincial debe promover «la remoción de obstáculos» que limiten la igualdad y la libertad o que impidan o entorpezcan su «pleno desarrollo y la efectiva participación en la comunidad» (Título I, capítulo único, artículo 5); al tiempo que debe «asegurar con absoluta prioridad la realización de sus derechos sin discriminación alguna» (Título I, capítulo único, artículo 6).

En su análisis, Ábalos, Centurión y Vitale (2009) sostienen que, para garantizar el acceso a los derechos que todos los/as niños/as y adolescentes requieren, las políticas públicas deben generar, a su vez, políticas específicas que contemplen medidas de protección especiales para grupos delimitados. En este sentido, señalan que en la normativa no se describe la forma que puede tener esta garantía, es decir cómo garantizar el acceso, en tanto principio que debe tenerse presente en cada una de las intervenciones, entendidas como «el conjunto de acciones estatales destinadas a producir una mejora en la calidad de vida de un niño ya sea protegiendo o promoviendo sus derechos» (Ábalos, Centurión \& Vitale, 2009, p. 20). 
Los autores ubican un cambio estructural con respecto a la ley anterior, en tanto se traspasa el diseño de la política pública de manos del/de la juez/a al Poder Ejecutivo, quien deberá pensar estrategias trasversales e integrales para la atención de los derechos vulnerados. El cambio reside, entonces, en la dimensión de la institucionalización de otras políticas públicas estatales en clave de derecho y en la destitución de mecanismos de poder de soberanía que operaban en la figura del/de la juez/a de menores.

En este sentido, ubicamos el Sistema de Promoción y Protección Integral de los derechos de niños, niñas y adolescentes (SPPID) como un dispositivo mediante el cual el Poder Ejecutivo, a través de la implementación de las políticas públicas, tiene la obligación de garantizar la plena y efectiva satisfacción de los derechos sociales de los/as niños/as y adolescentes; y el Poder Judicial, la obligación de asegurar el acceso a la exigibilidad de los derechos, toda vez que estos no sean satisfechos.

El funcionamiento del sistema en una lógica de transversalidad implica una unidad central de aplicación que dirige la implementación de las políticas públicas a través del diseño de estrategias de intervención y de la desconcentración, de allí que la política pública de infancia está coordinada por la Subsecretaria de Niñez y Adolescencia dependiente del Ministerio de Desarrollo Social (Ábalos, Centurión \& Vitale, 2009), denominada en la actualidad Organismo de la Niñez y Adolescencia.

En este punto radica, desde nuestra perspectiva, uno de los elementos diferenciales más fuertes respecto al dispositivo del patronato: si allí quien coordinaba se ubicaba en la punta de la pirámide en ejercicio de un poder soberano, como era el/la juez/a de menores, aquí el responsable de esta función, quien hace funcionar esos sistemas, no es un individuo, sino un organismo estatal que, a su vez, está contenido en un sistema más grande.

Consideramos oportuno ubicar el contexto político que posibilitó, no solo la derogación del Decreto Ley 10.067/83 del Patronato de Menores, sino también el diseño de todo un dispositivo de promoción y de protección integral de la niñez y la adolescencia, y sus grupos familiares. Tal contexto, como fue desarrollado en los antecedentes, se caracteriza por el diseño de políticas públicas inclusivas, entre ellas la Asignación Universal por Hijo 
e Hija (AUH), a través de la cual, a la obligatoriedad de los padres y las madres de la asistencia de sus hijos/as a la escuela se le garantiza un derecho; a la obligación del cuidado de la salud de sus hijos/as se le garantiza un derecho; ya que para que tales obligaciones puedan efectuarse es necesario garantizar el acceso al trabajo y a un sueldo digno, que posibiliten satisfacer las necesidades básicas.

De modo tal que la $\mathrm{AUH}$ es una política pública dirigida a un sector de las familias, aquellas que se encuentran en situación de vulneración efectiva del derecho al trabajo, que asigna un monto de dinero mensual por hijo/a (como también a las mujeres embarazadas que se encuentren en dicha situación de vulneración), quienes deben cumplir con el plan de vacunación y con la educación escolar de sus hijos/as.

Tal política pública conlleva una serie de estrategias de poder biopolíticas y disciplinares sobre la vida de la población, pero de un modo totalmente distinto al anterior, puesto que la pobreza no resulta objeto de políticas públicas tutelares, vía su judicialización. Esta diferencia que no es ajena a las prácticas que realizan los/as psicólogos/as en los establecimientos del Organismo de la Niñez y Adolescencia de la provincia de Buenos Aires, dado que delimita y que determina cuándo, por qué y para qué ingresan los/as niños/as y adolescentes a los mismos.

Ahora bien, la aplicación de tales normativas, tanto de SPPID como de SRPJ, solo puede darse en el marco de un Estado que garantice el acceso a derechos, dado que, cuando tales políticas se rigen por la lógica del mercado se generan mayores sectores de la población bajo la línea de la pobreza y un vaciamiento de las instituciones públicas estatales, lo que impacta en la población que ingresa al SPPID.

Al decir de los/as psicólogos/as entrevistados/as:

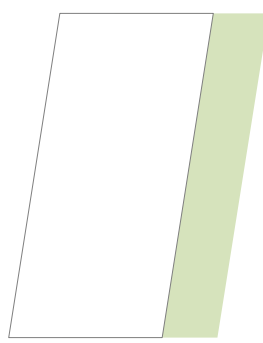

¡Quiere volver! ¡No! Lo que pasa es que no tienen para comer. La semana pasada vino una chica desde el conurbano a buscar trabajo. Eso habla de la ausencia del Estado. Se encuentran con una realidad difícil, la están pasando mal, realmente, gente con hambre... La está pasando muy mal la gente. Nunca nos había pasado que las chicas volvieran a buscar trabajo para poder comer. 
Desde que estoy acá no había pasado... pero a mí me parece que hay algo que tiene que ver con lo ideológico, con cómo está armado el sistema, para qué responde el sistema, qué es lo que pensamos cuando tenemos que intervenir (E14, Psic., 2016).

Pensamos en los derechos vulnerados del niño y no pensamos en la vulneración de los derechos de la familia que son derechos sociales; entonces, en esa escisión que hacemos no podemos pensar que muchas de las cosas que les pasan a los pibes son por las condiciones de precarización de ellos, de sus territorios... Me parece que si uno olvida esa dimensión, fragmenta, trabaja con la punta del iceberg, no sobre las causas reales. No digo todas las causas, porque tenemos chicos que son abusados, tenemos perversiones, pero la verdad es que esos chicos que están en el sistema son un porcentaje mínimo respecto a todos los que entraron, muchos en este último año y medio [en referencia a 2017-2018], por eso se ha incrementado la demanda de vacantes. El sistema está desbordado, porque hay muchos niños que las condiciones sociales y económica han permeado (E15, Psica., 2016).

Tales situaciones económicas y sociales derivan en un mayor ingreso de niños/as y adolescentes con medidas de abrigo institucional por razones de pobreza, lo que implica una alteración en el orden de prioridad respecto a las medidas a tomar, según las cuales se delimita que, cuando lo que causa la amenaza o la violación de derechos son necesidades básicas insatisfechas, carencias o dificultades materiales, laborales o de vivienda, las medidas de protección a implementarse son vía los programas que brinden tales recursos «para el mantenimiento y fortalecimiento de los vínculos familiares» (Título II, capítulo IV, artículo 34).

En coincidencia con Fasciolo (2018), puntuamos aquí un elemento determinante en los dispositivos de intervención con los/as niños/as y adolescentes que ingresan a los establecimientos por tales condiciones: si bien las nuevas normativas se proponen la desinstitucionalización se continuó «institucionalizando» un gran número de niños/as y adolescentes mediante las llamadas "guardas institucionales», «medidas de abrigo» y otras modalidades de intervención propias de los fueros civiles y de familia. 


\section{El distanciamiento territorial}

EI SPPID establece la existencia de dispositivos territoriales, bajo la figura de los Servicios Locales de protección de derechos que en cada municipio debe establecer la Autoridad de Aplicación, cuya función es facilitar que los/as niños/as y adolescentes que tengan amenazados o violados sus derechos puedan acceder a los programas y a los planes disponibles en su comunidad y «buscar la alternativa que evite la separación del niño de su familia o de las personas encargadas de su cuidado personal, aportando directamente las soluciones apropiadas para superar la situación que amenaza con provocar la separación» (Título II, capítulo II, artículo 18).

Tanto la Ley 13.298/05, como su Decreto Reglamentario 300/05, nos posibilitan ubicar sobre qué sector de la población de niños/as y adolescentes intervienen los/as psicólogos/as que trabajan en los establecimientos del actual Organismo de la Niñez y Adolescencia de la provincia de Buenos Aires: aquellos/as que se encuentran bajo una medida de protección de derechos, como es una medida de abrigo institucional en un establecimiento del Organismo. Tal medida es tomada por el equipo técnico que integra el SPPID en el territorio, y debe durar hasta que se diseñen otras que preserven o que restituyan los derechos vulnerados.

Ahora bien, de las entrevistas emerge que las medidas de abrigo son decididas por un equipo en el territorio y su cumplimiento se materializa en un establecimiento cuyo equipo técnico está compuesto por otros/as profesionales, diferentes a quienes la tomaron; de lo que se deriva la necesidad de una articulación permanente entre ambos equipos.

Sin embargo, cuando el SPPID no dispone de establecimientos en las ciudades de pertenencia y de referencia de los/as niños/as y adolescentes, ¿a qué distancia de las mismas se cumplen las medidas de abrigo institucional? Pregunta que abre otro interrogante: ¿cómo, a través de qué dispositivos, es posible la intervención sobre las condiciones que causaron tal medida de protección cuando opera una distancia geográfica que imposibilita el encuentro del equipo técnico profesional con los grupos de pertenencia y de referencia comunitarios y familiares? 
Puntuamos aquí un elemento de fuerte determinación en los dispositivos de intervención que implementan los/as psicólogos/as, dado que la posibilidad de trabajar sobre las condiciones que produjeron la medida de protección de derecho queda determinada por la distancia geográfica y por las posibilidades de coordinación entre los equipos del establecimiento donde se encuentra el/la niño/a o el/la adolescente y los equipos de los servicios locales.

\section{La claridad del debido proceso}

La Ley 13.634/07 del Fuero de Familia y del Fuero Penal del Niño establecen que el/la joven en situación de transgresión a la ley penal es sujeto de derecho al debido proceso. De esto se deriva que la medida a cumplir ya no dependerá de la decisión unipersonal del/de la juez/a, sino que será el resultado de un proceso donde el/la joven deberá ser escuchado/a.

Respecto al impacto de esta ley en los dispositivos de intervención implementados por los/as psicólogos/as, los/as profesionales entrevistados/as señalan:

[La ley] es más clarificadora respecto del rol. Todavía me parece que nos hace falta trabajarlo mucho. Pero le dio más claridad a esto de intervenir en la cuestión penal. Antes era muy poco clara. El pibe venía porque estaba acusado de un hecho penal y había que trabajar la famosa responsabilidad, ¿responsabilidad de qué? Si ni siquiera sabíamos si era culpable o inocente. Se confundía mucho en ese momento lo penal con lo asistencial.

(...) Hoy el pibe está detenido, claramente, con una prisión preventiva o con una medida alternativa a la privación de libertad o con una semi-libertad en el caso de los Centros de Contención. Y me parece que está más claro. Te delimita respecto de quién es ese sujeto que vos tenés, por qué está ahí... Y poder empezar a laburar a partir de eso (E16, Psica., 2017).

Nosotros sabemos que con los chicos que hoy vienen acá hay una intervención judicial clara, con una acción judicial clara, porque el pibe tiene alguien que lo asiste y alguien que lo defiende, y un juez de garantías que vela durante todo 


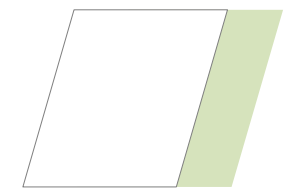

el proceso. Antes el juez decía: «A este chico, por las dudas, porque puede ser que mañana mate a alguien, porque es pobre, lo vamos a internar». ¿Entendés? Esa es la gran diferencia (E9, Psica., 2017).

Tal diferencia determina que en un mismo establecimiento penal no se encuentren jóvenes con problemáticas muy disimiles; esto es, «un pibe que había robado en el quiosco y que la primera noche se hizo pis en la cama, con aquel con una situación más compleja». En este sentido, los/as entrevistados/as demarcan la diferencia entre «tener un sistema y no un régimen».

Puntuamos aquí un elemento clave, dado que el debido proceso destituye el poder soberano del/de la juez/a productor/a de encerronas que son consideradas trágicas, «por configurar una situación en la cual alguien depende de alguien que lo maltrata o lo destrata quitándole la condición de sujeto, y que al negar tal condición se instauran cultural y jurídicamente sistemas de tutelaje arbitrarios»(Ulloa, 1995, p. 185). Destitución que implica pensar en clave de ternura y, con ella, «la renuncia al apoderamiento del infantil sujeto» (Ulloa, 1995, p. 135). Al decir de los/as psicólogos/as entrevistados/as: «Se trata de que allí siempre haya un sujeto».

\section{Determinaciones institucionales}

En las entrevistas realizadas hemos localizado que para el diseño de los dispositivos de intervención con los/as niños/as y adolescentes los/as psicólogos/as efectúan un primer movimiento vinculado a la lectura y al análisis de las tramas institucionales.

Al decir de los/as profesionales: "Pensar cuáles son los quiebres institucionales», «qué te demanda la institución», para «ver por dónde ir y por dónde no», e implementar dispositivos de intervención que posibiliten «instalar otra manera de escuchar a los pibes», lo que evidencia en los elementos que disponen una intencionalidad vinculada 
a introducir movimientos en las relaciones de poder-saber fijadas en los establecimientos, para intervenir en situaciones de objetalización sin, en el mismo movimiento de intervención, objetalizar tutelando.

En otras palabras, los dispositivos que implementan los/as psicólogos/as entrevistados/as se proponen introducir en el dispositivo institucional otro juego de fuerzas de poder-saber.

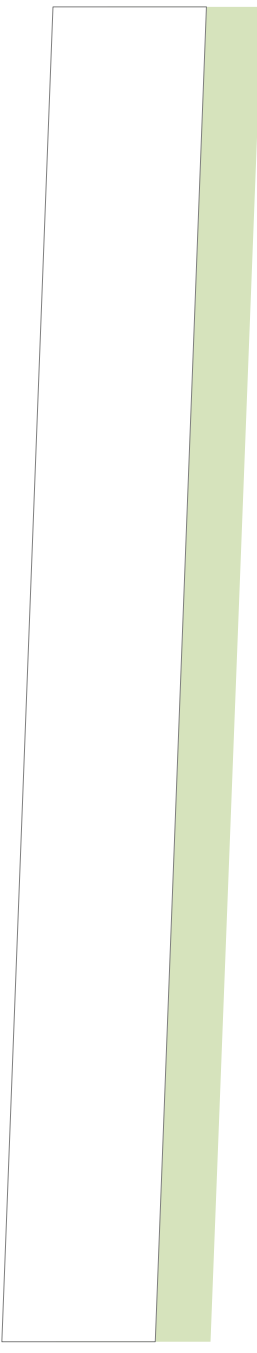

Es una institución que hace años que está estallada, porque es un modelo que ya no resiste; que se preserva, pero que se debiera haber caído hace quince años, y lo seguimos sosteniendo porque no hay una propuesta mejor. Entonces, sabiendo todo eso, que las instituciones son instituciones que ya están vencidas, que son obsoletas, que su funcionamiento sigue siendo el funcionamiento del patronato, ¿no?

Aun sabiendo eso, lo que intentamos es pensar los quiebres institucionales por donde poder instalar otra manera de escuchar a los pibes, a la familia, de pensar que tienen que estar el menor tiempo posible y cómo en ese tiempo podemos neutralizar de alguna manera los efectos institucionales. Cómo potenciar aquellas cosas que el pibe sí puede, aun cuando éramos pocos los que pensábamos que ni bien el pibe entra la institución tiene que ser reparadora.

Eso es como permanente, es un trabajo que nos tenemos que dar con nosotros mismos y con los compañeros que no lo entienden de esa manera. No es una meta a alcanzar, es un objetivo cotidiano. Lo que me parece que está bueno es que, superada la idea de la queja, de pensar que está todo mal, darnos un momento para pensar qué cosas sí se podían y, a partir de pensar qué cosas sí se pueden, empiezan a aparecer posibilidades de intervención (E13, Psica., 2018).

En tales juegos de fuerzas los/as «maestros/as», los/as «operadores/as», que están en contacto cotidiano con los/as niños/as y adolescentes, y el/la director/a de los establecimientos son caracterizados como aquellos/as que, en el cumplimiento de sus funciones, componen focos locales de reproducción de un tipo de poder instituido, y por ello estable. 


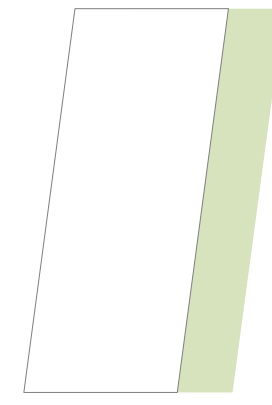

Las guardias son de 24 por 48, y jhacen 180 horas! Están todo el día de guardia, están más presos que los pibes. Entonces, esto empieza a generar roces, situaciones... Estas fantasías del asistente de «si yo te doy esto entonces vos me lo vas a agradecer y me vas a responder como espero». No te lo dicen, pero uno lo ve y el chico responde como responde. $Y$, bueno, empiezan lo roces (E11, Psica., 2016).

Sobre tales instituidos es que los dispositivos que implementan los/as psicólogos/as entrevistados/as se proponen intervenir, para bloquear y/o para neutralizar líneas de fuerza tutelares, productoras de encerronas trágicas que objetalizan, y para instalar otras fuerzas de saber-poder productoras de sujetos.

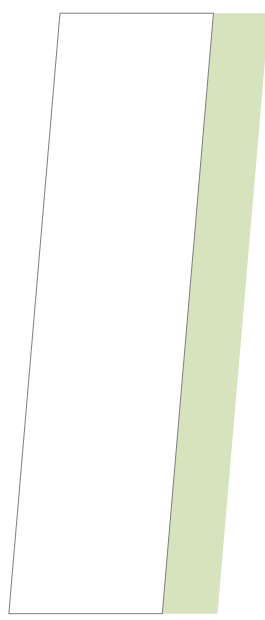

Creo que uno no solo tiene que intervenir con el/la joven sino también con la institución; es decir, un profesional que está dentro de una institución tiene que intervenir con la institución. Nosotros tenemos la responsabilidad de trabajar con nuestros compañeros que un día los pusieron a trabajar en una institución sin capacitaciones. Entonces, claramente no estaban con la posibilidad de poder plantear esta distancia óptima con el otro y no creer que el otro -el/la niño/a o adolescente- tiene que ser como yo quiero que sea, no es mi espejo (...). Creo que nuestra función tiene ser, insisto, intervenir con el/la joven y en la institución (E11, Psica., 2016).

Entre las líneas que se anudan en las tramas institucionales de los establecimientos, a continuación, distinguimos aquellas que se presentan en las entrevistas como determinantes a la hora de diseñar y de implementar dispositivos de intervención.

\section{Violentaciones y miedos}

Respecto a las violencias, recuperamos aquí los aportes de Ulloa (1995) y de Kaminsky (2011), dado que toda institución es un dispositivo de violencia; en tanto dispositivo de las relaciones sociales anclado históricamente es un espacio producido y productor de múltiples modalidades de violencias. En esta línea, la creación de toda institución supone 
cierta violentación legítimamente acordada, que hace posible establecer normas necesarias para el funcionamiento de las actividades de esa institución, propio de un proceso que implica el pasaje de lo privado a lo público.

Sin embargo, cuando tal violentación se torna arbitraria en grados y en orígenes diferentes se configura lo que Ulloa (1995) denomina «Síndrome de Violentación Institucional (SVI)», que implica diversos grados de acostumbramiento y de intimidación que atentan contra la necesaria intimidad para investir de interés personal la tarea que se desarrolla, y que imposibilita la resonancia íntima que hace posible alojar el decir del otro.

En las entrevistas se describen situaciones caracterizadas como «violencia institucional, institucionalizada más que institucional», en las cuales el «maltrato o destrato» se presenta con marcada insistencia y produce encerronas trágicas que objetalizan tanto a los/as niños/as y adolescentes como a los/as trabajadores/as.

Ahora bien, cada situación de violentación institucional es acompañada de un dispositivo para intervenir en la misma, hayan podido efectuarlo o no; pero la intensidad en el relato de afectos ligados con la alegría de encontrar los espacios por donde interrumpir tales violencias insiste casi al mismo ritmo que los enojos por los obstáculos y las resistencias, evidenciándose ciertos «tempos» en los juegos de fuerzas que pujan en la tensión instituido-instituyente-institucionalización.

Estos «ritmos polifónicos» (Kaminsky, 2011), que se mueven entre la estabilización mortecina (Ulloa, 1995) y la invención de dispositivos para interrumpirla, nos muestran ciertos juegos de fuerzas, que en ocasiones se intensifican y en otras se aplanan. Interrogar «qué te pide la institución», «qué es lo que sucede», produce un primer movimiento de interrupción de líneas inertes, repetitivas de lo mismo.

Un elemento que se destaca en tales pujas de fuerzas instituidas-instituyentes es que los dispositivos que se diseñan, sean implementados o no, según el tipo de dirección y de gestión, tienen la característica de intervenir sobre los efectos que la institución produce, sea en los/as niños/as y adolescentes, sea con el equipo técnico o con los/as operadores/as y/o maestros/as, lo que muestra que la institución se ha transformado en 
«clienta de ella misma» (Ulloa, 1995), muy alejada de sus objetivos específicos: cuidar, proteger de los riesgos morales o materiales, en tiempos tutelares; y restituir derechos, en tiempos de sujetos de derechos.

En los/as entrevistados/as, los efectos de tales pujas de fuerzas son nombrados como «padecimientos», «desgastes», «frustraciones», «te liman la cabeza», «sentí alivio cuando me fui». El decir de una psicóloga entrevistada, visibiliza esta dimensión: «Sabíamos que la cosa no iba a ser fácil y que seguro se iba a intentar que fracase, y que la línea venía por otro lado. Entonces me jubilé... Vos no sabés lo que era esa época. Era horrible» (E13,Psica, 2018).

El miedo se desliza por varias de las escenas relatas, que a su vez contienen la potencia de visibilizar la cotidianeidad de la violentaciones productoras de tales miedos, centralmente, orientados a los/as jóvenes y a lo jurídico. En referencia a los/as jóvenes: «Los tipos calan a ver si vos tenés miedo y demás (...). Salvo que sea demasiado frágil, tampoco está autorizado a contarte que tiene miedo, ¿no? Entonces, el tema es ingeniártelas para poder intervenir».

La seguridad pasa por otro lado, eso lo aprendés de ciertas experiencias. Pero, bueno, sin esas experiencias esa situación la hubiera vivido de otra manera. Lo que hice fue buscar al chico, y como no me conocían los chicos me presenté. Los saludé a todos con un beso. Me miraron como diciendo: «¿Qué hace este flaco acá?».

Pero si vos no los ves como peligrosos, no pasa nada, ¿qué va a pasar? Entré, saludé, me presenté, le pregunté a un chico si quería hablar conmigo. Y un día, en una reunión por una práctica de forense, uno de los chicos que se acordaba de eso me lo dijo: «Vos una vez viniste y te metiste en la recreación. No nos tuviste miedo». Lo vio como algo valioso y venía por ahí la cosa. «Nos venís a buscar de otra manera». En ese sentido me dio esa experiencia el haber trabajado como asistente. El ir a buscar a un sujeto desde otro lugar (E10, Psic., 2018). 
Otro día, por ejemplo, estaba trabajando y veo una señora que corría gritando: «No, no...». Salí y la escena que me encontré era la señora que corría adelante -los pibes la odiaban porque los maltrataba- y detrás un pibe con un cuchillo. Entonces, le pregunté: «¿Qué estás haciendo?, ¡dame ese cuchillo!». Y me lo dio. Y la señora me dijo: «Muchas gracias, creí que me iba a matar».

También recuerdo ver pasar una psicóloga corriendo y detrás un pibe con un palo. Yo digo, no pueden trabajar con miedo sino los pibes los van a cagar a palos. O sea, cuando vos tenés tanto miedo o haces una alianza para no tener miedo o te pasan estas cosas. Esto es muy difícil transmitirlo. Yo les decía siempre a los estudiantes, lo que no hay que hacer es mentirles, porque todos les mienten. Si ustedes les dicen la verdad no les van a pegar (...). Esta cosa del miedo hace que sea poco lo que puedas ponerte en el lugar del otro y entender lo que procesa el pibe.

Siempre digo, tengo tantos motines sobre la espalda, pero nunca me pasó nada. Lo que creo es que hay una cosa que es percibida inconscientemente y en esa percepción inconsciente de los miedos del otro aparece una respuesta. Es muy difícil. Muchas veces les puse a los asistentes de minoridad el siguiente ejemplo: si el personal de terapia intensiva piensa y siente que todos los pacientes que entran a terapia intensiva se van a morir, se van a morir. Esto es parecido. Si vos pensás que son unos hijos de puta, van a ser hijos de puta. Si vos tenés miedo, te lo van a hacer (E3, Psica., 2018).

El miedo a «lo jurídico» es un elemento que insiste, aun habiéndose destituido en las leyes el poder soberano del/de la juez/a:

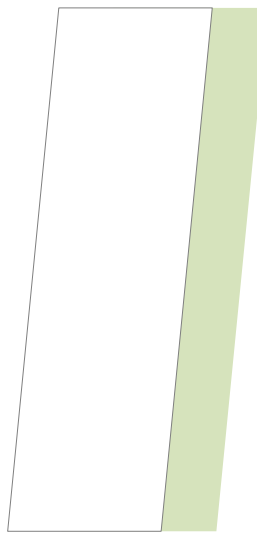

Lo jurídico todavía talla en los agentes, siempre con temor a que si después pasa algo la responsabilidad sea de ellos. Yo digo que se repone el patronato, porque lo jurídico no se ha corrido, la dimensión de lo jurídico sigue estando presente, aunque en los hechos sea el ejecutivo el que tome la medida o el que intervenga; al menos de forma amenazante, como una sombra, el patronato sigue estando presente. En los pasillos se dice: «El fantasma de menores que se los come a todos. Que se los traga a todos». Se escucha que hay intentos de cambio que uno termina repitiendo (E11, Psica., 2016). 


\section{Las fragmentaciones entre los/as asistentes y el equipo técnico}

El personal denominado «asistente de minoridad», que está en contacto cotidiano con los/as niños/as y adolescentes, es caracterizado por los/as psicólogos/as entrevistados/as como «una serie de adultos que no siempre quieren estar ahí donde están, que no siempre los quieren cuidar, que tienen también sus derechos laborales precarizados», y cuyos roles y funciones producen malestares y sufrimientos, máxime cuando, siendo un cargo encuadrado en la Ley 10.430/96 de Estatuto y Escalafón para el Personal de la Administración Pública de la Provincia de Buenos Aires, «tienen que reducir a un pibe para que no se pelee, requisarlo o abrir un candado».

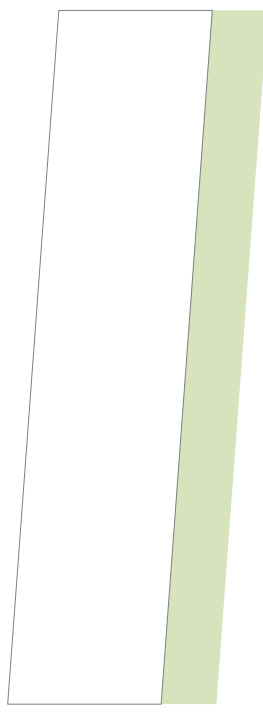

Porque hay que estar, también, recibiendo las demandas de los chicos, y a veces con herramientas muy limitadas. $Y$ estar con pibes que te piden: «Che, ¿me pasás tal cosa?». Y si no podés hacer la lectura de que un termo no es un termo y que puede significar otra cosa se te complica mucho la tarea. Si vos lo pensás como «este pibe me está hinchando las pelotas», entonces, es un trabajo que genera mucho malestar (E10, Psic., 2018).

Es la misma gente la que genera los desbordes de los cuales después vienen a quejarse. Van al pibe y «jlevántate!» y el pibe hace una crisis, y «uh, ¿viste este chico las crisis que hace?». Todo el tiempo trabajar con la gente para esto del detalle (E2, Psic., 2016).

Puntuamos aquí un elemento que muestra la producción de grados de violentación, que configura síntomas asociados al Síndrome de Violentación Institucional (SVI) y que imposibilita la resonancia íntima que permite alojar el decir del otro; en este caso, de los/as niños/as o adolescentes a quienes tienen la función de «cuidar».

Como ya desarrollamos, uno de los síntomas del SVI es la tendencia a la fragmentación en el entendimiento, que hace obstáculo a la construcción de un acompañamiento solidario, al refugio en el propio quehacer, y que produce enfrentamientos entre el equipo técnico y los/as asistentes. Tales efectos se presentan como determinantes al momento de intervenir con los/as niños/as y adolescentes. 


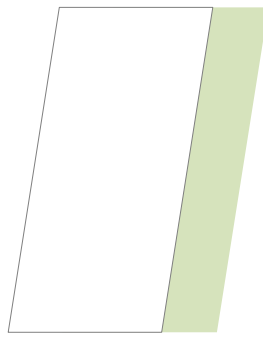

Es muy difícil. Hay una división, como que la psicóloga «no sabe cómo trabajar con los chicos», «no está con los chicos». Aparece este prejuicio. «No está en el patio, ella está allá adelante, en su lugarcito, y no sabe cuál es la realidad. Y los chicos le mienten, le cuentan cualquier cosa». Hay un prejuicio terrible con los «psi». Son muy expulsivos los institutos para los psicólogos (E16, Psica., 2017).

Ahora bien, tales «enfrentamientos» $\mathrm{y}$ «quiebres» se presentan en las pujas respecto a la información sobre los/as niños/as y adolescentes, leídos por los/as psicólogos/as entrevistados/as como situaciones en y con las cuales requieren operar.

Una de las psicólogas caracteriza como una «lucha» la circulación de dicha información, entre otras razones, porque la información que los/as psicólogos/as tienen es «muy subestimada», debido a que los/as asistentes «sienten que ellos tienen la verdad sobre lo que les pasa a los pibes».

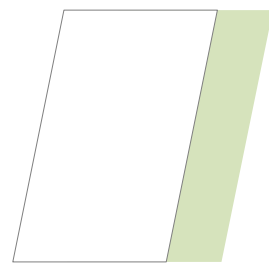

Yo hice un caminito y me han ido tomando lo que tenía para decir, y ya me conocen. Les dije: «Yo no estoy compitiendo con ustedes, ustedes están las 24 horas, seguro que saben más que yo. Yo no estoy las 24 horas, porque mi trabajo es otro (E8, Psica, 2018).

La importancia de la construcción de un acompañamiento solidario en el quehacer institucional se muestra en la siguiente situación relatada por una psicóloga:

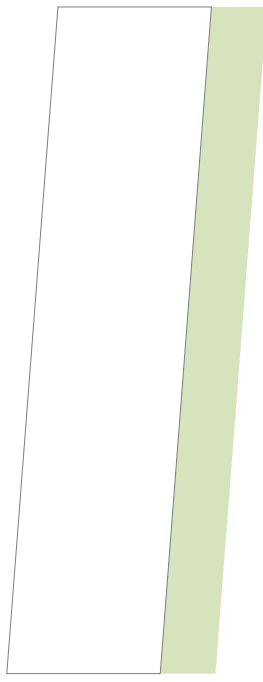

Una vez le dije a un maestro: «Mirá, a este pibe ya lo entrevisté y, mirá, cuanto más tranquilo preocúpate más. Es un pibe que si va a pegar a alguien no hace bulla, va a esperar a que este todo tranquilo». No pasaron 10 minutos, yo me fui a la oficina y el pibe vio pasar a uno, le pegó una piña y le rompió el tabique. Después que pasó todo eso, el maestro vino y me dijo: «Era como vos decías». «Viste, yo no te lo digo para marcarte el terreno, ni para hacerme la sabionda. Seguramente, hay información que vos tenés del pibe que yo necesito, y hay información que yo tengo que te la tengo que dar porque te estoy cuidando». Porque el asistente terminó no solo parando al pibe para tener que separarlo, y poner el cuerpo, sino que terminó en la policía, 


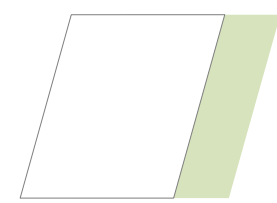

con denuncia, demostrando que no fue él el que le rompió el tabique al otro pibe. Con el tiempo, los asistentes fueron comprendiendo un poco más; son bastantes resistentes, también (E8, Psica, 2018).

Una de las operaciones que efectúa otro psicólogo para intervenir en las fracturas entre el equipo y el «personal de patio» es mostrar que «tu intervención también hace, pero, bueno, también son lugares que uno tiene que ir construyendo. Por ejemplo, decirle a un asistente: "¿Te hago una pregunta? ¿Qué pensás de tal pibe?"».

En las experiencias relatadas, acercarse al/a la asistente, preguntar sobre un/a «pibe/a», posibilita construir una relación de trabajo.

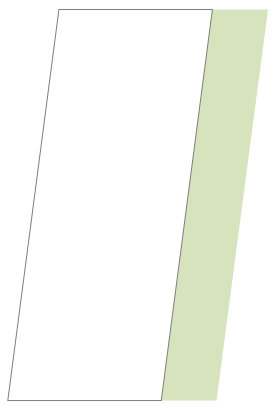

Si había que buscar algún operador o asistente que tuviera más honda para trabajar con un/a pibe/a, buscaba. Iba, hablaba, preguntaba: «Che, ¿cómo lo viste?». O advertía: «Che, fijate que por ahí quedó movilizado por algunas cuestiones que trabajamos de su historia. Miralo, tenelo en cuenta. Avisame cualquier cosa». Y les decía que cualquier cosa me llamaran (E10, Psic., 2018).

El efecto de esta situación fue un movimiento de acercamiento del asistente a la psicóloga para transmitirle: «Che, fijate que tal está angustiado, no pudo comunicarse con la familia».

El libro de guardia es un elemento institucional en el que se plasma la información referida a la vida cotidiana de los/as niños/as y adolescentes en la institución. Allí se debe registrar todo, cada acto del cotidiano queda allí asentado. Al respecto, uno de los psicólogos entrevistados sostiene:

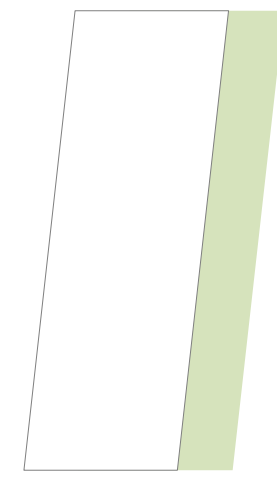

Es algo en relación con el saber, ellos/as saben. Dicen: «Los chicos les dicen a los profesionales lo que quieren escuchar, vienen un ratito y nada más. Nosotros estamos todo el día con los chicos». Parece que también pasa un poco por la manera de mirar, por la manera en la que, en general, los profesionales nos posicionamos ante los saberes adquiridos por los que están trabajando con los chicos. Entonces, no se toman en cuenta como un insumo, no se pregunta: «Che, ¿qué paso acá? ¿Vos qué pensás de esto?». 
Más allá de que se le diga mentiroso al libro de guardia, por lo menos está para ir a preguntar, para ir a convocar a otros saberes, porque de lo contrario quedás cerrado ahí. Y me parece que si eso no aparece se propician las fracturas. Si está todo el día, en la cotidianeidad, ¿cómo no preguntarle? También hay que ver a quién preguntarle, por supuesto. Pero bueno, que el otro tenga un saber ahí que también puede aportarte a vos (E10, Psic., 2018).

Otro de los elementos que se evidencia como productor de fragmentaciones entre los/las asistentes y el equipo técnico refiere a la desigualdad en la cantidad de horas de trabajo que cumplen unos/as y otros/as; diferencias que producen quiebres entre el equipo técnico y el personal de patio, y que derivan en situaciones con distintos grados de conflictividad con los/as niños/as y adolescentes.

Vemos aquí lo señalado por Domínguez Lostaló (1999) respecto al personal de contacto, al señalar que la función que cumplen los/as coloca en una situación de riesgo psicosocial productora de rigidez, de burocratización, de desvalorización del rol e impotencias, las cuales derivan en situaciones de violencias frente a los/as niños/as y adolescentes. Una función para la cual, en general no están preparados/as.

En dos entrevistas, se relatan situaciones de violentaciones efectuadas por los/as «maestros/as» y vinculadas a encerrar a los/as psicólogos/as con los/as jóvenes:

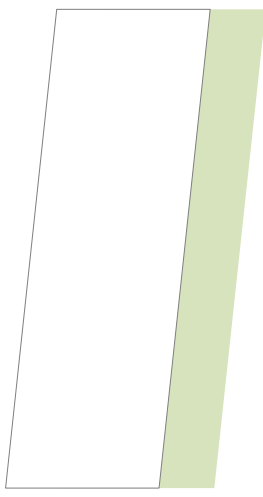

Yo era el más pibe que había entrado, con lo cual me enchufaron los 15 pibes más hijos de puta que había, y no era joda. Te cerraban del lado de afuera y te quedabas encerrado en el aula con los pibes. Había mucha violencia, mucha agresión (E2, Psic., 2016).

Cuando entré a trabajar al $X$, sin saber que yo antes había trabajado de asistente, fui a buscar a un chico, una de las primeras veces, y me engomaron, me encerraron con candado con el resto de los chicos (E10, Psic., 2018).

Estas situaciones muestran el tipo de pujas de poder presentes en las tramas institucionales, y las violentaciones producidas por las vulnerabilizaciones de los/as propios/as trabajadores/as, sean estos/as asistentes o profesionales. 


\section{Las fragmentaciones en los equipos técnicos}

Otro de los efectos que producen las violentaciones institucionales son las fragmentaciones al interior de los equipos técnicos, que los/as psicólogos/as entrevistados/as enmarcan como producidas por las políticas institucionales que «empezaron a fracturar los equipos con determinados acuerdos»; acuerdos ligados con la cantidad de horas de trabajo que, a su vez, al instalar desigualdades con otros/as trabajadores/as del establecimiento producen entre el equipo y el personal de patio quiebres que derivan en situaciones con distintos grados de conflictividad.

Tales fragmentaciones obstaculizan la construcción de pensamiento colectivo y producen una suerte de refugio en el quehacer propio, con el consabido aislamiento que este genera. Al decir de una de las psicólogas: «Creo que cada uno tiene sus respuestas individuales, el que se las pregunta tiene sus respuestas. Nos falta ese espacio para compartir y debatir, para explicitar ejes de trabajo comunes, metodologías de trabajo en general».

Leemos en las entrevistas que ante tales «intentos» de fragmentación algunos equipos han sostenido, con las dificultades del caso, los espacios de reuniones, a la vez que se describen situaciones cuyo grado de sufrimiento y de maltrato motorizaron armados colectivos para pensar y para hacer. Entre tales situaciones, una de ellas visibiliza el carácter trágico de las encerronas (Ulloa, 1995) y la urgencia del estar con otros/as.

Vivimos el suicidio de un chico. Nunca nos había pasado. Eso era algo que nunca podía pasar. Y nos afectó un montón, nos movilizó. A partir de ahí, nos juntamos varios profesionales. Hicimos numerosas denuncias. El psicólogo que atendía al chico había hecho un montón de denuncias, no solo escritas sino dichas, que están en los libros, en las actas, verbalizadas con la gente, con los operadores, con el director, advirtiendo sobre cierta situación compleja del chico que finalmente se mata. Incluso, el chico se quita la vida en un lugar que hacía rato que nosotros veníamos denunciando que no tenía que estar, que se llaman buzones, habitaciones solos. Chicos que están solos cuando se pelean o sucede alguna situación que se considera grave, grave en función de cuidar. 


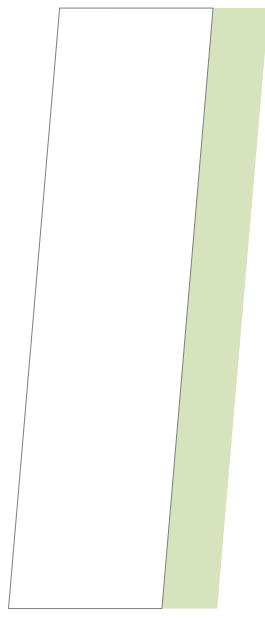

Se supone que se cuida el derecho de varios por sobre el pibe y, a la vez, como una forma de cuidar al mismo chico se lo aísla respecto del pabellón con el que tuvo el problema, hasta que se supone que se trabaje para ver qué es lo que pasó. Entonces, el psicólogo venía diciendo, gritando, ya no sabía cómo más decir, y venía también diciendo al poder judicial algunas cosas en relación con este chico, que era necesario un cambio de medida, por $\mathrm{x}$ motivos de su situación particular. Y el juzgado fue el primer sordo, digamos, se empecinó en dejar al chico ahí. Se advirtió, se advirtió, se advirtió... Y se dejó al chico ahí (E16, Psica., 2017).

Una de las situaciones relatadas muestra tanto las políticas de fragmentación como los dispositivos creados para interrumpirlas. Un ejemplo es un momento en el cual la gestión decidió sacar a todos los equipos de los institutos y centralizarlos, ante lo cual algunos/as profesionales propusieron que en cada institución hubiera una pareja de psicólogo/a y trabajador/a social, denominada «la pareja institucional», y que se centralizaran, también, parejas de psicólogos/as y trabajadores/as sociales para trabajar con los casos en los distintos institutos.

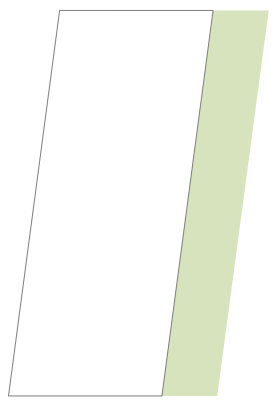

Si un/a pibe/a les cuenta que los cagan a palos, no es lo mismo que se lo cuente al psicólogo de adentro. Eso generó resistencias; con ese dispositivo les rompías el culo a todos. Porque no tenías al psicólogo sometido al poder del Director de la institución, que le decía «sacame a este» o «haceme un informe así de este». El informe no dependía de vos. Por eso te digo que generaba paranoia. Entonces, no era funcional (E2, Psic., 2016).

Ahora bien, en los relatos referidos a los equipos técnicos insisten los verbos en tercera persona del plural y en tiempo pasado, tiempos en los cuales tales fragmentaciones no existían: «Teníamos que luchar mucho», «luchábamos», «había que pelear», «trabajamos mucho para que...», «militábamos mucho la ley», y que indican un tiempo que ya no es.

Al respecto, algunos/as psicólogos/as entrevistados/as sitúan que los equipos técnicos ya no son o no funcionan como antes: 


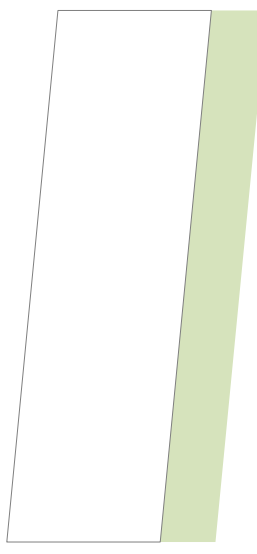

Yo creo que, en otro momento, los equipos tenían un peso que no sé si tienen ahora. Antes, los equipos técnicos tenían otra jerarquía. Al menos en mi experiencia, tuve la suerte de caer en equipos muy fuertes, con compañeros con mucha trayectoria; entonces, el peso del equipo era otro. La palabra del equipo tenía un valor que hoy no tiene. De hecho, existía el fantasma de que los equipos volteaban a los directores... Que tenía que ver con que cuando los equipos empezaron a fortalecerse denunciaban situaciones de maltrato, situaciones de violencia institucional (E1, Psica., 2016).

De modo tal que las fragmentaciones se presentan como tecnologías de poder dirigidas a interrumpir espacios colectivos, grupales, asamblearios, de equipos, por la potencia de transformación que tales espacios contienen.

\section{La resistencia a los dispositivos grupales}

Entre las determinaciones de las tramas institucionales jugadas en los distintos establecimientos, vemos que insisten las características de la dirección. El interrogante que introduce uno de los psicólogos entrevistados posibilita ver el grado de determinación que presenta el tipo de dirección que dirige el establecimiento:

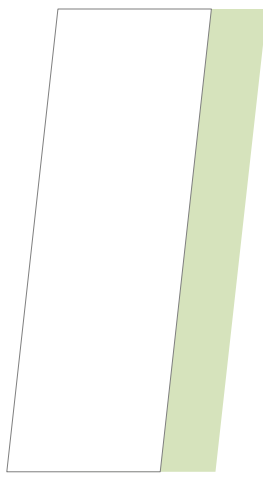

¿Qué es lo que pasa cuando trabajás en una institución? Vos tenés un Director, que lo que quiere es la funcionalidad del lugar. Con lo cual, si tenés a alguien quilombero, sácalo, expúlsalo. Tu eficiencia como psicólogo radica ahí, en que despejes rápido lo que hace problema. Eso es lo que te pide la institución. Eso es Freud. Cuando la institución te convoca, preguntate para qué te convoca. No es para que los chicos estén contentos, es para que no rompan las bolas, para que no te quemen todo (E2, Psic., 2016).

Hemos puntuado la insistencia de resistencias a la implementación o al funcionamiento sistemático de distintos dispositivos grupales, sean para trabajar con los/as niños/as o adolescentes, con los equipos técnicos, con los/as asistentes en minoridad, o para llevar a cabo asambleas con todo el personal del establecimiento. Por el contrario, no vemos 
operar tales resistencias para la implementación de dispositivos de entrevistas individuales, más aún, tales dispositivos son pedidos o son demandados por los/as asistentes o por los/as directores/as: «Que lo/a vea el/la psicólogo/a».

Las resistencias a los dispositivos grupales insisten en los relatos: en ocasiones, dichos espacios se interrumpen; en otras, no es posible su efectiva implementación; en otras, se toman medidas que imposibilitan a los/as jóvenes asistir a los grupos («tiene que limpiar», «está sancionada/o», etc.).

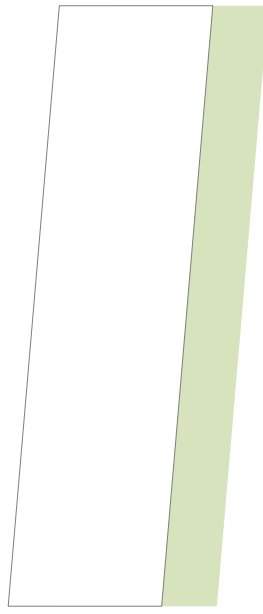

El grupo se cerró ahí. No lo continué. Lo sostuve meses, pero había más obstáculos por fuera, como los horarios. Cada vez se me hacía más difícil juntarlos y llegó un punto en que me cansé. Era estresante, porque era organizar a los chicos, y siempre alguno no podía ir porque estaba sancionado. O tenían que ir a la escuela, o limpiar, o en ese horario tenían que ir a oficios o tenían que estudiar porque tenían que ir a la escuela. Sobre todo el director, él decía: «En este horario tiene que hacer». Llega un punto en el que una está sola. Me agoté. Me cansé. Preferí trabajar de manera individual y acomodarme a los tiempos de cada uno (E11, Psica., 2016).

En otra de las entrevistas se señala que entre los efectos que producía la grupalidad estaba que surgían reclamos y que se ponían en palabras «las cosas que pasan».

La institución tiene que tener ganas de escuchar. Es como la gente. Nosotras, a veces tenemos ganas, otras veces no... O no tenemos posibilidades. Más teóricamente, sería la disposición para poder escuchar. Si no está la disponibilidad lo boicotean, ni se hacen los grupos. Son como pequeños síntomas que evidencian las resistencias de la institución. Yo lo pienso como un inconsciente institucional. $Y$ cuando leo que pasa eso y vengo trabajando en grupo, en general, hablo con el director (...). Porque lo que pasa es que los pibes empiezan a decir lo que pasa. Ahora que tenemos reunión de equipo, desde hace tres años, son cosas que se hablan en la reunión de equipo. Son cosas que se hablan (E8, Psica., 2018). 
Una de las psicólogas relata que había diseñado un dispositivo para trabajar con los padres y las madres, pero que no fue posible llevarlo a cabo. Se relatan dos experiencias en las cuales se diseñaron dispositivos grupales para trabajar que no pudieron ser implementados: «Nunca me dieron el espacio para organizar con los padres. El horario de visita es sagrado y hacerlo un rato antes no se pudo. Es difícil que te den un espacio».

Tales experiencias visibilizan para los espacios grupales movimientos irregulares, de apertura y de cierre en las tramas institucionales, lo que constata la potencia instituyente de los dispositivos grupales, tal como hemos visto en la descripción de tales dispositivos.

Puntuamos aquí una insistencia que conecta con experiencias realizadas por los/as primeros/as psicólogos/as que ingresaron a trabajar en la Dirección de Niñez, delimitadas en los antecedentes. Sin embargo, consideramos oportuno señalar la persistencia de unos modos de funcionamiento en los establecimientos respecto a los dispositivos grupales.

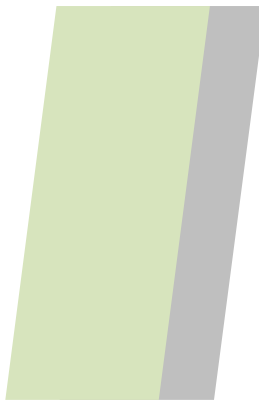

[En 1971, implementar dispositivos grupales] significaba una especie de conflicto importante con el director/a, y con los, denominados en ese momento, preceptores, ellos se enfrentaban con nosotros porque veíamos que obstaculizaban la posibilidad de que esos chicos se agrupen y construyan amistades entre sí y buscaban siempre tenerlos disgregados (...). Con lo cual se armó una revolución bastante considerable (Moratti, Veloz \& Cattani, 2013, p. 5).

Se evidencia, a la vez, la persistencia de un modo de hacer de los/as psicólogos/as en tales instituciones que trasciende las corrientes teóricas psicoanalíticas en las cuales se inscriben.

\section{Determinaciones teóricas}

Las insistencias en los relatos, como hemos indicado, no remiten a una homogenización de los dispositivos que implementan los/as psicólogos/as, sino que evidencian conexiones que nos posibilitan la construcción de líneas de determinaciones que, siendo siempre múltiples, son posibles de delimitar. 
Entre tales determinaciones, insiste el psicoanálisis como un elemento de saber que moviliza y que orienta los dispositivos de intervención. ${ }^{26}$ Insistencia que no referencia a una sola corriente psicoanalítica, dado que los/as psicólogos/as entrevistados/as no se inscriben en una misma corriente u orientación psicoanalítica.

\section{La búsqueda de efectos sujeto}

En el trabajo en los hogares, tanto en tiempos normativos de tutela como en tiempos de sujetos de derechos, insiste la implementación de dispositivos orientados a que la institución pueda efectuar las funciones de cuidado y de sostén, de acuerdo a los tiempos y a las necesidades subjetivas de los/as niños/as y adolescentes, funciones propias de lo que Ulloa (1995) denomina «institución de la ternura».

Los saberes respecto a los tiempos de estructuración subjetiva y del desarrollo del yo fundaron la implementación de dispositivos de atención centrados en crear los mecanismos para propiciarlos; dispositivos siempre singulares y atentos al detalle. En palabras de uno de los psicólogos, esto implica que lo diseñado para un/a niño/a o adolescente «no se repite necesariamente en otro. Y eso es atender la singularidad».

Aquí, puntuamos también la insistencias en los propósitos que orientan los dispositivos implementados como "generar condiciones para la emergencia del sujeto», «escuchar la palabra de los niños, las niñas y los adolescentes», para la producción de efectos «subjetivos» o de «efectos sujetos», «apostando siempre a que ahí hay un sujeto».

La categoría sujeto se presenta como una de las determinaciones que orientaba el diseño y la implementación de los dispositivos de intervención de los/as psicólogos/as aun en tiempos normativos de los/as niños/as y adolescentes como objetos de tutela. El «aun» refiere a que en tiempos donde los dispositivos institucionales materializaban políticas públicas tutelares, los/as psicólogos/as implementaban dispositivos que se proponían tanto interrumpir los efectos de objetalización como producir efectos sujetos; dicho de otro modo, que la palabra de los/as niños/as y adolescentes emerja y sea escuchada.

26 Tal insistencia se presenta en quince de los/as dieciséis psicólogos/as entrevistados/as. 
En las entrevistas también emergen diferencias entre los/as psicólogos/as referidas a la modalidad de trabajo: «Cuando te cruzás con colegas y empezás a dialogar te das cuenta que no pensás lo mismo, que pareciera que sí, pero que no hacés lo mismo, no te planteás la práctica de la misma manera». Entre tales diferencias, insiste aquella vinculada al modo de entender la «demanda», que determina la atención o no de los/as niños/as y adolescentes. Es decir, se observa la utilización de una misma categoría teórica, pero que moviliza diversos dispositivos de intervención.

En la voz de una de las psicólogas entrevistada, respecto a un/a colega:

Si los pibes no lo llaman no los entrevista; para él tiene que haber demanda. Yo considero que no va a haber demanda de parte del pibe porque si no entiende el espacio, entonces, no va a haber demanda (E8, Psica., 2018).

Está el psicólogo o la psicóloga que no atiende porque no hay demanda, o porque esto no le corresponde, porque esto lo tiene que hacer el Estado; entonces, no lo hace. La delgada línea entre «o generás la demanda del chico o no hacés nada», y te quedás ahí esperando que te llame. Y actúas a demanda de la institución, del operador, del director: «Si no me llama, para qué lo voy a ver. Si está el trabajador social, que lo vea el trabajador social» (E16, Psica., 2017).

Para mí es una forma de hacer clínica en estos contextos, en estas instituciones. Es decir, yo no necesitaba de las cuatro paredes. Obvio que en un caso específico sí, lo pedía, lo buscaba y aseguraba esa condición. Pero, al principio, con un pibe tenés que construir una relación para que después te llame. En general, los pibes que atendí sabían qué día los atendía, esperaban, sabían esperar, o aprendían, me llamaban. Yo soy psicóloga, tengo formación psicoanalítica, y la psicología habilita a un campo y, desde ahí, fundamentar lo que hacía para con mis compañeros (E11, Psica., 2016).

La eterna discusión sobre si se puede hacer alguna psicoterapia, para ponerle un nombre. Pero digo, ahondar en la subjetividad de un joven dentro de una institución es algo que cuesta mucho que los equipos técnicos entiendan. 
Y cualquier intervención es terapéutica cuando vos la planteás así. La palabra transmite cuestiones que apuntan a modificar otras cuestiones de la subjetividad de un joven, y no importa que esté el encuadre, si no está lo armás, vas generándolo, si querés (E5, Psica., 2017).

Los/as psicólogos/as entrevistados/as delimitan diferencias entre los dispositivos que implementan en el ámbito público y en el ámbito privado, lo que evidencia que la utilización de tal categoría no implica un movimiento de traspolación de un espacio privado a un espacio público; sino que depende del modo en el que tal categoría se instrumenta. Esperar la demanda para intervenir supone, entonces, la espera de algo que debiera emerger de los/as niños/as y adolescentes.

Una de las escenas relatadas muestra los efectos de estos modos de pensar la demanda:

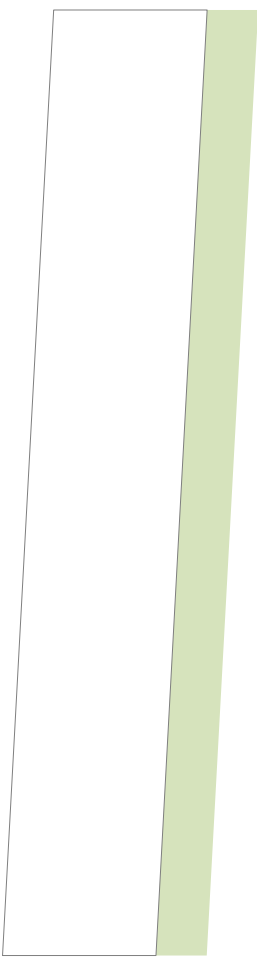

Me llama el director y me dice: «Hay un problema. Hay un pibe que no quiere entrar». La hora del acueste es la hora más crítica. Le digo: «Bueno, no hagan nada, no le peguen, yo ahora voy». Ahí fui, llegué y entré. Veo al jefe de guardia, que me dice que ya había entrado. Entro a la celda y tenía puesta una trompada. Le pregunto si le pegaron, dice «sí, pero yo también pegué». Era un pibe de 18 años. Le pregunto qué pasó y me dice: «Yo estoy mal. Mi novia tuvo él bebe, no pudo venir a verme, vino mi mamá, no sé si tienen para comer. La verdad, estoy mal». «Bueno», le digo, «vamos a ver qué podemos hacer». Al día siguiente voy a ver al equipo técnico y les cuento que a la noche había tenido que ir y pregunto quién veía a ese chico. Y la psicóloga me dice: «Yo lo veo y hago los informes». «¿Hacés los informes y nada más?». «Lo que pasa es que no hay demanda», me contestó. Pero la demanda se construye, un pibe que grita, patalea, ¿no es una demanda? ¿Qué esperás, que te pidan un turno? (E3, Psica., 2018).

El movimiento de traspolación de un ámbito a otro, visible en las prácticas de los/as psicólogos/as que «esperan la demanda» para intervenir, son relatadas a través de escenas como la siguiente: 


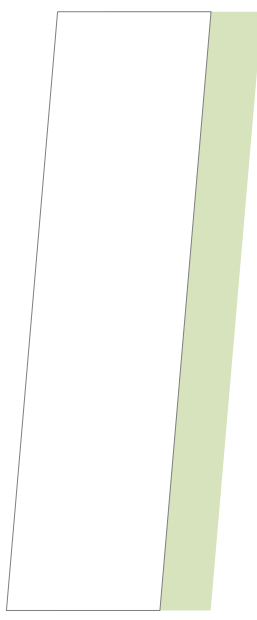

Por ejemplo, una psicóloga dijo: «Tengo a los hermanos X. Están internados acá. Veo a uno y puedo trabajar perfectamente; después, cuando voy a ver al otro, no me da ni cinco de bola y me cierra la puerta». Entonces le digo: «Bueno, está bien, pensemos. Una preguntita, ¿vos en privado atendés a dos hermanos?». «No...». «¿Y por qué acá sí?». ¿Ves lo que la institución te genera?». Eso es para ahorrar el llamado telefónico, porque tenemos en una misma causa a los dos, entonces cuando llamamos por uno, hablamos por los dos (...) Es una obviedad, pero había que trabajarlo. Ahora, eso, vos sabés que esa estructura se te burocratiza enseguida (E2, Psic., 2016).

Otra escena refiere a una conversación con un equipo técnico de una institución:

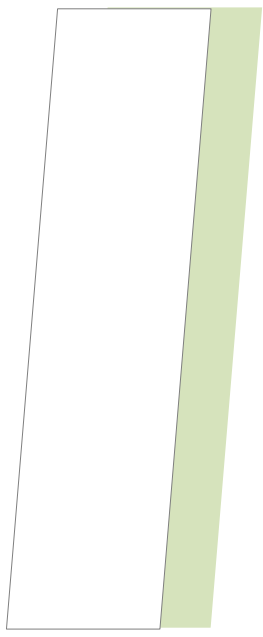

Tenían todas frases de Lacan, ¿viste? en el equipo, y querían ser psicoanalistas. Lo cual fue el ideal que nos han propuesto siempre desde la Facultad. Entonces, yo a propósito, les decía: «¿Y qué quiere decir eso que está ahí?». «No, porque nosotros queremos hacer psicoanálisis». «¿Ustedes se analizan? ¿Pero vos te analizas? ¿Te has analizado en serio?».

Es decir, que vos tengas deseo de ser psicoanalista a mí me parece fenómeno, andate a las distintas escuelas de $\mathrm{X}$ y hacé la práctica que quieras, pero no confundas tu deseo de ser con la práctica posible. Lo cual no significa renunciar al psicoanálisis (E2, Psic., 2016).

Deseo de ser e ideales de una época marcada por los efectos, tanto en la formación académica como en los espacios de trabajo en las instituciones públicas. Efectos que produjeron modos de pensarse como psicólogos/as, ya no como agentes de cambio ni trabajadores de la salud mental, sino como «psicoanalistas».

Visualizamos allí un punto de coincidencia entre las investigaciones situadas en los antecedentes y el relato de los/as psicólogos/as entrevistados/as, referido a la existencia de tales dispositivos de atención «a demanda de los/as niños/as y adolescentes» que efectúan algunos/as psicólogos/as. Es visible la imposibilidad de homogeneizar y de universalizar, en este caso, qué hacen todos/as los/as psicólogos/as, máxime si se consideran las múltiples dimensiones que determinan tales modos de hacer. 


\section{Referencias}

Ábalos, C., Centurión, F. y Vitale, G. (2009). «Ley 13.298. De la Promoción y Protección Integral de los Derechos de los Niños». En E. García Méndez y G. Vitale (Comps.), Infancia y democracia en la Provincia de Buenos Aires. Comentario crítico sobre las leyes 13.298 y 13.634 (pp. 13-66). Ciudad Autónoma de Buenos Aires, Argentina: Ediciones del Puerto.

Bouilly, M. R. y Andersen, M. J. (2012). «Directores, "maestros" y profesionales: agentes del habitus minoril». En A. Daroqui, A. L. López y R. F. Cipriano García (Comps.), Sujetos de castigos. Hacia una sociología de la penalidad juvenil (pp. 221-252). Rosario, Argentina: HomoSapiens.

Domínguez Lostaló, J. C. (1999). Los pibes marginados. Por el derecho a ser joven. Ciudad Autónoma de Buenos Aires, Argentina: Cuadernos del Caleuche.

Fasciolo, M. (2018). ¿Quién tiene las llaves de la prisión? Funciones del trabajo social en centros cerrados para jóvenes con causas penales. La Plata, Argentina: Dynamis.

Foucault, M. (2006). Seguridad, territorio y población. Ciudad Autónoma de Buenos Aires, Argentina: Fondo de Cultura Económica.

Kaminsky, G. G. (2011). Dispositivos institucionales. Democracia y autoritarismo en los problemas institucionales. Ciudad Autónoma de Buenos Aires, Argentina: Lugar editorial.

Moratti, M. F., Veloz, J. y Cattani, J. P. (noviembre 2013). Psicólogos/as y políticas públicas. Una historización acerca de la inserción en el ámbito de Niñez y Adolescencia. 1960-1970. Trabajo presentado en el $V$ Congreso Internacional de Investigación y Práctica Profesional en Psicología de la Universidad de Buenos Aires.

Ulloa, F. (1995). Novela clínica psicoanalítica. Historial de una práctica. Ciudad Autónoma de Buenos Aires, Argentina: Paidós.

\section{Normativas}

Decreto Reglamentario 300 (2005). Decreto Reglamentario de la Ley 13.298. Ley de Promoción y Protección Integral de los Derechos de los Niños.

Boletín Oficial de la Provincia de Buenos Aires. La Plata, 23/3/2005. 
Decreto Ley Provincial 10.067 (1983). Patronato de Menores.

Boletín Oficial de la Provincia de Buenos Aires. La Plata, 9/12/1983.

Ley Provincial 10.430 (1996). Estatuto y Escalafón para el Personal de la Administración Pública de la Provincia de Buenos Aires.

Boletín Oficial de la Provincia de Buenos Aires. La Plata, 25/06/1996.

Ley Provincial 13.298 (2005). Promoción y Protección Integral de los Derechos de los Niños.

Boletín Oficial de la Provincia de Buenos Aires. La Plata, 27/1/2005.

Ley Provincial 13.634 (2007). Principios Generales del Fuero de Familia y del Fuero Penal del Niño.

Boletín Oficial de la Provincia de Buenos Aires. La Plata, 2/2/2007.

\section{Fuentes}

E1 | Psicóloga, actualmente en funciones. Entrevistada en 2016.

E2 | Psicólogo, jubilado. Entrevistado en 2016.

E3 | Psicóloga, jubilada. Entrevistada en 2018.

E5 | Psicóloga, actualmente en funciones. Entrevistada en 2017.

E8 | Psicóloga, actualmente en funciones. Entrevistada en 2018.

E9 | Psicóloga, actualmente en funciones. Entrevistada en 2017.

E10 | Psicólogo, actualmente en funciones. Entrevistado en 2018.

E11 | Psicóloga, actualmente en funciones. Entrevistada en 2016.

E13 | Psicóloga, jubilada. Entrevistada en 2018.

E14 | Psicólogo, actualmente en funciones. Entrevistado en 2016.

E15 | Psicóloga, actualmente en funciones. Entrevistada en 2016.

E16 | Psicóloga, actualmente en funciones. Entrevistada en 2017. 
CONCLUSIONES 


\section{CONCLUSIONES}

Al modo de la miel, que contiene la memoria genética del panal que la produjo, tanto las instituciones que alojan niños/as y jóvenes en situación de vulneración o en conflicto con la ley penal como los dispositivos que efectúan los/as psicólogas que integran los equipos técnicos, parecen contener la memoria histórica de las urgencias a las cuales respondieron sus creaciones.

El objetivo central que dio origen a la presente tesis fue caracterizar los dispositivos de intervención que diseñaron e implementaron los/as psicólogos/as en los establecimientos del Organismo de la Niñez y Adolescencia de la provincia de Buenos Aires, entre los años 2000-2015, para visibilizar algunos de los elementos que los determinan, entre ellos, el impacto que producen las diferentes normativas.

La derogación del Decreto Ley 10.067/83 del Patronato de Menores de la última Dictadura cívico militar y la sanción de la leyes 13.298 de Promoción y Protección Integral de los Derechos de los Niños (2005) y 13.634 del Fuero de Familia y del Fuero Penal del Niño y sus respectivos Decretos Reglamentarios, impulsó el movimiento de investigación.

La relevancia histórica y política de la sanción de tales leyes se centra en que fundan, en lo normativo, nuevas políticas públicas frente a la anterior judicialización de la pobreza. En tal sentido, constituyen una herramienta fundamental para el diseño de políticas en clave de derechos, aunque por sí solas no garantizan su materialización, sino que requieren de un movimiento de fuerzas instituyentes en los diversos organismos y establecimientos de protección de derechos y de responsabilidad penal juvenil. 
Los/as psicólogos/as componen, a través de los dispositivos que implementan, las tramas del funcionamiento institucional y, por ello, son agentes que materializan políticas públicas. En este sentido, no hay neutralidad que mueva las estrategias que orientan sus dispositivos, sino que estos se constituyen en focos locales de ejercicio de poder.

Situamos allí un punto de cruce entre políticas públicas para un sector de la población de niños/as y adolescentes, materializadas en dispositivos institucionales concretos, y dispositivos de intervención diseñados e implementados por profesionales psicólogos/as. Esto determinó que se tornara ineludible un recorrido que indagara en el nacimiento de tales dispositivos y en las urgencias históricas a la cuales respondieron, tanto en tiempos del menor «como objeto de tutela» como en tiempos de los/as niños/as como «sujetos de derechos».

Dispositivo cuya función estratégica dominante fue la intervención específica del Estado sobre un sector de la población de niños/as y adolescentes, orientadas a producir y a moldear de manera directa las condiciones de vida de un sector, a través estrategias de poder biopolíticas y de estrategias de poder disciplinares materializadas en los establecimientos destinados a los/as niños/as y adolescentes devenidos en menores.

\section{Encuentro inaugural \\ Entre políticas públicas \\ y dispositivos de intervención}

Los inaugurales desarrollos de Bugani y Láttaro (1971) arrojaron luz sobre los primeros dispositivos implementados por los/as psicólogos/as en los establecimientos de «menores», dispositivos que interrumpían, o que se proponían interrumpir, los efectos de la institucionalización en y sobre los/as niños/as y adolescentes, movilizados por saberes y por modos de pensar la función de los/as psicólogos/as en tanto agentes de cambio y trabajadores/as de la salud mental. 
La implementación de dispositivos asamblearios y grupales, sostenidos en un modo de pensar a los niños/as y a los/as jóvenes como producidos por las condiciones socioeconómicas, familiares, institucionales y políticas, y desde una perspectiva teórica psicoanalítica, posibilitó advertir que, aún en tiempos en los que la Convención Internacional sobre los Derechos del Niño (CIDN) (1989) no había sido declarada, el derecho a la palabra, a ser escuchados/as regía los propósitos que orientaban los dispositivos y los procedimientos profesionales de los/as psicólogas.

Primeros dispositivos de intervención que fundaron un encuentro inaugural con un dispositivo sociohistórico de intervención sobre un sector de la población de niños/as y adolescentes que compuso una melodía desafinada: uno producía niños/as y jóvenes como objetos de tutela; otro se proponía producir efectos sujetos.

\section{La necesaria adecuación de las prácticas institucionales}

Los desarrollos de García Méndez (1991) y Fasciolo (2018) evidencian que la Doctrina de la Situación Irregular para los menores de edad, perfeccionada por el Decreto Ley 10.067/83 del Patronato de Menores, no fue penetrada con la incorporación de la Convención Internacional sobre los Derechos del Niño en la Constitución Nacional (1994) hasta su derogación, en 2007, y a partir de la puesta en vigencia de las leyes 13.298 y 13.634 que emergen de la Doctrina de la Protección Integral.

A nivel normativo, los estudios de Aguirre y Ponce Nuñez (2009), Ábalos, Centurión y Vitale (2009), Coriolano (2009) y Uriarte (2006) demuestran que en este plano se produce una modificación central, que incluye el modo de nominar a la población destinataria: la categoría de niños/as y adolescentes como «sujetos de derechos» sustituye a la de «menores en riesgo» y en tanto «objetos de tutela», al tiempo que se prescriben otros campos de intervención: en la medida en que se prioriza la permanencia de los/as niños/as y adolescentes con sus grupos familiares y en sus comunidades de pertenencia, la separación se constituye en una medida de último recurso, lo que implica mirar en forma diferente, registrar información diversa y proponer dispositivos de intervención distintos a los implementadas en el marco de la ley anterior. 
Respecto a los establecimientos donde se efectúan las medidas de último recurso, los decretos reglamentarios de ambas leyes establecen como «imperiosa» la adecuación de la normativa interna, la organización y las prácticas institucionales para el cumplimiento de las medidas.

De allí que consideramos oportuno recuperar la afirmación realizada por Pérez (2015):

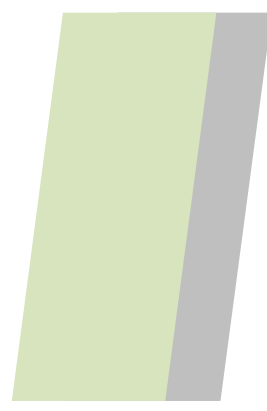

Las nuevas leyes sancionadas derivarán en nuevas políticas y programas que desafían nuestra imaginación y potencian nuestro pensamiento. Será necesario construir y pensar herramientas específicas, a la vez que se requiere interpelar los modos actuales en que se producen las prácticas concretas que realizan los psicólogos/as en esos espacios. Crear lo nuevo es la tarea pendiente y el desafío de este tiempo (p. 10).

Desafío que requirió de dos grandes movimientos: conocer los dispositivos implementados y establecer qué elementos los determinaban. A los que se suma, aquí, un movimiento final: la propuesta de dispositivos y de instancias de capacitación.

\section{Primer movimiento}

Conocer los dispositivos implementados

\section{Dispositivos grupales}

En tiempos del Patronato del Menor, con los/as jóvenes alojados en institutos penales, los/as psicólogos/as implementaron dispositivos grupales y asambleas multifamiliares.

Los primeros, implementados con los/as jóvenes y guiado por el propósito de posibilitar entre ellos/as el encuentro y la circulación de la palabra, se presentaban, también, como dispositivos que posibilitaban trabajar con el resto del personal ciertas dimensiones del funcionamiento institucional. Los segundos, implementados en el establecimiento durante los días de visita, se orientaban a alojar y acompañar a las familiares de los/as jóvenes. 
El desarrollo de tales dispositivos dependía de los «momentos institucionales» y del tipo de dirección a cargo del establecimiento, a la vez que movían resistencias, evidenciadas en movimientos que interrumpían su implementación.

En tiempos del Sistema de Responsabilidad Penal Juvenil (SRPJ), iniciado con la sanción de la Ley 13.634 de Fuero de Familia y del Fuero Penal del Niño (2007), se diferencian dos tipos de dispositivos grupales según el propósito que los orienta: el dispositivo asambleario, para trabajar situaciones institucionales, y el dispositivo de grupos pequeños, para trabajar aquellos temas o problemas que, a modo de emergentes, surgen de los/as jóvenes.

Puntuamos que los dispositivos grupales concentran los mayores grados de resistencia institucional a su implementación o a su funcionamiento sistemático, tanto en relación con los grupos de niños/as y de jóvenes como con los integrantes de los equipos técnicos y con el personal del establecimiento.

La ausencia de implementación de dispositivos grupales con niños/as y con jóvenes en los establecimientos que aplican medidas de abrigo institucionales, otrora asistenciales, no deja de interrogar y de pulsar la apertura de nuevos recorridos de investigación.

\section{Dispositivos individuales}

En ambos tiempos normativos, se implementan dispositivos de entrevista individual.

En lo penal, estos se llevaban/llevan a cabo tanto en espacios físicos dentro del establecimiento, en un encuadre con días y horarios fijos, como en espacios y en días no determinados de antemano, fuera del establecimiento o en el patio, durante el almuerzo o en algún espacio-lugar del cotidiano institucional. Cada psicólogo/a contaba/cuenta con casos asignados para cuya atención establecía/establece un encuadre predeterminado.

En esta misma línea se ubican las intervenciones que se efectúan en distintos espaciostiempos del cotidiano institucional, lo que deriva en intervenciones que se efectúan «por fuera» del encuadre de trabajo establecido con el/la niño/a y/o joven. 
En los actuales establecimientos de Protección de Derechos, antes asistenciales, el dispositivo de entrevista individual era/es implementado para escuchar al/a la niño/a o al/a la adolescente y para diseñar un dispositivo de abordaje singular a partir de conocer las causas que originaron la medida.

Otro dispositivo individual que se implementa es aquel que se orienta a brindar tratamiento terapéutico para los/as niños/as y los/as jóvenes que lo requieren. En algunas situaciones, tales tratamientos se llevan a cabo en otras instituciones públicas de salud.

Puntuamos que los dispositivos individuales no presentan variaciones en los distintos tiempos normativos y, dentro de ellos, los de entrevista individual son los menos resistidos y los más demandados por los distintos agentes institucionales.

\section{Dispositivos con grupos familiares}

\section{y/o referentes vinculares}

Con los grupos familiares y/o con los referentes vinculares, otrora de jóvenes con causas penales, en la actualidad con medidas de responsabilidad penal, se implementaban / implementan entrevistas realizadas en la institución durante los días de visita; en general, los fines de semana.

En tiempos del Patronato del Menor, con aquellos/as niños/as y adolescentes con causas asistenciales que se encontraban alojados en hogares convivenciales, los dispositivos de intervención con los grupos familiares y/o con los referentes vinculares se efectuaban: en sus comunidades, cuando los/as niños/as y adolescentes provenían de la ciudad de La Plata, sus alrededores y/o del conurbano bonaerense; y de manera telefónica, cuando provenían del interior de la Provincia.

De este modo, mientras en el primer caso, los/as psicólogos/as realizaban con los grupos familiares visitas y entrevistas presenciales, en el segundo caso las comunicaciones eran telefónicas, excepto que algún referente familiar visitara el hogar, debido a que para viajar a las comunidades los profesionales dependían de vehículos del organismo provincial. 
En tiempos del Sistema de Promoción y Protección de Derechos (SPPD), en los hogares donde se implementan medidas de protección de derechos el equipo desarrolla dispositivos de intervención con los grupos familiares que viven en la ciudad de Plata o Gran La Plata. Con aquellas familias que viven en otras ciudades ese trabajo lo realizan los equipos de los servicios territoriales, denominados Servicios Zonales o Servicios Locales. Otro tipo de dispositivo de intervención en tal situación es la entrevista en el hogar, que se produce cuando los referentes familiares y afectivos van de visita al hogar.

Aunque para las nuevas normativas son centrales, los dispositivos de intervención con los grupos familiares en y con las comunidades de origen no presentan variaciones respecto de los que se implementaban en tiempos normativos tutelares; es decir, se trata de dispositivos que no variaron con los cambios normativos.

Uno de los determinantes que produce tal inercia lo ubicamos en la distancia geográfica entre el territorio en el que se toma la medida de abrigo y el establecimiento donde esta se materializa, en tanto elemento que imposibilita la implementación plena del sistema.

Puntuamos que la distancia geográfica produce que se fragmenten las intervenciones y que la posibilidad de trabajar sobre las condiciones que produjeron la medida de protección de derecho quede determinada por la capacidad de coordinación entre los equipos del establecimiento donde se encuentra el/la niño/a o el/la adolescente y los equipos de los servicios zonales o locales.

\section{Segundo movimiento}

\section{Establecer las líneas de determinaciones}

Las normativas componen uno de los elementos de las políticas públicas que, a través de estrategias de poder biopolíticas, fijan el tipo de población que ingresa a los establecimientos así como los diseños de los dispositivos a implementar. En otras palabras, no son los/as psicólogos/s de los equipos técnicos de los establecimientos los que definen la población sobre la que intervienen, pero sí que las características de la misma, determina los dispositivos que los/as profesionales diseñan e implementan. 
En tiempos del Patronato del Menor, las políticas públicas para con el sector de los niños/as y adolescentes pertenecientes a los sectores más empobrecidos eran la judicialización y la institucionalización en hogares, debido a su situación de «peligro moral o material». A la vez que el ingreso y el tiempo de permanencia dependía del/de la juez/a de menores quien, en cumplimiento de su función soberana, decidía sobre la vida de cada niño/a y/o adolescente.

En tiempos del Sistema de Promoción y Protección de Derechos, la aplicación de las normativas, tanto de PPD como de RPJ, requiere de la implementación de políticas públicas que garanticen el acceso a derechos, debido a que se tornó visible que el ingreso y/o la permanencia de los/as niños/as y los/as jóvenes en los establecimientos del sistema giraba en torno a la pobreza.

Esta determinante problematiza a algunos equipos técnicos, que no ubican en causas psicológicas aquello que es producido por las condiciones de pobreza. En este sentido, ubicamos una diferencia respecto al planteo de Llobet (2014), quien sostiene que las condiciones de desigualdad e injusticia no son incluidas lo que produce una psicologización de lo social. De acuerdo a lo señalado por los/as psicólogos/as entrevistados/as, las condiciones de pobreza son tenidas en cuenta y no derivan en un movimiento de psicologización.

En lo que respecta al Sistema de Responsabilidad Penal Juvenil, se constata que la implementación del Fuero Penal Juvenil produjo un efecto instituyente en los dispositivos que implementan los/as psicólogos/as, en tanto el debido proceso "clarifica». En este sentido, dado que la medida a cumplir ya no depende de la decisión unipersonal del/de la juez/a sino que es resultado de un proceso donde el/la joven debe ser escuchado/a, se clarifica el qué y el para qué de los dispositivos de intervención con los/as jóvenes.

Ahora bien, lo que no varía en los distintos tiempos normativos es el sector de la población sobre la cual el sistema interviene; por el contrario, la pertenencia de clase se muestra como un determinante que insiste. 
Intervención sobre un sector de la población que ubicamos entre las urgencias sociohistóricas a las cuales respondió la creación de los dispositivos del Patronato del Menor, mediante la Ley Agote, en 1919.

Otro de los elementos normativos que determinaron los dispositivos de intervención en tiempos del Patronato de Menores se ubica en el lugar de «auxiliar» del/de la juez/a de menores que ocupaba el organismo del Estado Provincial. Sobre tal efecto de determinación, los/as psicólogos/as efectuaban ciertos procedimientos que, desde nuestra lectura, implicaron el corrimiento del lugar y de la función de auxiliares del/de la juez/a.

Leemos allí puntos de resistencias en el juego de poder soberano que el dispositivo del Patronato de Menores ejercía a través de la figura de los/as magistrado/as. Tales puntos de resistencias no se presentaban como una práctica homogénea que englobaba a todos/as los/as psicólogos/as que integraban los equipo técnicos, dado que en las entrevistas se sitúa que había equipos técnicos que, efectivamente, funcionaban como «auxiliares» de los/as jueces/zas de menores.

No obstante, en las entrevistas se sitúa que en los actuales tiempos normativos el «temor al juez» opera en los/as trabajadores/as como «una sombra»: el patronato devenido en «un fantasma que te come». Desde nuestra perspectiva, este efecto visibiliza que la destitución legal de la figura del/de la juez/a no implica la destitución de la significación imaginaria institucional. Es decir, aunque la destitución en la normativa es necesaria, no resulta suficiente.

Ahora bien, en referencia al escaso movimiento instituyente de las nuevas normativas en las prácticas institucionales efectivas, sostenemos que, entre otras causas, esto se produce como efecto de la centralidad que las normativas adquieren; en tanto que tal centralidad invisibiliza otros saberes y otras prácticas disciplinares, así como los juegos de poder que operan en los dispositivos institucionales.

La centralidad que presentan los elementos legales produce la ilusión de que modificada la ley se modificarán los dispositivos de intervención. Ilusión que parte de ver un único elemento -en este caso, normativo- allí donde hay varios; de pensar el poder como algo que alguien tiene y no en que se ejerce mediante un juego de fuerzas, siempre móviles. 
En este sentido, acordamos con las/os autoras/es respecto a que las nuevas normativas requieren de un cambio en las prácticas institucionales, tal como lo establecen los respectivo Decretos Reglamentarios.

Tal revisión, empero, requiere del diseño y de la implementación de un dispositivo que aporte visibilidad, que posibilite distinguir las múltiples líneas que se anudan y se materializan en cada establecimiento y que determinan los modos de hacer.

En lo que respecta a las determinaciones de las tramas institucionales, las vemos operar en la intencionalidad que orienta los dispositivos de intervención que diseñan y que implementan los/as psicólogos/as cuando se proponen introducir movimientos en las relaciones de poder-saber fijadas en los establecimientos -productoras de efectos de objetalización de los/as niños/as y los/as jóvenes- para instalar otras fuerzas de saberpoder productoras de efectos sujetos.

Entre las líneas que componen tales tramas institucionales, se distinguieron como determinantes aquellas vinculadas con violentaciones y con encerronas, producidas por situaciones caracterizadas como violencia «institucional institucionalizada», que movilizaron en los/as psicólogos/as a diseñar dispositivos de intervención orientados a interrumpirlas, tanto con niños/as y jóvenes como con asistentes y directores/as.

Que tales dispositivos se propongan intervenir sobre los efectos que la institución produce nos muestra, además, que esta se ha transformado en «clienta de ella misma» (Ulloa, 1995); esto es, muy alejada de sus objetivos específicos: cuidar y proteger de los riesgos morales o materiales, en tiempos tutelares; restituir derechos, en tiempos de sujetos de derechos.

Entre los efectos producidos en los/as trabajadores/as, vemos aquellos que componen los síntomas del Síndrome de Violentación Institucional, como sucede con las fragmentaciones entre los/as asistentes y el equipo técnico, y las fragmentaciones en los equipos técnicos, que son leídas por los/as psicólogos/as como juegos de poder dirigidos a interrumpir espacios colectivos, grupales y asamblearios, producto de la potencia de transformación que contienen. 
Otra línea que leemos como determinante en el diseño y la implementación de los dispositivos, en relación con las tramas institucionales, se anuda con ciertas características de la dirección de los establecimientos, que, para lograr la funcionalidad del lugar, demanda algunas intervenciones al tiempo que imposibilita otras.

En este sentido, hemos puntuado insistencias de resistencias a la implementación o al funcionamiento sistemático de distintos dispositivos grupales, tanto con los grupos de niños/as o de jóvenes, como con los integrantes de los equipos técnicos y con el personal del establecimiento.

Otra línea de determinaciones fueron visibilizadas en los saberes que movilizan y que orientan los dispositivos de intervención, donde puntuamos la insistencia de aquellos que provienen del psicoanálisis.

Ubicamos la insistencia de los saberes referidos a los tiempos de estructuración subjetiva, tanto en tiempos normativos de tutela como en tiempos de sujetos de derechos, en el diseño y la implementación de los dispositivos. Tales saberes orientan el propósito de intervenir para que la institución pueda efectuar las funciones de cuidado y de sostén, de acuerdo a los tiempos y a las necesidades subjetivas de los/as niños/as y adolescentes, funciones propias de lo que Ulloa (1995) denomina «institución de la ternura».

Tales saberes fundaron, por ejemplo, la creación e implementación de dispositivos «singulares y atentos al detalle», lo que implica que lo diseñado para un/a niño/a o adolescente no es pertinente, adecuado o pasible de ser traspolado a otro/a.

Ubicamos un punto de anudamiento entre los dispositivos así diseñados e implementados y el análisis que desarrollan Ábalos, Centurión y Vitale, (2009), quienes sostienen que la universalidad de las políticas públicas, para garantizar el acceso a los derechos que todos/as los/as niños/as y adolescentes requieren, debe generar a su vez políticas específicas que contemplen medidas especiales de protección para grupos específicos. Por ello no es posible describir de antemano cómo garantizarlo, sino que es un principio que debe tenerse presente en cada una de las intervenciones. 
A la vez, las insistencias en los propósitos que orientan los dispositivos que se implementan respecto a generar condiciones para la producción de efectos sujetos, introduce un punto de diferencia con el planteo de Di lorio (2010), quien señala la existencia de narrativas que ubican al/a la niño/a como sujeto de derechos, pero que al mismo tiempo sostienen prácticas que lo/a abordan como objeto de intervención, con tendencias a la psicopatologización y desde una perspectiva individual.

Puntuamos como otro determinante la categoría teórica de demanda. El modo en el que cada profesional interpreta tal categoría funda dispositivos de intervención diferentes: esperar la demanda para intervenir o intervenir para la producción de alguna demanda posible. Esperar la demanda supone la espera de algo que debiera emerger de los/as niños/as y los/as jóvenes para intervenir, lo que leemos como un efecto de traspolación del dispositivo de cura del ámbito privado a los dispositivos de tratamiento en las instituciones públicas.

Respecto a las revisiones de las prácticas institucionales, consideramos que la función de la universidad pública es ineludible al respecto, aunque no puede, ni debe, hacerlo sola, ni en una posición de exterioridad, sino que tales revisiones requieren de múltiples actores y de decisiones políticas emanadas del Estado.

Por ello, delineamos a continuación algunos de los aportes que la presente tesis puede acercar, desde una mirada disciplinar, como es la psicología. Contribuciones que recuperan las experiencias relatadas por los/as psicólogos/as entrevistados/as.

\section{Tercer movimiento}

Proponer dispositivos colectivos y de capacitación

El recorrido de la investigación muestra algunos de los focos de ejercicio de poder que resisten a la implementación de dispositivos para la producción de efectos sujeto, centralmente, frente a los dispositivos grupales y/o colectivos. Resistencias de los organizados-instituidos que insisten en los distintos tiempos normativos y que dificultan y/o imposibilitan su implementación. 
Desde nuestra perspectiva, tales resistencias muestran la potencia que alojan tales dispositivos en relación con la producción de efectos de transversalidad que movilizan los grados de comunicación entre los diferentes niveles institucionales y las relaciones de poder institucionales.

Por ello, consideramos que el diseño y la implementación de este tipo de dispositivos, tanto con los/as niños/as y los/as jóvenes como con los/as trabajadores/as posibilitarán la producción de efectos sujetos y, con esto, la interrupción y la tramitación de los efectos que produce el Síndrome de Violentación Institucional (Ulloa, 1995).

Así orientados, tales dispositivos contienen la potencia de interrumpir las violentaciones, los tratos crueles y las fragmentaciones que objetalizan tanto a los/as niños/as y a los/as jóvenes como a los/as trabajadores/as.

\section{Dispositivos colectivos}

Con los/as profesionales: orientados a problematizar las experiencias concretas de intervención y a propiciar la construcción colectiva de herramientas y de procedimientos de intervención comunes, lo que derivará en la interrupción de las fragmentaciones tanto al interior de los equipos técnicos, como entre los equipos de los distintos establecimientos.

Con quienes cumplen la función de asistentes de minoridad: orientados a posibilitar la puesta en común de las tareas que tal función requiere y los problemas que conlleva, así como la construcción colectiva de herramientas y de procedimientos de intervención específicos, lo que derivará en la problematización de una función no menor, como es el contacto cotidiano con los/as niños/as y los/as jóvenes. Una función que se presenta como la menos pensada pero que resulta la de mayor impacto en el devenir institucional, en tanto que en las tramas institucionales presenta focos de ejercicio de poder. 


\section{Dispositivos de capacitación}

Con quienes tienen la función de dirección de los establecimientos: dado que quienes desempeñan dichos cargos requieren, además de los sabereshaceres burocráticos de funcionamiento, de herramientas teóricas y técnicas que posibiliten la implementación de modos de dirección orientados a la circulación de la palabra y a la construcción <generación> de espacios colectivos para el diseño de estrategias de intervención comunes; máxime cuando parte de su función es constituirse en punto de articulación entre los distintos actores institucionales.

Con los/as psicólogos/as: orientados a la construcción de espacios grupales tendientes a problematizar el trabajo profesional en instituciones públicas. En función de lo advertido en la presente tesis, tales espacios de capacitación deben contener herramientas tanto para el diseño y la implementación de dispositivos grupales y/o colectivos -en las instituciones, en las comunidades y con los grupos familiares-, como para la deconstrucción y la elucidación de la categoría teórica de «demanda», a fin de interrumpir los movimientos de traspolación del ámbito privado de ejercicio profesional al ámbito público.

Con los equipos técnicos del sistema: para el diseño y la implementación de dispositivos con los grupos familiares, en y con las comunidades de origen. Esta propuesta parte de visibilizar que aunque tales dispositivos son centrales en las nuevas normativas no presentan variaciones respecto de los que se implementaban en tiempos tutelares. La distancia territorial entre el lugar donde se toma una medida de abrigo y el lugar donde se efectúa determina la imposibilidad de un abordaje integral de las causas que la originaron en su comunidad de pertenencia y con el grupo familiar. Entendemos que tal dimensión depende de decisiones vinculadas a la gestión de políticas que garanticen en cada territorio-comunidad la creación de espacios institucionales, además de la implementación de dispositivos de capacitación. 
Ahora bien, mientras tales decisiones no se materialicen, consideramos que la coordinación entre el equipo técnico del establecimiento donde se implementa una medida de abrigo institucional y el equipo técnico que la determinó no puede quedar a expensas de las buenas voluntades existentes, sino que requiere de la implementación de dispositivos específicos que lo garanticen. Dispositivos que para su diseño demandan de un primer movimiento de escucha de los equipos técnicos de los establecimientos, de los servicios zonales y de los servicios locales -cuyos integrantes son quienes transitan la experiencia concreta- y de elementos que es necesario disponer para interrumpir las fragmentaciones que se producen en las intervenciones y que derivan en un alargamiento de las medidas de abrigo institucional; esto es, del tiempo que los/as niños/as y los/as jóvenes permanecen en los establecimientos.

Para la implementación de tales propuestas, sostenemos la necesaria articulación entre la universidad pública y el Organismo de Niñez y Adolescencia; una articulación que parta de comprender que en la implementación de políticas públicas en clave de derechos la universidad no solo tiene algo que decir y hacer, sino que es parte responsable en tanto productora de profesionales que, en sus prácticas cotidianas, las materializan.

En tal sentido, y a modo de cierre, es pertinente señalar que la presente tesis se propone contribuir a uno de los campos de ejercicio profesional de la psicóloga, como es el de la niñez y la adolescencia en situación de vulneración de derechos y en conflicto con la ley penal, y se ofrece como un aporte a la revisión de las prácticas institucionales, en pos de la construcción de un sistema que garantice la producción efectiva de niños/as y adolescentes como sujetos de derechos. 


\section{Referencias}

Ábalos, C., Centurión, F. y Vitale, G. (2009). «Ley 13.298. De la Promoción y Protección Integral de los Derechos de los Niños». En E. García Méndez y G. Vitale (Comps.), Infancia y democracia en la Provincia de Buenos Aires. Comentario crítico sobre las leyes 13.298 y 13.634 (pp. 13-66). Ciudad Autónoma de Buenos Aires, Argentina: Ediciones del Puerto.

Aguirre, A. y Ponce Nuñez, M. (2009). «Los niños y jóvenes son el ideal de nuestro presente y la base de nuestro futuro». En E. García Méndez y G. Vitale (Comps.), Infancia y democracia en la Provincia de Buenos Aires. Comentario crítico sobre las leyes 13.298 y 13.634 (pp. 7-10). Ciudad Autónoma de Buenos Aires, Argentina: Ediciones del Puerto.

Bugani, P. y Láttaro, M. (1971). Analítica institucional en un internado de adolescentes mujeres. Polémica en Psicología, I(1).

Coriolano, M. L. (2009). «Garantías procesales mínimas. Necesarias e insuficientes». En E. García Méndez y G. Vitale (Comps.), Infancia y democracia en la Provincia de Buenos Aires. Comentario crítico sobre las leyes 13.298 y 13.634 (pp. 69-80). Ciudad Autónoma de Buenos Aires, Argentina: Ediciones del Puerto.

Di lorio, J. (2010). Infancia e institucionalización: abordaje de problemáticas sociales actuales. Pesquisas e Práticas Psicossociais, 4(2), 143-150. Recuperado de https://tinly.co/GXKkC

Fasciolo, M. (2018). ¿Quién tiene las llaves de la prisión? Funciones del trabajo social en centros cerrados para jóvenes con causas penales. La Plata, Argentina: Dynamis.

García Méndez, E. (1991). «Prehistoria e historia del control socio-penal de la infancia. Política jurídica y Derechos Humanos en América Latina». En E. García Méndez y M. Bianchi (1991) (Comps.), Ser niño en América Latina. De las necesidades a los derechos (pp. 11-20). Ciudad Autónoma de Buenos Aires, Argentina: Galerna.

Llobet, V. (2014). Reflections Upon a Misunderstanding: Production of Children's Needs Within Rights Protection Policies. Psicologia em Estudio, 19(3), 1-11. Doi: http://dx.doi.org/10.1590/1413-73722222501

Ulloa, F. (1995). Novela clínica psicoanalítica. Historial de una práctica. Ciudad Autónoma de Buenos Aires, Argentina: Paidós. 
Uriarte, C. (2006). Vulnerabilidad, privación de libertad de jóvenes y Derechos Humanos. Montevideo, Uruguay: Fundación de Cultura Universitaria.

\section{Normativas}

Naciones Unidas (1989). Convención Internacional sobre los Derechos del Niño. Recuperado de https://www.ohchr.org/SP/Professionallnterest/Pages/CRC.aspx

Decreto Ley Provincial 10.067 (1983). Patronato de Menores. Boletín Oficial de la Provincia de Buenos Aires. La Plata, 9/12/1983.

Ley Provincial 13.298 (2005). Promoción y Protección Integral de los Derechos de los Niños.

Boletín Oficial de la Provincia de Buenos Aires. La Plata, 27/1/2005.

Ley Provincial 13.634 (2007). Principios Generales del Fuero de Familia y del Fuero Penal del Niño.

Boletín Oficial de la Provincia de Buenos Aires. La Plata, 2/2/2007. 
REFERENCIAS, NORMATIVAS Y FUENTES 


\section{Referencias}

Ábalos, C., Centurión, F. y Vitale, G. (2009). «Ley 13.298. De la Promoción y Protección Integral de los Derechos de los Niños». En E. García Méndez y G. Vitale (Comps.), Infancia y democracia en la Provincia de Buenos Aires. Comentario crítico sobre las leyes 13.298 y 13.634 (pp. 13-66). Ciudad Autónoma de Buenos Aires, Argentina: Ediciones del Puerto.

Aguirre, A. y Ponce Nuñez, M. (2009). «Los niños y jóvenes son el ideal de nuestro presente y la base de nuestro futuro». En E. García Méndez y G. Vitale (Comps.), Infancia y democracia en la Provincia de Buenos Aires. Comentario crítico sobre las leyes 13.298 y 13.634 (pp. 7-10). Ciudad Autónoma de Buenos Aires, Argentina: Ediciones del Puerto.

Aguilo, J. C. (2005). Políticas Sociales en Argentina: de la Sociedad de Beneficencia a la focalización compulsiva. Recuperado de http://lanic.utexas.edu/project/etext/lilas/vrp/aguilo.pdf

Ariès, F. [1962] (1987). El niño y la vida familiar en el antiguo régimen. Madrid, España: Taurus.

Baremblitt, G. F. (1994). «La concepción institucional de la transferencia». En M. J. Acevedo y J. C. Volnovich (Comps.), El espacio institucional 1 (pp. 11-22). Ciudad Autónoma de Buenos Aires, Argentina: Lugar editorial.

Borakievich, S., Cabrera, C., Ortiz Molinuevo, S. y Fernández, A. (2014). La indagación de las implicaciones y el pensar-en-situación: una contribución de la metodología de problematización recursiva. Sujeto, Subjetividad y Cultura, (8), 21-28. Recuperado de https://bit.ly/2OHYONg

Borinsky, M. (2005). «Todo reside en saber qué es un niño». Aportes para una historia de la divulgación de las prácticas de crianza en la Argentina. Anuario de investigación de la Facultad de Psicología, XIII, 117-125.

Bouilly, M. R. y Andersen, M. J. (2012). «Directores, "maestros" y profesionales: agentes del habitus minoril». En A. Daroqui, A. L. López y R. F. Cipriano García (Comps.), Sujetos de castigos. Hacia una sociología de la penalidad juvenil (pp. 221-252). Rosario, Argentina: HomoSapiens. 
Bourdieu, P. (2013). El sentido práctico. Ciudad Autónoma de Buenos Aires, Argentina: Siglo XXI.

Bugani, P. y Láttaro, M. (1971). Analítica institucional en un internado de adolescentes mujeres. Polémica en Psicología, I(1).

Bustelo Graffigna, E. (2012). Notas sobre infancia y teoría: un enfoque latinoamericano. Salud Colectiva, 8(3), 287-298. https://doi.org/10.18294/sc.2012.168

Carli, S. (Comp.) (1999). De la familia a la escuela. Infancia, socialización y subjetividad. Ciudad Autónoma de Buenos Aires, Argentina: Santillana.

Carli, S. (2010). Notas para pensar la infancia en la Argentina (1983-2001). Figuras de la historia reciente. Educacao em revista, 26(1), 351-381. https://dx.doi.org/10.1590/S0102-46982010000100017

Carpintero, E. y Vainer, A. (2004). Las huellas de la memoria. Psicoanálisis y salud mental en la Argentina de los '60 y '70. Ciudad Autónoma de Buenos Aires, Argentina: Topia.

Castoriadis, C. (1993). La institución imaginaria de la sociedad. Vol. 1: Marxismo y teoría revolucionaria. Ciudad Autónoma de Buenos Aires, Argentina: TusQuets.

Castoriadis, C. (1995). Los dominios del hombre: encrucijadas del laberinto. Barcelona, España: Gedisa.

Castoriadis, C. (1997). El avance de la insignificancia. Ciudad Autónoma de Buenos Aires, Argentina: Eudeba.

Castoriadis, C. (2001). Figuras de lo pensable. Ciudad Autónoma de Buenos Aires, Argentina: Fondo de Cultura Económica.

Corea, C. (1999). «Ensayo sobre la destitución de la niñez. Introducción». En C. Corea e I. Lewkowicz, ¿Se acabó la infancia? Ensayo sobre la destitución de la niñez (pp. 11-137). Ciudad Autónoma de Buenos Aires, Argentina: Lumen.

Corea, C. y Lewkowicz, I. (1999). ¿Se acabó la infancia? Ensayo sobre la destitución de la niñez. Ciudad Autónoma de Buenos Aires, Argentina: Lumen. 
Coriolano, M. L. (2009). «Garantías procesales mínimas. Necesarias e insuficientes». En E. García Méndez y G. Vitale (Comps.), Infancia y democracia en la Provincia de Buenos Aires. Comentario crítico sobre las leyes 13.298 y 13.634 (pp. 69-79). Ciudad Autónoma de Buenos Aires, Argentina: Ediciones del Puerto.

Cosse, I. (2009). La emergencia de un nuevo modelo de paternidad en Argentina (1950-1975). Estudios demográficos y urbanos, 24(2). Recuperado de https://estudiosdemograficosyurbanos.colmex.mx/index.php/edu/a rticle/view/1339

Costa, M. y Gagliano, R. S. (2000). «Las Infancias de la minoridad. Una mirada histórica desde las políticas públicas». En S. Duschatzky (Comp.), Tutelados y asistidos. Programas sociales, políticas públicas y subjetividad (pp. 69-119). Ciudad Autónoma de Buenos Aires, Argentina: Paidós.

D’Agostino, A. (2017). Imaginarios estudiantiles acerca de las prácticas profesionales de los psicólogos en el campo de las políticas públicas sociales en salud. Un estudio en la Facultad de Psicología, UNLP (2012-2016) (Tesis de doctorado). Recuperado de http://sedici.unlp.edu.ar/handle/10915/61465

Dagfal, A. (2009). Entre París y Buenos Aires. La invención del Psicólogo (1942-1966). Ciudad Autónoma de Buenos Aires, Argentina: Paidós.

Danani, C. (1996). «Algunas precisiones sobre la política social como campo de estudio y la noción de población objeto». En S. Hintze (Coord.), Políticas sociales: contribución al debate teórico-metodológico (pp. 21-38). Ciudad Autónoma de Buenos Aires, Argentina: Universidad de Buenos Aires.

Daroqui, A. y López, R. F. (2012). «Introducción. Contextos socio-históricos en la construcción y gobierno de "la minoridad"». En A. Daroqui, A. L. López y R. F. Cipriano García (Comps.), Sujeto de castigos. Hacia una sociología de la penalidad juvenil (pp. 49-59). Santa Fe, Argentina: HomoSapiens.

Del Cueto, A. M. (2013). Grupos, instituciones y comunidades. Coordinación e intervención. Ciudad Autónoma de Buenos Aires, Argentina: Lugar editorial. 
Deleuze, G. [1987] (2008). Foucault. Barcelona, España: Paidós.

Deleuze, G. (2007). Dos regímenes de locos. Textos y entrevistas (1975-1995). Valencia, España: Pre-Textos.

Deleuze, G. (2014). El poder. Curso sobre Foucault. Tomo II. Ciudad Autónoma de Buenos Aires, Argentina: Cactus.

DeMause, LL. (1974). La evolución de la infancia. Recuperado de https://es.scribd.com/doc/151505563/La-evolucion-de-la-infanciaLloyd-de-Mause

Di lorio, J. (2010). Infancia e institucionalización: abordaje de problemáticas sociales actuales. Pesquisas e Práticas Psicossociais, 4(2), 143-150. Recuperado de https://tinly.co/GXKkC

Domínguez Lostaló, J. C. (1987). Problemática respecto del menor en situación de riesgo. Enfoques e instrumentos eficientes para su protección integral. Ciudad Autónoma de Buenos Aires, Argentina: Honorable Cámara de Senadores de la Nación / UNICEF.

Domínguez Lostaló, J. C. (1996). ¿Cómo contener el conflicto? Presentación de una propuesta. La clínica de la vulnerabilidad. En ¿Es necesario encerrar? El derecho a vivir en comunidad (pp. 25-48). La Plata, Argentina: P.I.F.A.T.A.C.S - Cuadernos del Caleuche - Universidad Nacional de La Plata.

Domínguez Lostaló, J. C. (1999). Los pibes marginados. Por el derecho a ser joven. Ciudad Autónoma de Buenos Aires, Argentina: Cuadernosdel Caleuche.

Domínguez Lostaló, J. C. (2001). 30 años de práctica profesional del psicólogo (Conferencia en las Primeras Jornadas sobre la Formación Universitaria y Práctica Profesional del Psicólogo, octubre de 1989). Revista No-Temas, 1(1), 9-19.

Donzelot, J. (1990). La policía de las familias. Valencia, España: Pre-Textos.

Facio Fernández, T., Lavintman Weinstein, S. y Domínguez Lostaló, J. C. (1981). Informe Paterra. Inédito. 
Fasciolo, M. (2018). ¿Quién tiene las llaves de la prisión? Funciones del trabajo social en centros cerrados para jóvenes con causas penales. La Plata, Argentina: Dynamis.

Fernández, A. M. (1996). La Psicología como profesión: de la salud de la formación a la formación para la salud [Desgrabación de clase]. La Plata, Argentina: Universidad Nacional de La Plata.

Fernández, A. M. (1999). Instituciones estalladas. Ciudad Autónoma de Buenos Aires, Argentina: Eudeba.

Fernández, A. M. (2007). Las lógicas colectivas. Imaginarios, cuerpos y multiplicidades. Ciudad Autónoma de Buenos Aires, Argentina: Biblos.

Fernández, A. M. (2011). Política y subjetividad. Asambleas barriales y fábricas recuperadas. Ciudad Autónoma de Buenos Aires, Argentina: Biblos.

Foucault, M. (1976). Vigilar y castigar. Ciudad de México, México: Siglo XXI.

Foucault, M. (1978). El juego de Michel Foucault (trad. Javier Rubio) [entrevista]. Diwan, (2-3), 171-202.

Foucault, M. [1977] (2008). La voluntad del saber. Historia de la Sexualidad 1. Ciudad Autónoma de Buenos Aires, Argentina: Siglo XXI.

Foucault, M. (2000). Defender la sociedad. Ciudad Autónoma de Buenos Aires, Argentina: Fondo de Cultura Económica.

Foucault, M. (2006). Seguridad, territorio y población. Ciudad Autónoma de Buenos Aires, Argentina: Fondo de Cultura Económica.

García Linera, A. (2010). La construcción del Estado. Recuperado de http://biblioteca.clacso.edu.ar/Argentina/iecconadu/20171115043333/pdf_939.pdf

García Méndez, E. (1991). «Prehistoria e historia del control socio-penal de la infancia. Política jurídica y Derechos Humanos en América Latina». En E. García Méndez y M. Bianchi (1991) (Comps.), Ser niño en América Latina. De las necesidades a los derechos (pp. 11-20). Ciudad Autónoma de Buenos Aires, Argentina: Galerna. 
García Méndez, E. y Bianchi, M. (Comps.) (1991). Ser niño en América Latina. De las necesidades a los derechos. Ciudad Autónoma de Buenos Aires, Argentina: Galerna.

García Méndez, E. y Vitale, G. (Comps.) (2009). Infancia y democracia en la Provincia de Buenos Aires. Comentario crítico sobre las leyes 13.298 y 13.634. Ciudad Autónoma de Buenos Aires, Argentina: Ediciones del Puerto.

Giberti, E. (1997). «La niñez y el hacer política». En E. Giberti (Comp.), Políticas y niñez (pp. 21-113). Ciudad Autónoma de Buenos Aires, Argentina: Losada.

Golbert, L. (2010). De la Sociedad de Beneficencia a los Derechos Sociales. Ciudad Autónoma de Buenos Aires, Argentina: Ministerio de Trabajo, Empleo y Seguridad Social.

Grinberg, J. (2013). La gestión de las «negligencias»: interpretaciones y dilemas en los organismos de protección de la infancia. Revista de Antropología, (22), 11-31. Recuperado de http://www.ava.unam.edu.ar/images/22/pdf/n22a01.pdf

Guatari, F. (1976). Psicoanálisis y transversalidad. Crítica psicoanalítica de las instituciones. Ciudad Autónoma de Buenos Aires, Argentina: Siglo XXI.

Guemureman, S. y Daroqui, A. (1999). La niñez ajusticiada. Ciudad Autónoma de Buenos Aires, Argentina: Ediciones del Puerto.

Kaminsky, G. G. (2011). Dispositivos institucionales. Democracia y autoritarismo en los problemas institucionales. Ciudad Autónoma de Buenos Aires, Argentina: Lugar editorial.

Kamisnsky, G. G. y Varela, C. (1994). «Una gramática institucional: organigramas y diagramas y...». En M. J. Acevedo y J. C. Volnovich (Comps.), El espacio institucional 1 (pp. 112-118). Ciudad Autónoma de Buenos Aires, Argentina: Lugar editorial.

Kliun, M. y Fernández, G. (2009). «Los desafíos de los equipos técnicos en las nuevas leyes de infancia de la provincia de Buenos Aires». En E. García Méndez y G. Vitale (Comps.), Infancia y democracia en la Provincia de Buenos Aires. Comentario crítico sobre las leyes 13.298 y 13.634 (pp. 3-6). Ciudad Autónoma de Buenos Aires, Argentina: Ediciones del Puerto. 
Larrandart, L. (1991). «Prehistoria e historia del control socio-penal de la infancia». En E. García Méndez y M. Bianchi (Comps.), Ser Niño en América Latina. De las necesidades a los derechos (pp. 21-39). Ciudad Autónoma de Buenos Aires, Argentina: Galerna.

Leonardi, M. C. (2014). Justicia penal juvenil en la provincia de Buenos Aires. Anales de la Facultad de Ciencias Jurídicas y Sociales, 11(44), 148-161. Recuperado de http://sedici.unlp.edu.ar/handle/10915/43587

Lewkowicz, I. (1999). «Tres observaciones sobre el concepto infancia». En C. Corea e I. Lewkowicz, ¿Se acabó la infancia? Ensayo sobre la destitución de la niñez (pp. 164-173). Ciudad Autónoma de Buenos Aires, Argentina: Lumen.

Llobet, V. (2006). Las políticas sociales para la infancia vulnerable. Algunas reflexiones desde la Psicología. Revista Latinoamericana de Ciencias Sociales, Niñez y Juventud, 4(1). Recuperado de http://revistaumanizales.cinde.org.co/rlcsnj/index.php/RevistaLatinoamericana/article/view/391

Llobet, V. (2013). «La producción de la categoría "niño-sujeto-de-derechos" y el discurso psi en las políticas públicas en Argentina. Una reflexión sobre el proceso de transición institucional». En V. Llobet (Comp.), Pensar la infancia desde América Latina. Un estado de la cuestión (pp. 209-235). Ciudad Autónoma de Buenos Aires, Argentina: Consejo Latinoamericano de Ciencias Sociales (CLACSO).

Llobet, V. (2014). Reflections Upon a Misunderstanding: Production of Children's Needs Within Rights Protection Policies. Psicologia em Estudio, 19(3), 1-11. Doi: http://dx.doi.org/10.1590/1413-73722222501

Llobet, V., Litichever, C. y Magisttris, G. (2012). La construcción del «beneficiario» en los programas sociales dirigidos a niñas, niños y adolescentes en el área metropolitana bonaerense. Revista de Ciencias Sociales, IV(138), 77-92.

Lorente, P. (22 de noviembre de 2018). Discurso brindado en el acto por el «60 Aniversario de la creación de la carrera de Psicología en la Universidad Nacional de La Plata. 
Lucesole, N. (2012). Políticas Públicas de Niñez y Adolescencia en la provincia de Buenos Aires. Análisis del proceso de implementación del Sistema de Responsabilidad Penal Juvenil: un estudio de caso en el Centro de Referencia La Plata. ¿Asistencialismo penal o penalismo asistencial? (Tesis de maestría). Ciudad Autónoma de Buenos Aires, Argentina: Facultad Latinoamericana de Ciencias Sociales (FLACSO).

Lucesole, N. (diciembre de 2016). Recorrido legal e institucional de las principales políticas públicas para la niñez y adolescencia en Argentina: de la Sociedad de Beneficencia a la Protección Integral de Derechos. Trabajo presentado en las IX Jornadas de Sociología de la Universidad Nacional de La Plata. Recuperado de http://www.memoria.fahce.unlp.edu.ar/trab_eventos/ev.8980/ev.8980.pdf

Macchioli, F. (2012). Los inicios de la Terapia Familiar en la Argentina. Implantación, configuración y desarrollo de un nuevo campo disciplinar. 1960-1979. Estud. pesqui. psicol., 12(1), 681-689. Recuperado de http://pepsic.bvsalud.org/scielo.php?script=sci_arttext\&pid=S180842812012000200020

Macchioli, F. (2013). Familia y salud mental en la Argentina de 1957. Salud mental: Interdisciplina e inclusión social como ejes de intervención. Ciudad Autónoma de Buenos Aires, Argentina: Asociación Argentina de Salud Mental.

Macchioli, F. (2014). «La inclusión de los padres en el cuadro de la situación analítica». Familia, disciplinas psi y valores en la Argentina de los cincuenta. Universitas Psychologica, 13(5), 1881-1891.

https://doi.org/10.11144/Javeriana.upsy13-5.ipcs

Marre, D. (2013). «Prólogo: de infancias, niños y niñas». En V. Llobet (Comp.), Pensar la Infancia desde América Latina (pp. 9-25). Ciudad Autónoma de Buenos Aires, Argentina: Consejo Latinoamericano de Ciencias Sociales (CLACSO).

Mendoza, F. y Ruiz, A. (abril de 2019). Cómo citar con las normas APA. [Presentación]. Taller Cómo citar con las normas APA. Facultad de Bellas Artes, Universidad Nacional de La Plata. Recuperado de http://sedici.unlp.edu.ar/handle/10915/73909 
Montenegro, R. (2004). Dispositivos de enunciación: las operaciones de distinción y de puntuación. Trabajo presentado en las XI Jornadas de Investigación de la Universidad de Buenos Aires. Recuperado de http://www.aacademica.org/000-029/164

Moratti, M. F., Veloz, J. y Cattani, J. P. (noviembre 2013). Psicólogos/as y políticas públicas. Una historización acerca de la inserción en el ámbito de Niñez y Adolescencia. 1960-1970. Trabajo presentado en el $V$ Congreso Internacional de Investigación y Práctica Profesional en Psicología de la Universidad de Buenos Aires.

Morey, M. [1987] (2008). «Prólogo». En G. Deleuze, Foucault (pp. 11-21). Barcelona, España: Paidós.

Oszlak, O. (1997). La formación del Estado argentino. Orden, progreso y organización nacional. Ciudad Autónoma de Buenos Aires, Argentina: Planeta.

Oyhandy Cioffi, A. G. (2004). La infancia en riesgo: entre la caridad y la ciudadanía. Un estudio de caso sobre la gestión de la infancia y la adolescencia en riesgo en la Argentina contemporánea. La Plata, 2000-2003. Ciudad de México, México: Facultad Latinoamericana de Ciencias Sociales (FLACSO).

Pérez, E. A. (2012). Los psicólogos en el ámbito público: ayer y hoy. Salud, desarrollo social, seguridad y justicia (2012-2016). Proyecto acreditado por la Secretaria de Ciencia y técnica, UNLP. Res. N²427/93. Ministerio de Cultura y Educación de la Nación.

Pérez, E. A. (Comp.) (2014). Psicología institucional. La Plata, Argentina: EDULP.

Pérez, E. A. (2015). Ejercicio de derechos y producciones de subjetividad. Un estudio en redes intersectoriales en instituciones de La Plata y Gran La Plata (2016-2018) [Proyecto de investigación]. La Plata, Argentina: Universidad Nacional de La Plata.

Ruiz, A. (2018). La incorporación de citas en los textos científico académicos. Estilos y consideraciones para su redacción (apunte de cátedra). Taller de Edición Técnica, Facultad de Periodismo y Comunicación Social, Universidad Nacional de La Plata. Recuperado de http://sedici.unlp.edu.ar/handle/10915/73792 
Rustoyburu, C. (2014). Hijo mío...! Disputas por el sentido en torno de la infancia. Argentina, en la década de 1930. Trabajo presentado en el I Encuentro Internacional de Educación de la Universidad Nacional del Centro de la Provincia de Buenos Aires. Recuperado de http://www.ridaa.unicen.edu.ar/xmlui/handle/123456789/144

Salazar Villava, C. M. (2004). Dispositivos: máquina de visibilidad. En Anuario de investigación 2003 (pp. 291-299). Ciudad de México, México: Universidad Autónoma de México.

Sardá, L. (Coord.) (2012). Situación de niños, niñas y adolescentes sin cuidados parentales en la República Argentina. Relevamiento nacional y propuestas para la promoción y el fortalecimiento del derecho a la convivencia familiar y comunitaria. Ciudad Autónoma de Buenos Aires, Argentina: Ministerio de Desarrollo Social / UNICEF. Recuperado de https://bit.ly/2Sraefz

Ulloa, F. (1995). Novela clínica psicoanalítica. Historial de una práctica. Ciudad Autónoma de Buenos Aires, Argentina: Paidós.

Uriarte, C. (2006). Vulnerabilidad, privación de libertad de jóvenes y Derechos Humanos. Montevideo, Uruguay: Fundación de Cultura Universitaria.

Varela, C. (agosto de 2010). La psicología institucional argentina. Orígenes y fundamentos. Trabajo presentado en el II Congreso Nacional y I Encuentro Internacional de Psicosociología Institucional de la Universidad Nacional de Salta. Recuperado de http://www.cristianvarela.com.ar/textos/a-institucionalargentinaorigenes-fundamentos

Vasilachis de Gialdino, I. (Coord.) (2006). Estrategias de investigación cualitativa. Barcelona, España: Gedisa.

Volnovich, J. C. (1999). El niño del «siglo del niño». Ciudad Autónoma de Buenos Aires, Argentina: Lumen.

Weissmann, P. (2002). Mariano J. Barilari. Medicina psicosomática y educación para la salud en la Argentina de los años `30. Temas de historia de la Psiquiatría Argentina, (15). Recuperado de http://www.polemos.com.ar/docs/temas/Temas15/1a\%20parte.htm 
Zapiola, M. C. (2010). «La ley del Patronato de Menores de 1919: ¿una bisagra histórica?». En L. Lionetti y D. Míguez (Comps.), Las infancias en la historia argentina. Intersecciones entre prácticas, discursos e instituciones (pp. 117-132). Ciudad Autónoma de Buenos Aires, Argentina: Prohistoria.

\section{Normativas}

Código Civil. Título III. De la patria potestad. Recuperado de http://servicios.infoleg.gob.ar/infoleglnternet/anexos/105000109999/109481/texactley340_librol_S2_titulolll.htm

Código de Ética del Colegio de Psicólogos de la Provincia de Buenos Aires (1985). Recuperado de http://www.colpsibhi.org.ar/leyes_profesionales/codigo_de_etica

Decreto Ley Nacional 22.278 (1980). Régimen Penal de la Minoridad. Boletín Oficial de la República Argentina. Buenos Aires, 28/8/1980.

Decreto Ley Nacional 22.803 (1983). Ley N²2.278 - Modificación. Boletín Oficial de la República Argentina. Buenos Aires, 9/5/1983.

Decreto Ley Provincial 10.067 (1983). Patronato de Menores.

Boletín Oficial de la Provincia de Buenos Aires. La Plata, 9/12/1983.

Decreto Ministerial 151 (2007).

Boletín Oficial de la Provincia de Buenos Aires. La Plata, 22/3/2007.

Decreto Provincial 907 (1994).

Boletín Oficial de la Provincia de Buenos Aires. La Plata, 9/5/1994.

Decreto Provincial 44 (2007).

Boletín Oficial de la Provincia de Buenos Aires. La Plata, 2/2/2007.

Decreto Reglamentario 300 (2005). Decreto Reglamentario de la Ley 13.298. Ley de Promoción y Protección Integral de los Derechos de los Niños.

Boletín Oficial de la Provincia de Buenos Aires. La Plata, 23/3/2005.

Ley Nacional 1.420 (1884). Educación primaria.

Boletín Oficial de la República Argentina. Buenos Aires, 8/7/1884. 
Ley Nacional 4.144 (1902). Residencia de Extranjeros.

Boletín Oficial de la República Argentina. Buenos Aires, 25/11/1902.

Ley Nacional 10.903 (1919). Patronato de Menores.

Boletín Oficial de la República Argentina. Buenos Aires, 27/10/1919.

Ley Nacional 15.244 (1959). Consejo Nacional de Protección de Menores. Boletín Oficial de la República Argentina. Buenos Aires, 24/12/1959.

Ley Nacional 17.132 (1967). Arte de Curar.

Boletín Oficial de la República Argentina. Buenos Aires, 31/1/1967.

Ley Nacional 23.277 (1985). Ejercicio Profesional de la Psicología. Boletín Oficial de la República Argentina. Buenos Aires, 15/11/1985.

Ley Nacional 23.742 (1989). Modifícase la Ley № 22.278.

Boletín Oficial de la República Argentina. Buenos Aires, 25/10/1989.

Ley Nacional 23.849 (1990). Convención sobre los Derechos del Niño. Boletín Oficial de la República Argentina. Buenos Aires, 22/10/1990.

Ley Nacional 24.521 (1995). Ley de Educación Superior.

Boletín Oficial de la República Argentina. Buenos Aires, 10/8/1995.

Ley Nacional 26.061 (2005). Protección Integral de los Derechos de las Niñas, Niños y Adolescentes.

Boletín Oficial de la República Argentina. Buenos Aires, 26/10/2005.

Ley Provincial 4.547 (1937). Dirección General de Protección a la Infancia Boletín Oficial de la Provincia de Buenos Aires. La Plata, 15/5/1937.

Ley Provincial 4.664 (1937). Tribunales para menores.

Boletín Oficial de la Provincia de Buenos Aires. La Plata, 11/2/1938.

Ley Provincial 6.661 (1961). Consejo de la Minoridad de la provincia de Buenos Aires.

Boletín Oficial de la Provincia de Buenos Aires. La Plata, 11/12/1961.

Ley Provincial 10.306 (1985). Colegio de Psicólogos de la Provincia y Regulación del Ejercicio Profesional de la Psicología.

Boletín Oficial de la Provincia de Buenos Aires. La Plata, 6/9/1985. 
Ley Provincial 11.175 (1991). Ley de Ministerios (Derogada por Ley 12.355/99).

Boletín Oficial de la Provincia de Buenos Aires. La Plata, 11/12/1991.

Ley Provincial 11.519 (1994). Ley de Ministerios (Derogada por Ley 12.355/99).

Boletín Oficial de la Provincia de Buenos Aires. La Plata, 19/4/1994.

Ley Provincial 11.737 (1995). (Derogada por Ley 12.355/99).

Boletín Oficial de la Provincia de Buenos Aires. La Plata, 19/12/1995.

Ley Provincial 10.430 (1996). Estatuto y Escalafón para el Personal de la Administración Pública de la Provincia de Buenos Aires.

Boletín Oficial de la Provincia de Buenos Aires. La Plata, 25/06/1996.

Ley Provincial 12.607 (2000). Protección Integral de los Derechos del Niño y el Joven.

Boletín Oficial de la Provincia de Buenos Aires. La Plata, 29/12/2000.

Ley Provincial 13.298 (2005). Promoción y Protección Integral de los Derechos de los Niños.

Boletín Oficial de la Provincia de Buenos Aires. La Plata, 27/1/2005.

Ley Provincial 13.634 (2007). Principios Generales del Fuero de Familia y del Fuero Penal del Niño.

Boletín Oficial de la Provincia de Buenos Aires. La Plata, 2/2/2007.

Naciones Unidas (1985). Reglas mínimas de las Naciones Unidas para la administración de la justicia de menores (Reglas de Beijing). Recuperado de https://www.ohchr.org/SP/Professionallnterest/Pages/BeijingRules.aspx

Naciones Unidas (1989). Convención Internacional sobre los Derechos del Niño. Recuperado de https://www.ohchr.org/SP/Professionallnterest/Pages/CRC.aspx

Naciones Unidas (1990). Directrices de las Naciones Unidas para la prevención de la delincuencia juvenil (Directrices de Riad). Recuperado de https://bit.ly/2vTQzfw

Naciones Unidas (1990). Reglas de las Naciones Unidas para la protección de los menores privados de libertad. Recuperado de https://bit.ly/2Jxqsyp 
Resolución Ministerial 166 (2007).

Boletín Oficial de la Provincia de Buenos Aires. La Plata, 3/7/2007.

Resolución Ministerial 172 (2007).

Boletín Oficial de la Provincia de Buenos Aires. La Plata, 4/4/2007.

\section{Fuentes}

E1 | Psicóloga, actualmente en funciones. Entrevistada en 2016.

E2 | Psicólogo, jubilado. Entrevistado en 2016.

E3 | Psicóloga, jubilada. Entrevistada en 2017.

E4 | Psicóloga, actualmente en funciones. Entrevistada en 2015.

E5 | Psicóloga, actualmente en funciones. Entrevistada en 2017.

E6 | Psicóloga, jubilada. Entrevistada en 2015.

E7 | Psicóloga, actualmente en funciones. Entrevistada en 2015.

E8 | Psicóloga, actualmente en funciones. Entrevistada en 2018.

E9 | Psicóloga, actualmente en funciones. Entrevistada en 2017.

E10 | Psicólogo, actualmente en funciones. Entrevistado en 2018.

E11 | Psicóloga, actualmente en funciones. Entrevistada en 2016.

E12 | Psicóloga, actualmente en funciones. Entrevistada en 2015.

E13 | Psicóloga, jubilada. Entrevistada en 2018.

E14 | Psicólogo, actualmente en funciones. Entrevistado en 2016.

E15 | Psicóloga, actualmente en funciones. Entrevistada en 2016.

E16 | Psicóloga, actualmente en funciones. Entrevistada en 2017. 
